\title{
The Seismic Response of Concrete Arch Bridges With focus on the Bixby Creek Bridge Carmel, California
}

\begin{abstract}
A research and development project sponsored by the California Department of Transportation
\end{abstract}

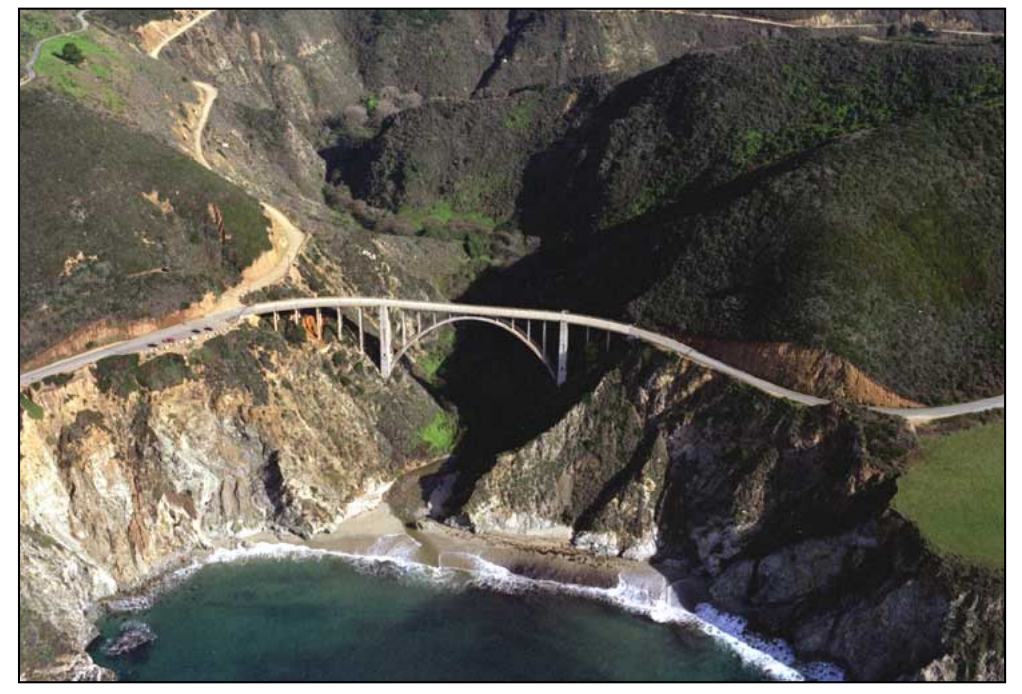

David McCallen

Center for Complex Distributed Systems

Lawrence Livermore National Laboratory
Charles Noble

New Technologies Engineering Division

Lawrence Livermore National Laboratory

Matthew Hoehler

New Technologies Engineering Division

Lawrence Livermore National Laboratory

June 1999 


\section{DISCLAIMER}

This document was prepared as an account of work sponsored by an agency of the United States Government. Neither the United States Government nor the University of California nor any of their employees, makes any warranty, express or implied, or assumes any legal liability or responsibility for the accuracy, completeness, or usefulness of any information, apparatus, product, or process disclosed, or represents that its use would not infringe privately owned rights. Reference herein to any specific commercial product, process, or service by trade name, trademark, manufacturer, or otherwise, does not necessarily constitute or imply its endorsement, recommendation, or favoring by the United States Government or the University of California. The views and opinions of authors expressed herein do not necessarily state or reflect those of the United States Government or the University of California, and shall not be used for advertising or product endorsement purposes.

This report has been reproduced directly from the best available copy.

Available to DOE and DOE contractors from the Office of Scientific and Technical Information P.O. Box 62, Oak Ridge, TN 37831

Prices available from (423) 576-8401

Available to the public from the National Technical Information Service

U.S. Department of Commerce 5285 Port Royal Rd., Springfield, VA 22161 
Technical Report Documentation Page

\begin{tabular}{|c|c|c|c|c|}
\hline $\begin{array}{l}\text { 1. Report No. } \\
\text { UCRL - ID - } 134419\end{array}$ & \multicolumn{2}{|c|}{ 2. Government Accession No. } & \multicolumn{2}{|c|}{ 3. Recipient's Catalog No. } \\
\hline \multirow{2}{*}{\multicolumn{3}{|c|}{$\begin{array}{l}\text { 4. Title and Subtitle } \\
\text { THE SEISMIC RESPONSE OF CONCRETE ARCH BRIDGES } \\
\text { WITH FOCUS ON THE BIXBY CREEK BRIDGE } \\
\text { CARMEL, CALIFORNIA }\end{array}$}} & \multicolumn{2}{|l|}{$\begin{array}{l}\text { 5. Report Date } \\
\text { June, } 1999\end{array}$} \\
\hline & & & \multicolumn{2}{|c|}{ 6. Performing Organization Code } \\
\hline \multicolumn{3}{|l|}{\begin{tabular}{|l} 
\\
7. Author(s)
\end{tabular}} & \multirow{2}{*}{\multicolumn{2}{|c|}{$\begin{array}{l}\text { 8. Performing Organization Report No. } \\
\text { UCRL - ID - } 134419\end{array}$}} \\
\hline \multicolumn{3}{|c|}{ David B. McCallen, Charles Noble, Matthew S. Hoehler } & & \\
\hline \multirow{2}{*}{\multicolumn{3}{|c|}{$\begin{array}{l}\text { 9. Performing Organization Name and Address } \\
\text { Lawrence Livermore National Laboratory } \\
\text { PO Box } 808 \\
\text { Livermore, CA } 94551-9900\end{array}$}} & \multicolumn{2}{|c|}{ 10. Work Unit No. (TRAIS) } \\
\hline & & & \multicolumn{2}{|c|}{$\begin{array}{c}\text { 11. Contract or Grant No. } \\
\text { 59A0042 }\end{array}$} \\
\hline \multirow{2}{*}{\multicolumn{3}{|c|}{$\begin{array}{l}\text { 12. Sponsoring Agency Name and Address } \\
\text { California Department of Transportation } \\
1801 \text { 30th Street } \\
\text { Sacramento, CA } 95816\end{array}$}} & \multicolumn{2}{|c|}{$\begin{array}{l}\text { 13. Type of Report and Period Covered } \\
\text { Final Report } \\
\text { April, } 1998 \text { - June, } 1999\end{array}$} \\
\hline & & & \multicolumn{2}{|c|}{ 14. Sponsoring Agency Code } \\
\hline \multicolumn{5}{|l|}{ 15. Supplementary Notes } \\
\hline \multicolumn{5}{|c|}{$\begin{array}{l}\text { 16. Abstract } \\
\text { The analysis, and subsequent retrofit, of concrete arch bridges during recent years has relied } \\
\text { heavily on the use of computational simulation. For seismic analysis in particular, computer sim- } \\
\text { ulation, typically utilizing linear approximations of structural behavior, has become standard } \\
\text { practice. This report presents the results of a comprehensive study of the significance of model } \\
\text { sophistication (i.e. linear vs. nonlinear) and pertinent modeling assumptions on the dynamic } \\
\text { response of concrete arch bridges. The study uses the Bixby Creek Bridge, located in California, } \\
\text { as a case study. In addition to presenting general recommendations for analysis of this class of } \\
\text { structures, this report provides an independent evaluation of the proposed seismic retrofit for the } \\
\text { Bixby Creek Bridge. }\end{array}$} \\
\hline \multicolumn{5}{|c|}{$\begin{array}{l}\text { Results from the study clearly illustrate a reduction of displacement drifts and redistribution of } \\
\text { member forces brought on by the inclusion of material nonlinearity. The analyses demonstrate } \\
\text { that accurate modeling of expansion joints, for the Bixby Creek Bridge in particular, is critical to } \\
\text { achieve representative modal and transient behavior. The inclusion of near-field displacement } \\
\text { pulses in ground motion records was shown to significantly increase demand on the relatively } \\
\text { softer, longer period Bixby Creek Bridge arch. Stiffer, shorter period arches, however, are more } \\
\text { likely susceptible to variable support motions arising from the canyon topography typical for this } \\
\text { class of bridges. }\end{array}$} \\
\hline \multicolumn{2}{|c|}{$\begin{array}{l}\text { 17. Key Words } \\
\text { Bixby Creek Bridge, Arch Bridges, Seismic } \\
\text { Retrofit, Near-Field Motion, Caltrans, Non- } \\
\text { linear Analysis, Topographic Amplification. }\end{array}$} & \multicolumn{3}{|l|}{$\begin{array}{l}\text { 18. Distribution Statement } \\
\text { Unlimited }\end{array}$} \\
\hline $\begin{array}{l}\text { 19. Security Classif. (of this report) } \\
\text { Unclassified }\end{array}$ & $\begin{array}{r}20 \text { Security Cla } \\
\text { Unclassif }\end{array}$ & $\begin{array}{l}\text { sif. (of this page) } \\
\text { ed }\end{array}$ & $\begin{array}{c}\text { 21. No. of Pages } \\
170\end{array}$ & 22. Price \\
\hline
\end{tabular}

Form DOT F 1700.7 (2-86)

Reproduction of completed page authorized 


\title{
The Seismic Response of Concrete Arch Bridges
}

\author{
With focus on the Bixby Creek Bridge \\ Carmel, California
}

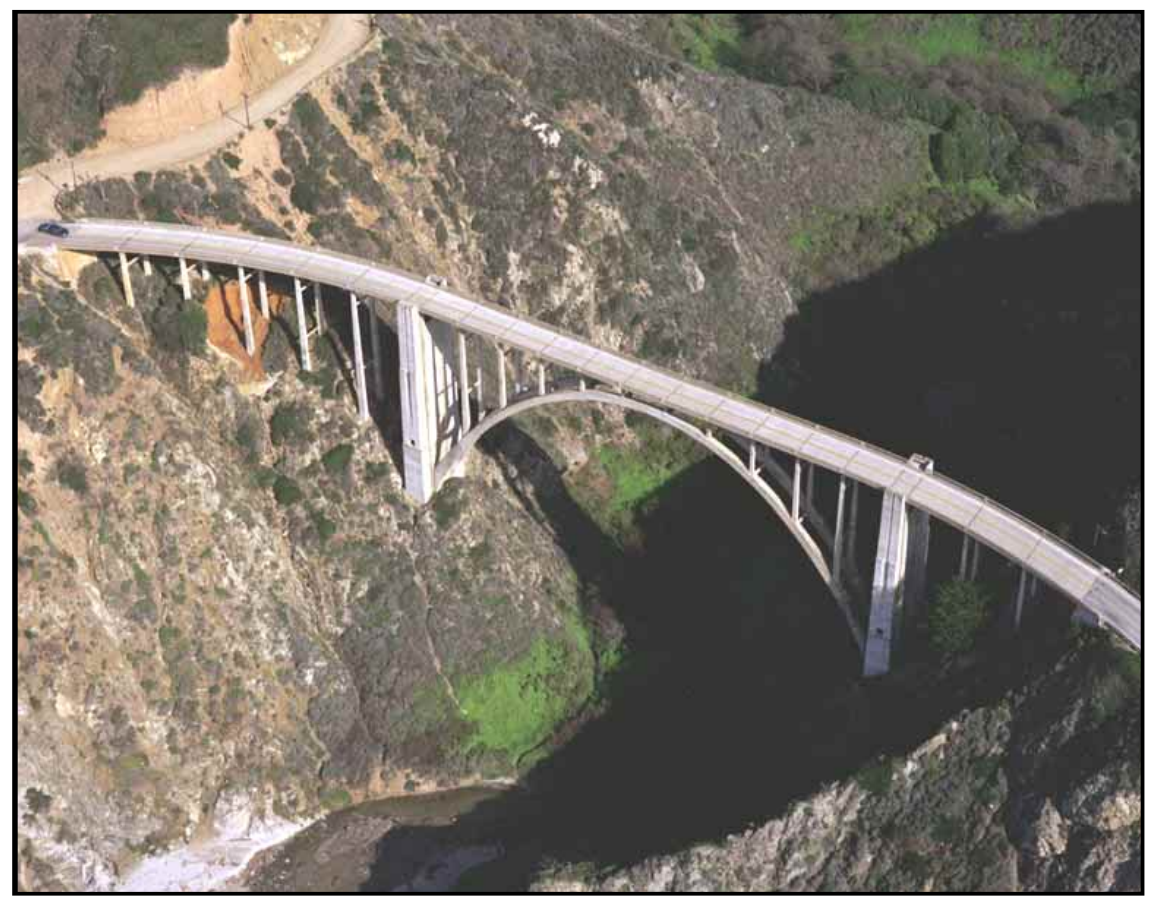

\section{Table of Contents}

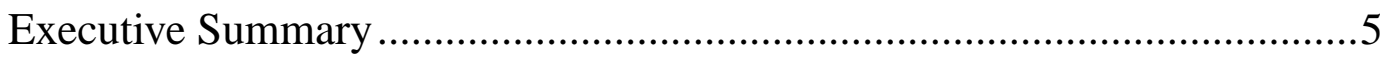

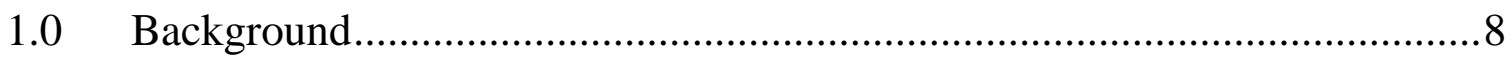

$2.0 \quad$ Earthquake ground motions ............................................................... 16

2.1 Simulation of wave scattering in the Bixby Creek Canyon.................................. 19

2.2 Measured ground motions at the Bixby Creek site .............................................. 31

3.0 Nonlinear finite element simulation model of the as-built Bixby Creek

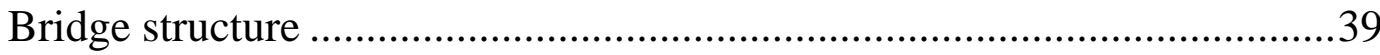

3.1 Geometric nonlinearities: deck articulations and impact/contact......................43

3.2 Physical nonlinearities: the nonlinear concrete model .....................................45

3.2.1 Evaluation of the concrete model - comparison with UCSD experiments ..........49 


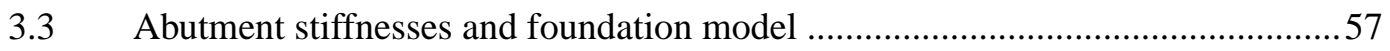

3.4 Energy dissipation mechanisms in the computational model..............................64

4.0 Natural modeshapes and frequencies of the as-built bridge system ............65

5.0 Vibrational measurements of the as-built bridge structure ...........................76

5.1 Analysis of bridge vibrational response data.................................................... 80

5.2 Comparison of computed and observed frequencies ........................................ 83

6.0 Transient response of the as-built structure to Caltrans design earthquake

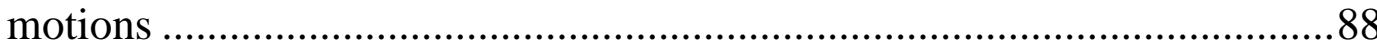

6.1 Transient response of the as-built structure model with linear materials and free expansion joints (Seed and Idriss time histories)

6.2 Transient response of the as-built structure model with linear materials and contacting expansion joints (Seed and Idriss time histories).

6.3 Transient response of the as-built structure model with nonlinear materials and contacting expansion joints (Seed and Idriss time histories).

6.4 Transient response of the as-built structure model with nonlinear materials and merged-deck, non-opening expansion joints (Seed and Idriss time histories) .....92

6.5 Transient response of the as-built structure model with nonlinear materials and tied collars at the expansion joints (Seed and Idriss time histories) .....................96

6.6 Member strains and demand-to-capacity ratios (Seed and Idriss time histories).96

6.7 Shear demand-to-capacity check for the as-built structure .............................. 106

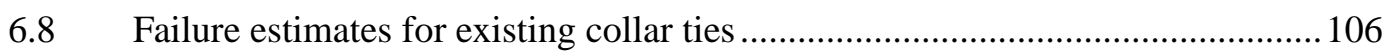

7.0 Transient response of the as-built structure to Caltrans ground motions including near-field terms

7.1 Transient response of the as-built structure model with nonlinear materials and contacting expansion joints (Caltrans updated time histories with near-field motions) 
7.2 Member strains (Caltrans updated time histories with near-field motions)

7.3 Comparison of structural response between original retrofit design ground motions and Caltrans updated near-field ground motions

8.0 Push-over analysis of the bridge structure

9.0 Nonlinear finite element simulation model of the retrofit Bixby Creek Bridge structure

10.0 Natural modeshapes and frequencies of the retrofit bridge system

\subsection{Transient response of the retrofit structure to Caltrans design earthquake motions}

11.1 Transient response of the retrofit model with linear and nonlinear materials (Seed and Idriss time histories)

11.2 Member strains and demand-to-capacity ratios (Seed and Idriss time histories).....

11.3 Shear demand-to-capacity check for the retrofit structure (Seed and Idriss time histories)

12.0 Transient response of the retrofit model with nonlinear materials to the Caltrans ground motions including near-field terms

12.1 Transient response of the retrofit structure with material nonlinearities (Caltrans updated time histories with near-field motions)

12.2 Member strains and demand-to-capacity ratios (Caltrans updated time histories with near-field motions)

12.3 Shear demand-to-capacity check for the retrofit structure (Caltrans updated time histories with near-field motions)

12.4 Comparison of displacements from as-built and retrofit structures

12.5 Demand-to-capacity values for the abutment piles

13.0 Summary of analysis and field measurement results 


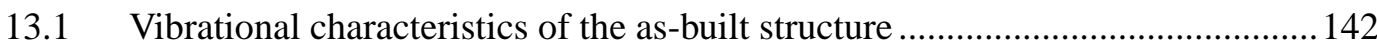

13.2 Synthetic earthquake ground motions for the Bixby Creek site......................... 144

13.3 Variable support motion in the Bixby Creek Canyon......................................... 144

13.4 Transient response and the effect of expansion joint behavior.......................... 147

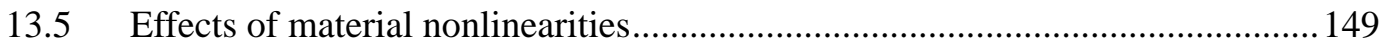

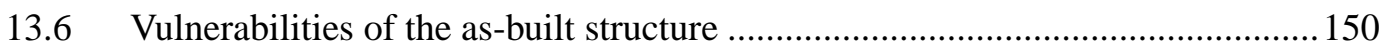

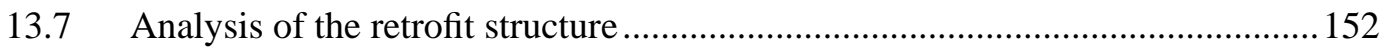

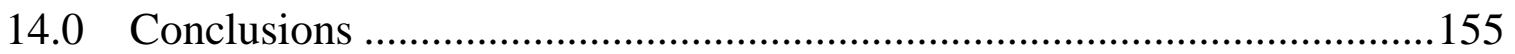

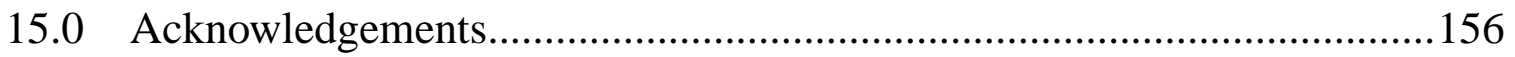

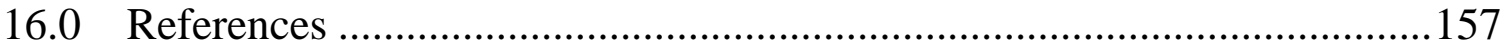

APPENDIX A: Retrofit strategies for a number of California arch bridges ... 


\section{Executive Summary}

A complete and thorough understanding of the dynamic response of bridge structures to strong earthquake motions continues to present a difficult and challenging technical problem. The precise character of earthquake ground motion waveforms which can be expected at a bridge site due to a particular causative fault is very difficult to estimate apriori and any ground motion estimate contains a high degree of uncertainty. In addition to ground motion uncertainties, the transient dynamic response of bridge structures can be very complex. When subjected to strong ground motions, it can be expected that most bridge structures will exhibit yielding and cracking of the bridge components, changes in the global bridge geometry, or changes in the stiffness of the foundations and soil on which the structure is supported. These effects result in significant nonlinear behavior of the bridge system, which considerably complicates the task of understanding and predicting the bridge behavior and estimating the damage that might be expected.

Engineers are now highly dependent on computational simulations to understand the complex behavior of a particular bridge structure during an earthquake. The preponderance of computational simulations for bridge design and retrofit studies have consisted of linear simulations, in which the bridge is "linearized" about some geometric configuration (for example expansion joints assumed open and noncontacting or expansion joints assumed closed and locked), and the material sections are linearized about some idealized material configuration (for example, some reduced member "cracked sections" are assumed to approximate the effects of material failure in concrete members). In recent years, particularly since the 1989 Loma Prieta California earthquake, there has been a major push to employ more advanced, nonlinear computational models which offer the potential for understanding the true nonlinear response of bridge systems. The benefits of understanding the true nonlinear behavior of bridge systems, as opposed to an idealized, fictitious linear behavior are clear - the safest and most economical designs will be realized only when the true complex behavior of bridge systems is completely understood and can be computationally simulated with a high degree of accuracy and confidence.

The California Department of Transportation (Caltrans) has been at the cutting edge of bridge analysis and design for many years, and is currently the nation's leader in bridge research aimed at understanding the true (as opposed to idealized) behavior of bridge structures. The research study described in this report constitutes one element of Caltrans' research and development work to advance understanding of the response of bridges to strong earthquake motions. The study described herein focused on the seismic response of concrete arch bridges with a case study of the famous Bixby Creek Bridge, located along the scenic Big Sur Pacific coast of California. The primary purpose of this study was to perform a detailed evaluation of the effect of various modeling idealizations and assumptions on the predicted response of this type of bridge structure. This included consideration of nonlinearities in the bridge due to contact and impact at expansion joints, material nonlinearities due to concrete tensile cracking and concrete softening and reinforcing steel yielding. The potential for variable support ground motions due to scattering of incident seismic waves in the canyon topography typical of California's coastal arch bridges was 
also investigated. A secondary objective of this study was to perform an independent assessment of the adequacy of a seismic retrofit concept for this bridge structure. A Caltrans consultant previously developed a retrofit strategy for this structure and completed a seismic retrofit design. The retrofit design was based on computational simulations with linearized computational bridge models and an evaluation of the retrofit with nonlinear computational models provides insight into potential differences in design conclusions, which can occur as a result of modeling dissimilarities.

A large number of simulations and parameter studies have been performed in this study in order to provide understanding of the significance of modeling assumptions and the differences between models of different sophistications, ranging from simple linearized models to complex fully nonlinear models. The major conclusions reached during these extensive studies include:

- For this structure, the manner in which the expansion joints are modeled in a linearized model has a very large effect on the computed response of the bridge structure. For Bixby Creek, all of the bridge columns were originally constructed with the columns split in half over the top portion of the column creating a large number of expansion joints. If these joints are assumed to open and close freely, with no contact, the deck system cannot act as a continuous structural member and the entire bridge system appears very flexible. On the other hand, if the expansion joints are assumed locked in the linearized model, the deck can act as a continuous member and the structure appears considerably stiffer.

- Based on field experiments to observe the actual vibrational frequencies of the Bixby Creek Bridge structure, the small amplitude vibrations of the actual as-built structure exhibit frequencies which fall in between the frequencies computed with the linearized models based on locked or free expansion joints. This is expected because the expansion joints are not truly locked or free, but somewhere in between. By invoking expansion joint assumptions which are consistent with the kinematics expected from a fundamental transverse mode of vibration, the computer model can be brought into good correlation with the measured data for the fundamental mode of vibration.

- The fully nonlinear computational model predicts a bridge response which is quite different from the linearized models. The differences arise from nonlinearities associated with impact and contact at the bridge expansion joints and inelastic material behavior associated with cracking and softening of concrete and yielding of reinforcing steel.

- The type of computational model employed and the acceptance criteria for the structure (i.e. strength based criteria versus deformation based criteria) can significantly impact conclusions regarding the adequacy of the structural system.

- The natural periods of vibration of the as-built Bixby Creek structure are quite long due to the inherent flexibility of the structure, and multiple support input motions due to topographic scattering is not an issue - the wave scattering effects of the canyon only effect frequencies above the lower natural frequencies of the as-built structure. The retrofit structure, which is significantly stiffened relative to the as-built structure, is at the lower end of the frequency range where potential topographic wave scattering effects 
are beginning to become important. The higher modes of the retrofit structure (e.g. starting at mode \#3 at approximately $1.25 \mathrm{~Hz}$ frequency) may be susceptible to incoherent support motions.

- For the original design motions provided by Caltrans, the retrofit design appeared to be quite conservative based on nonlinear model simulations; however, with updated ground motions including near-field long period terms generated specifically for the current study, the retrofit design appears more appropriate.

- The inherent flexibility of long-span arches makes it essential that long period displacement components, which can occur in the near-field of an earthquake, be included in the site hazard assessment for structures located near a causative fault. These long period displacement pulses proved to be very damaging for the Bixby Creek Bridge.

The extensive body of computational studies completed for this study are documented herein. The reader is referred to the section "Summary of analysis results" and "Conclusions" for a quick highlight of the computational results and overview of this study. A Compact Disk has been included on the inside jacket of this report which contains QuickTime video animations of a number of the modal analyses and time history analyses of the bridge. These video sequences can be viewed to gain enhanced understanding of the dynamic characteristics of the bridge system. 


\title{
The Seismic Response of Concrete Arch Bridges
}

\author{
With focus on the Bixby Creek Bridge \\ Carmel, California \\ David McCallen $^{\dagger}$ \\ Charles Noble \\ Matthew Hoehler ${ }^{\text {क }}$ \\ † Center for Complex Distributed Systems \\ Lawrence Livermore National Laboratory \\ \$ New Technologies Engineering Division \\ Lawrence Livermore National Laboratory
}

\subsection{Background}

In the 1930's, a number of reinforced concrete arch bridges were constructed along the coast of California. These arch bridges typically span coastal watershed canyons and provide a stunning and visually appealing class of structure which nicely "fit" the natural environment and the rugged topography of the California coastline. In light of the vintage of these arch bridges, and the level of understanding of earthquake phenomenology in the 1930's, these structures tend to be seismically deficient by 1990's design standards. The California Department of Transportation (Caltrans) has recently developed an extensive program of seismic evaluation and retrofit design for a number of these arch bridges. The research project described herein was requested by Caltrans as part of the effort to understand arch bridge seismic response and to efficiently and effectively retrofit this class of bridge structure. In concert with Caltrans, the famous Bixby Creek arch bridge, located on State Highway 1 south of Carmel, California, was selected as a case study bridge for this research project. The Bixby Creek Bridge is a large deck-type concrete arch structure which will be undergoing seismic retrofit over the next year. Thus, consideration of this particular bridge allowed investigation of the seismic response of arch bridges in a general sense, but had the added benefit of providing seismic data on a critical structure about to undergo earthquake retrofit.

The Bixby Creek Bridge is located approximately 18 miles south of Carmel, California on State Highway 1. The bridge spans the Bixby Creek Canyon with a total length of approximately 714 feet (Figure 1 and Figure 2). The Bixby Bridge was considered a major civil engineering construction feat in 1932, and the construction of the bridge is summarized nicely in an article by Mitchell [Ref 1]. The main span structural configuration of the Bixby Creek Bridge is similar to nearby Highway 1 arch bridges; however, the length of 

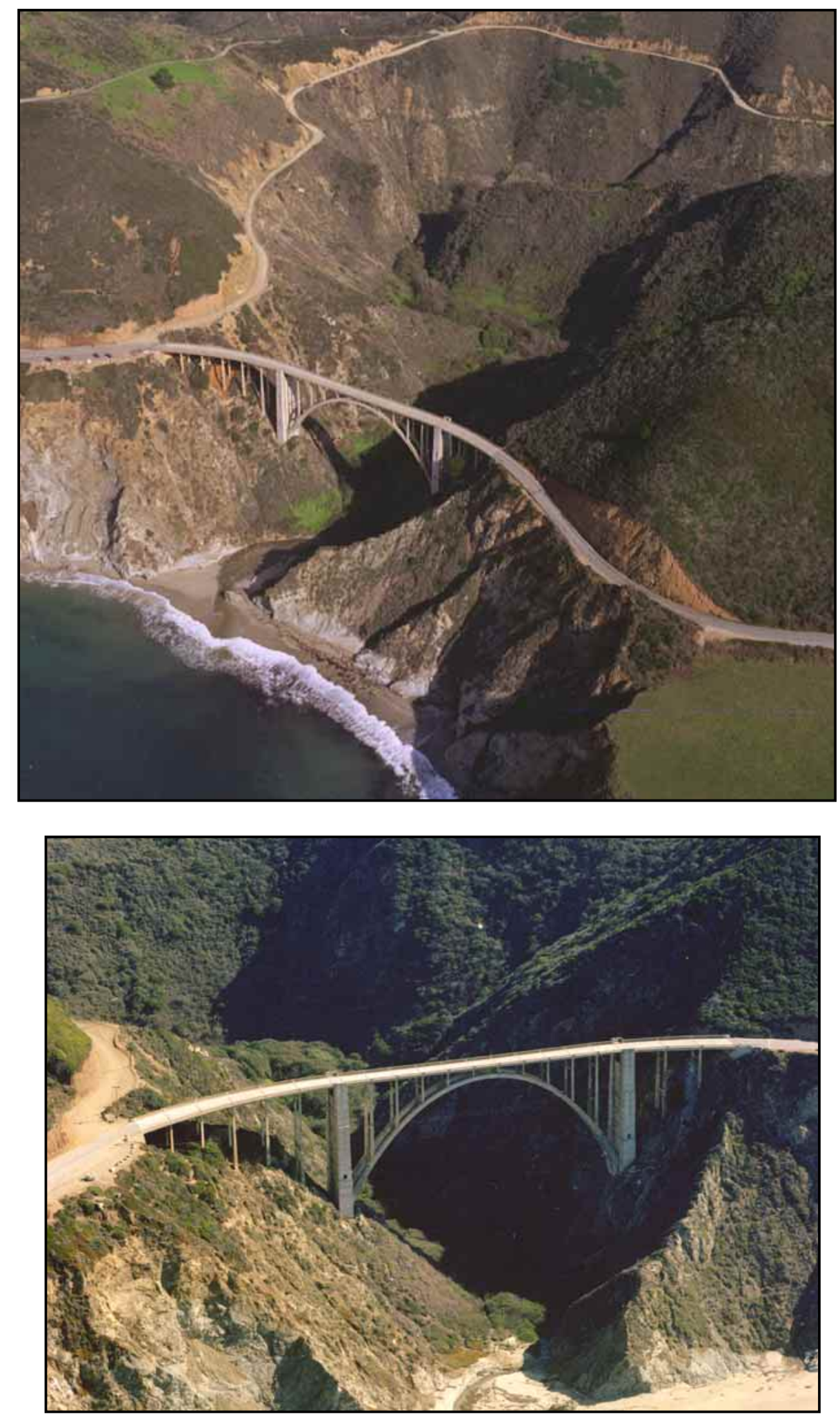

FIGURE 1. The Bixby Creek Bridge and the Bixby Creek Canyon. 
the Bixby Bridge main span is the longest of this group of arch bridges as indicated in Table 1 and as shown in Figure 3.

TABLE 1. Selected Highway 1 arch bridges.

\begin{tabular}{|c|c|c|}
\hline Arch Bridge & Span (ft.) & Height (ft.) \\
\hline Bixby Creek & 320 & 120 \\
\hline Rocky Creek & 239 & 56 \\
\hline Garrapata Creek & 150 & 45 \\
\hline Granite Creek & 120 & 45 \\
\hline Malpaso Creek & 117 & 30 \\
\hline
\end{tabular}

As part of this research project, LLNL also reviewed retrofit strategies which have been proposed for a larger number of arch bridges located throughout the state of California (see Appendix A). Bridge statistics were extracted from this retrofit database which illustrate where the Bixby Creek Bridge fits in terms of size and structural dynamics. The statistics from the retrofit database are shown in Figure 4. These comparisons indicate that the Bixby Creek Bridge is clearly one of the largest of this family of California bridges. The Bixby Creek retrofit study has been detailed in reports by the consulting firm of Buckland and Taylor [Ref 2], [Ref 3] and in the report of Anatech Corporation [Ref 4].

Arch bridges are capable of achieving long spans on the order of 150 to $1000 \mathrm{ft}$. The defining structural feature of arch bridges is the compressive load path by which gravity loads are transmitted through the main arch ribs into the supporting ground or abutments. The fact that arch bridges are compressive structures, as opposed to the tensile structures of other long span bridges (e.g. cable stayed and suspension), results in a fundamentally different structural behavior. Whereas tensile structures provide stiffening behavior when undergoing displacement, compressive arch structures provide softening behavior whereby the system stiffness can be reduced due to structural displacements as illustrated in Figure 5. There is thus an enhanced potential for instability in arch structures if displacements and forces are not appropriately designed for and controlled. In light of this fact, the three-dimensional transient seismic response of arch bridges requires careful consideration and study.

The three dimensional seismic response of arch bridges has recently been studied by Nazmy [Ref 5] and Nazmy and Konidaris [Ref 6]. The conclusions developed by Nazmy and his coworkers as a result of these studies included:

- To obtain realistic earthquake response, it is necessary to perform the analysis with three orthogonal components of earthquake motion acting simultaneously

- For long-span arch bridges, it is essential to perform both nonlinear static and nonlinear seismic analyses in order to obtain realistic results 

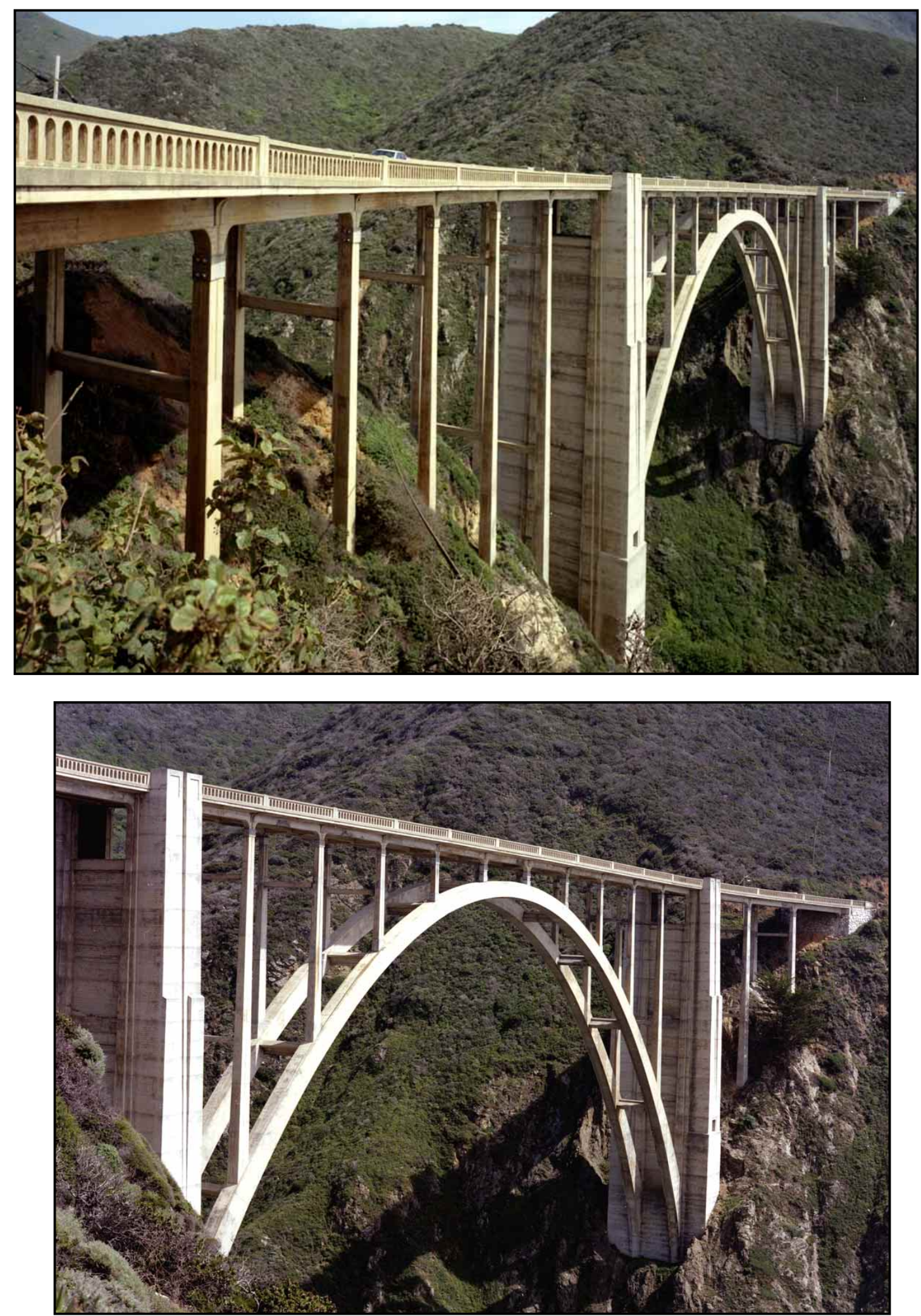

FIGURE 2. North approach and center arch span of the Bixby Creek Bridge. 

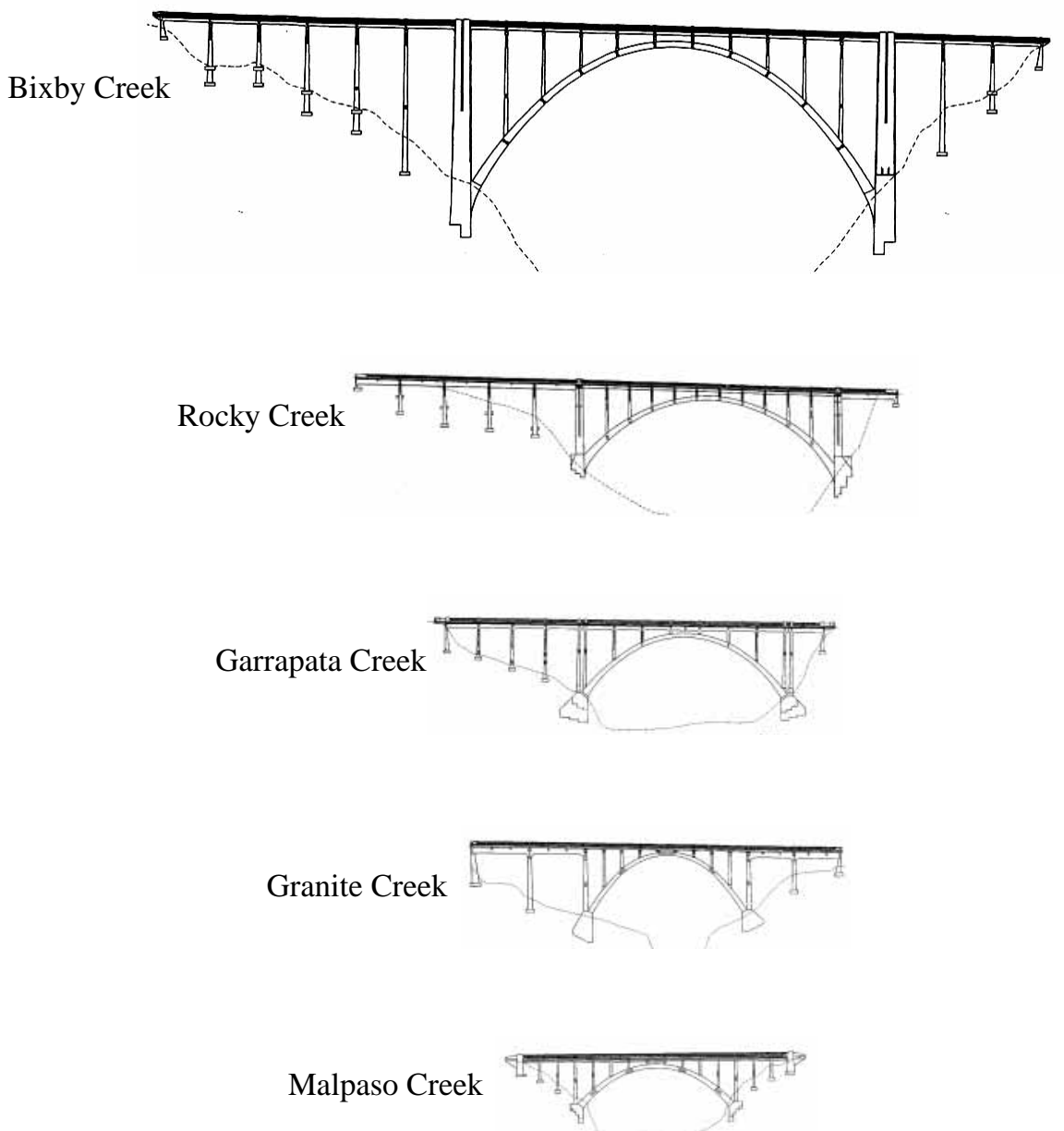

FIGURE 3. Highway 1 concrete arch bridges near Monterey and Carmel, California.

- Multiple support excitation considerably increases the seismic response of long-span arch bridges when compared to uniform excitations

In the study described herein, these and other issues are addressed for the specific case of the Bixby Creek Bridge. The scope of work for the Bixby Creek Bridge research study consisted of four primary areas:

- Computer simulation of the transient, nonlinear seismic response of the bridge system including a comparative study of nonlinear versus linear response computations, and an assessment of the effects of various modeling assumptions and idealizations on the bridge response computations. Particular attention was placed on the determination and quantification of the differences between computations performed with simpler, linearized structural models versus computations with complex, nonlinear structural models and how the differences in modeling might impact design decisions 

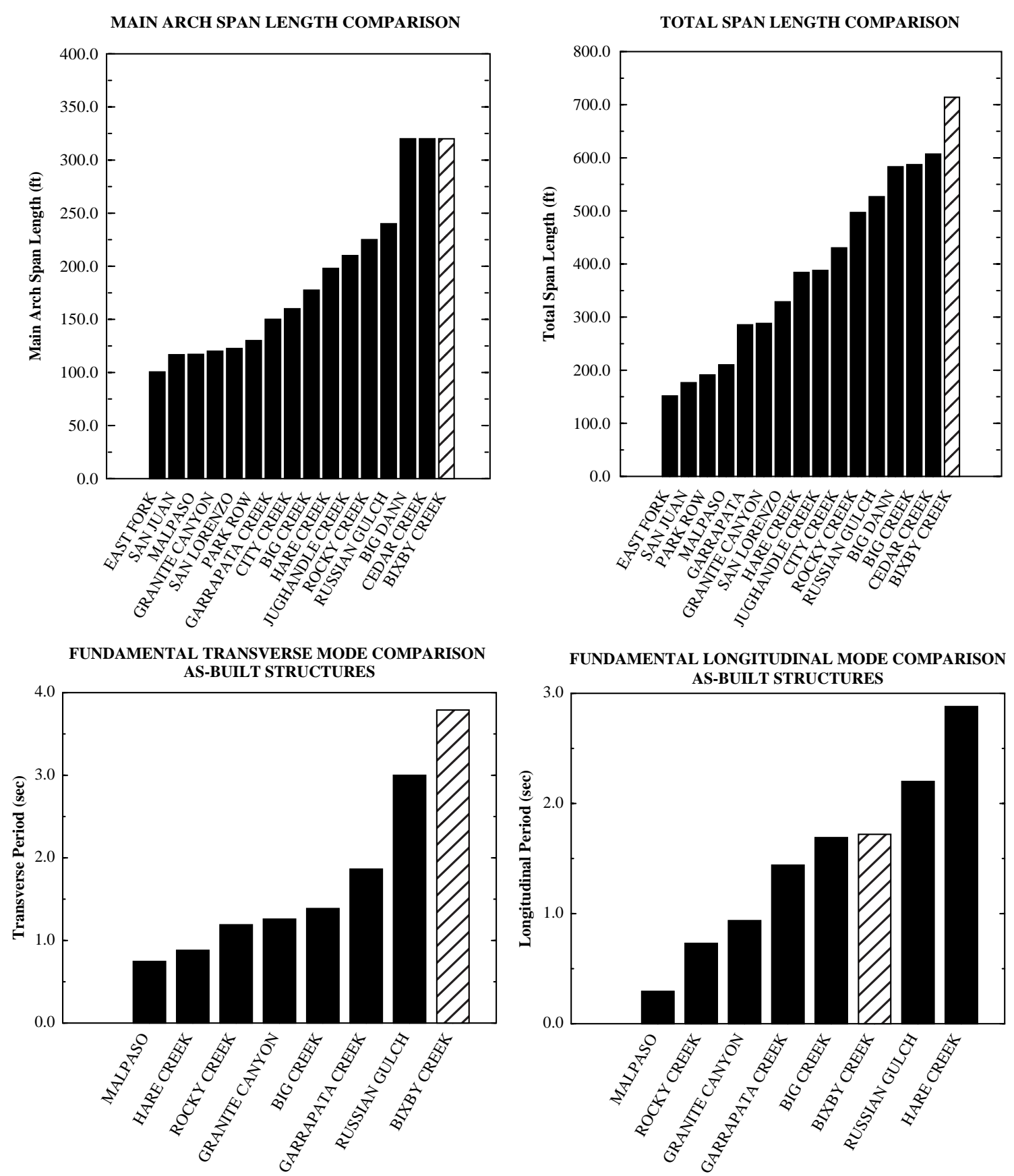

FIGURE 4. Comparison of bridge statistics from the database of arch bridge retrofits (bridge periods determined from consultant computational models).

- Field structural experimentation to ascertain the small amplitude, linear dynamics of the existing, as-built Bixby Creek Bridge system in order to provide a check on the frequency range predicted with the computational bridge models

- Placement of field seismological instrumentation to measure wave scattering in the Bixby Creek Canyon to assess the potential for multiple support input motions 

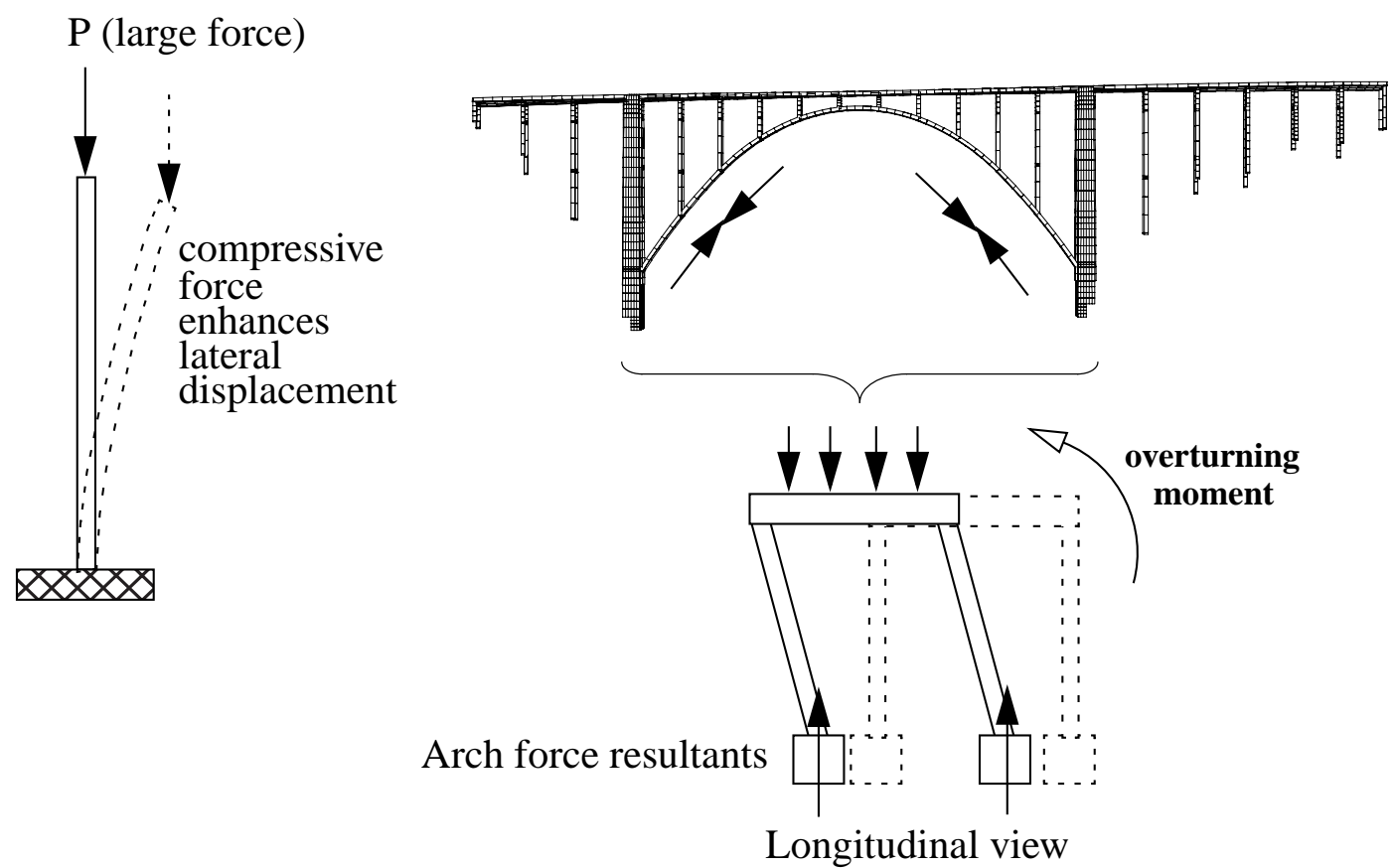

a) Softening structure: compression structure (arch bridge)

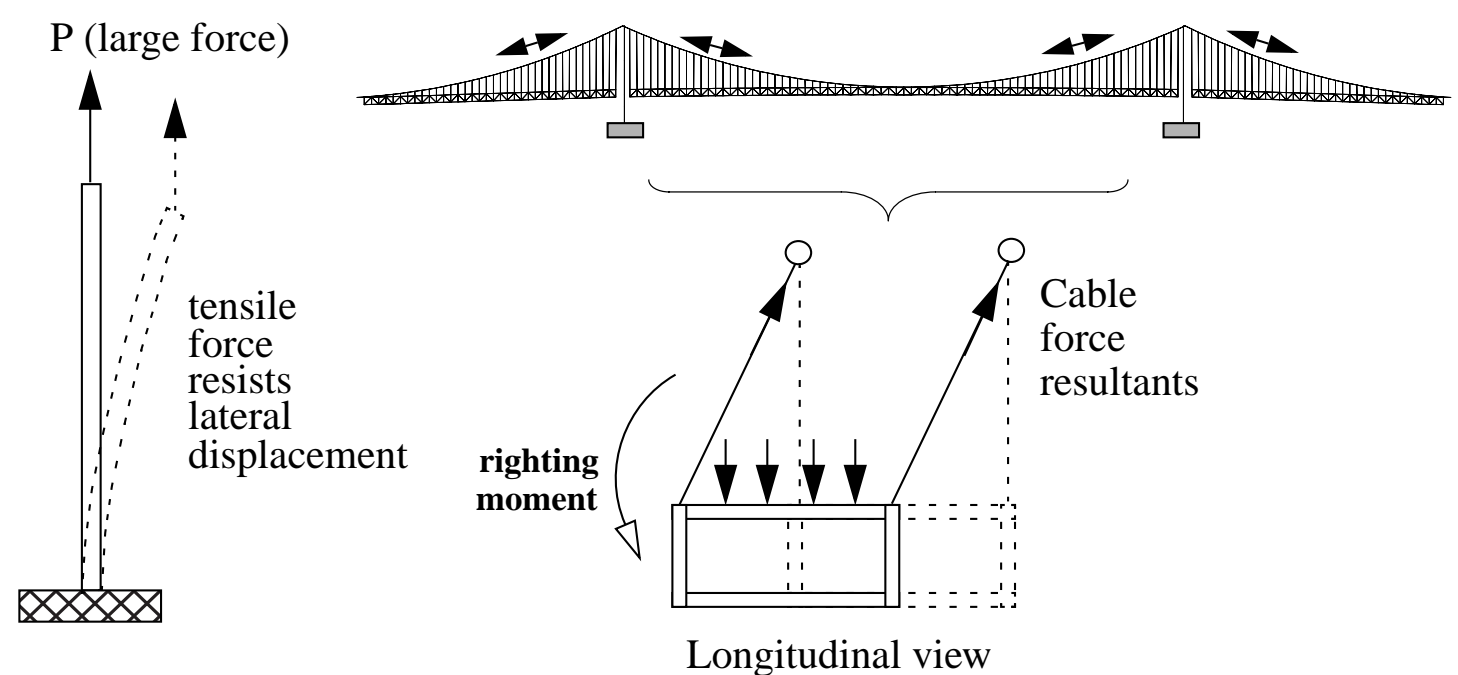

b) Stiffening structure: tension structure (cable bridge)

FIGURE 5. Structural resistance mechanics of compression and tension structures. a) Arch bridge; b) cable supported bridge. 
- Independent determination of the adequacy of the retrofit concept developed for the Bixby Creek structure by Caltrans consultants

The generic objectives of this work were to provide detailed understanding of nonlinear effects in a large arch bridge system and to understand the transient dynamics of large arch structures. The methodologies employed in this study and the results of this study are described and summarized in this report. 


\subsection{Earthquake ground motions}

The Bixby Creek Bridge is located approximately 18 miles south of Carmel, California on
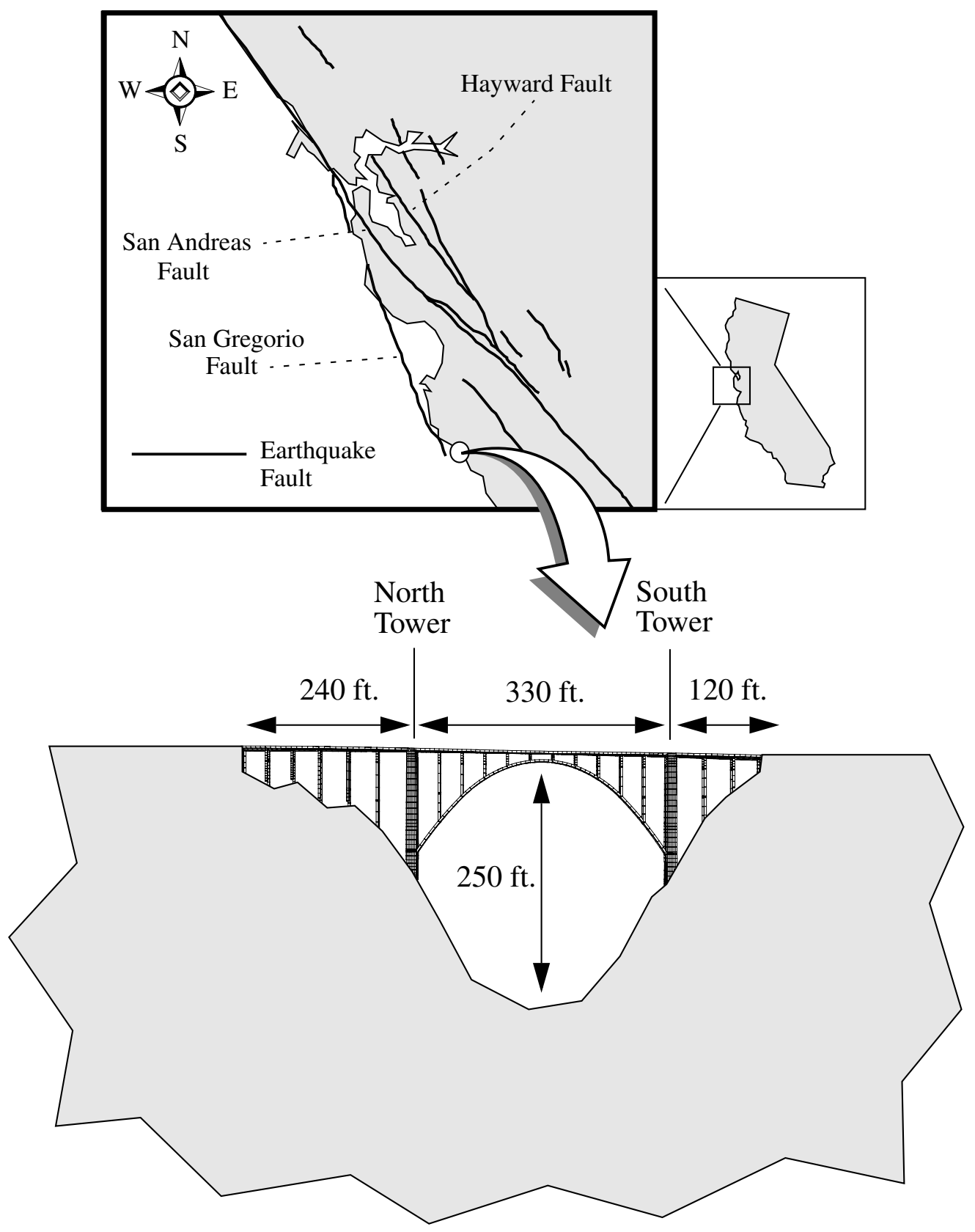

FIGURE 6. Location of the Bixby Creek Bridge and the topography of the Bixby Creek Canyon.

Highway 1. Figure 6 shows the location of the bridge site relative to major active earthquake faults and Figure 7 shows the topography in the immediate vicinity of the bridge. A Caltrans file letter of September 1994 from Chai and Jackura [Ref 7] summarizes the Caltrans earthquake hazard estimates for this site. Although this letter is labeled Preliminary 


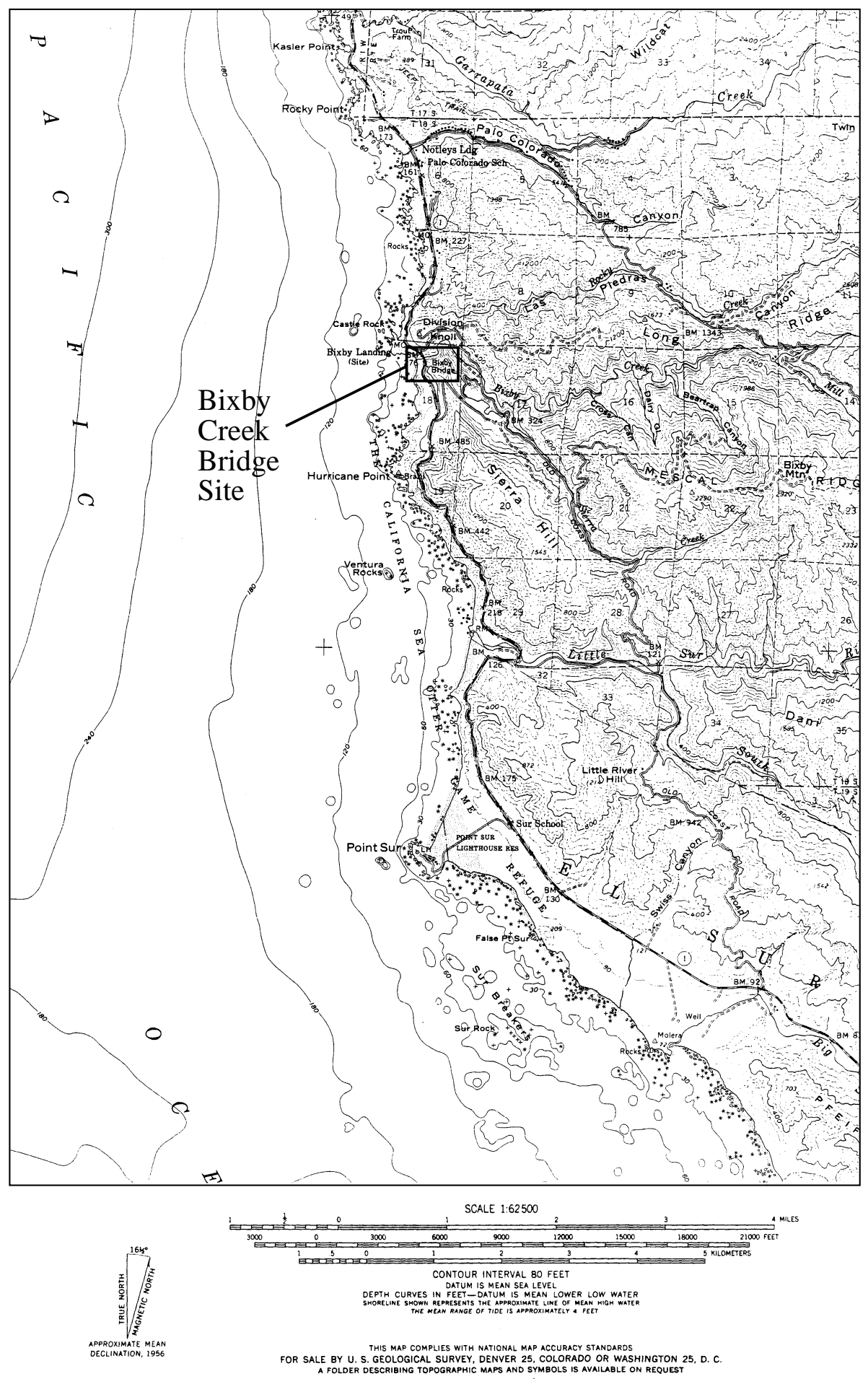

FIGURE 7. Topographic map of the vicinity of the Bixby Creek Bridge.

Site Specific Analysis, it provided the basis of the Bixby Creek retrofit design. In accordance with the California Division of Mines and Geology report, Peak Acceleration from Maximum Credible Earthquakes in California, Caltrans notes the controlling fault for this 
site is the Palo Colorado-San Gregorio fault system. The fault is stated to pass at a distance of approximately $1 \mathrm{~km}$ from the Bixby Creek site with a maximum credible earthquake potential of magnitude 7.5 , a $0.72 \mathrm{~g}$ peak horizontal ground acceleration and a $0.70 \mathrm{~g}$ peak vertical ground acceleration. Caltrans computed 50th percentile ground spectra based on the attenuation equation proposed by Geomatrix. Ground motion time histories for the site have been developed by Caltrans based on a target spectrum approach [Ref 7]. The Rascal computer program was used to modify existing ground motion records to fit the target spectrum. The first record used in the fitting process was the 1989 Loma Prieta Santa Cruz record (see Figure 8 and Figure 9), and the second record was a Seed and Idriss time history (see Figure 10 and Figure 11). The Caltrans ground motions did not account for potential variable support motion across the canyon site.

Based on the time frame in which the records described above were generated (early 90's), LLNL requested that Caltrans provide updated time histories which would reflect the latest information regarding near-field phenomenon in the ground motions. Of particular concern was the potential for large ground displacement pulses and permanent ground displacements at the Bixby Bridge site. Since the Bixby site is only about $1 \mathrm{~km}$ from the Palo Colorado-San Gregorio fault, significant long-period, near-field ground motions are likely to occur during a major earthquake. Based on this request, Caltrans provided new time histories for a maximum credible $M=7.5$ earthquake [Ref 8]. These time histories have three separate components: fault normal, fault parallel and vertical. The time histories and associated response spectrum for these records are shown in Figure 12 through Figure 14. Large displacement pulses are included in these records; however, the records do not include permanent ground displacements in the time histories. Fortunately, the natural vibration periods of the Bixby Creek structure (approximately 2.5-3 seconds for the unretrofit structure, and approximately 1.5 seconds for the retrofit structure) are short enough that the rise times associated with permanent displacements will likely be long relative to the natural periods of the bridge system.

For the transient analyses described in this report, the indicated earthquake time histories supplied by Caltrans were employed. Full development of synthetic ground motion records at this site was beyond the scope of this research project; however, one task was included to implement seismic monitoring equipment at the Bixby Site for investigation of potential variable support motion effects. This task included fielding a sparse ground motion array at the Bixby site to allow investigation of potential wave scattering effects in the deep Bixby Creek Canyon. Potential wave scattering in the canyon topography can lead to incoherence in the bridge support motions on opposite sides of the canyon. The LLNL site instrumentation consisted of three triaxial sensors with associated data acquisition systems. The instrument locations included one free-field sensor placed into competent rock to the north of the bridge, and one sensor located near the base of each tower as indicated in Figure 15.

To expedite the data acquisition process during the early stages of this project, the initial instrument deployment at the site consisted of existing Refraction Technology (RefTec) data acquisition systems which stored measured data locally on a disk. These instruments required site visits by LLNL technicians to retrieve measured data. The longer term data acquisition scheme developed for this research project included the construction of new 
acquisition systems which contained wireless, cellular phones for remote communication of measured data. These systems were tailored to the task of acquiring measured ground motion records, storing the data on computer disk, and allowing remote call-up of the data acquisition system with a laptop computer and modem. The systems also included a GPS unit on board for precision timing. The first operational system which was developed and constructed specifically for this project is shown in Figure 16.

\subsection{Simulation of wave scattering in the Bixby Creek Canyon}

The frequency dependent effects of wave scattering in the Bixby Creek Canyon have been investigated with a simple two dimensional finite element model of the canyon topography (Figure 17). The finite element model was employed to investigate wave scattering in the canyon as a function of wave frequency and the incidence angle of incoming waves relative to the canyon. The model represented a geologic segment of 3000 meters length by 1000 meters depth and mesh density leading to a model with approximately 22,000 nodes. For the sake of simplicity, the finite element model considered a homogenous material with material properties characteristic of typical gneiss like that found at the bridge site. The representative material properties employed in the model are summarized in Table 2. With the assumption of homogeneous material, it is noted that this simulation only addressed the effects of topography, not the potential effects due to heterogeneities of geologic properties.

TABLE 2. Assumed material properties for the geologic model.

\begin{tabular}{|c|}
\hline Mass density, $\rho=2750 \mathrm{~kg} / \mathrm{m}^{3}$ \\
\hline Poisson's ratio, $v=0.25$ \\
\hline Shear wave speed, $\mathrm{C}_{\mathrm{s}}=3000 \mathrm{~m} / \mathrm{s}$ \\
\hline Shear modulus, $\mathrm{G}=2.475 \times 10^{10} \mathrm{~N} / \mathrm{m}^{2}$ \\
\hline Elastic modulus, $\mathrm{E}=6.19 \times 10^{10} \mathrm{~N} / \mathrm{m}^{2}$ \\
\hline Compressional wave speed, $\mathrm{C}_{\mathrm{p}}=5197 \mathrm{~m} / \mathrm{s}$ \\
\hline
\end{tabular}

The finite element model was prepared by Hoehler for the DYNAFLOW finite element program at Princeton University [Ref 9], and the input motion to the computational domain consisted of a train of planar, sinusoidally varying shear waves with particle motions in the vertical plane (i.e. SV waves). The sub-surface boundaries of the computational domain were modeled with a transmitting boundary option in the DYNAFLOW program to allow waves reflecting from the free surface of the model to effectively transmit back out of the half-space and not become trapped in the computational domain and build up fictitious energy in the modeled region. The implementation of the planar propagating shear wave required appropriate phasing of the surface tractions applied to the non- 
a)
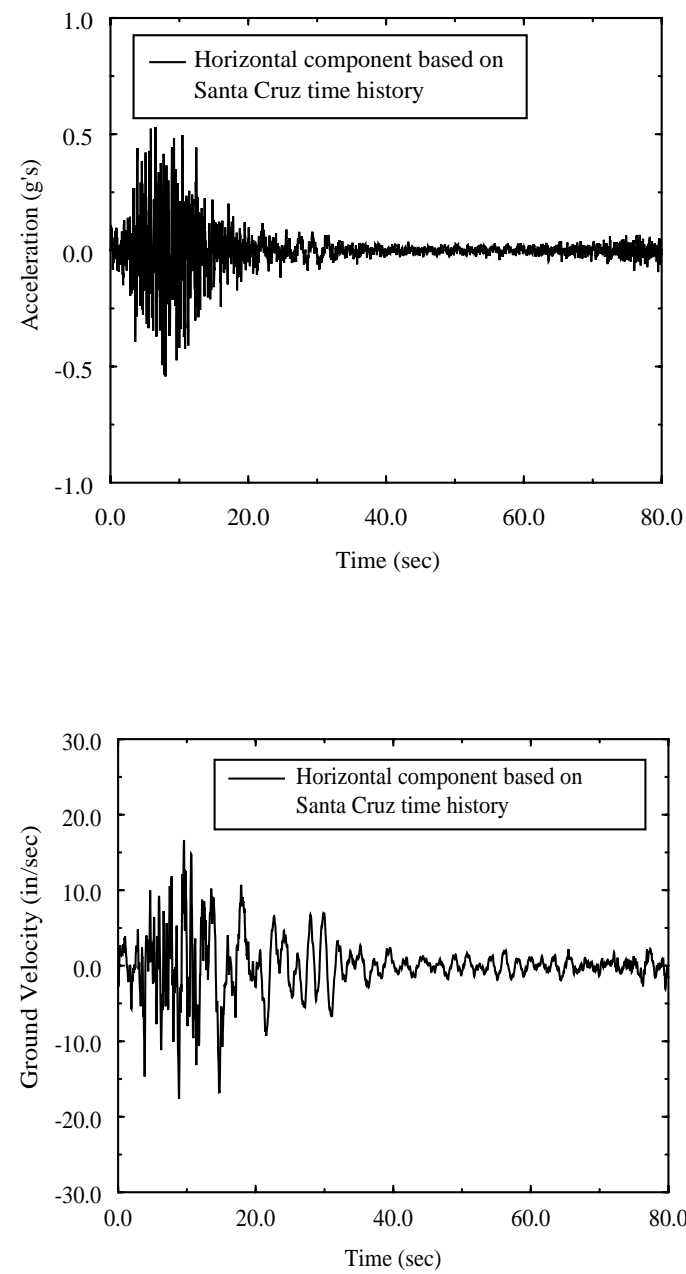

c)

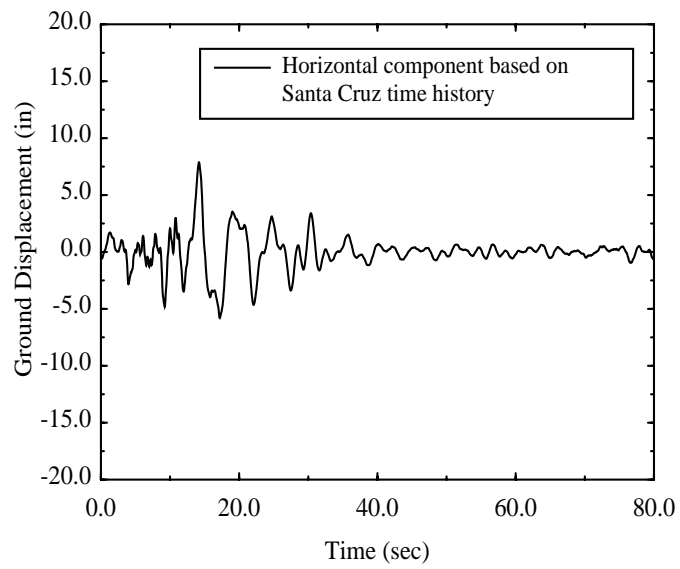

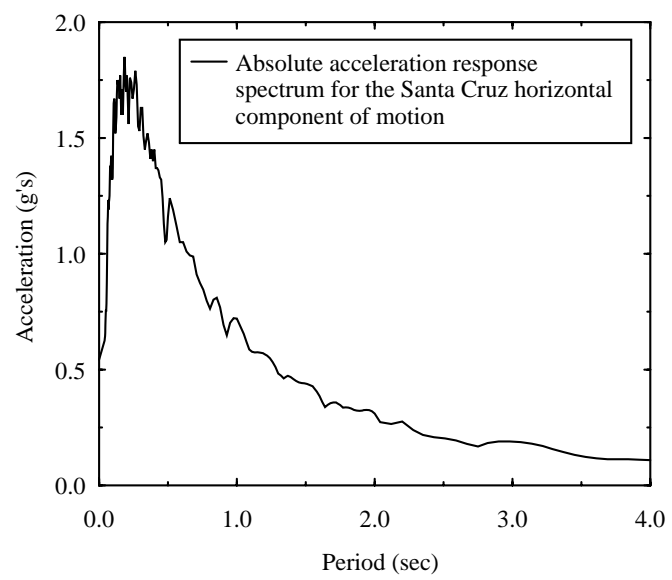
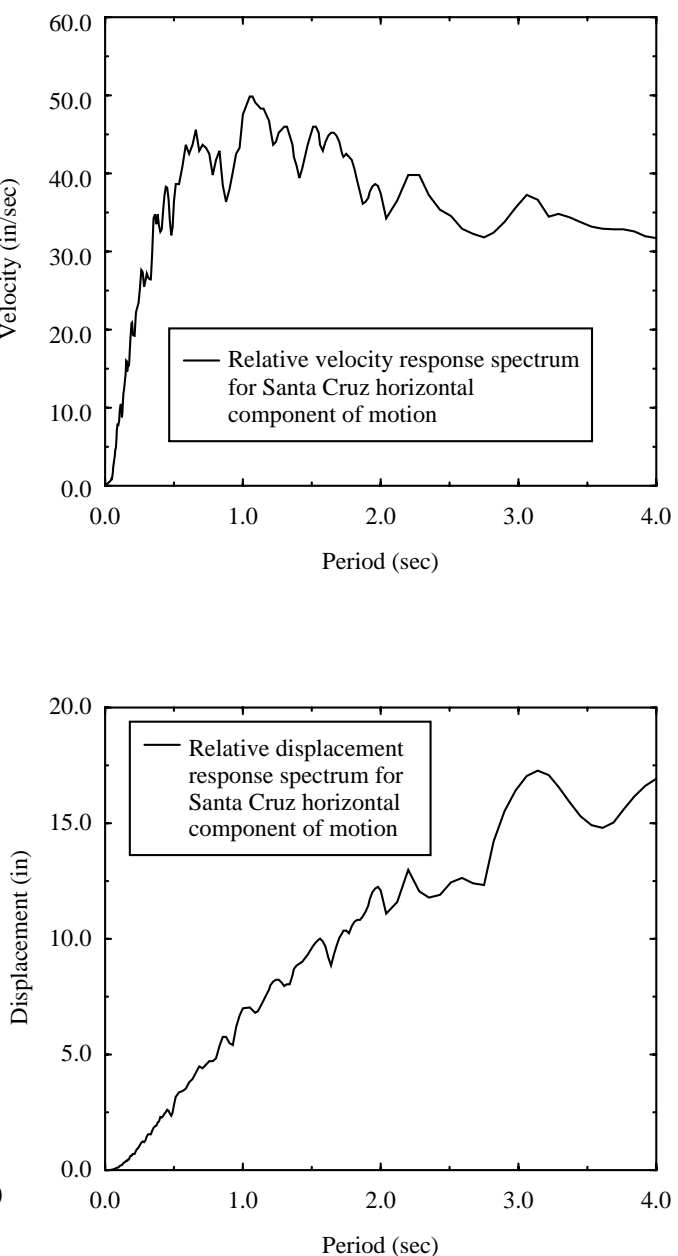

FIGURE 8. Bixby Creek ground motion based on Santa Cruz time history. a) Horizontal ground acceleration; b) horizontal ground velocity; c) horizontal ground displacement. 
a)
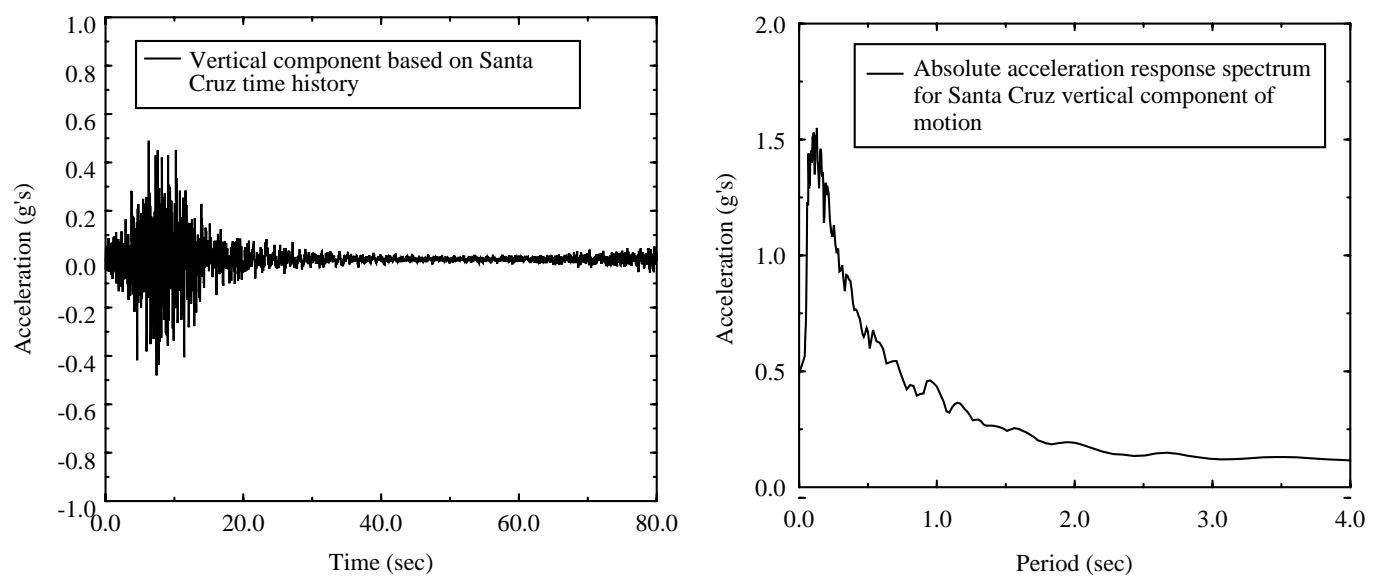

b)
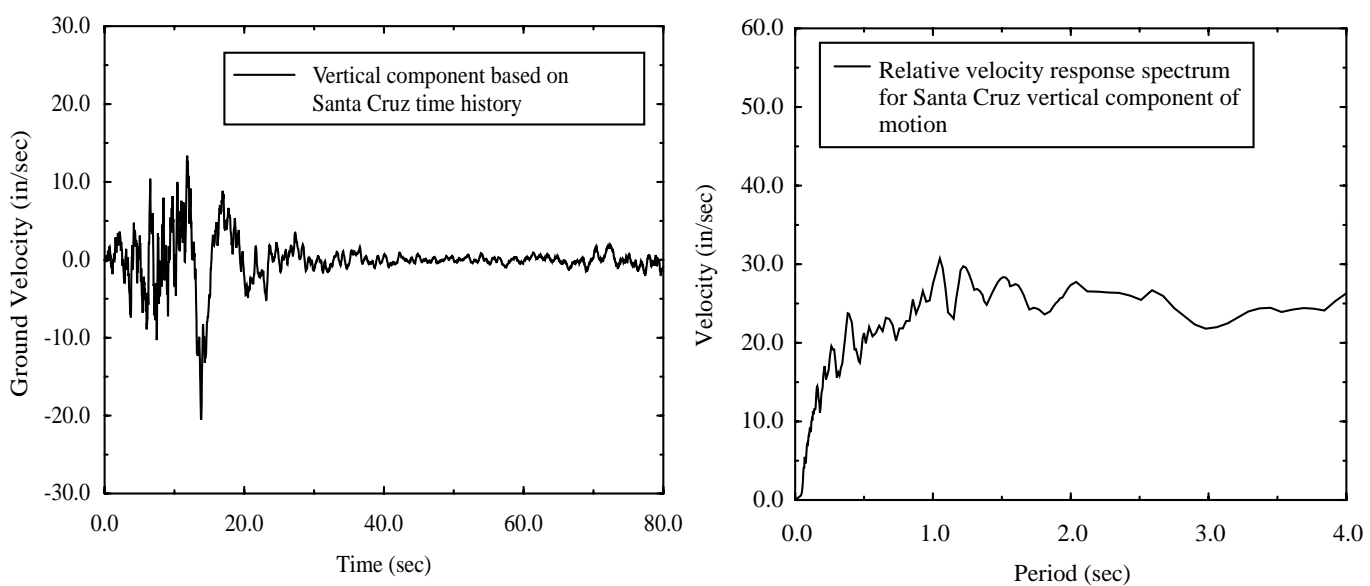

c)
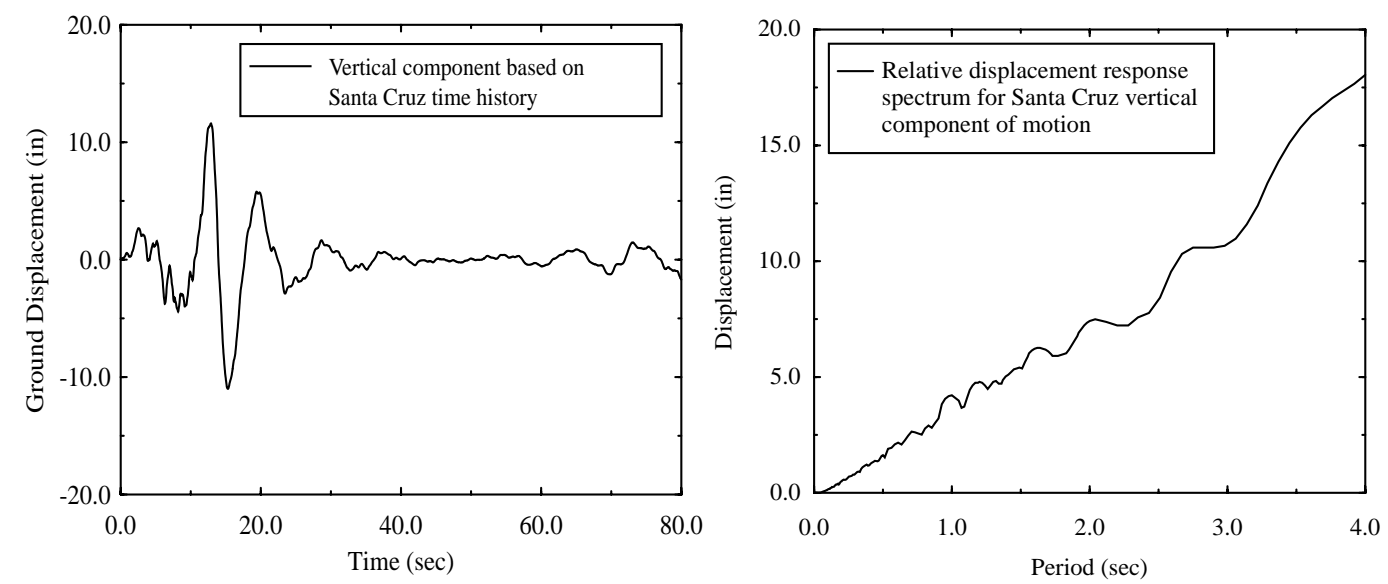

FIGURE 9. Bixby Creek ground motion based on Santa Cruz time history. a) Vertical ground acceleration; b) vertical ground velocity; c) vertical ground displacement. 
a)

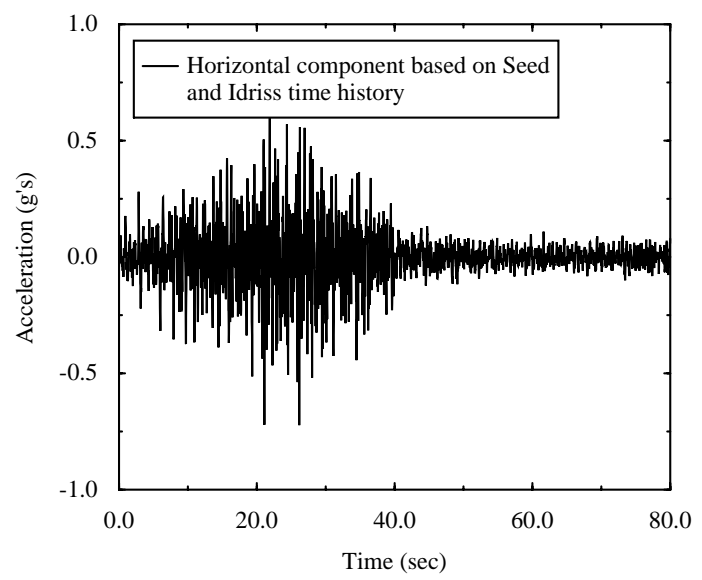

b)

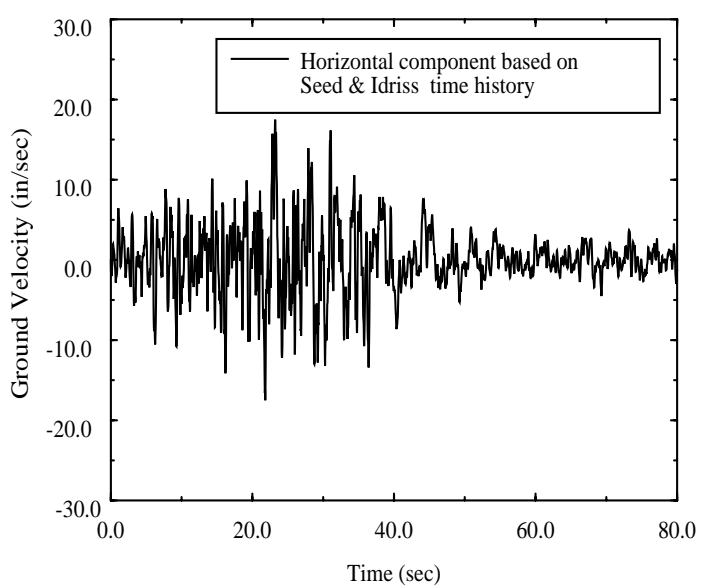

c)

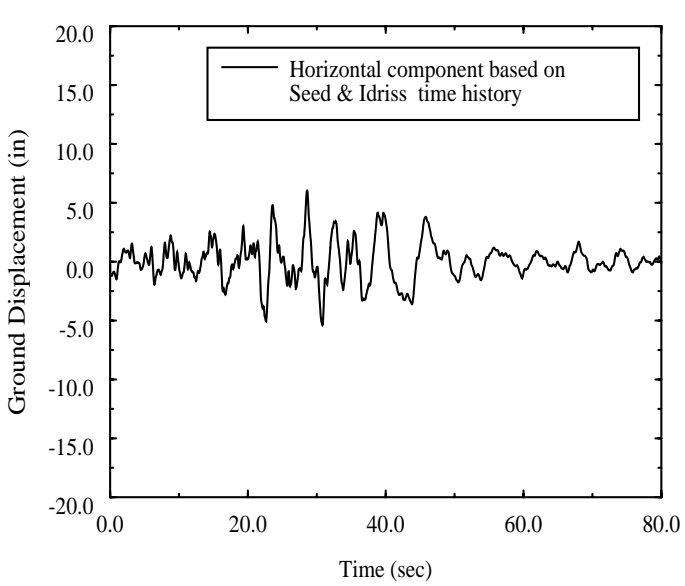

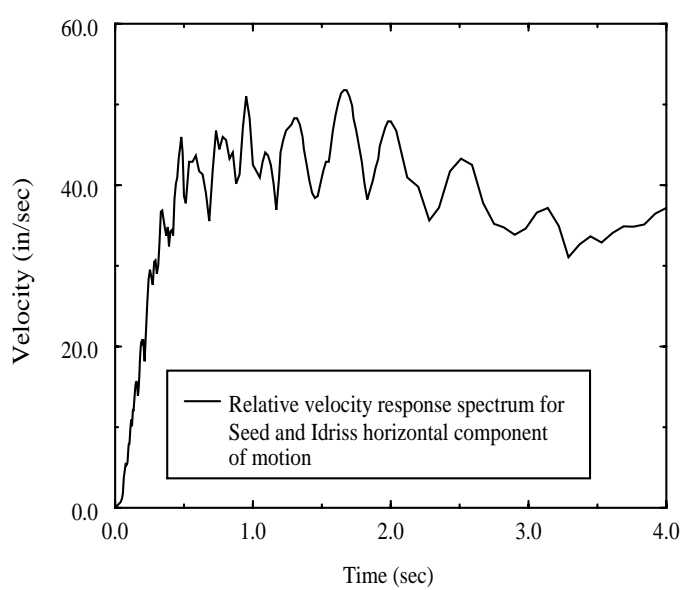
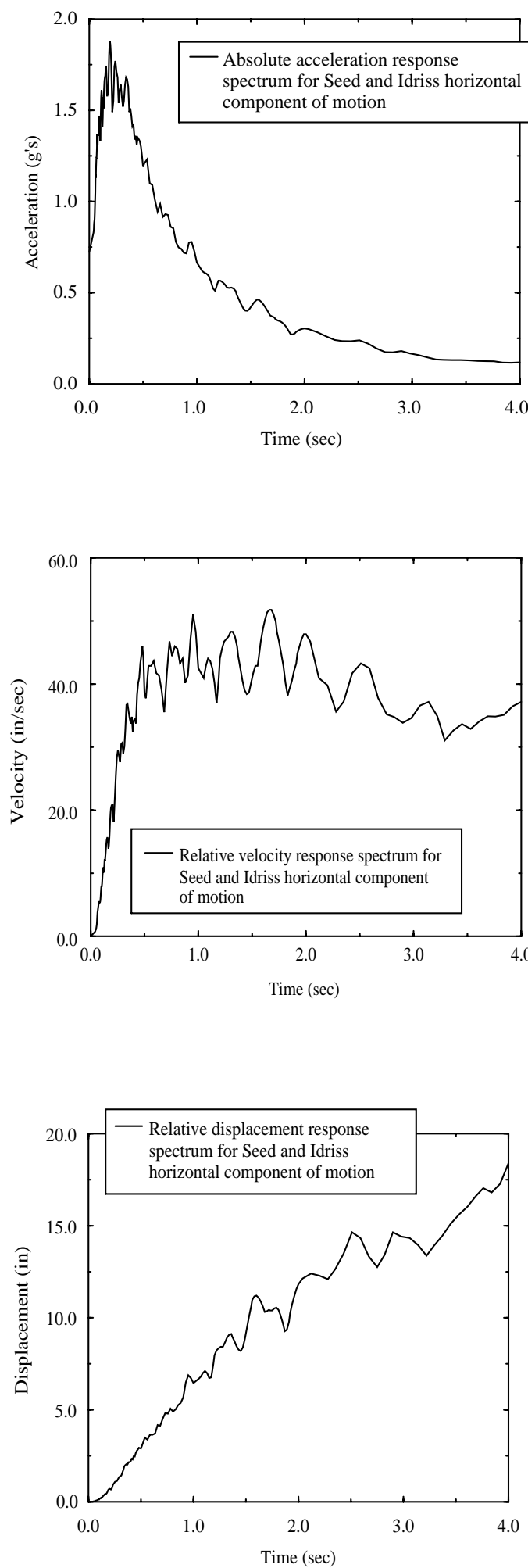

FIGURE 10. Bixby Creek ground motion based on Seed and Idriss time history. a) Horizontal ground acceleration; b) horizontal ground velocity; c) horizontal ground displacement. 
a)
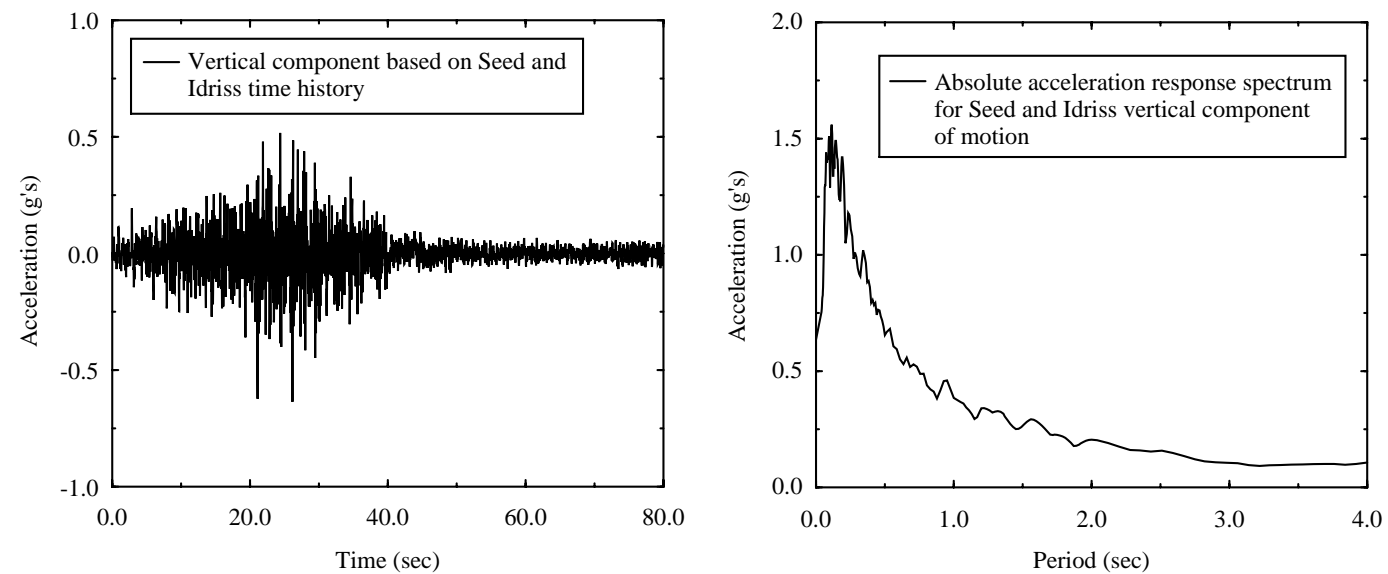

b)
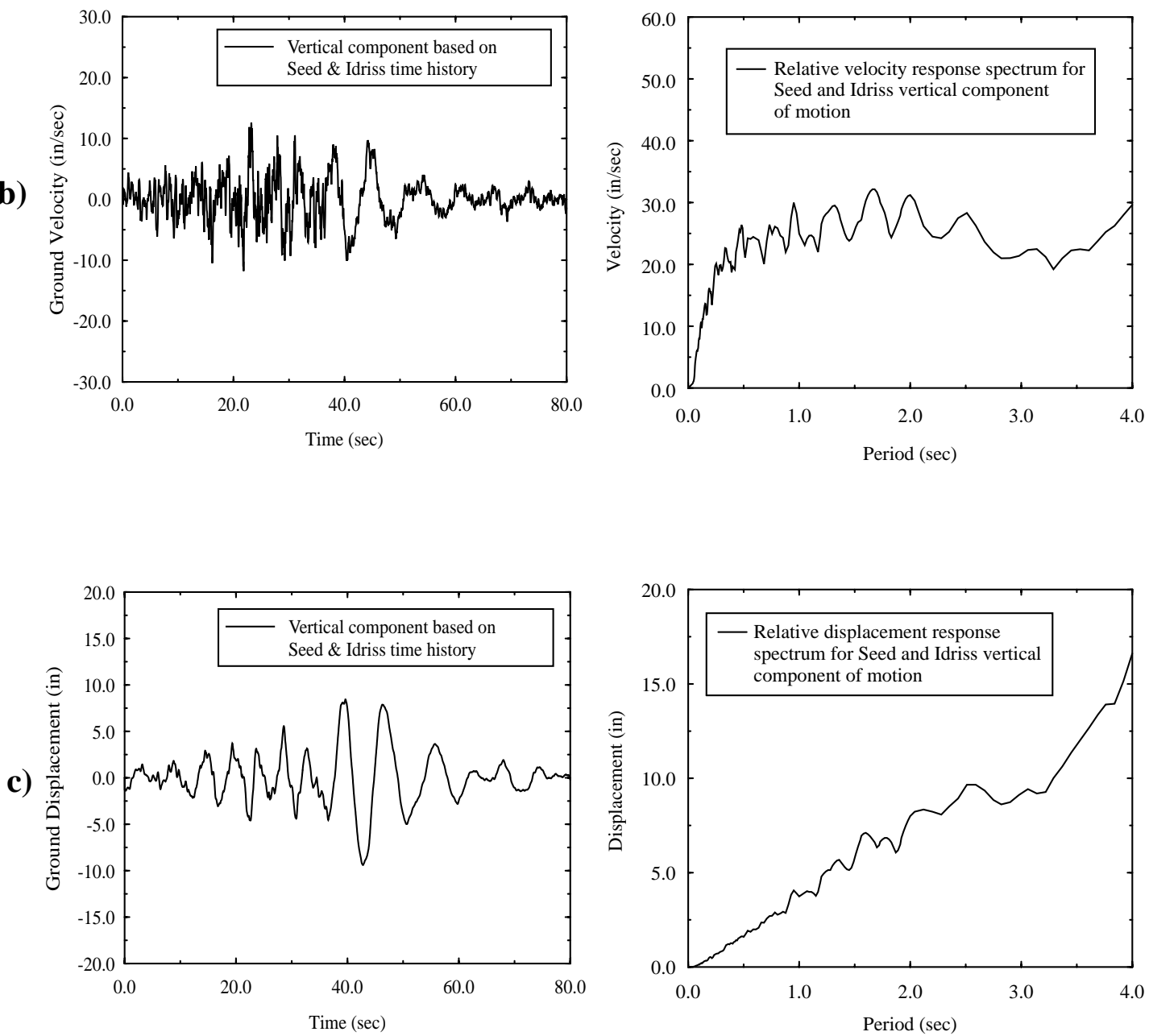

FIGURE 11. Bixby Creek ground motion based on Seed and Idriss time history. a) Vertical ground acceleration; b) vertical ground velocity; c) vertical ground displacement. 
a)
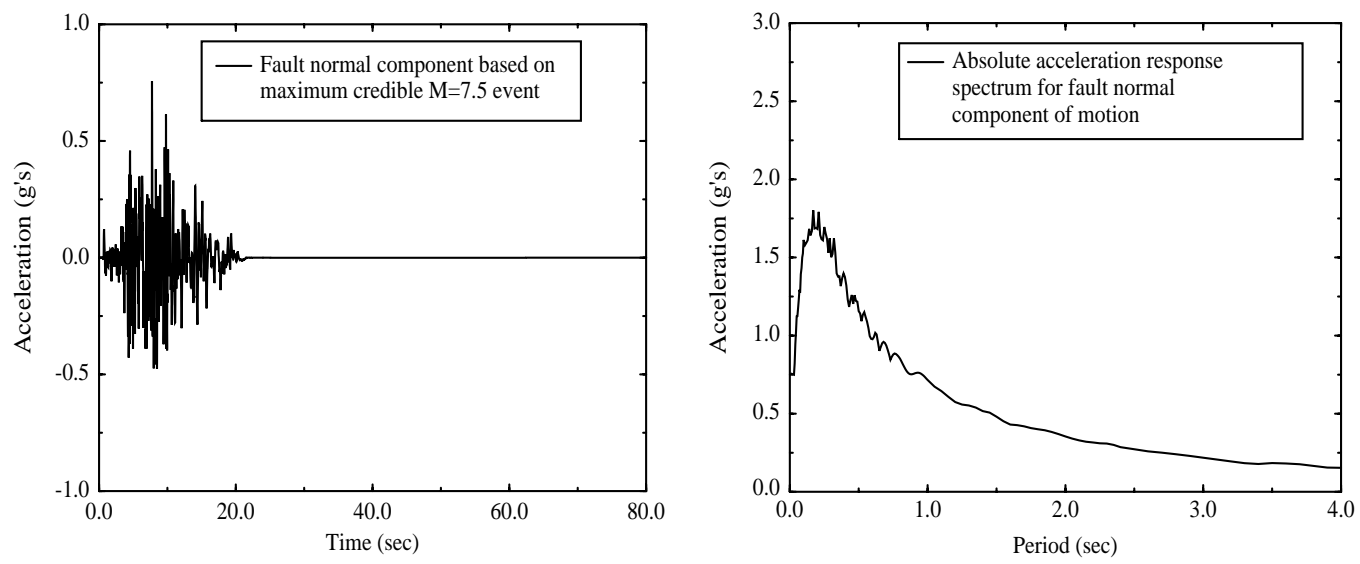

b)
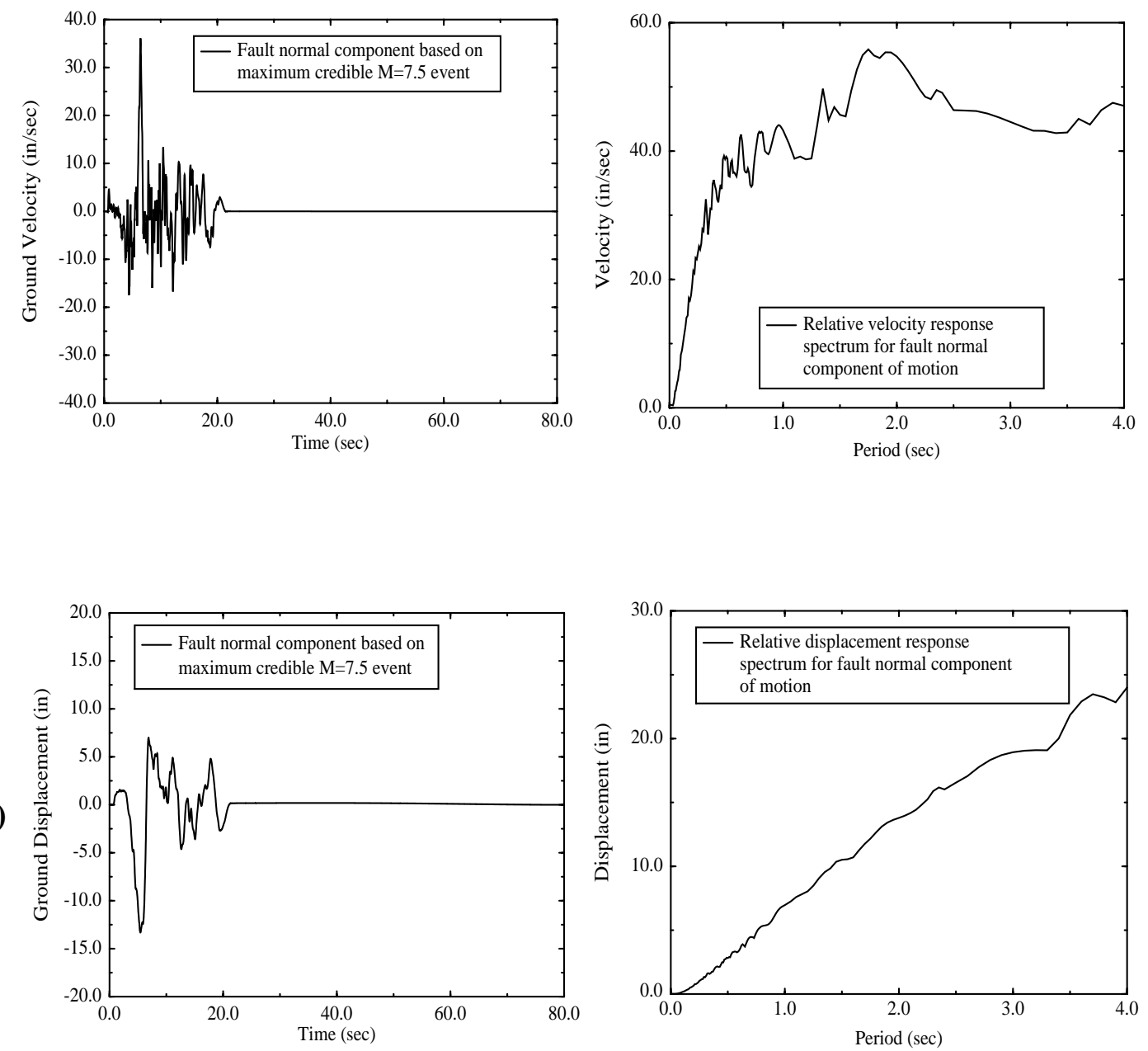

FIGURE 12. Bixby Creek ground motion based on maximum credible $M=7.5$ earthquake, including near-field terms. a) Fault normal ground acceleration; b) fault normal ground velocity; c) fault normal ground displacement. 
a)
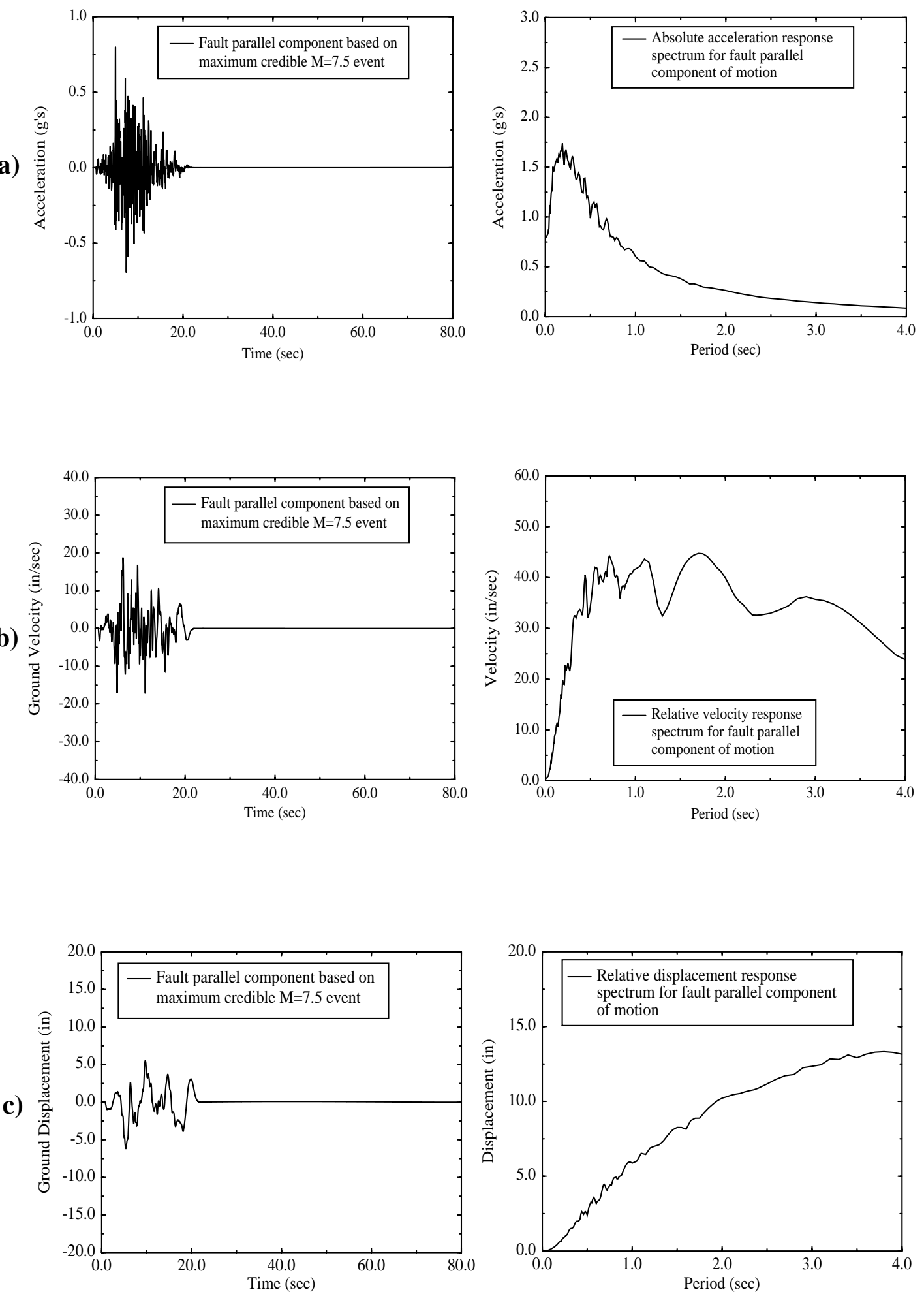

FIGURE 13. Bixby Creek ground motion based on maximum credible $M=7.5$ earthquake, including near-field terms. a) Fault parallel ground acceleration; b) fault parallel ground velocity; c) fault parallel ground displacement. 
a)
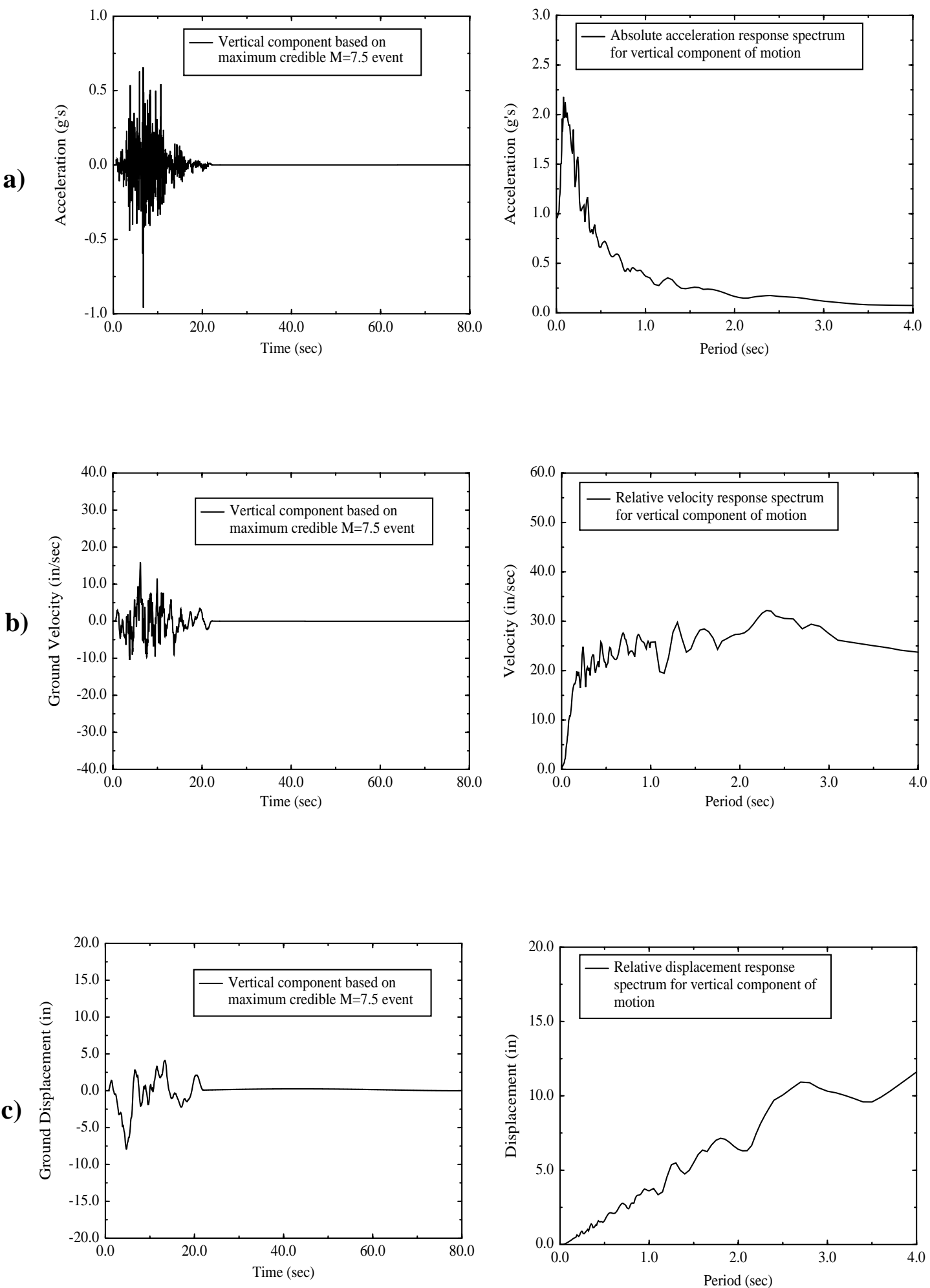

FIGURE 14. Bixby Creek ground motion based on maximum credible $M=7.5$ earthquake, including near-field terms. a) Vertical ground acceleration; b) vertical ground velocity; c) vertical ground displacement. 


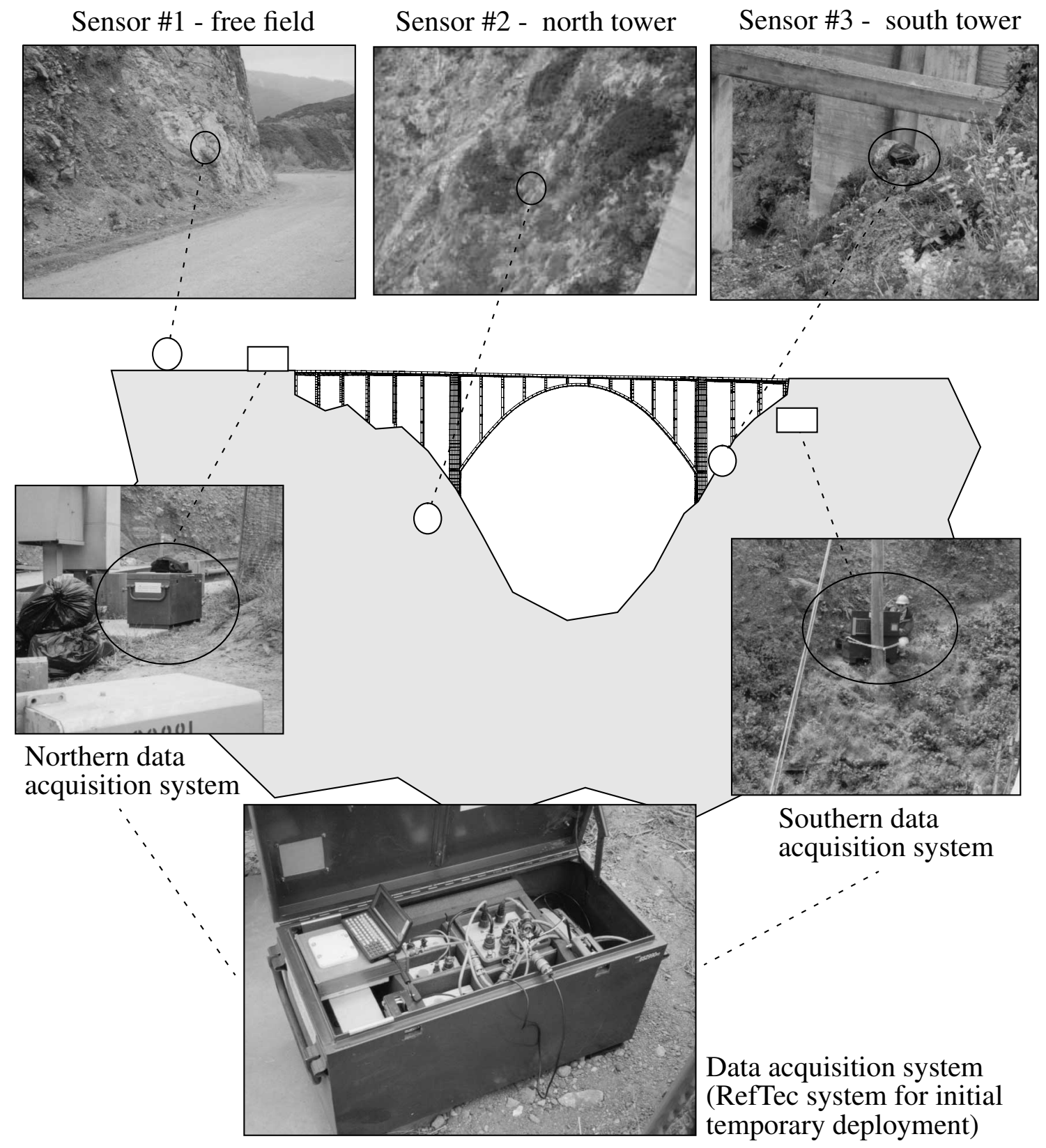

FIGURE 15. LLNL field instrumentation locations.

planar model boundaries, and the details of the motion input process are described by Hoehler [Ref 9].

The range of frequencies of interest relative to scattering in the canyon are a function of the shear wave velocity of the material and the dimensions of the canyon. Previous studies by Wong and Jennings [Ref 10] have indicated that the largest amplification effects due to topography for incident shear waves are expected when the wavelength of incident waves are equal to or less than the horizontal dimension of the specific topographic feature (i.e. 


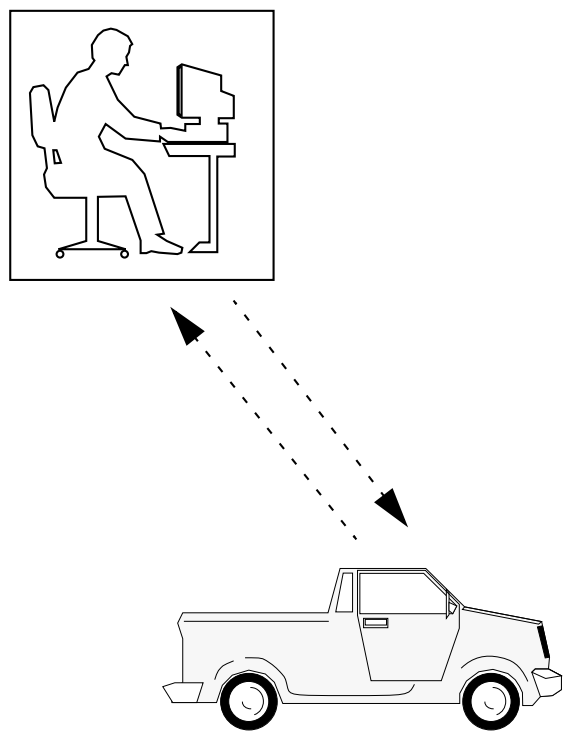

Site visits required for data retreival
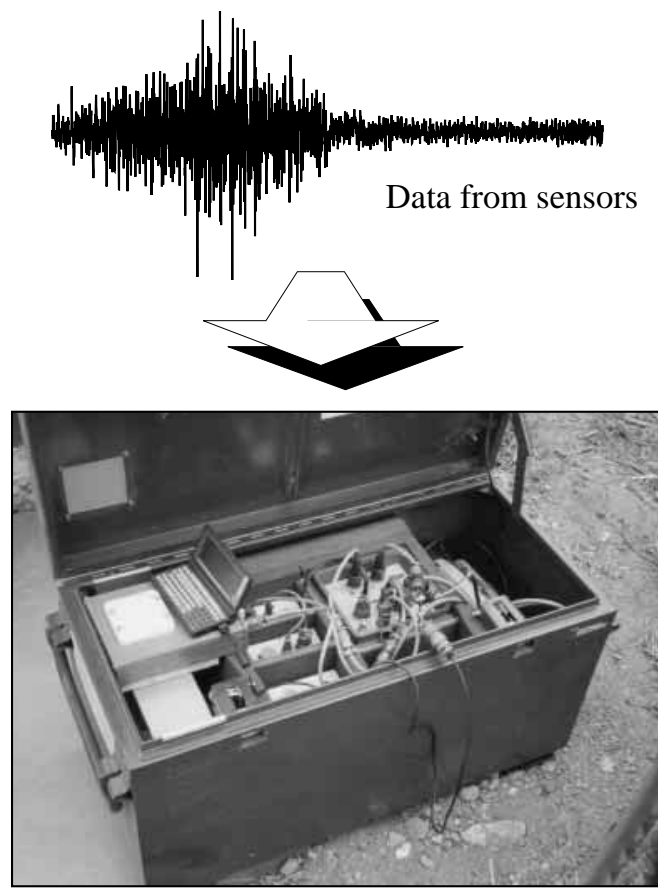

Remote site

(a)
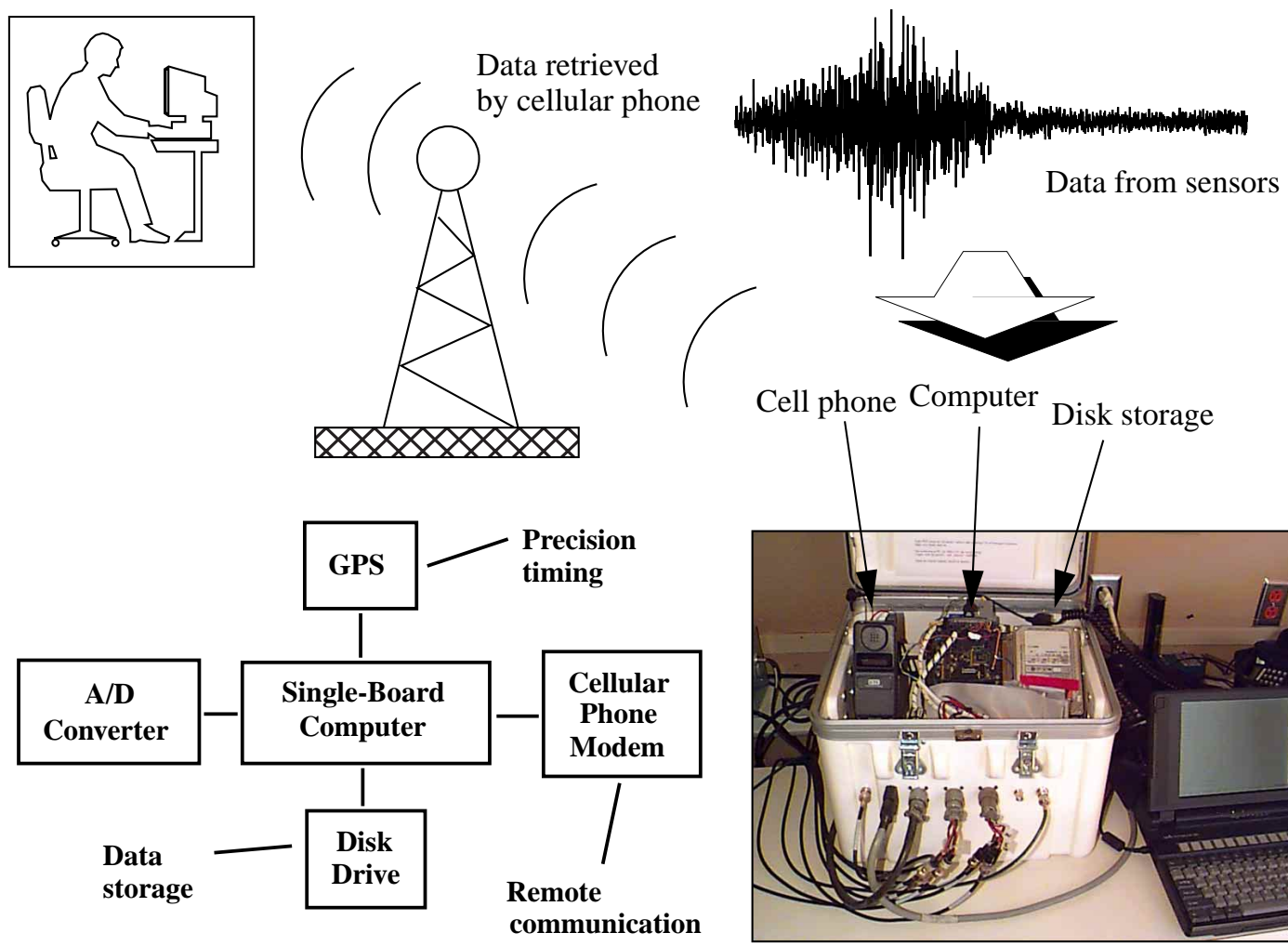

Components of acquisition system

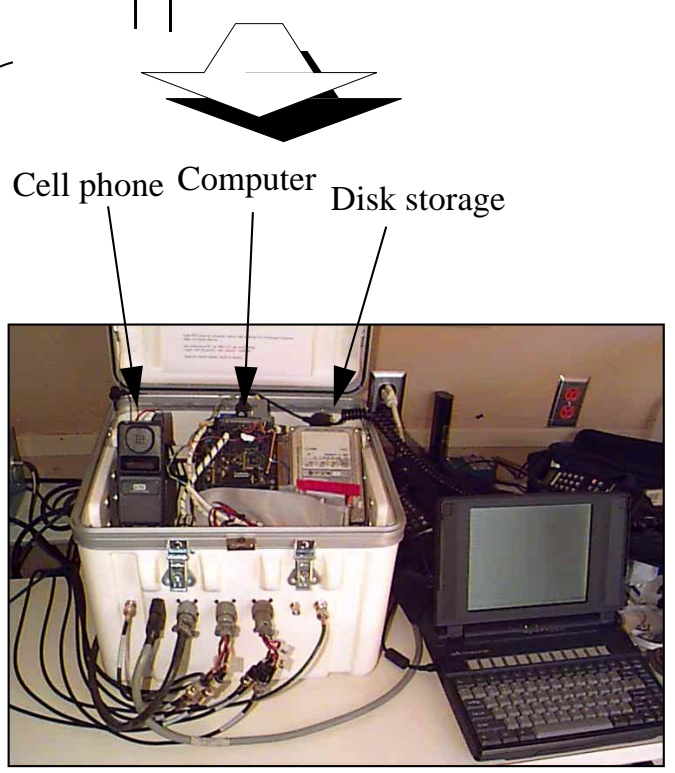

Remote site

FIGURE 16. Temporary and long-term instrumentation field deployments at the Bixby Creek site. a) Temporary data acquisition; b) long-term data acquisition. 


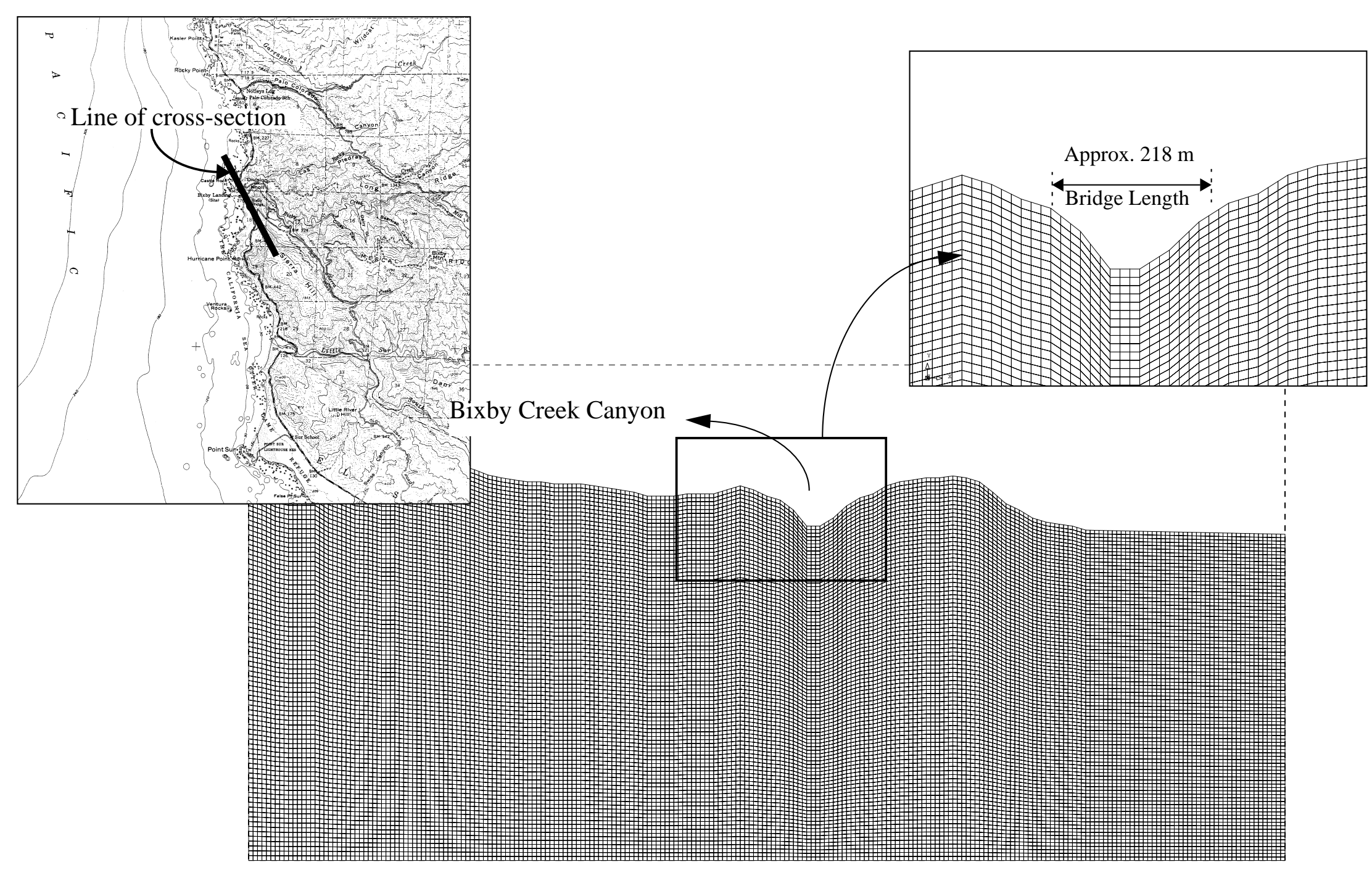

FIGURE 17. Two dimensional finite element model of the Bixby Creek Canyon. 
the Bixby Creek canyon in this case). If the total width of the canyon is assumed to be approximately $500 \mathrm{~m}$ (Figure 19), and the wave speeds of Table 2 are assumed, a waveform would theoretically require a frequency of approximately $6 \mathrm{~Hz}$ in order to have a wavelength comparable to the canyon's horizontal dimension.

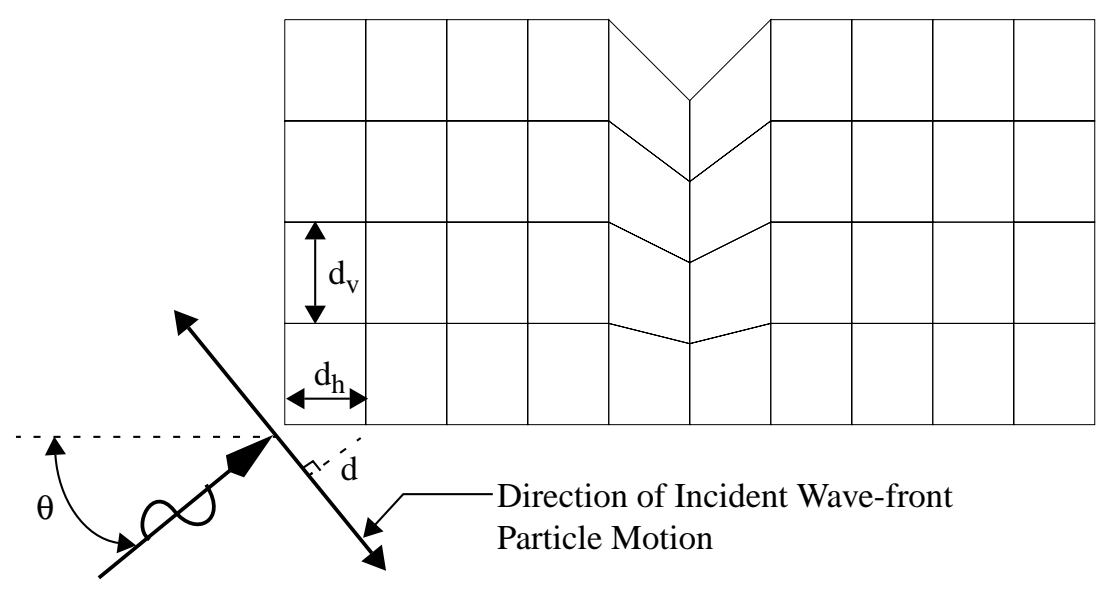

FIGURE 18. Input motion consisting of a sinusoidally varying planar SV wave.

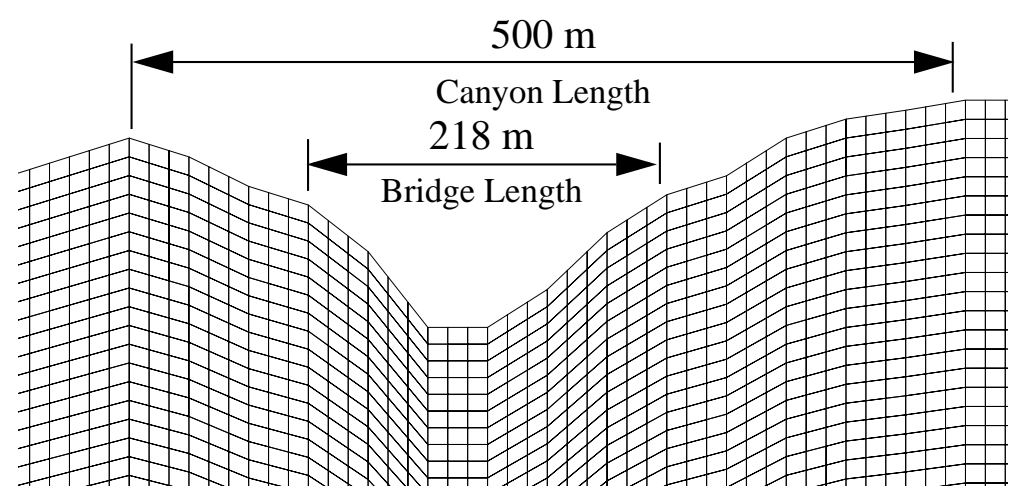

FIGURE 19. Relevant dimensions of the Bixby Creek Canyon for wave scattering.

To verify this observation, as well as to obtain a clearer picture of the effects of wave scattering, Hoehler investigated the displacement amplitudes across the canyon for a number of wave frequencies and angles of incidence. For each case, the steady state solution to incident sinusoidal motion was obtained and normalized displacement amplitudes were plotted as a function of location across the canyon as shown in Figure 20. The displacement plots are normalized to the amplitude of the incident waves. Thus for plots of surface displacement amplitudes, a displacement amplitude of 2 would correspond to the free surface amplification characteristic of a planar vertically propagating shear wave striking a free surface. 


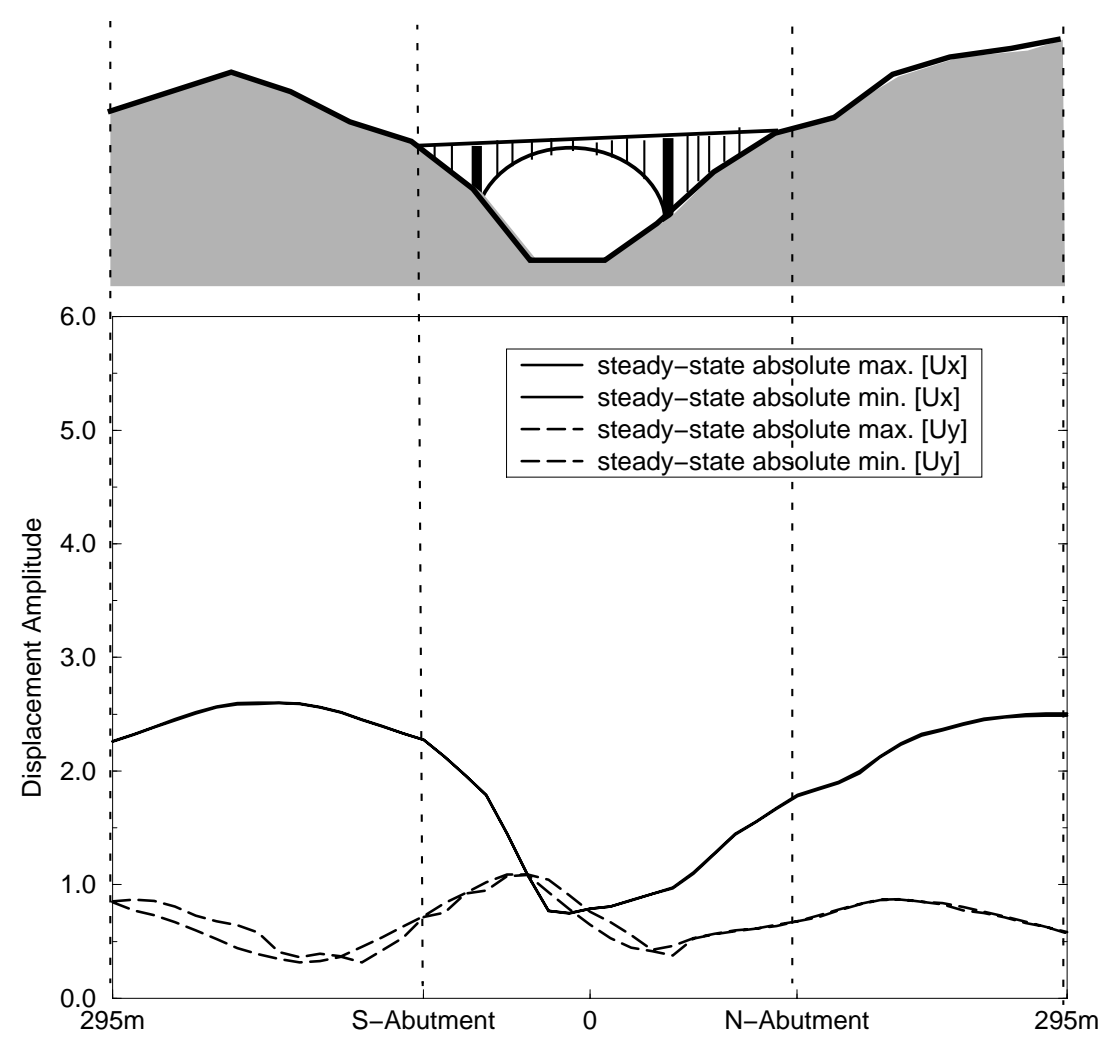

FIGURE 20. Plot of surface displacement amplitudes due to simple harmonic incident SV waves $\left(90^{\circ}\right.$ incidence at $5 \mathrm{~Hz}$ frequency).

The results of the two dimensional simulations are summarized in Figure 21. The effect of the topography is almost invisible at $1 \mathrm{~Hz}$ frequency, at $3 \mathrm{~Hz}$ the topographic effects start to become evident, and at $5-7 \mathrm{~Hz}$ the scattering effects become very pronounced.

\subsection{Measured ground motions at the Bixby Creek site}

The instrumentation placed at the Bixby Creek site is intended to monitor any measured earthquakes over an extended period of time to gain insight into the potential for variable support motion across the bridge. Measured response data can provide information into the combined effects of the canyon topography and geologic heterogeneities on the variable support motions.

To this point in time, a number of small earthquake motions have been recorded at the site. One of the best data sets consists of a recorded aftershock from the July 1998 magnitude 4.5 Hollister, California earthquake. The aftershock, of magnitude 3.0, occurred on July 22,1998 . The seismic sensors at the Bixby site record velocity measurements, and these velocities have been integrated and filtered to obtain displacements. The displacement time histories for each station is shown in Figure 22 and Figure 23. A search of the UC Berkeley seismic recording database indicated Berkeley measured an event seven seconds before the event measured at Bixby Creek and specifics of the event as reported by UCB are summarized in Table 3. 

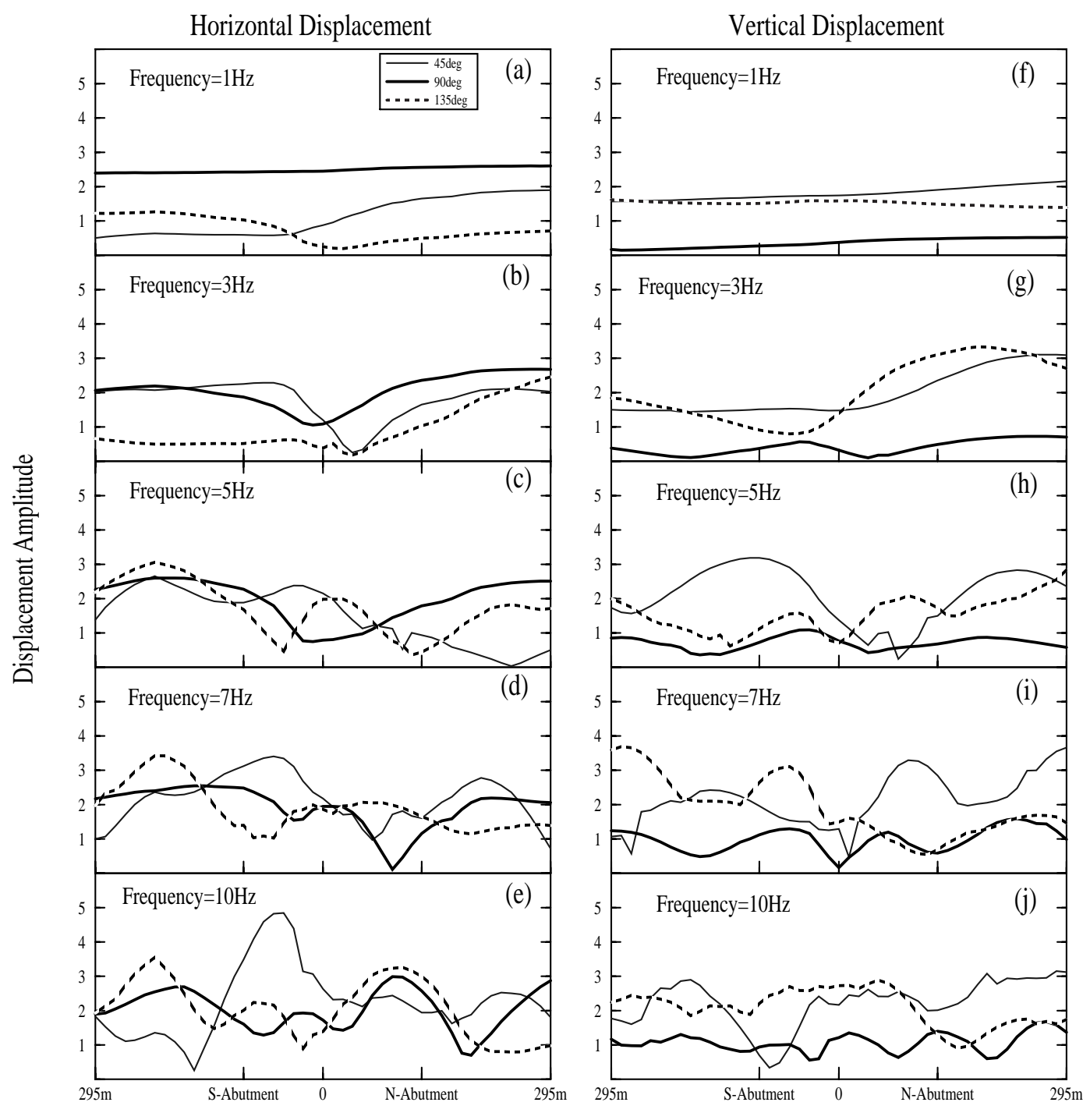

FIGURE 21. Surface displacement amplitudes due to incident SV waves with different angle of incidence and frequency.

The great circle distance between Bixby Creek (lat. 36 $22^{\prime} 25^{\prime \prime}$, long. $\left.-121^{\circ} 54^{\prime} 00^{\prime \prime}\right)$ and the UCB specified epicenter is $84 \mathrm{Km}$. To verify that is indeed the measured earthquake, the epicentral distance can be estimated from the difference in arrival time between the $S$ and $\mathrm{P}$ waves. The distance to the earthquake epicenter is given by,

$$
\text { Distance }=\frac{C_{s} T_{d}}{\left(\frac{1}{C_{p} / C_{s}}-1\right)}
$$


Displacement Time Histories from Bixby Creek
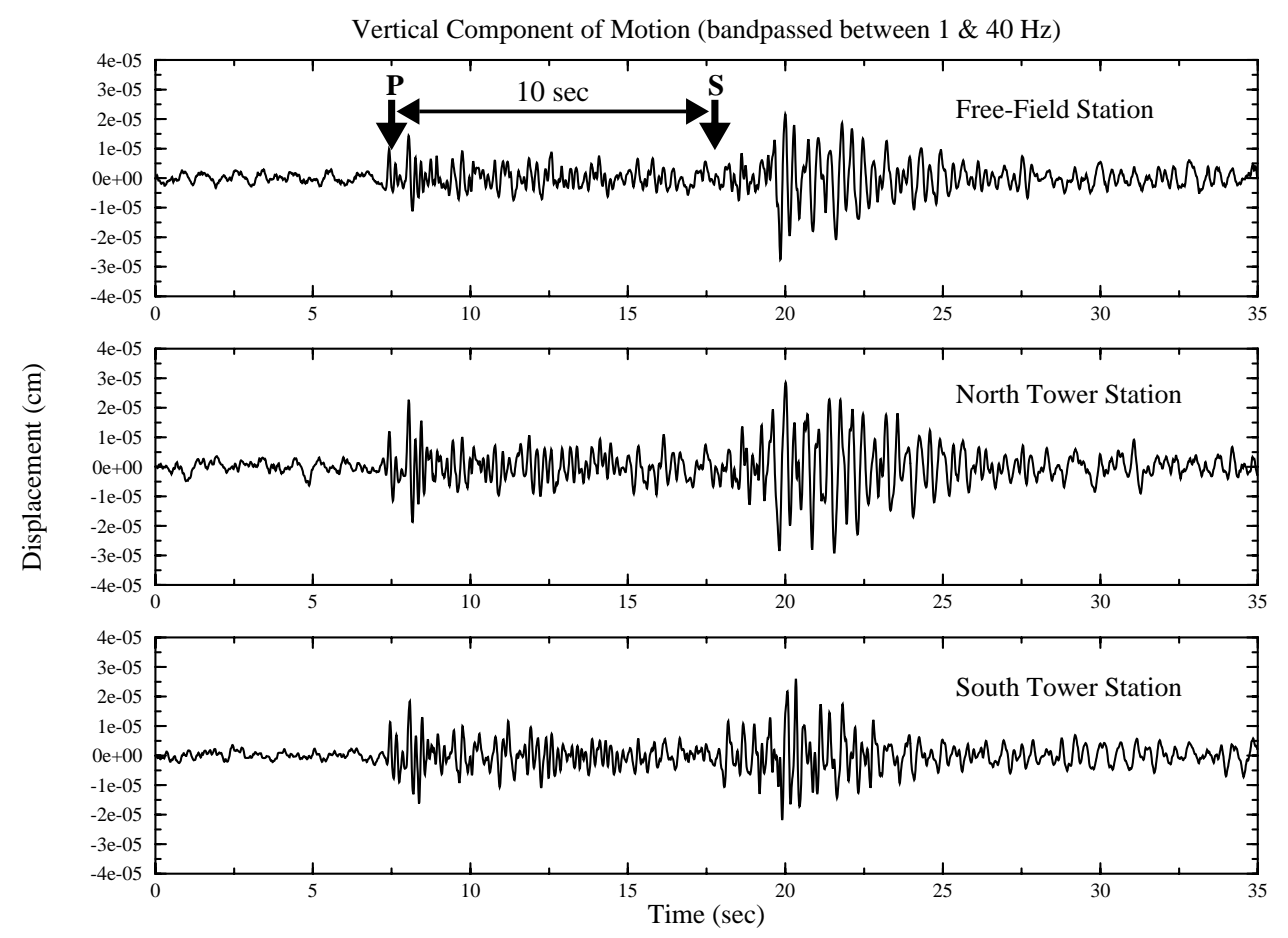

Displacement Time Histories from Bixby Creek
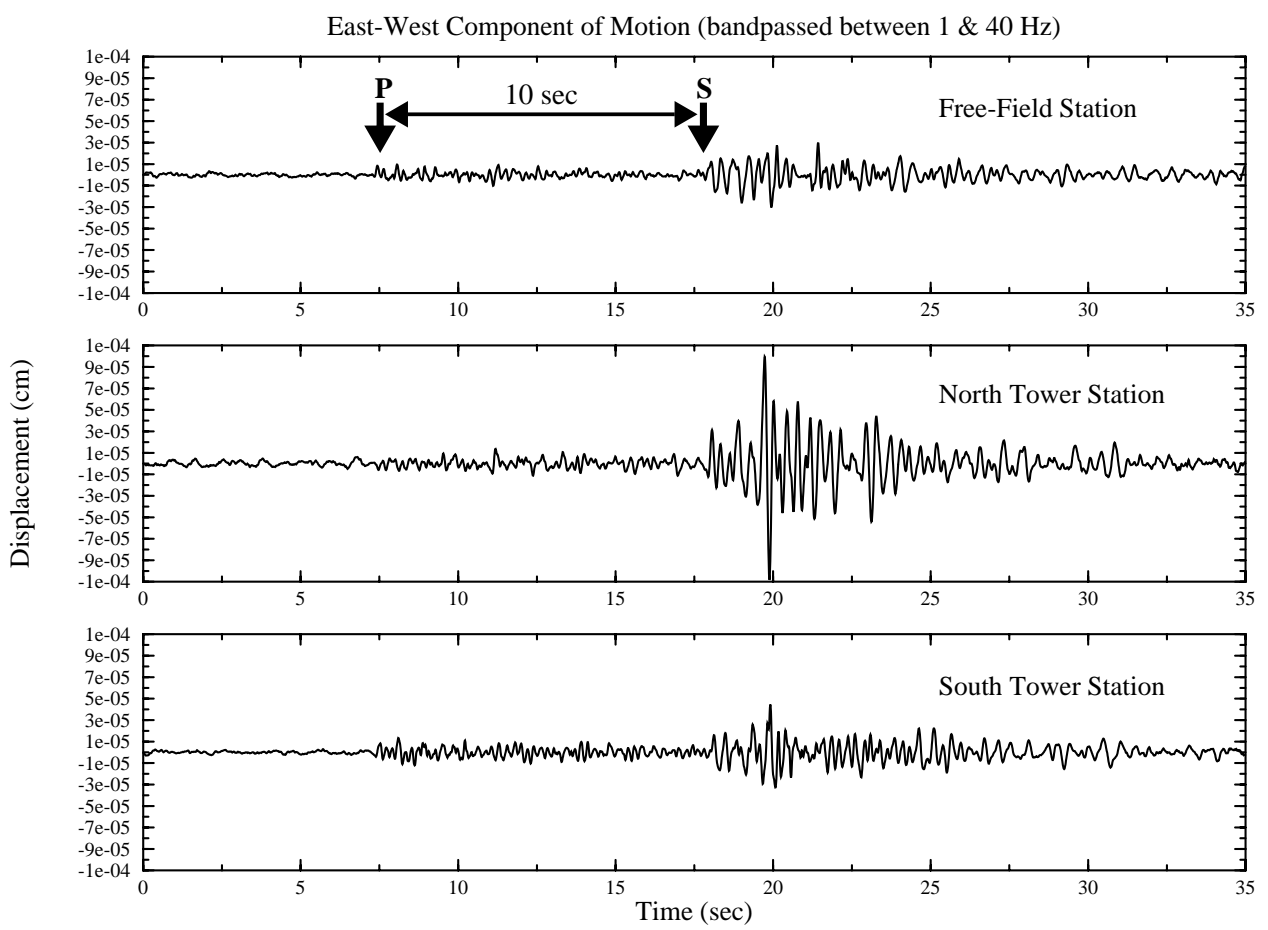

$\stackrel{P}{\downarrow}$ Indicates P wave arrival $\quad \stackrel{S}{\downarrow}$ Indicates S wave arrival

FIGURE 22. Displacement time histories obtained from the $M=3$ earthquake. 


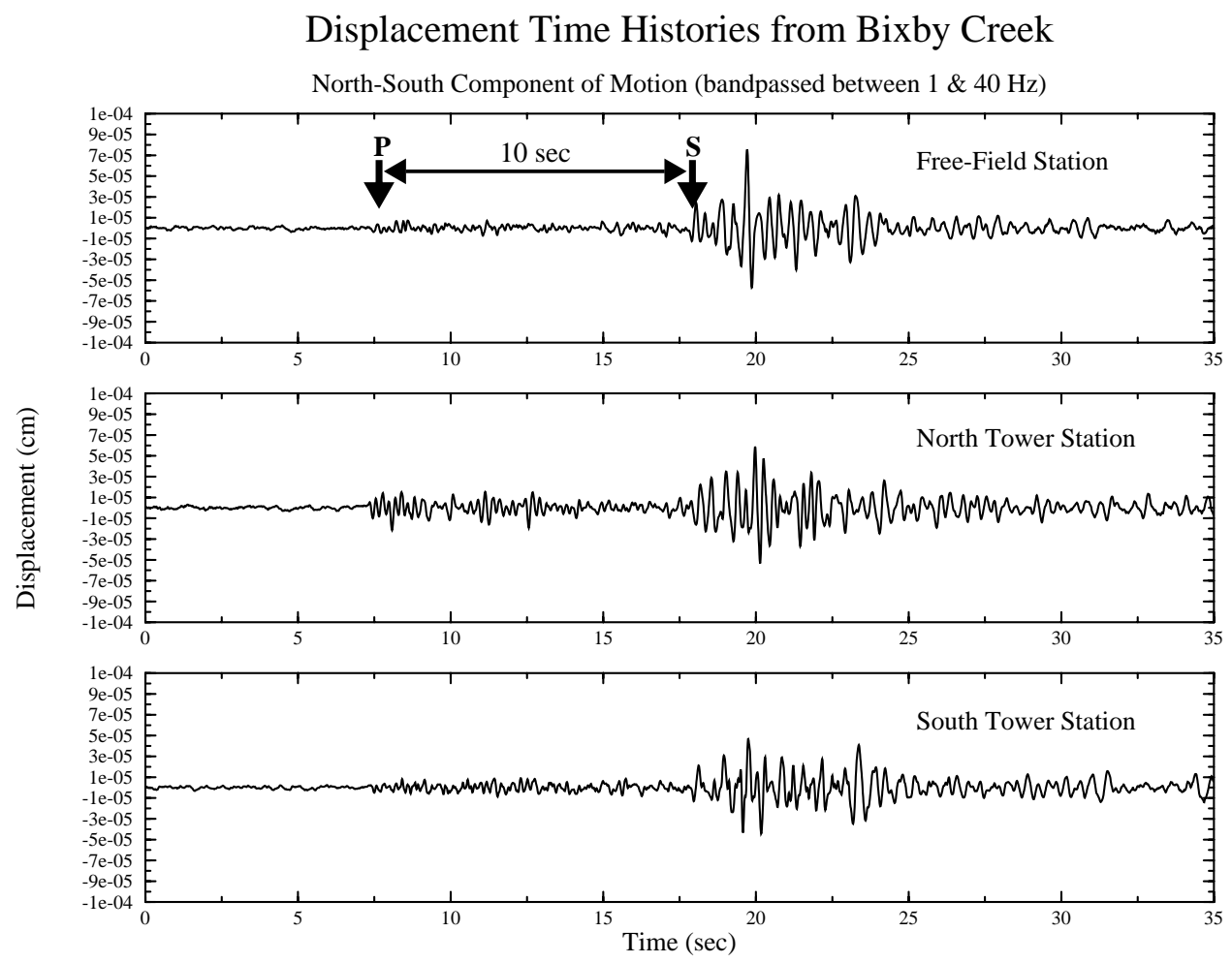

FIGURE 23. Displacement time histories obtained from the $M=3$ earthquake.

where $\mathrm{C}_{\mathrm{s}}=$ Shear wave speed, $\mathrm{C}_{\mathrm{p}}=$ Compression wave speed and $\mathrm{T}_{\mathrm{d}}=$ Time differential between compression and shear wave arrivals. Given that $\mathrm{C}_{\mathrm{s}}=3500 \mathrm{~m} / \mathrm{s}, \mathrm{C}_{\mathrm{p}} / \mathrm{C}_{\mathrm{s}}=1.75$ and $\mathrm{T}_{\mathrm{d}}=10 \mathrm{sec}$, the epicentral distance is given by

$$
\text { Distance }=\frac{3500 \times 10}{\left(\frac{1}{1.75}-1\right)}=82 \mathrm{~km}
$$

Which concurs with the Berkeley event at a distance of $84 \mathrm{Km}$.

The frequency range over which the measured data contains adequate signal-to-noise ratio can be observed by comparing the Fourier amplitude spectra for the portion of the measured record where significant signal exists with the Fourier amplitude spectra of a portion of the record which records only background motion levels. The plot in Figure 24 indicates that the spectra of the measured data only rises above the background spectra at about $1.5 \mathrm{~Hz}$. Below $1.5 \mathrm{~Hz}$ the measured signal is in the noise of the sensor and recording system. Thus, the data measured for this particular event is only good at frequencies above 1.5 Hz. The measured time histories have been processed to determine the degree of relative motion between the two tower bases of the bridge. Figure 25 through Figure 26 show the relative displacements, and to provide a sense of the amplitude of the relative displacements, the relative displacement between the north and south tower is plotted alongside the displacement of the north tower in Figure 27. 
Frequency Domain Response for Signal \& Noise

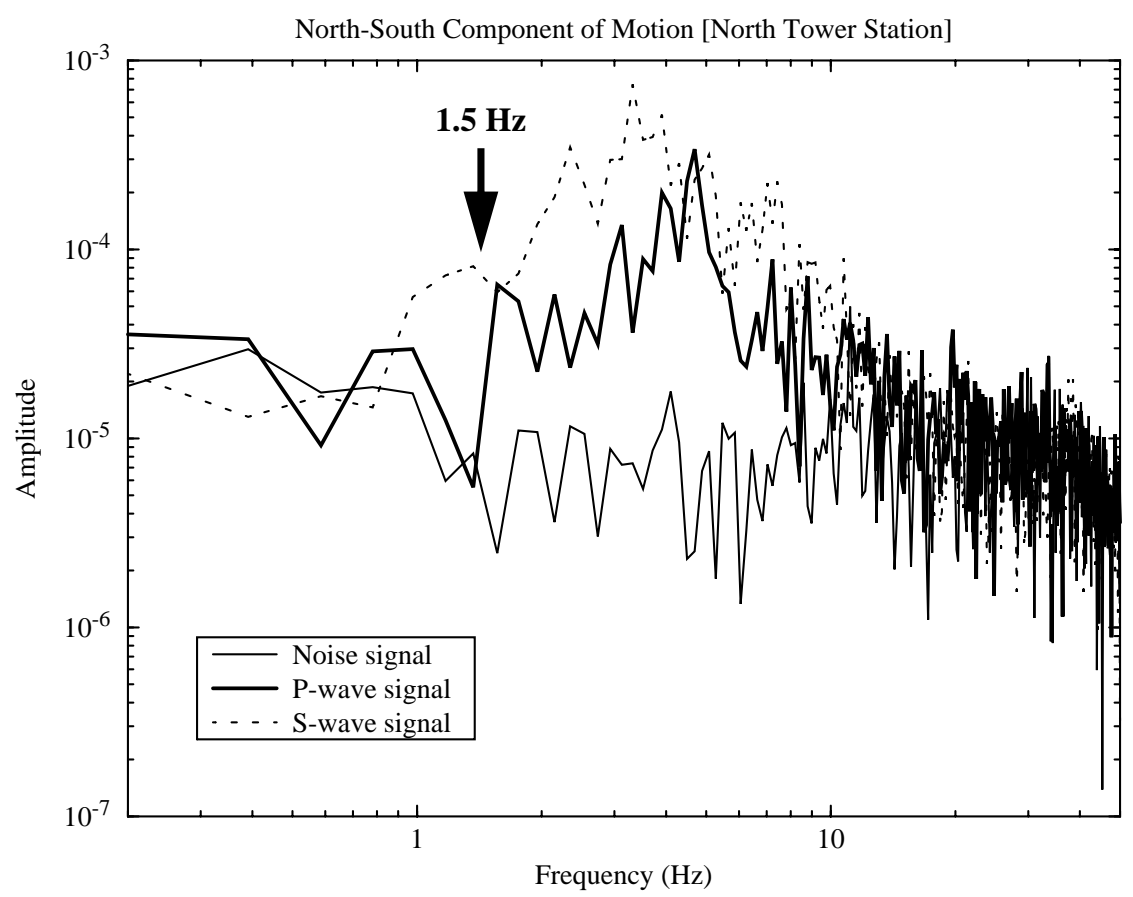

FIGURE 24. Spectral comparison to determine appropriate signal - to - noise threshold.

Comparison of Displacement Amplitude to Differential Displacement Amplitude
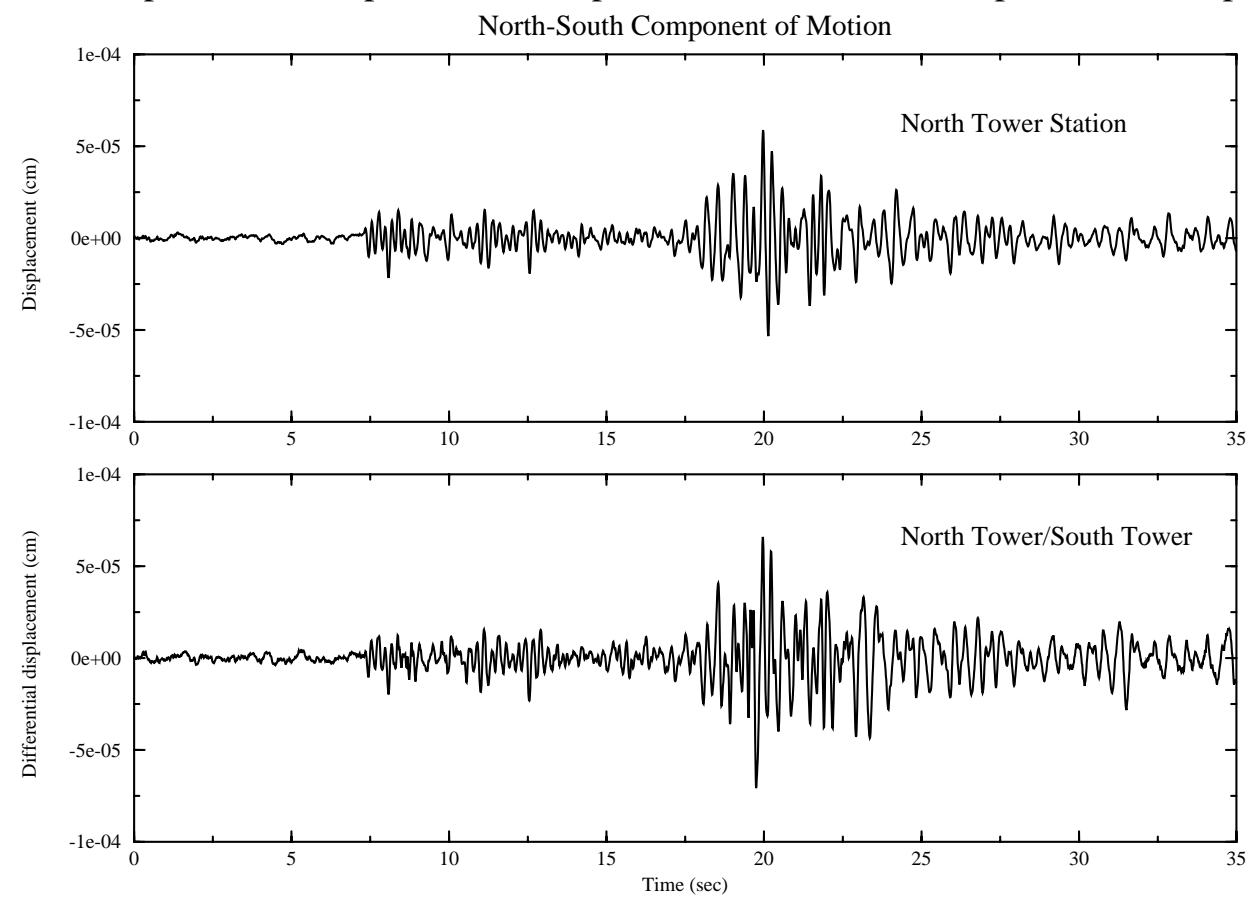

FIGURE 27. Comparison between tower displacement and relative displacements. 
Differential Displacement Time Histories

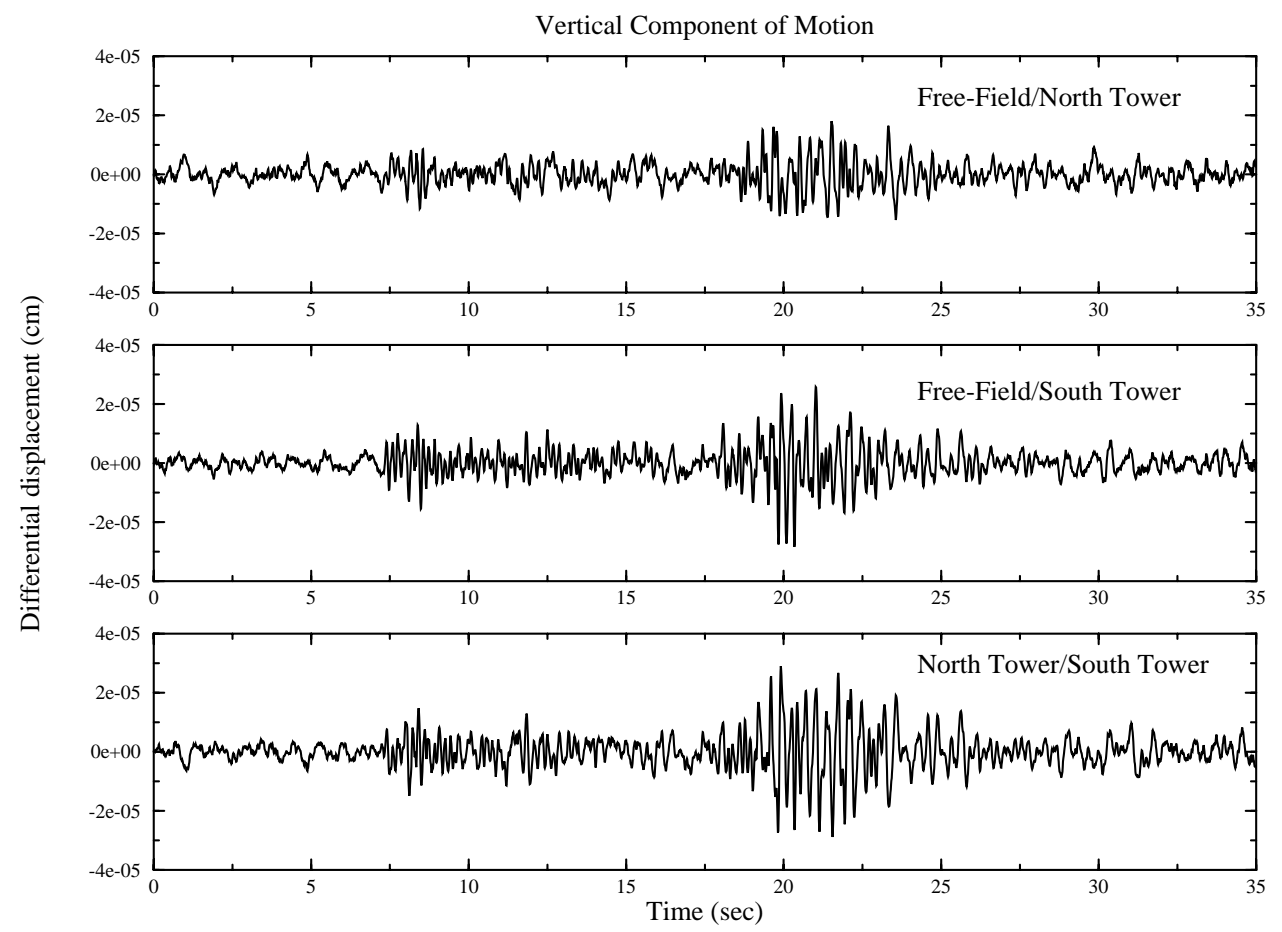

Differential Displacement Time Histories

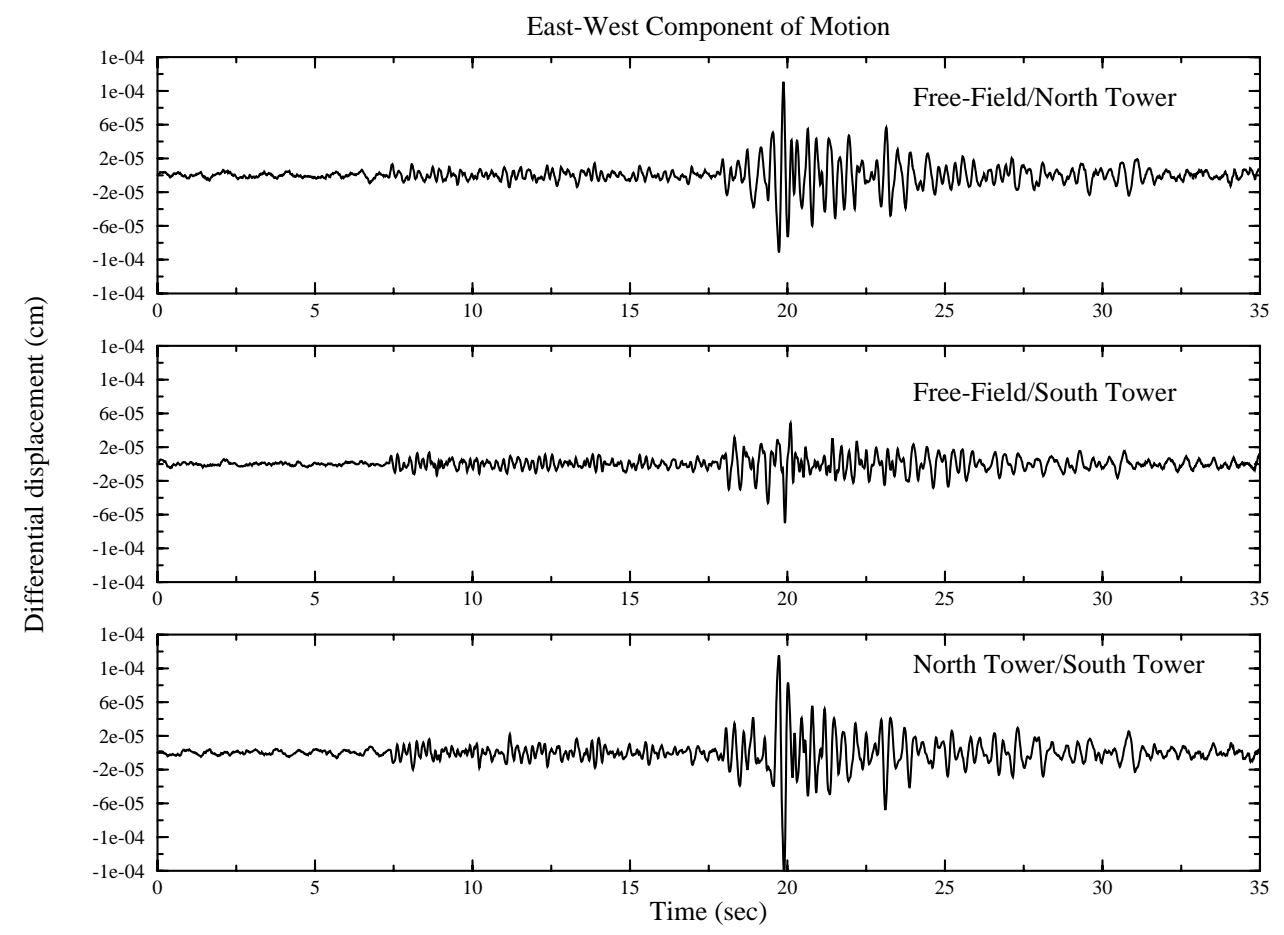

FIGURE 25. Differential displacement time histories. 
Differential Displacement Time Histories

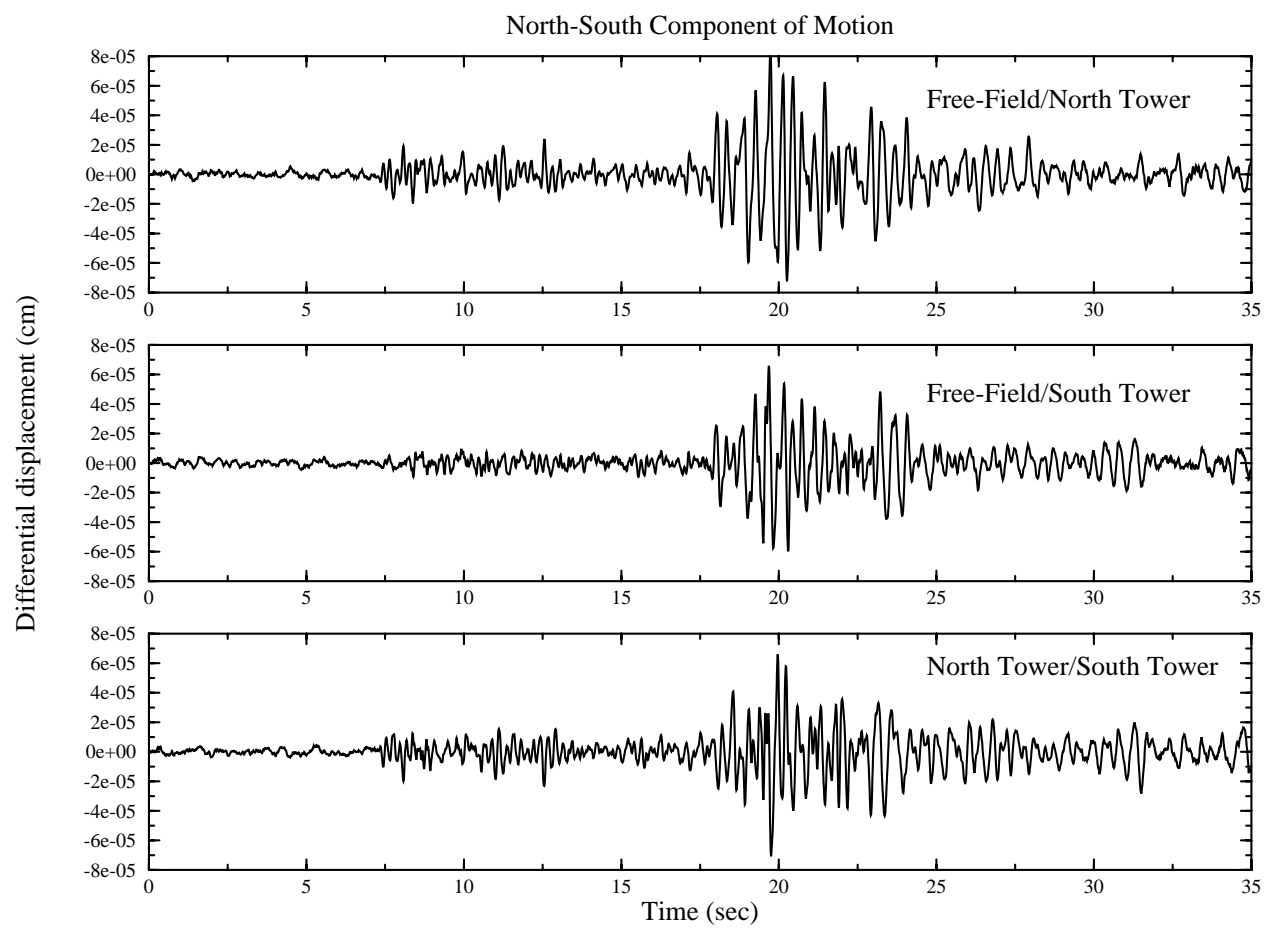

FIGURE 26. Differential displacement time histories.

To provide a clear picture of the variability of motion, the measured records can be bandpassed to highlight a particular frequency range, and the time histories can be overlaid. For the north-south component of motion, the time histories in the region of $2 \mathrm{~Hz}$ are shown in Figure 28 and the motions in the region of $5 \mathrm{~Hz}$ are shown in Figure 29. The potential for some variable support motion is beginning to become evident at $2 \mathrm{~Hz}$ and at $5 \mathrm{~Hz}$ it is clear that the north and south tower motions can be completely out of phase. This observation concurs with the canyon simulation, where the topography began to have an effect at 2-3 Hz (Figure 21).

TABLE 3. Parameters of the measured earthquake.

\begin{tabular}{|c|c|}
\hline \multicolumn{2}{|c|}{ Measured earthquake data } \\
\hline Date & $7 / 22 / 1998$ \\
\hline Time & $18: 54: 19.17$ \\
\hline Epicenter Latitude & 37.0592 \\
\hline Epicenter Longitude & -121.4963 \\
\hline Epicenter Depth & $4.46 \mathrm{Km}$ \\
\hline Magnitude & 3.0 \\
\hline
\end{tabular}




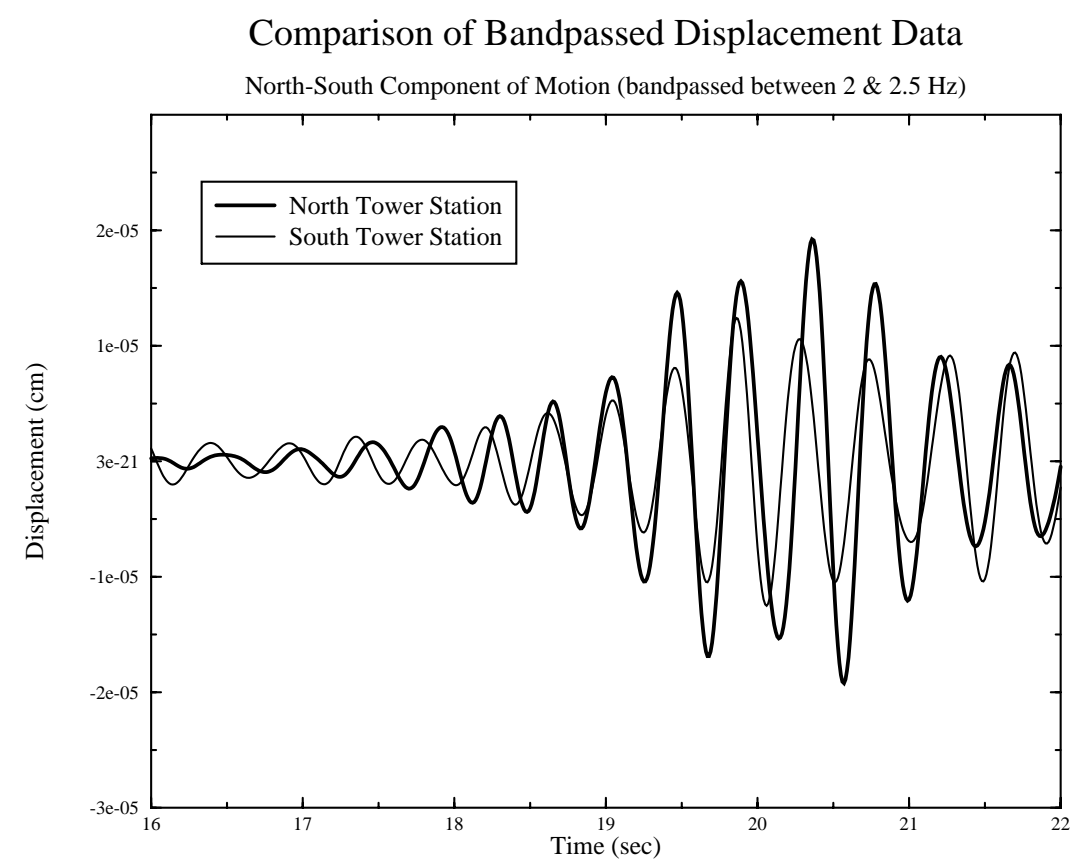

FIGURE 28. Overlaid displacement time histories (bandpassed records).

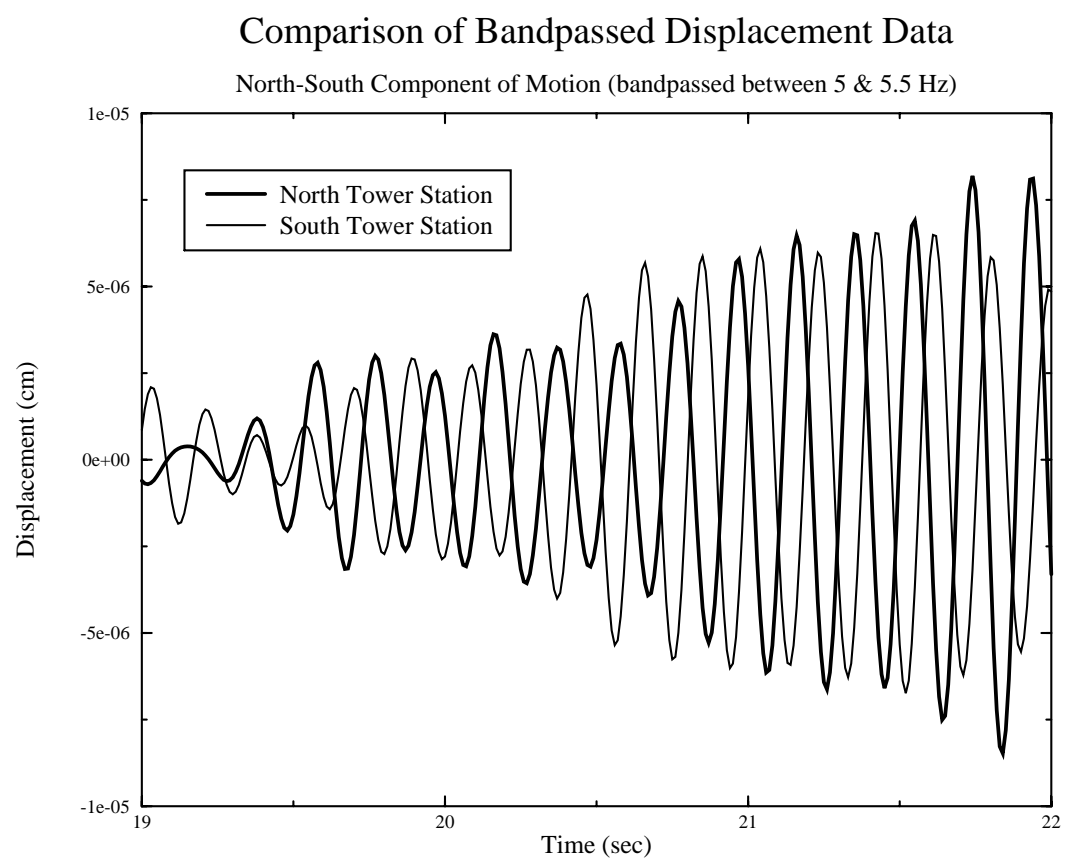

FIGURE 29. Overlaid displacement time histories (bandpassed records). 


\subsection{Nonlinear finite element simulation model of the as-built Bixby Creek Bridge structure}

Under strong earthquake ground excitation, it is expected that most structures will undergo some degree of inelastic deformation. The seismic adequacy of a particular structure will be determined by the structure's ability to undergo significant inelastic action without suffering unacceptable damage or catastrophic collapse. If the inelasticity is controlled and the behavior is ductile, the occurrence of nonlinear inelastic deformations in a structure can be very beneficial. Inelastic action can enhance energy dissipation and can thus help mitigate the maximum force levels in the structure. Adequate structural ductility will also guard against sudden, brittle, explosive type failure associated with nonductile structures. On the other hand, the softening associated with inelastic action may also have less desirable effects when large compressive forces exist in a particular structure. Inelastic action may result in increased structural displacements with a proportionate increase in secondary forces resulting from change of geometry of the structure (i.e. enhanced P- $\Delta$ effect from gravity dead load). This effect can be quite important in arch structures where the overall structural system is essentially a compression structure. Accurate computer simulation of the seismic response of a structure undergoing inelastic seismic deformations necessitates a nonlinear structural model which can adequately represent important nonlinear response features.

One of the primary objectives of the current study was to investigate the transient nonlinear response of large concrete arch bridges. This was accomplished with a detailed three dimensional nonlinear model which captures both geometric and material nonlinearities. A three dimensional nonlinear model of the Bixby Creek structure was created for the implicit nonlinear finite element program NIKE3D [Ref 11]. As constructed, the NIKE3D model utilizes finite deformation, linear-elastic shell elements for the bridge towers and the deck slab and linear-elastic beam elements for the deck beams (see Figure 30 and Figure 31). The below-deck structural members, including the columns, arch ribs and struts are modeled with finite deformation, inelastic fiber beam elements to capture inelastic action in the concrete and reinforcing steel in the arch system.

Contact and impact in bridge decks can be a source of sudden and severe nonlinearity which significantly influences the global transient response in terms of member forces and structural displacements. Field observations of bridge earthquake response have indicated impact phenomenon and large acceleration pulses associated with short duration impact [Ref 12]. Consideration of impact and contact in a numerical simulation model can complicate the model and lead to a major increase in computational effort. Contact between disjoint parts typically results in substantial changes in the global structural stiffness matrix, leading to strong system nonlinearity. Rigorous modeling of the impact often requires multiple equilibrium iterations to achieve the appropriate transient solution. The as-built configuration of the Bixby Creek Bridge provides a structure with the potential for dynamic impact and contact. To accommodate thermal expansion and contraction, the columns of the Bixby Creek Bridge are split through the top of the sections as shown in Figure 32 and the deck system is also discontinuous with an expansion joint at each bent. As a result of recognized seismic vulnerabilities of the split columns at the expansion joints, Caltrans has previously retrofit the joints with banded steel collars which are 
intended to restrain excessive displacements across the expansion joints. A typical steel collar is shown in Figure 32 and the details of the collars are shown in Figure 33.

Potential contact and impact across the bridge expansion joints has been modeled with NIKE3D discrete elements, which allow a user defined force-displacement behavior to be specified between any two model nodes which displace relative to one another. The dis-
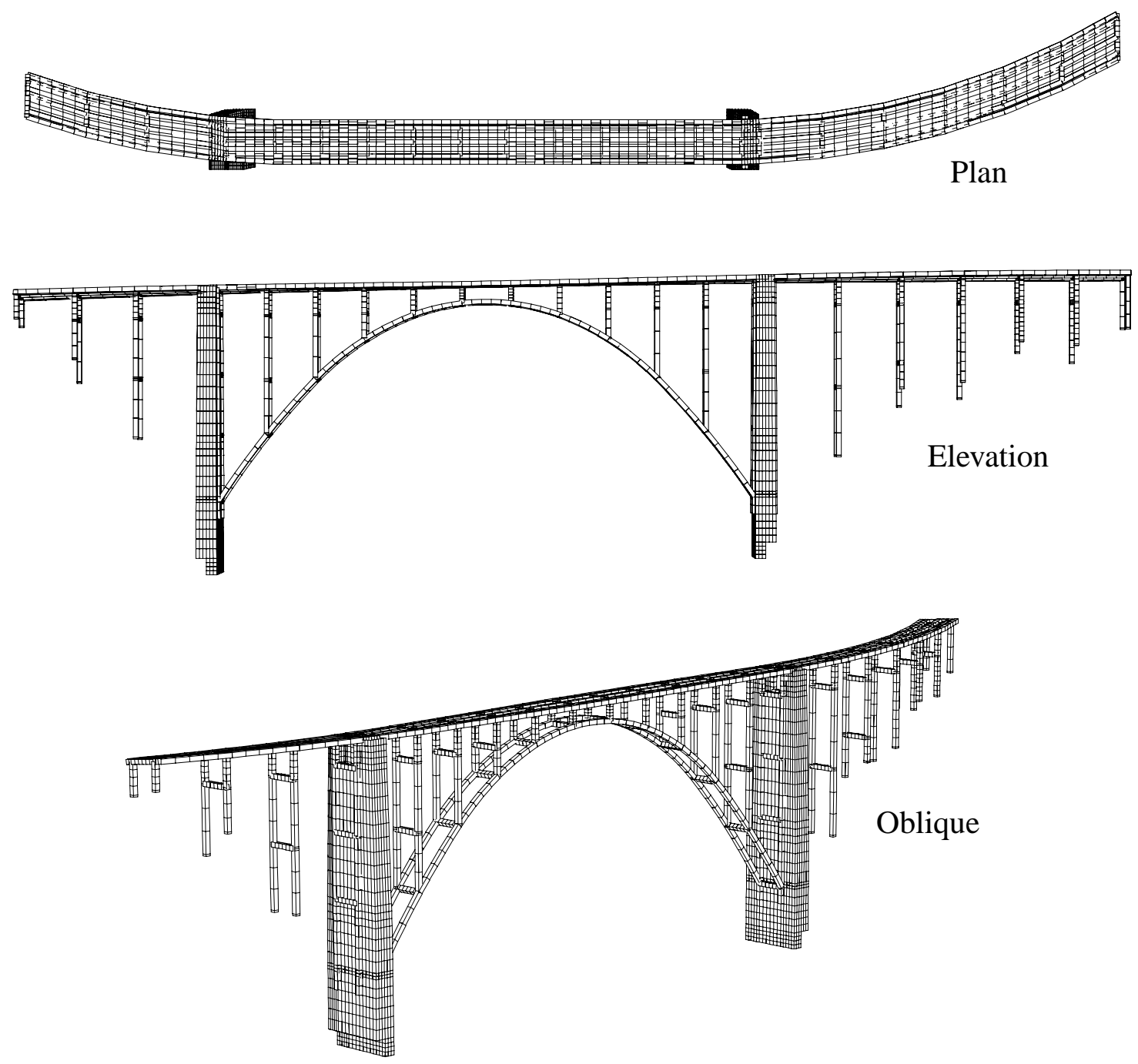

FIGURE 30. Three dimensional NIKE3D model of the Bixby Creek Bridge structure.

crete elements are placed across the expansion joints to enforce displacement compatibility between the bridge deck segments. The discrete elements track the relative displacement between two specified nodes, and when the relative location of the two nodes closes to within a specified distance, a node-to-node force is developed and penetration of one deck segment into another is prevented. 


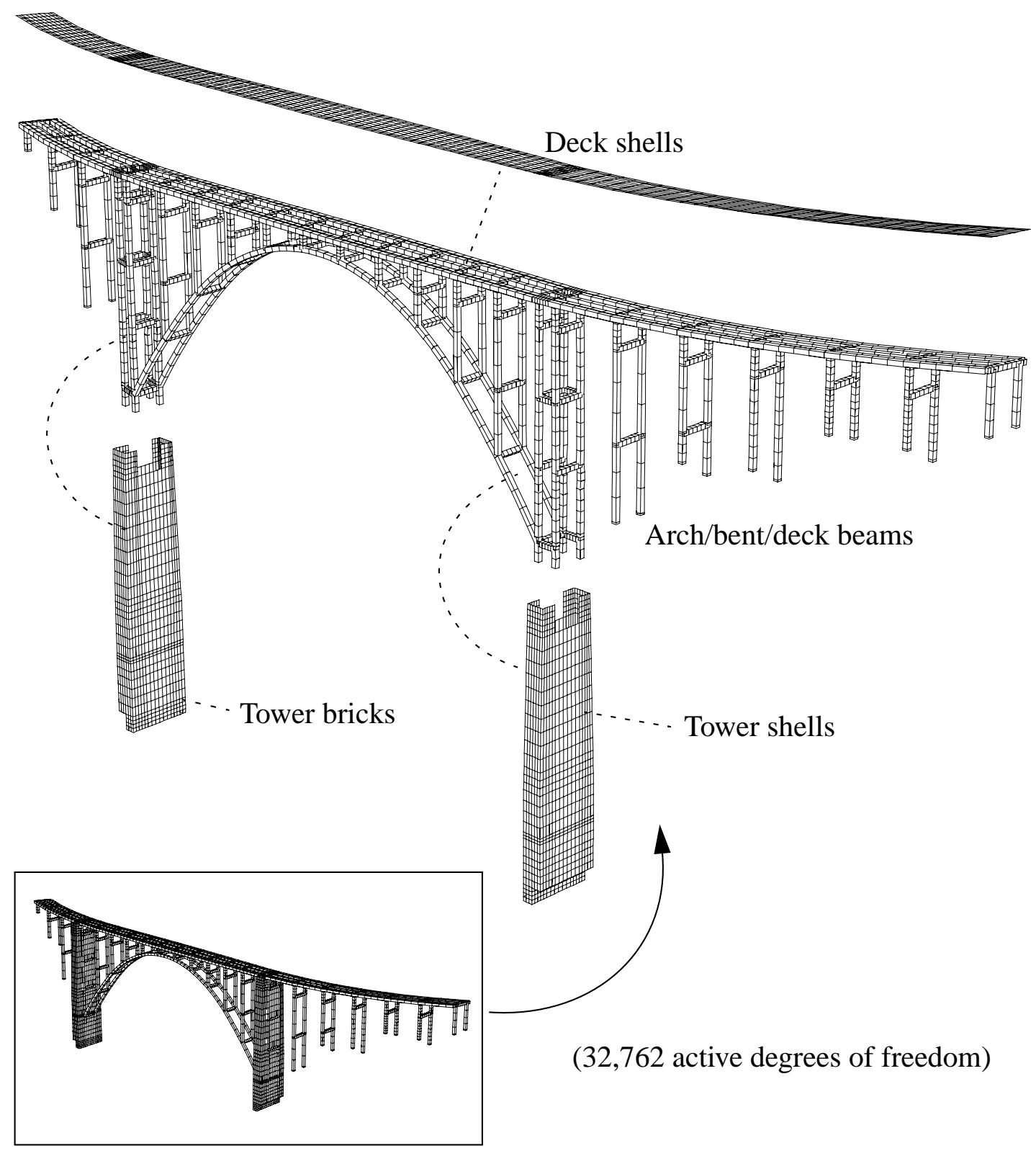

FIGURE 31. Finite element model of the Bixby Creek Bridge.

In the NIKE3D model, finite displacements are rigorously accounted for by updating the model geometry based on local element updated Lagrangian coordinate systems, i.e. an element local coordinate system which tracks and follows the finite element as it displaces through space. The NIKE3D program utilizes Newmark-Beta temporal integration and equilibrium iterations are performed based on an economical Broyden-Fletcher-GoldfarbShanno (BFGS) quasi-Newton algorithm, which provides super-linear convergence without full tangent stiffness reforms and factorizations. With the quasi-Newton algorithm, NIKE3D only performs full tangent stiffness updates when the BFGS based iterations fail to provide adequate convergence. This approach to stiffness reformation management provides a robust, yet highly economical nonlinear solution procedure. Equilibrium conver- 


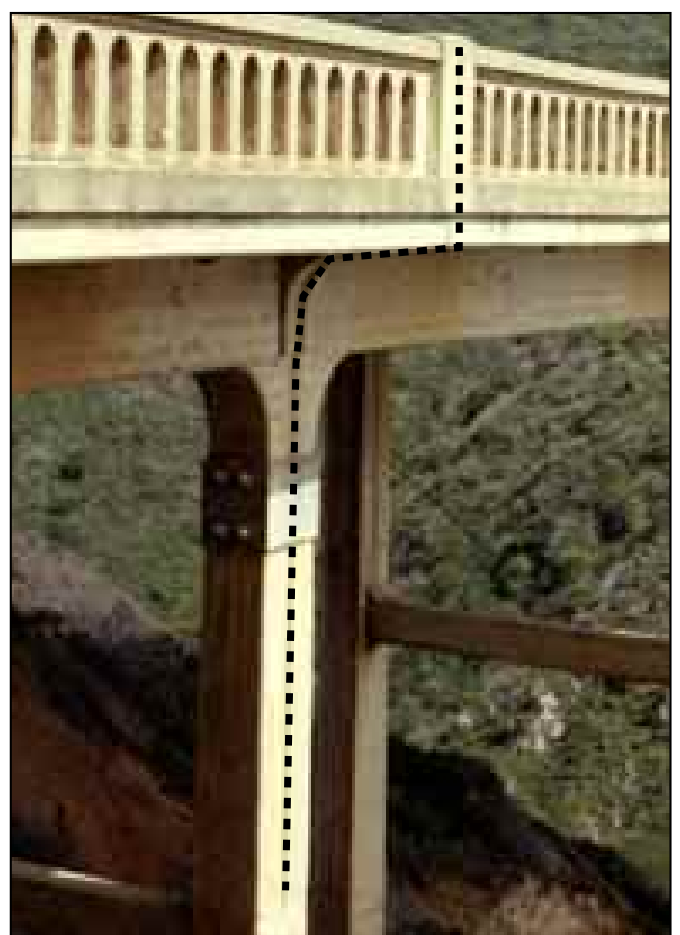

Approach structure

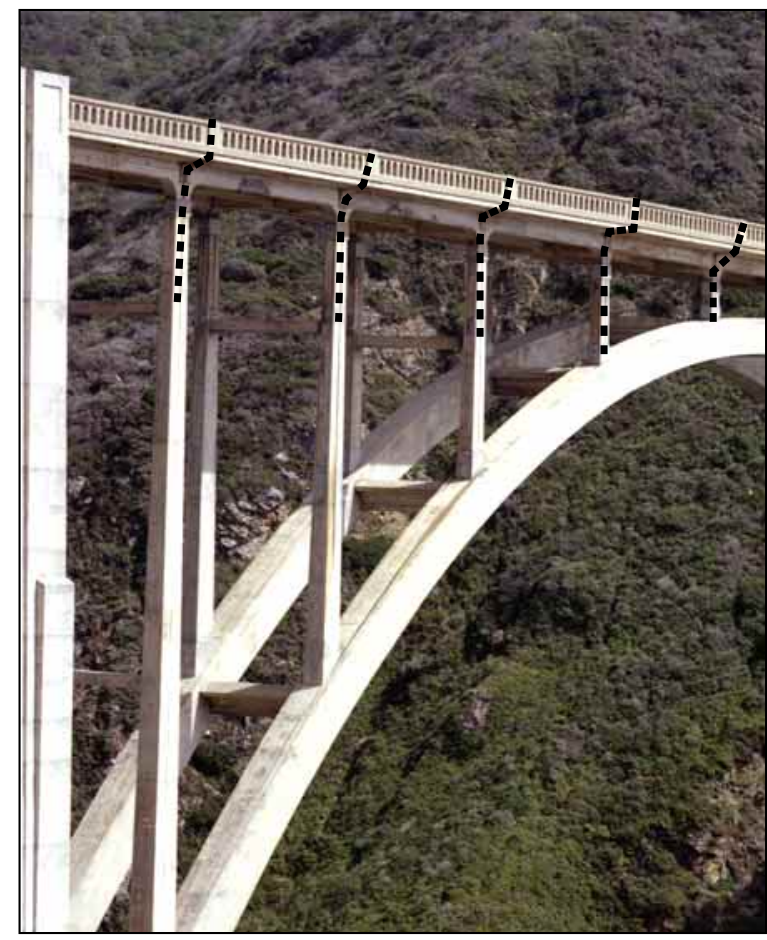

Center span

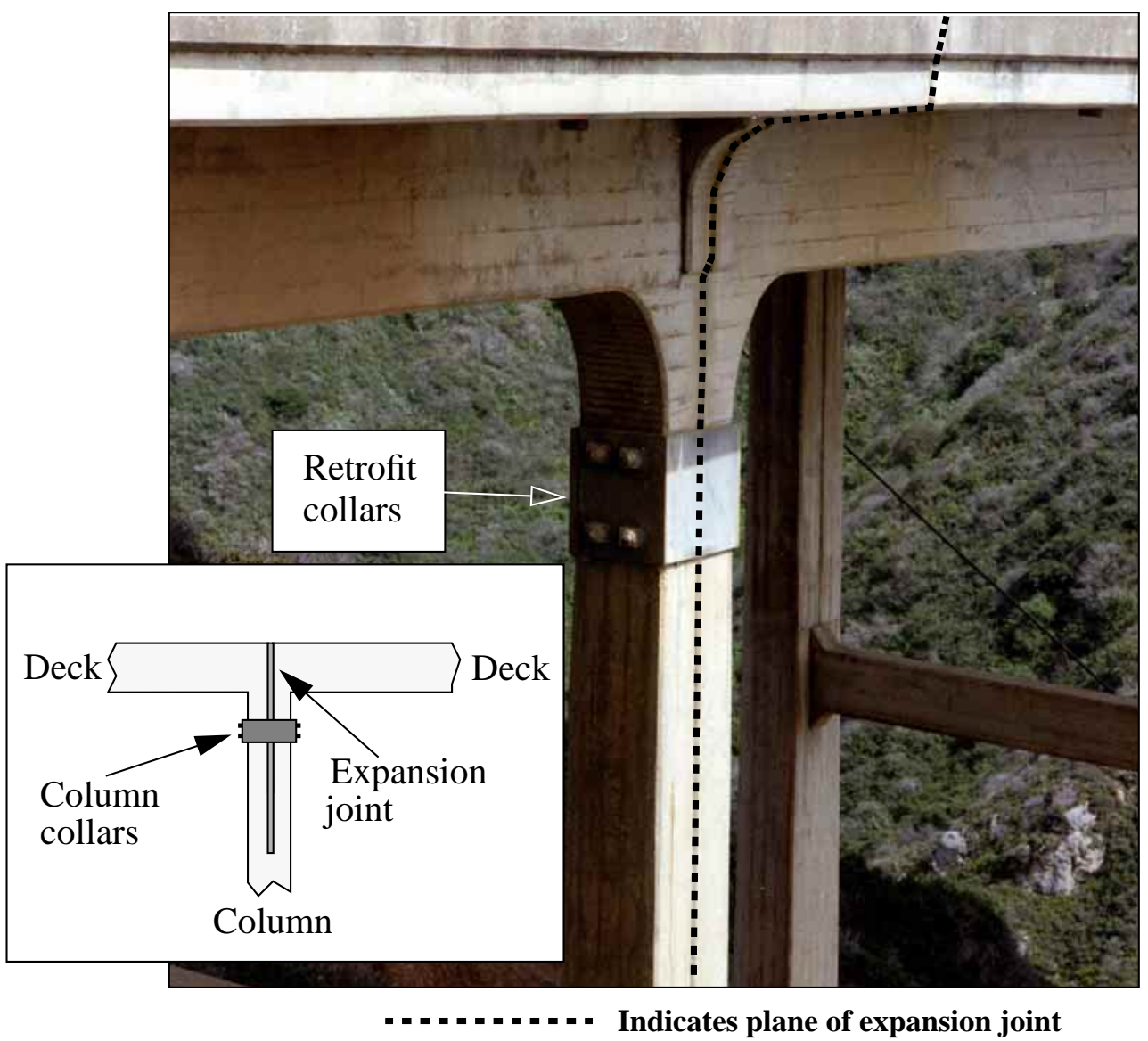

FIGURE 32. Expansion joints in the Bixby Creek Bridge structure bents. 


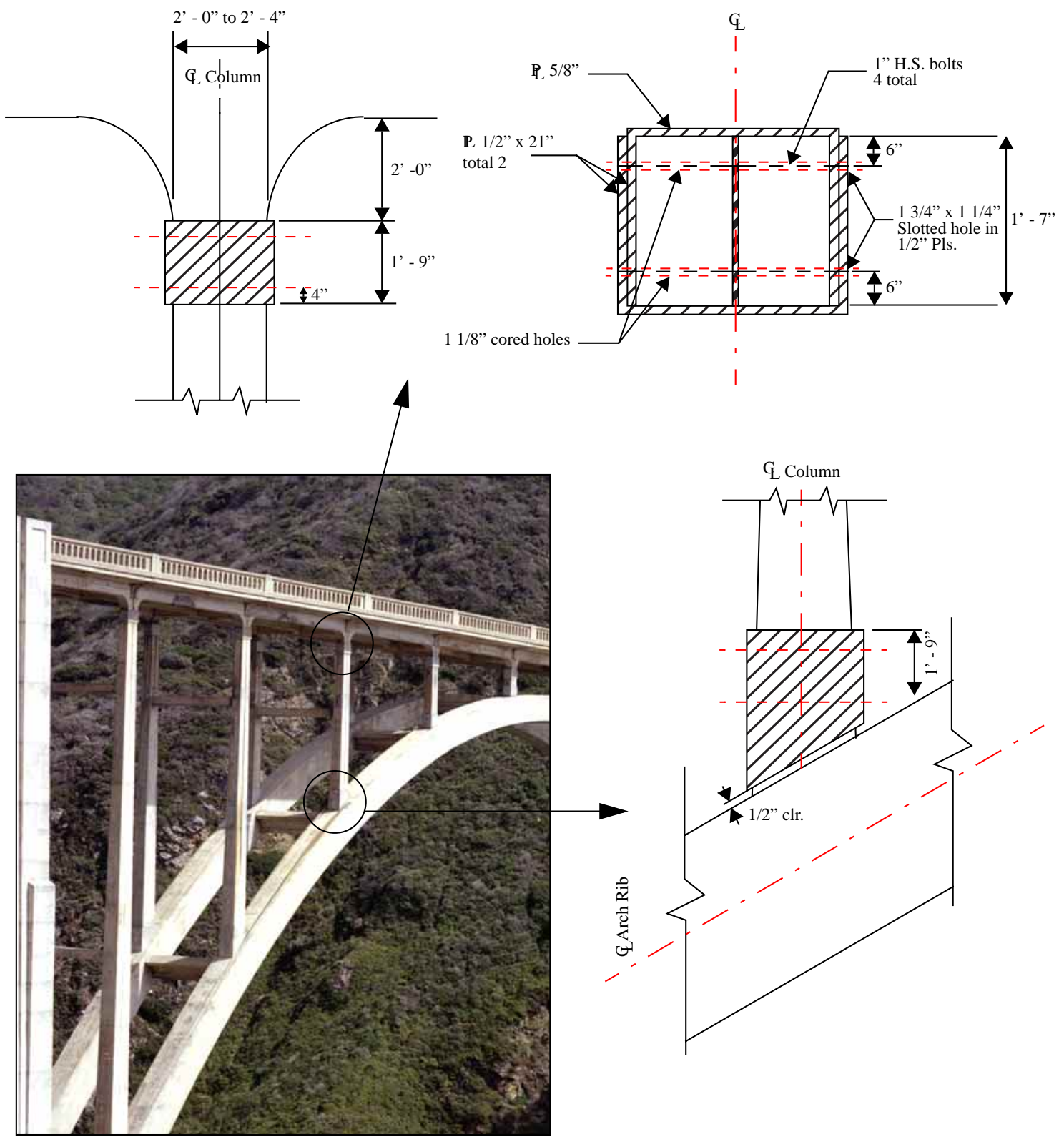

FIGURE 33. Connection collars for existing columns (from previous retrofit).

gence in NIKE3D is evaluated based on both displacement and energy norms. Within a given time or load step, equilibrium iterations are performed until the displacement and energy norms are driven to acceptably small values.

\subsection{Geometric nonlinearities: deck articulations and impact/contact}

In the nonlinear model of the as-built structure, potential opening and closing of the expansion joints is modeled with the discrete element available in the NIKE3D program. The discrete element allows definition of compression-only behavior to occur between 

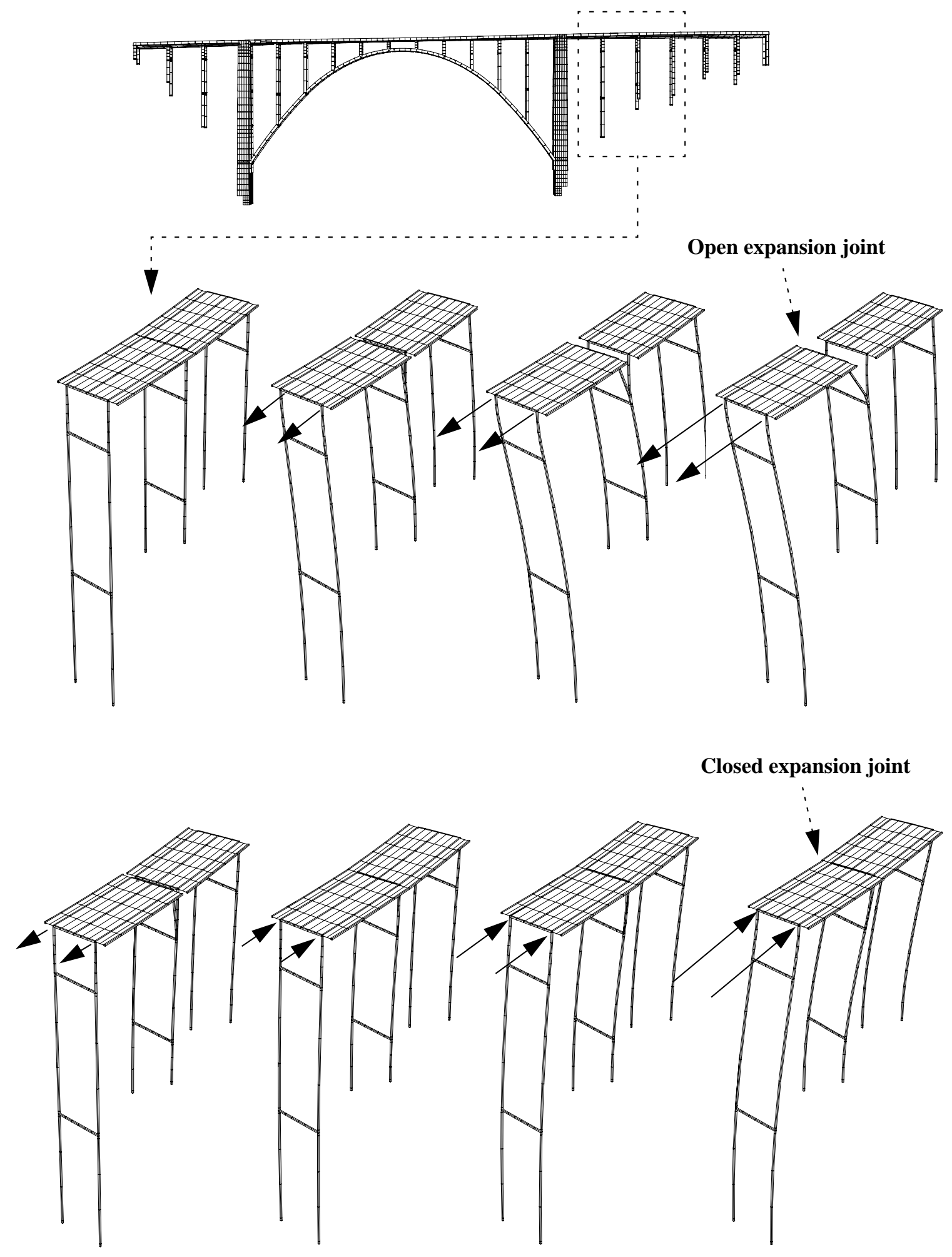

FIGURE 34. Pull-push test of a two span segment of the approach structure, steel collars not included. 
two specified nodes of a finite element model. An example of the manner in which the discrete element enforces displacement compatibility between two adjacent deck segments is shown in Figure 34, where a two span segment model is loaded with two nodal point loads. The simulation shown in Figure 34 considers first an increasing load which pulls the expansion joint open, followed by a load reversal and compression of the expansion joint. In transient analyses, this expansion joint model allows opening and closing of the expansion joint as the bridge shakes back and forth.

As discussed in a subsequent section, when performing an eigensolution to determine the natural modeshapes and frequencies, the structural system must be linearized about a specified configuration. This linearization has been achieved by idealizing the structural model about three different configurations of the expansion joints. In one case the collars are neglected and the expansion joints are assumed free to open, in the second case the expansion joints are assumed fully closed and locked, and in the third case the expansion joints are assumed free to open, but the columns are assumed to be tied together at the location of the steel collars. For the transient nonlinear earthquake analyses, the same linearizations of the expansion joints were analyzed in addition with the fully nonlinear impacting model, which included expansion joint opening and closing (as shown in Figure 34).

Investigation of the as-built structure was also performed with a simple representation of the stiffness of the column ties to determine potential failure of the ties and to account for the coupling effect of the ties at the split columns. The ties were represented with a simple linear beam element stiffness for which the stiffness properties were adjusted to represent the effective stiffness of the collar ties (Figure 35). The beam element also allowed for direct estimation of the axial force and shears to which the tied collars were subjected.

\subsection{Physical nonlinearities: the nonlinear concrete model}

The concrete elements of the as-built Bixby Creek Bridge structure, which are very lightly reinforced by todays codes and standards, are modeled with a fiber beam element which divides the reinforced concrete member cross section into concrete and steel zones as indicated in Figure 36. Following the work and model outlined by Taucer et. al. [Ref 13], the model employs the plasticity constitutive representation of Menegotto and Pinto [Ref 14] for the characterization of the reinforcing steel (Figure 37) and the modified Kent-Park model [Ref 15] for the concrete compressive stress-strain behavior (Figure 38).

The concrete compressive model accounts for softening in the concrete, and the ultimate compressive strength and the softening slope are a function of the degree of concrete confinement. Poorly confined concrete is represented by a steep softening slope, well confined concrete is represented by a shallower softening slope (Figure 38).

The concrete constitutive law for compression is governed by three regions of behavior, for $\varepsilon_{c} \leq \varepsilon_{0}$ 

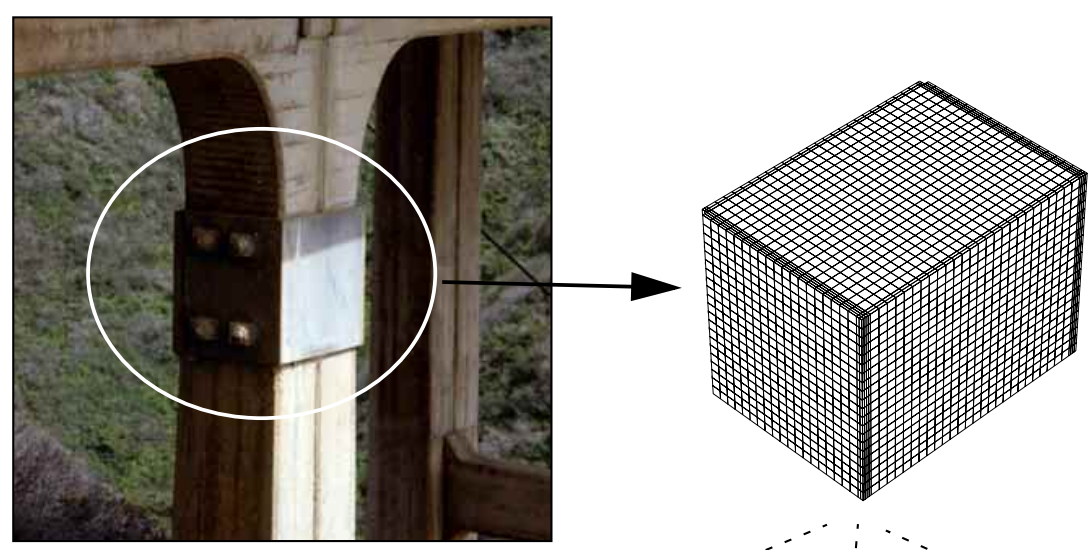

3D model of tied collar

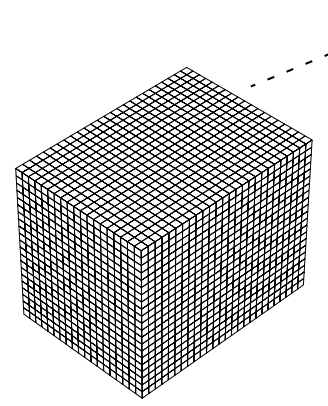

Concrete column sections

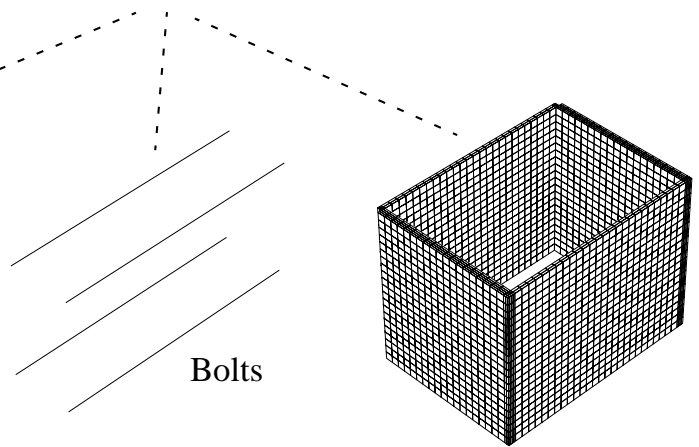

Steel bands

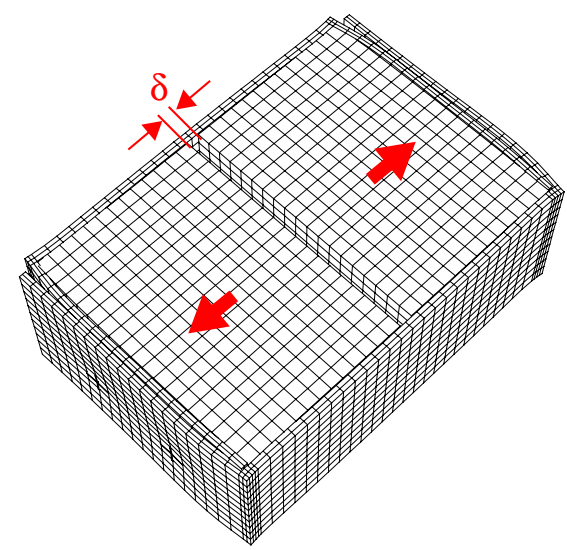

Longitudinal pull for axial stiffness
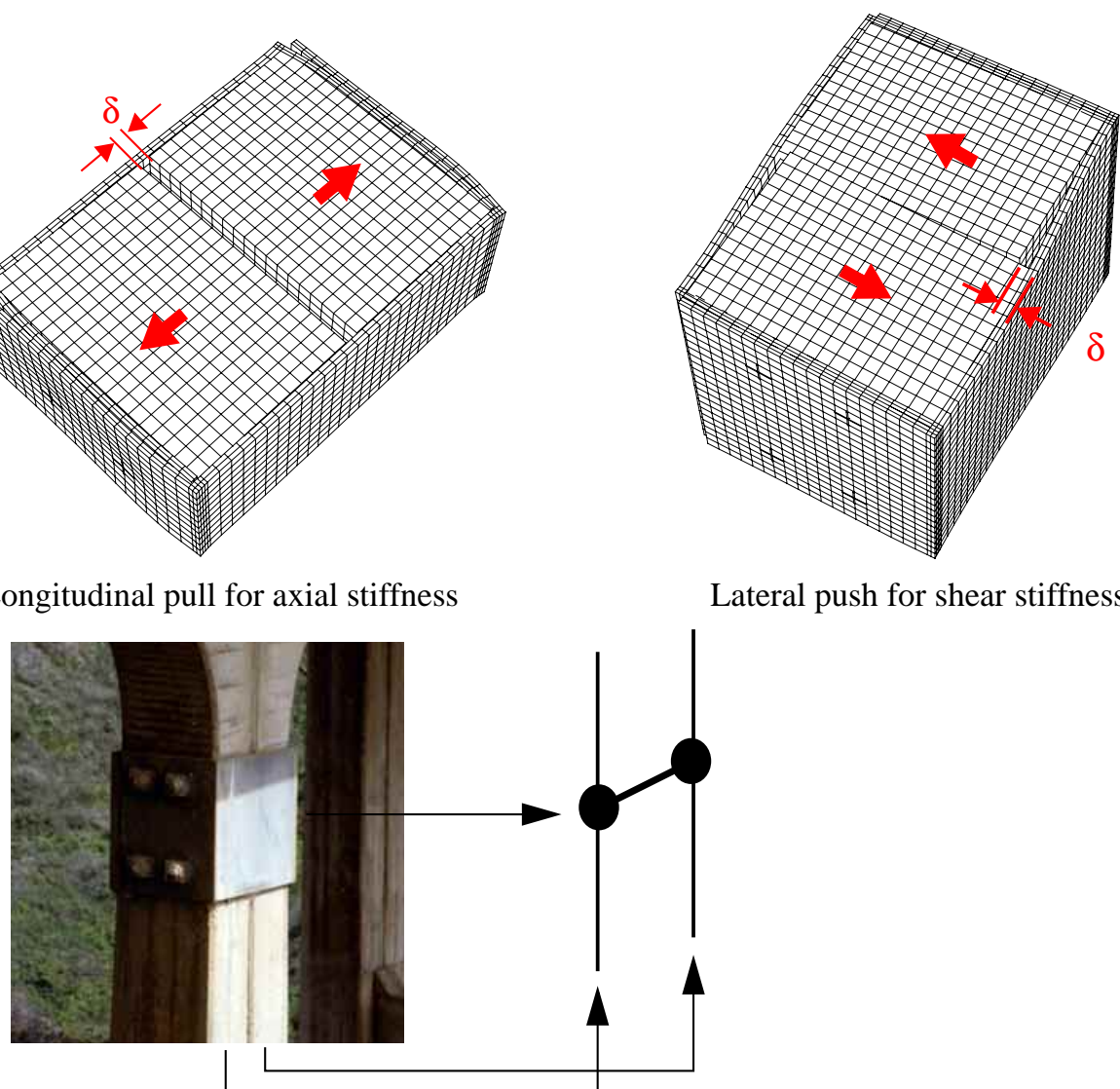

Lateral push for shear stiffness

FIGURE 35. Determination of an effective beam stiffness for representation of the split column ties. 


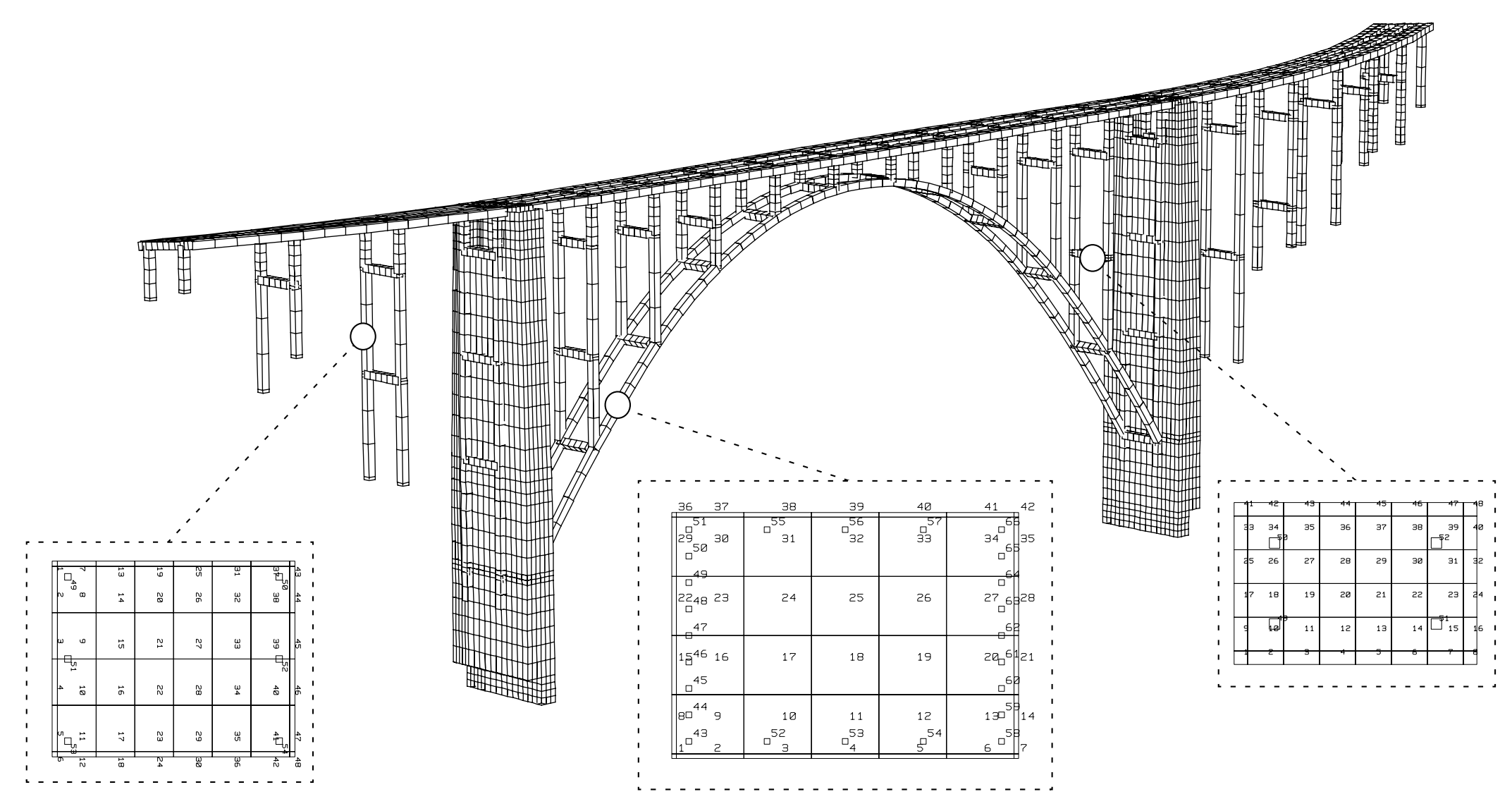

FIGURE 36. Fiber beam element representation of the reinforced concrete sections. 


$$
\sigma_{c}=K f_{c}^{\prime}\left[2\left(\frac{\varepsilon_{c}}{\varepsilon_{0}}\right)-\left(\frac{\varepsilon_{c}}{\varepsilon_{0}}\right)^{2}\right]
$$

for $\varepsilon_{0} \leq \varepsilon_{c} \leq \varepsilon_{u}$

$$
\sigma_{c}=K f_{c}^{\prime}\left[1-Z\left(\varepsilon_{c}-\varepsilon_{0}\right)\right] \geq 0.2 K f_{c}^{\prime}
$$

for $\varepsilon_{c} \geq \varepsilon_{u}$

$$
\sigma_{c}=0.2 K f_{c}^{\prime}
$$

where

$$
\begin{gathered}
\varepsilon_{0}=0.002 K \\
K=1+\frac{\rho_{s} f_{y h}}{f_{c}^{\prime}}
\end{gathered}
$$

For simple rectangular columns with horizontal ties for shear reinforcement (i.e. the Bixby Creek as-built columns), an empirical relationship has been developed for the concrete softening slope (Z) term [Ref 16]. The empirical expression is given by,

$$
Z=\frac{0.5}{\frac{3+0.29 f_{c}^{\prime}}{145 f_{c}^{\prime}-1000}+0.75 \rho_{s} \sqrt{\frac{h^{\prime}}{s_{h}}}-0.002 K}
$$

Unloading from the compression curve follows a straight line from the point at which unloading starts (e.g. at strain $\varepsilon_{r}$ in Figure 38) to a point on the axis denoted by $\varepsilon_{p}$ where $\varepsilon_{p}$ is given by the equations,

$$
\frac{\varepsilon_{p}}{\varepsilon_{0}}=0.145\left(\frac{\varepsilon_{r}}{\varepsilon_{0}}\right)^{2}+0.13\left(\frac{\varepsilon_{r}}{\varepsilon_{0}}\right)
$$

when $\left(\frac{\varepsilon_{r}}{\varepsilon_{0}}\right)<2$ and

$$
\frac{\varepsilon_{p}}{\varepsilon_{0}}=0.707\left(\frac{\varepsilon_{r}}{\varepsilon_{0}}-2\right)+0.834
$$

when $\left(\frac{\varepsilon_{r}}{\varepsilon_{0}}\right) \geq 2$

At the time of initiation of this work, the existing material properties of the Bixby Creek structure were not well quantified. Caltrans had not performed core sampling, thus the existing concrete compressive strengths were not precisely known at the time of the retrofit design. Significant concrete strengthening has certainly occurred since the 1930's when the structure was built. For the nonlinear analyses, the material properties utilized by the Caltran's retrofit consultants were employed. These properties are summarized in Table 4. 
The influence of confinement on the effective ultimate compressive strength was also based on the empirical values determined from previous research. The $\mathrm{Z}$ factors defining the slope of the concrete softening were estimated based on the existing $\mathrm{Z}$ factors in the literature, and from existing formulas (EQ. 8) for the unjacketed portions of columns [Ref 16].

The reinforcing steel material model, which provides a reasonable representation of the Bauschinger effect, takes the form (see Taucer, Spacone and Filippou [Ref 13]),

$$
\begin{gathered}
\sigma^{n}=b \cdot \varepsilon^{n}+\frac{(1-b) \cdot \varepsilon^{n}}{\left(1+\varepsilon^{n R}\right)^{\frac{1}{R}}} \\
\varepsilon^{n}=\frac{\varepsilon-\varepsilon_{r}}{\varepsilon_{o}-\varepsilon_{r}} \\
\sigma^{n}=\frac{\sigma-\sigma_{r}}{\sigma_{o}-\sigma_{r}}
\end{gathered}
$$

This model provides the initial yield plateau typical of ductile steels upon first yield, and subsequently provides smoothed hysteresis loops for the saturated elasto-plastic behavior as shown in Figure 37. This model provides good agreement with cyclic tests for steel

TABLE 4. Material property sets assumed for the nonlinear seismic analyses.

\begin{tabular}{|c|c|c|c|}
\cline { 2 - 4 } \multicolumn{1}{c|}{} & Material description & $\begin{array}{c}\text { Effective concrete } \\
\text { compressive strength }\end{array}$ & $\begin{array}{c}\text { Reinforcing steel yield } \\
\text { strength }\end{array}$ \\
\hline $\begin{array}{c}\text { Material } \\
\text { property }\end{array}$ & $\begin{array}{c}\text { Original concrete, } \\
\text { unretrofit, poorly con- } \\
\text { fined }\end{array}$ & $4500 \mathrm{psi}$ & $40 \mathrm{ksi}$ \\
\hline
\end{tabular}

reinforcing bars.

The nonlinear concrete and steel models have been implemented in the NIKE3D finite element program fiber beam element for previous Caltrans funded work [Ref 17]. The NIKE3D element is based on the Hughes-Liu bending element and discretizes the column cross section into a number of user defined zones, with the uniaxial stress-strain behavior of each zone assigned the appropriate concrete or steel stress-strain law (Figure 38).

\subsubsection{Evaluation of the concrete model - comparison with UCSD experiments}

As part of the bridge seismic retrofit program, Caltrans has funded experimental testing of Bixby Creek type columns. The column testing was performed at the University of Cali- 


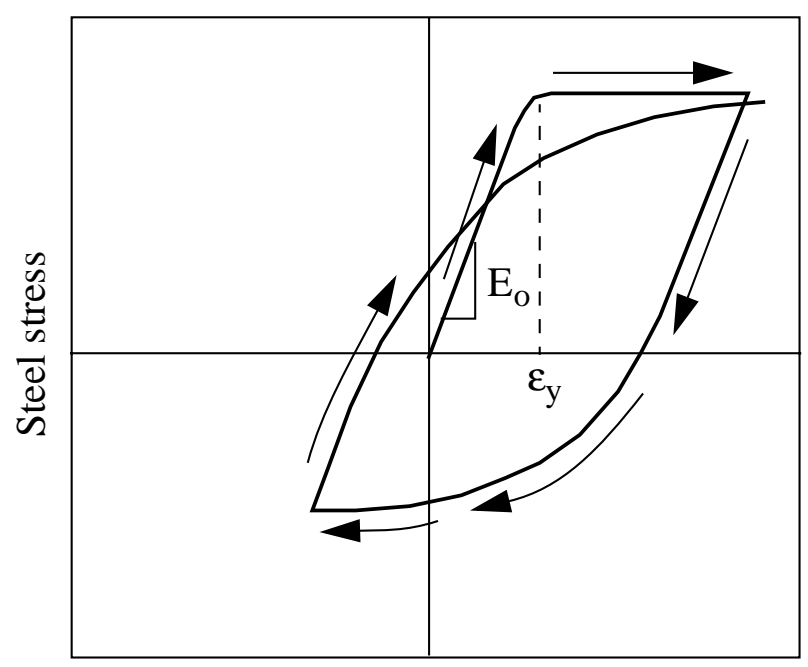

Steel strain

FIGURE 37. Menegotto-Pinto elasto-plastic model for reinforcing bars.

fornia at San Diego under the guidance of Professor Seible [Ref 18]. An evaluation of the nonlinear concrete model for the as-built Bixby Creek columns was performed by comparison with the scale model test of a typical Bixby Creek Bridge column performed at UC San Diego. In the UC San Diego experiment, a scale model column, constructed to be representative of a typical as-built Bixby Creek column, was loaded cyclically up to displacement ductilities of 8 . The experimental test apparatus for the column test and the column details are shown in Figure 39. Based on the material properties supplied in the San Diego study, a finite element model of the concrete column was constructed with multiple beam elements representing the column (Figure 40). The finite element model was used to model the UC experimental test to assess the model's ability to approximate the nonlinear behavior of the actual column. A comparison of the computed force-displacement relationship with the measured force-displacement relationship is shown in Figure 41. The correlation between computed and measured response is reasonable given the uncertainties in actual material properties. The computational model has appropriate pinching of the hysteresis loops and the energy loss per cycle, as defined by the area under the hysteresis loops, appears quite reasonable.

\subsubsection{Concrete cross section definitions for the Bixby Creek model}

The nonlinear fiber model requires definition of the column cross section for each column element for which the model will be used. In the global finite element model of the Bixby Creek structure, a selected number of representative column cross sections were identified. For each of the columns, arch rib and strut cross section definitions, the user defined integration points must be generated as input to the NIKE3D program. The global finite element model must update the stress at each user defined cross section integration point at 

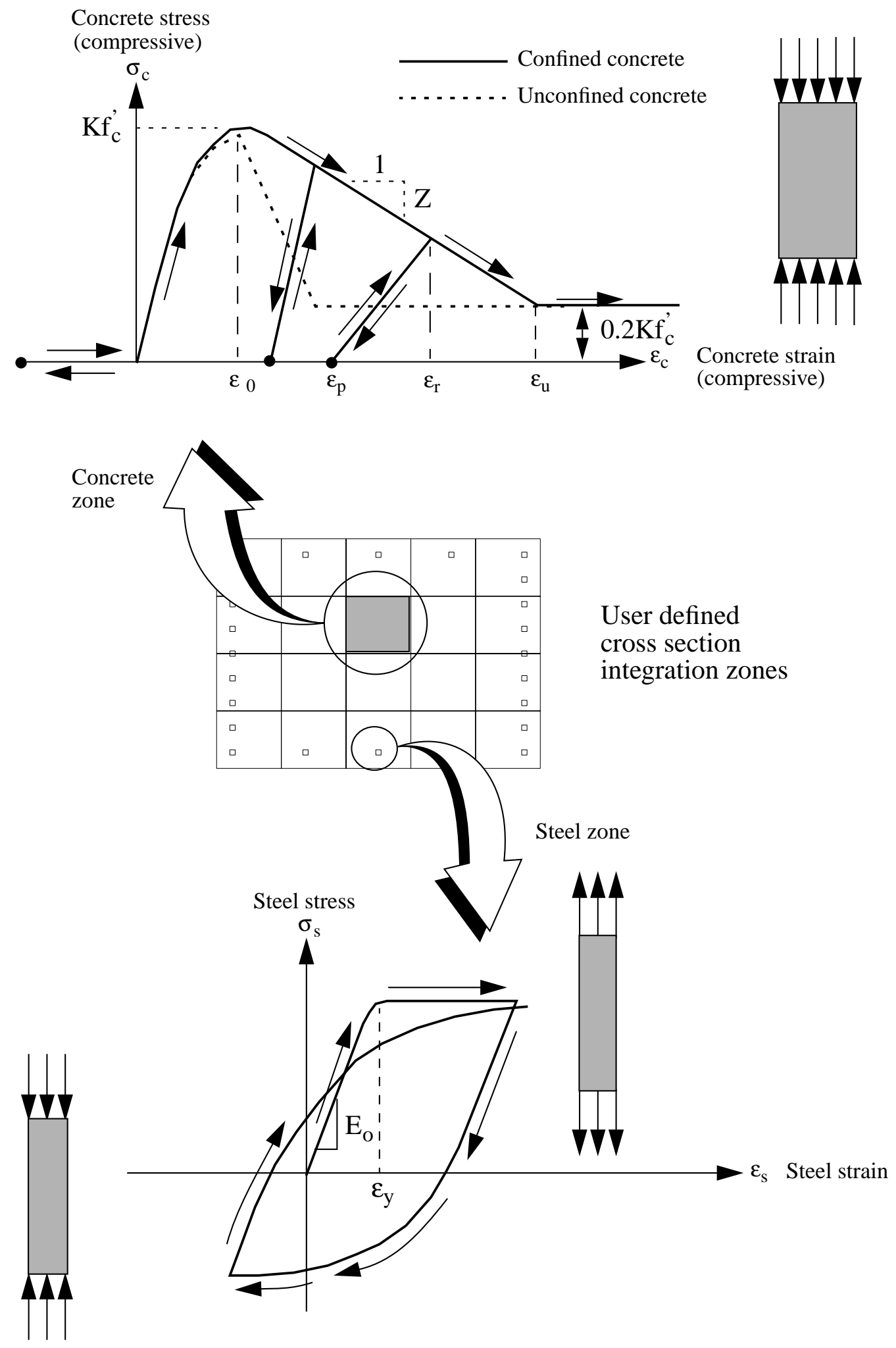

FIGURE 38. Characterization of concrete and steel in the fiber beam element. 

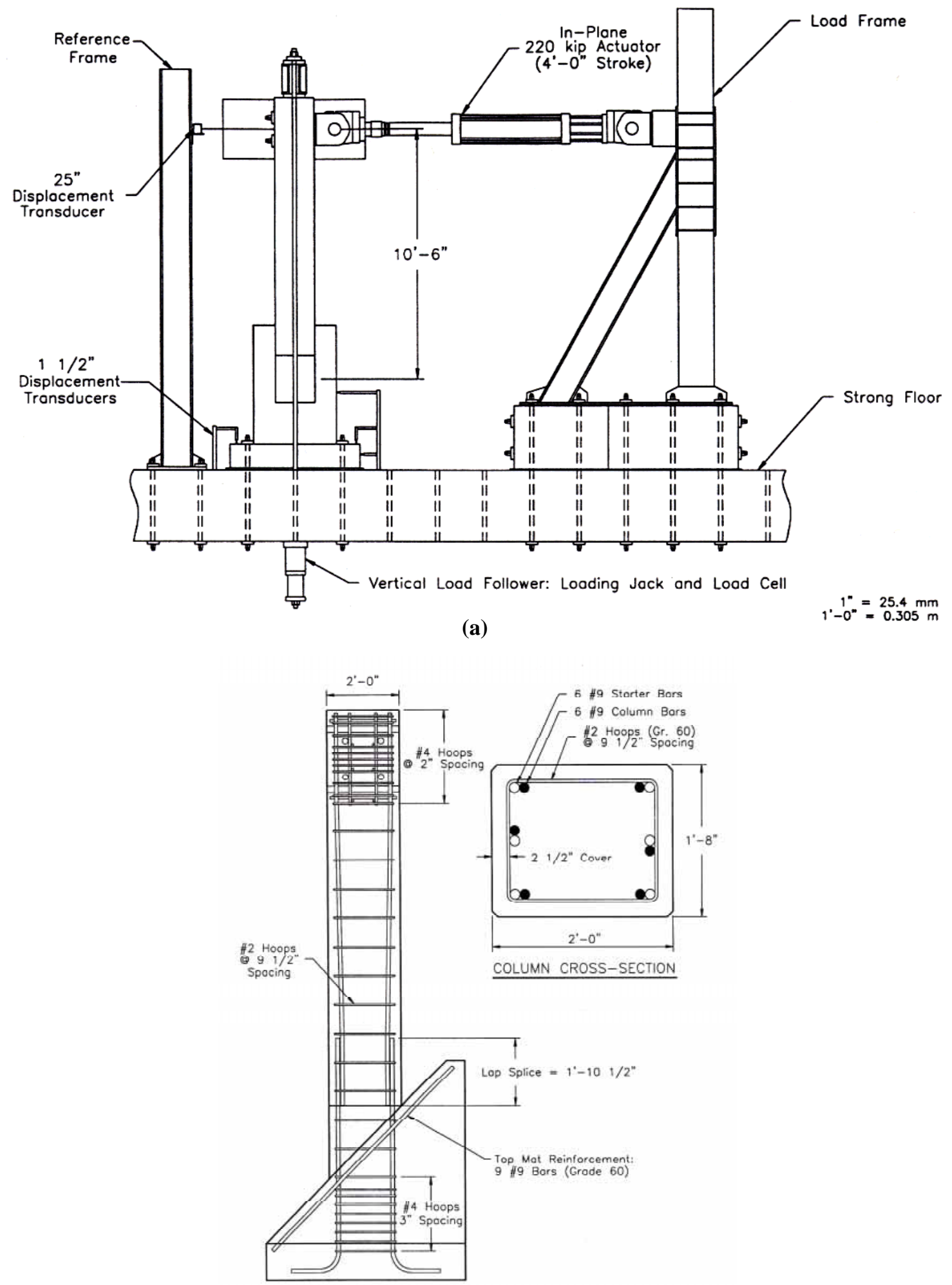
NOTES: All Column Bars and Starter Bars ore Grode 40.
\[ 1^{4}-0^{*}=0.305 \mathrm{~m} \text { and } 1^{*}=25.4 \mathrm{~mm} \]

(b)

FIGURE 39. Representative Bixby Creek Bridge as-built column for the UC San Diego push-pull test [Ref 18]. (a) Test configuration; (b) column details. 

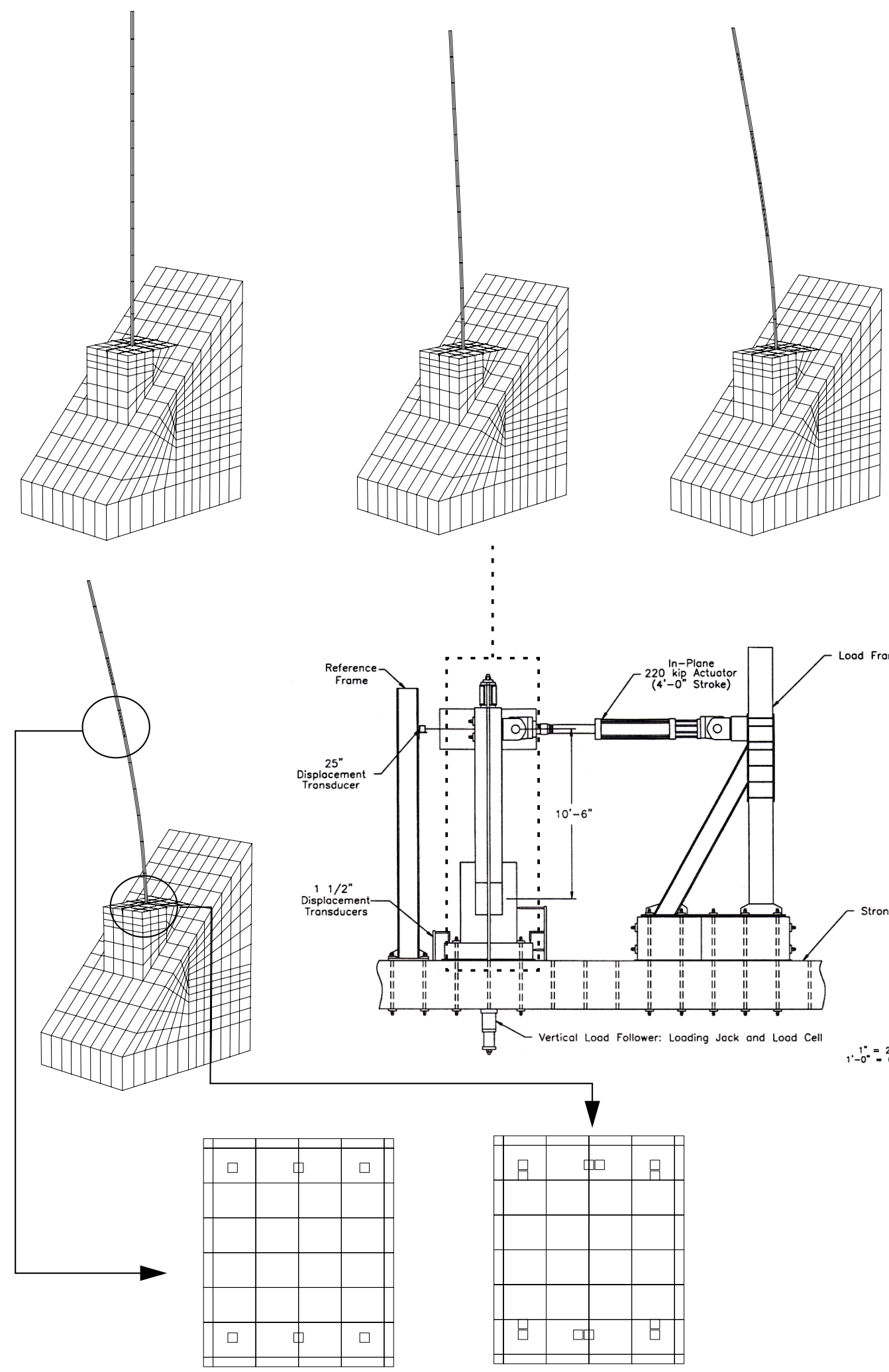

Nominal cross section

Lap splice cross section

FIGURE 40. Simulation model for the UCSD column test. 
each location throughout the structure. The LLNL finite element mesh generator SLIC

TABLE 5. Material properties and their corresponding sections on the model (Figure 42).

\begin{tabular}{|c|c|}
\hline Property & Section on model ${ }^{a}$ \\
\hline pcb10 & $b 10 r, b 10 l$ \\
\hline pcb2 & $b 2 r, b 2 l$ \\
\hline pcb3l & $b 3 r l, b 3 l l$ \\
\hline pcb3u & b3ru, b3lu \\
\hline pcb6l & $b 6 r l, b 6 l l$ \\
\hline pcb6u & b6ru, b6lu \\
\hline pcb7l & $b 7 r l, b 7 l l$ \\
\hline$p c b 7 u$ & $b 7 r u, b 7 l u$ \\
\hline pcb8 & $b 8 r, b 8 l$ \\
\hline$p c b 9$ & $b 9 r, b 9 l$ \\
\hline pes 11 & sb1rl, sb1ll, sb10rl, sb10ll \\
\hline $\operatorname{pcs} 1 u$ & sb1ru, sb1lu, sb10ru, sb10lu \\
\hline $\operatorname{pcs} 2$ & $s b 2 r, s b 2 l, s b 9 r, s b 9 l$ \\
\hline plab1 & $a b d 04 r, a b d 04 l, a b d 14 r, a b d 14 l$ \\
\hline plab2 & $a b d 05 r, a b d 05 l, a b d 13 r, a b d 13 l$ \\
\hline plab3 & $a b d 06 r, a b d 06 l, a b d 12 r, a b d 12 l$ \\
\hline plab4 & $a b d 07 r, a b d 07 l, a b d 11 r, a b d 11 l$ \\
\hline plab5 & $a b d 08 r, a b d 08 l, a b d 10 r, a b d 10 l$ \\
\hline plab6 & $a b d 09 r, a b d 09$ \\
\hline pabs 1 & sblas, sb10as \\
\hline pabs2 & sb2as, sb9as \\
\hline pabs3 & sb3as, sb8as \\
\hline pabs4 & sb4as, sb7as \\
\hline pabs5 & sb5as, sb6as \\
\hline pcs & $\begin{array}{l}b 2 s, b 3 s u, b 3 s l, s b 1 s u, s b 1 s l, s b 2 s, s b 3 s, s b 8 s, s b 9 s, s b 10 s u, s b 10 s l, b 6 s u, b 6 s l, b 7 s u, b 7 s l \text {, } \\
b 8 s, b 9 s, b 10 s\end{array}$ \\
\hline pcs3 & $s b 3 r, s b 3 l, s b 8 r, s b 8 l$ \\
\hline psd3 & $s d 06 n, s d 11$ \\
\hline$p s d 3 x$ & sd07, sd10n \\
\hline psd1 & $s d 01, s d 02, s d 03, s d 04 n, s d 05 s, s d 13 n, s d 14 s, s d 15 n, s d 16, s d 17, s d 18, s d 19, s d 20$ \\
\hline psd2 & $s d 05 n, s d 06 s, s d 12 n, s d 13 s$ \\
\hline
\end{tabular}



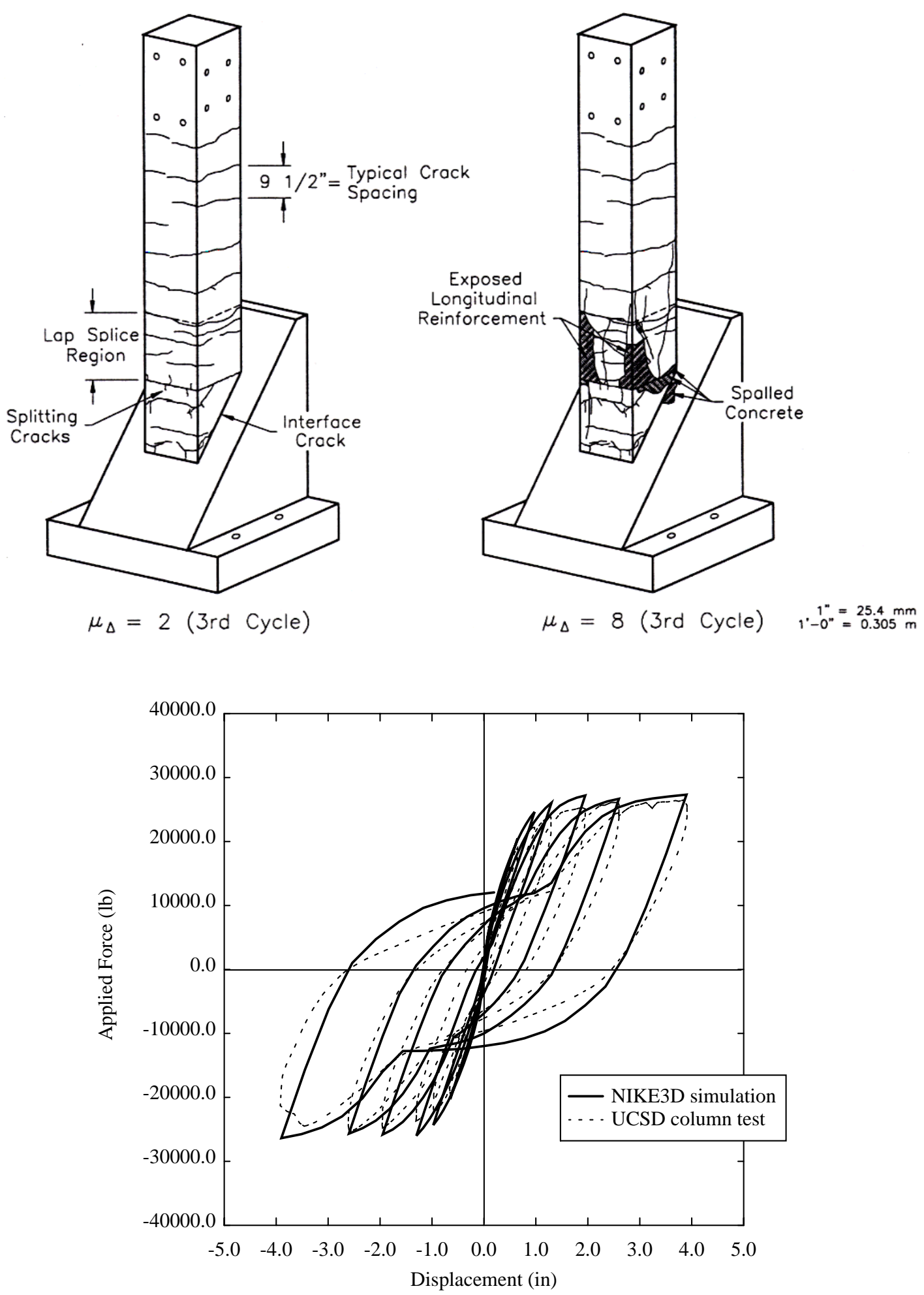

FIGURE 41. Column nonlinear test results. (a) Observed damage at ductilies of $\mathbf{3}$ and 8; (b) comparison of measured and computed force-displacement. 


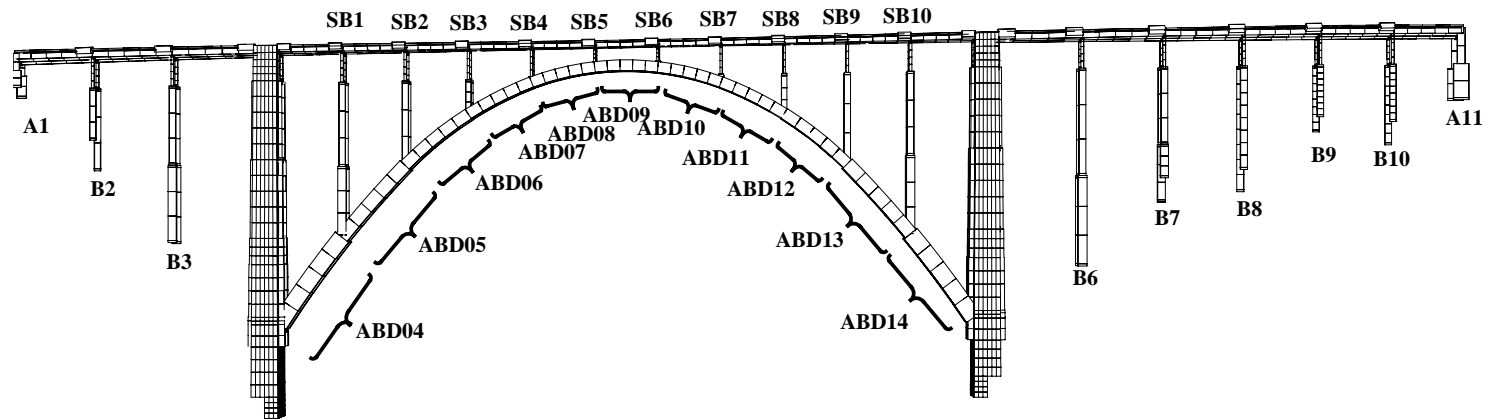

(a)

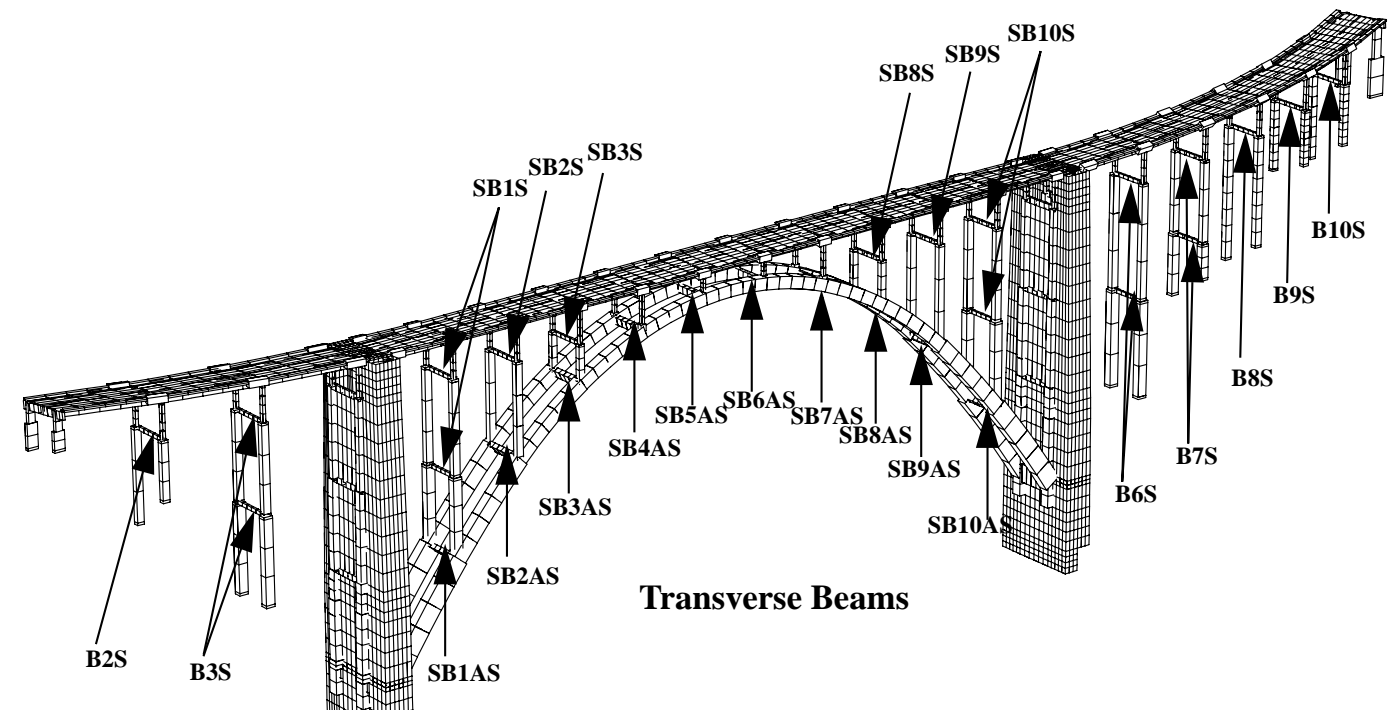

(b)

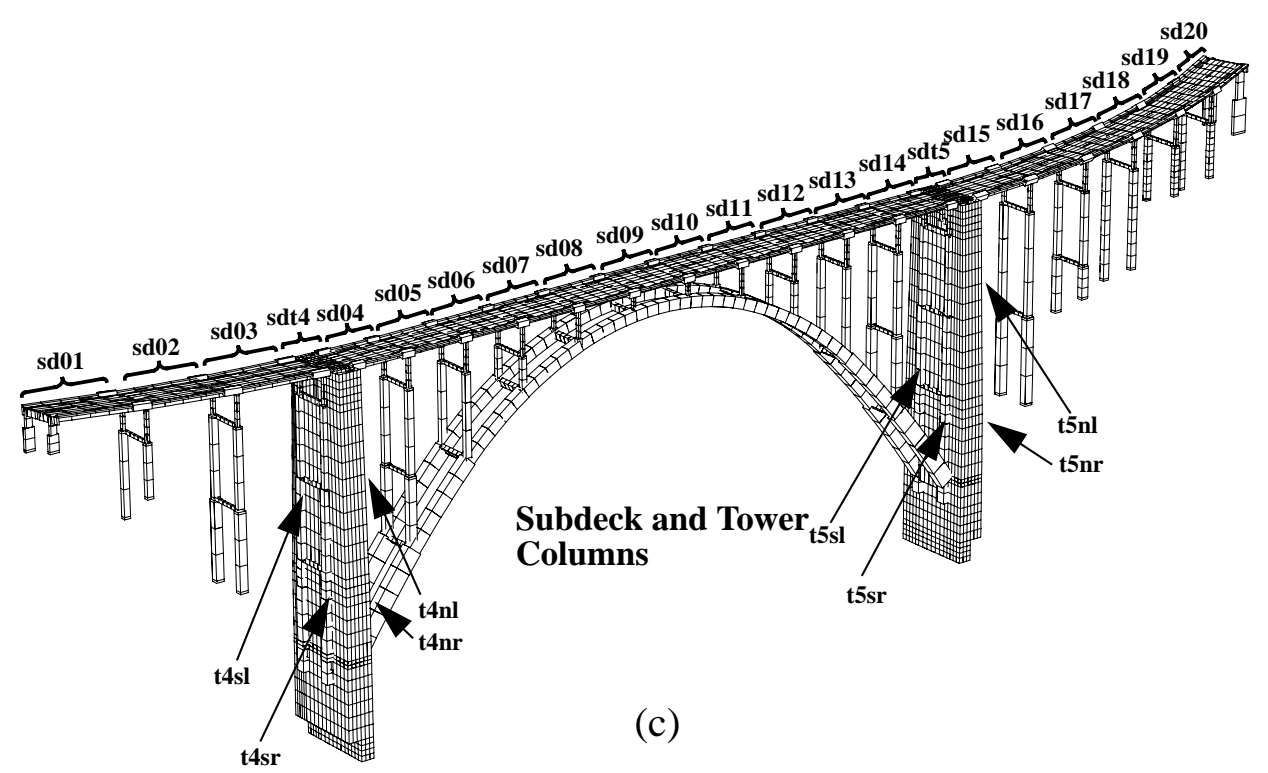

FIGURE 42. Model section numbers. 
TABLE 5. Material properties and their corresponding sections on the model (Figure 42).

\begin{tabular}{|l|l|}
\hline Property & \multicolumn{1}{|c|}{ Section on model $^{a}$} \\
\hline psd4 & $s d 08 n, s d 09, s d 10 s$ \\
\hline ptc1 & $t 4 s r 6, t 4 s l 6, t 4 n r 6, t 4 n l 6, t 5 s r 6, t 5 s l 6, t 5 n r 6, t 5 n l 6$ \\
\hline ptc2 & $t 4 s r 5, t 4 s l 5, t 4 n r 5, t 4 n l 5, t 5 s r 5, t 5 s l 5, t 5 n r 5, t 5 n l 5$ \\
\hline ptc3 & $t 4 s r 4, t 4 s l 4, t 4 n r 4, t 4 n l 4, t 5 s r 4, t 5 s l 4, t 5 n r 4, t 5 n l 4$ \\
\hline ptc4 & $t 4 s r 3, t 4 s l 3, t 4 n r 3, t 4 n l 3, t 5 s r 3, t 5 s l 3, t 5 n r 3, t 5 n l 3$ \\
\hline ptc5 & $t 4 s r 1, t 4 s r 2, t 4 s l 1, t 4 s l 2, t 4 n r 1, t 4 n r 2, t 4 n l 1, t 4 n l 2, t 5 s r l, t 5 s r 2, t 5 s l 1, t 5 s l 2, t 5 n r 1, t 5 n r 2$, \\
\hline ptsd & $t 5 n l 1, t 5 n l 2$ \\
\hline ptsd2 & $s d 03 n, s d 04 s, s d 14 n, s d 15 s$ \\
\hline pnslde & $s d t 4 s, s d t 4 n, s d t 5 s, s d t 5 n$ \\
\hline pnsldw & $d 01 r, d 02 r, d 03 r, d 15 r, d 16 r, d 17 r, d 18 r, d 19 r, d 20 r$ \\
\hline paslde & $d 04 r, d 05 r, d 06 r, d 07 r, d 08 r, d 09 r, d 10 r, d 11 r, d 12 r, d 13 r, d 14 r$ \\
\hline pasldw & $d 04 l, d 05 l, d 06 l, d 07 l, d 08 l, d 09 l, d 10 l, d 11 l, d 12 l, d 13 l, d 14 l$ \\
\hline
\end{tabular}

a.**Notes: In Figures 42a, 42b, and 42c, the majority of the names given to the different locations on the bridge begin with letters and end in numbers. The letters describe the part of the bridge and the numbers state the location. In Figure 42a, the "A" stands for abutment, "B" stands for bent, "SB" stands for the bents that span the arch, and "ABD" stands for the arched beams. The arch span components are numbered separately from the approach spans. Figure $42 \mathrm{~b}$ describes all of the transverse beams. All of the transverse beams, except for the ones connecting the two arches, are labeled similarly to the bents in Figure 42a. The only difference is that an " $\mathrm{S}$ " has been added to the bent locations so as to distinguish the transverse beams from their corresponding bents. The transverse beams of the arch (I-beams) are labeled the same way as the bent transverse beams of the arch span, except that an "A", which stands for arch, has been added after the number. Figure 42c describes the remaining locations. The "SD" stands for subdeck. The term "subdeck" describes the split columns that are directly below the deck segments. The numbers after "SD" label the individual deck segments. The label "T4" and "T5" has been given to the south tower and the north tower.

The "R" or " $\mathrm{L}$ " in a name describes either the right side or left side of the bridge when looking North. Therefore, "R" and " $L$ " stand for east and west. The "U" and "L" in a name usually describe whether the part is an upper part or lower part. For instance, a bent with two sections (disregarding the split column section) have been labeled as an upper part or a lower part. This same bent will have two transverse beams. One will be labeled as upper and one as lower. Other names will have an "N" or an "S" tagged on to the end as well. These labels stand for north and south. For example, the split columns of one deck segment will have two north columns and two south columns. If a name begins with a " $D$ ", the parts being described are related to the individual deck segments. For instance, "D01R" describes the right side of deck segment 1, which would correlate to the east girder of the first deck segment in the south approach.

was used to automate the construction of the user defined concrete cross sections for the Bixby Creek structure. All of the fiber beam element cross sections for the bridge are summarized in Table 5, and the sections are shown in Figure 43 through Figure 47.

\subsection{Abutment stiffnesses and foundation model}

For the as-built model, simple linear abutment springs were distributed across the end columns to approximate the distributed stiffness supplied by the soil mass at the end of the structure. Compression-only springs were applied at the two abutments utilizing the discrete elements in NIKE3D. The abutment stiffnesses for the as-built model were determined based on a Caltrans prescribed soil stiffness of $200 \mathrm{kips} / \mathrm{in} / \mathrm{ft}$ (this value is based on a material with $\mathrm{V}_{\mathrm{s}}=800 \mathrm{ft} / \mathrm{sec}$ and a 8 ' effective wall height). Only longitudinal springs were incorporated in the model since for this particular abutment configuration there was little identifiable load path for shear transfer between the abutment and the soil for pure translational motion. The discrete elements were distributed along all of the abutment bent 


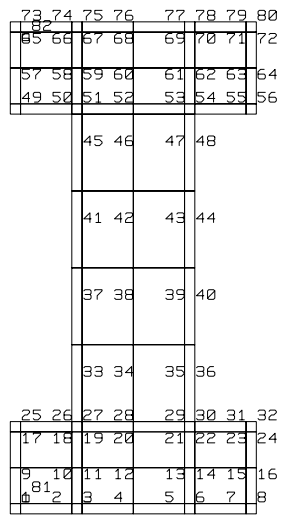

pabs1

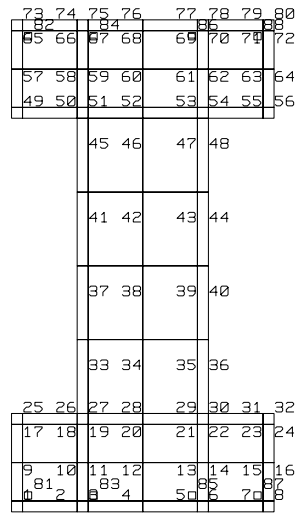

pabs 2

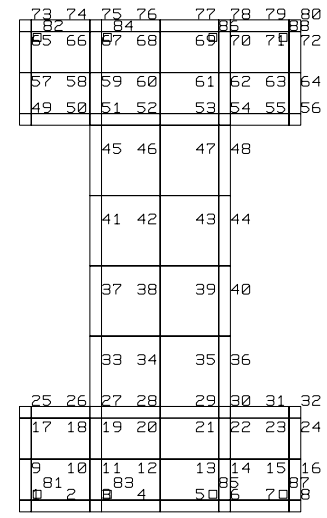

pabs3

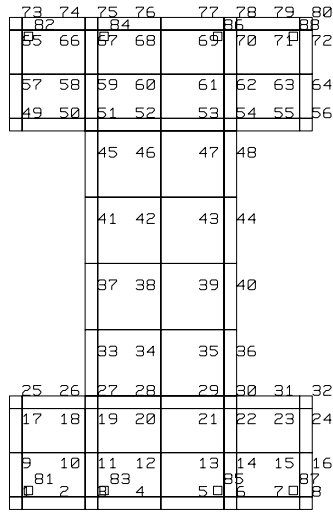

pabs4

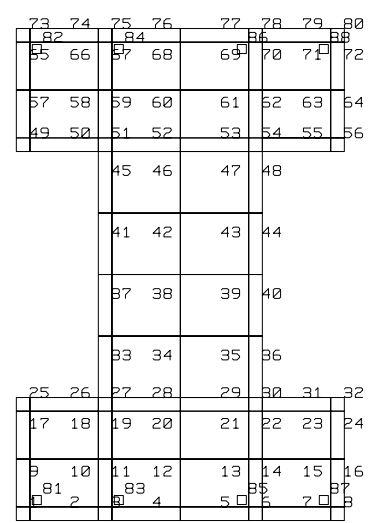

pabs 5

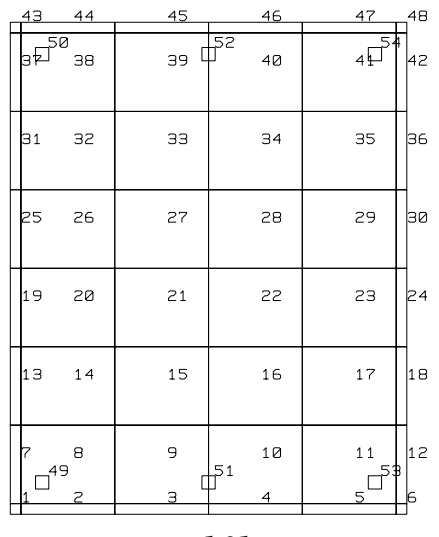

pcb3l

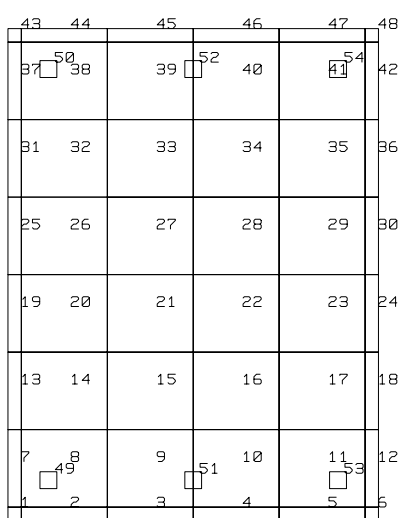

pcb10

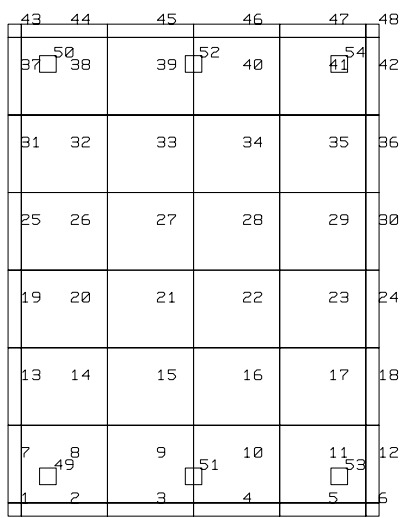

pcb3u

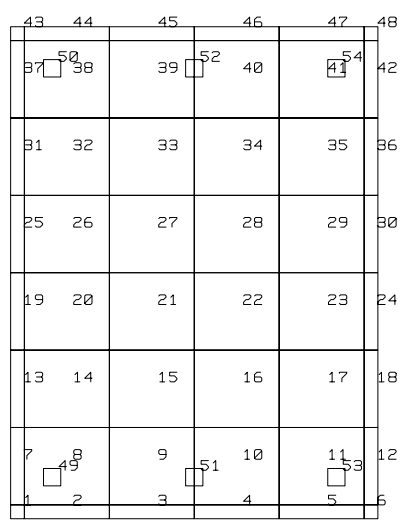

pcb2

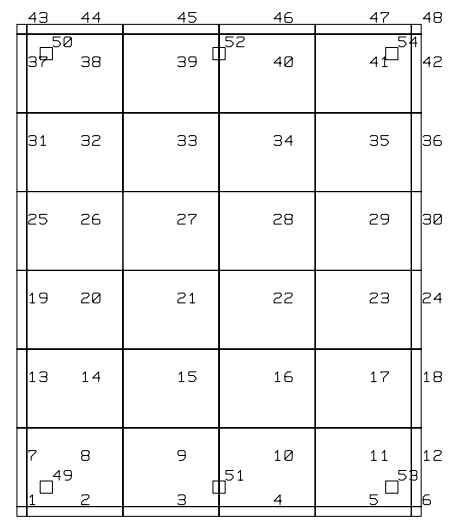

pcb6l

FIGURE 43. User defined integration cross sections for selected elements, (steel and concrete zones shown). 


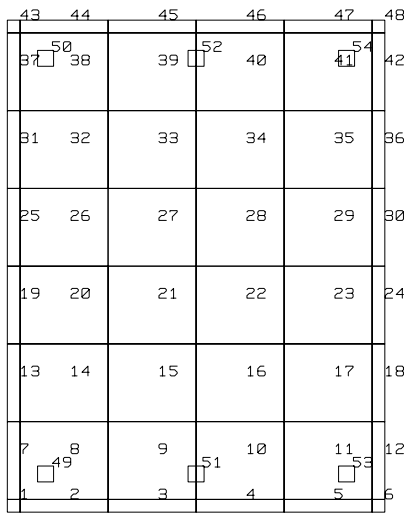

pcb6u
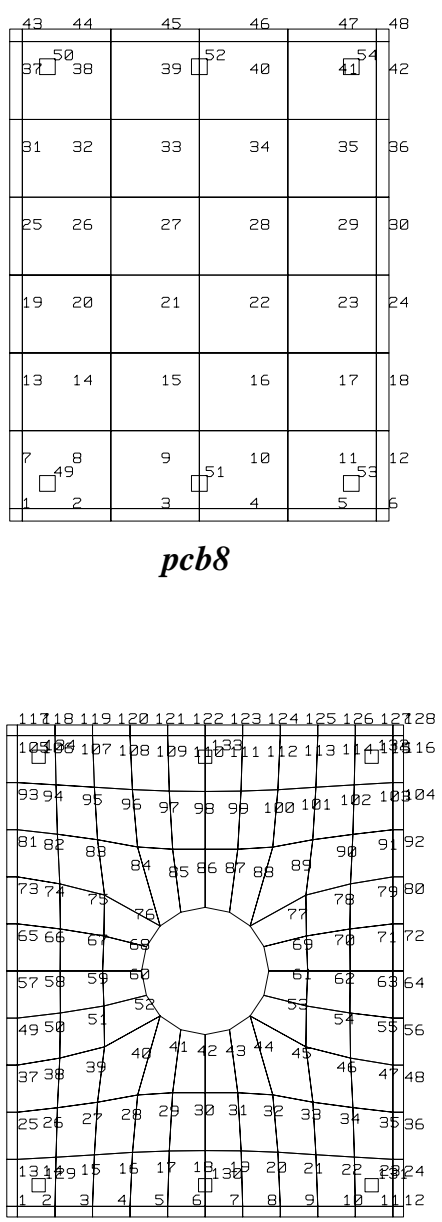

pcs1l

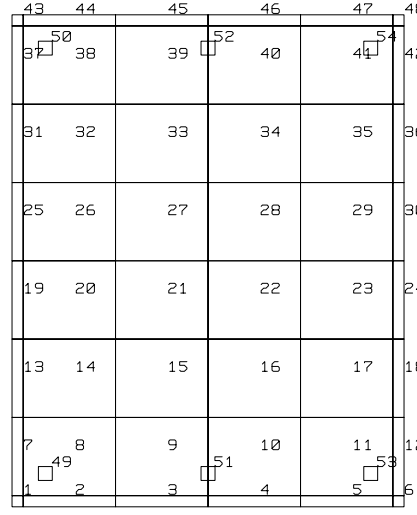

pcb7l

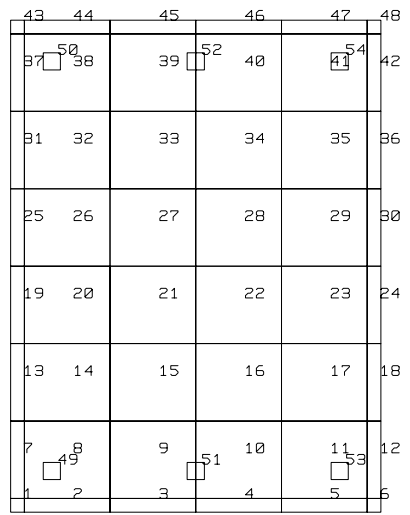

pcb9

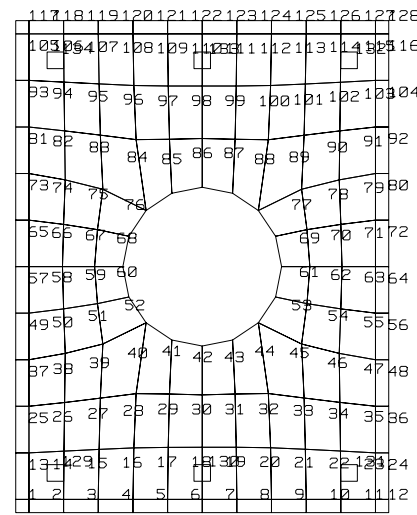

pes1u

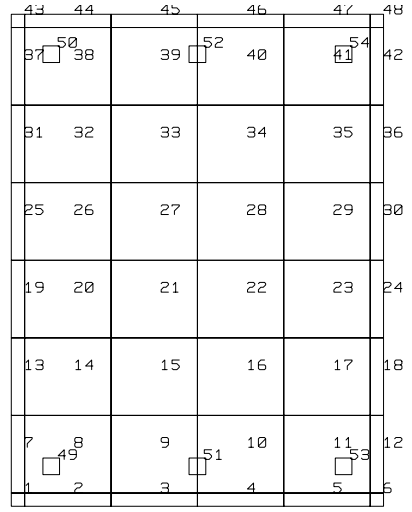

$p c b 7 u$

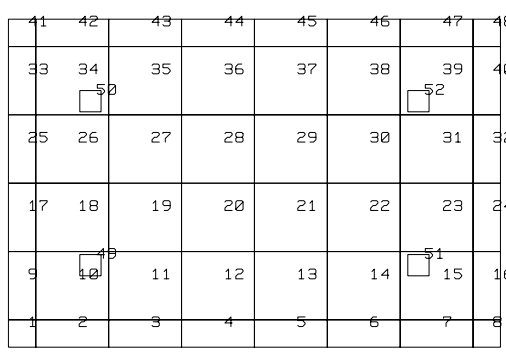

pcs

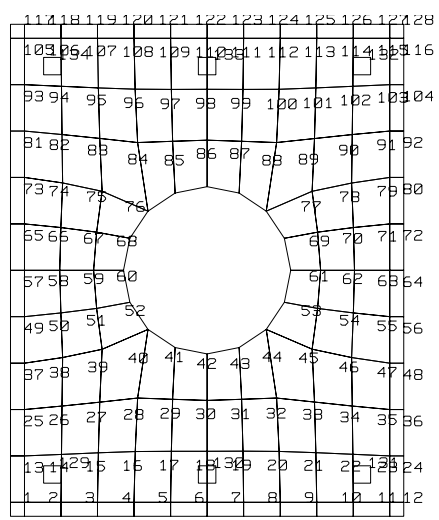

pcs 2

FIGURE 44. User defined integration cross sections for selected elements, (steel and concrete zones shown). 

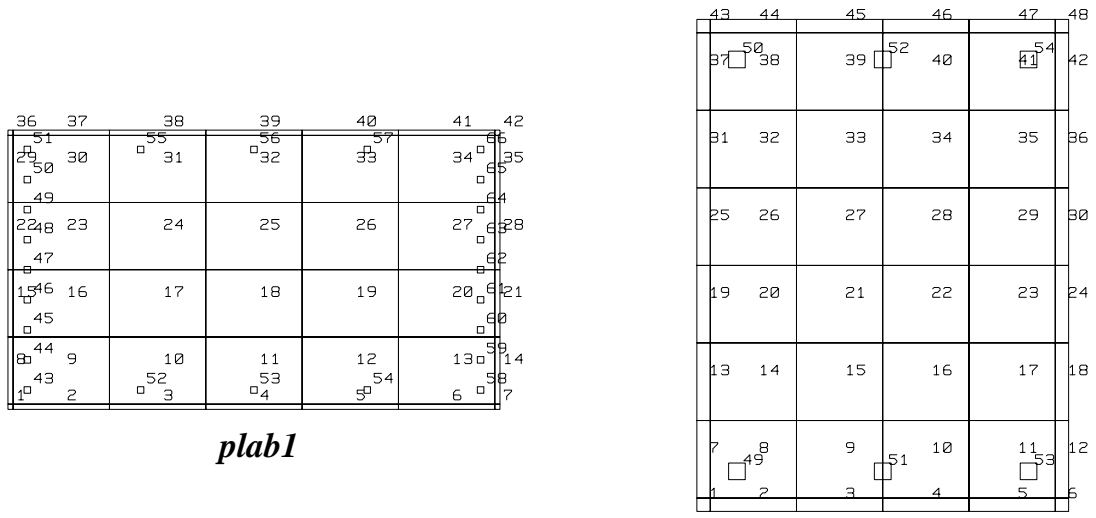

ptc1
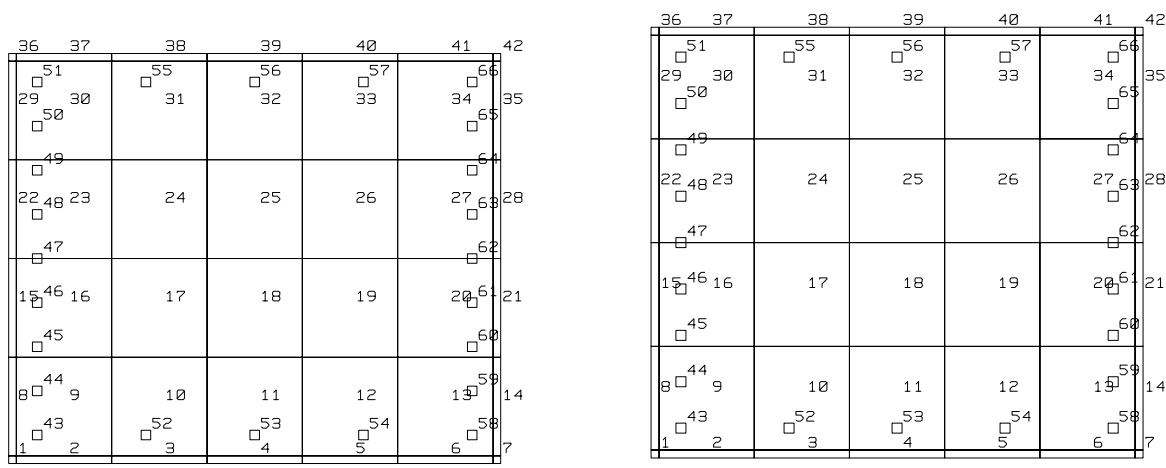

plab3

plab4

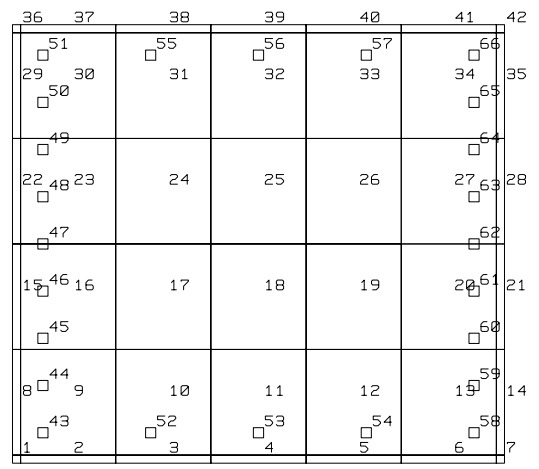

plab5

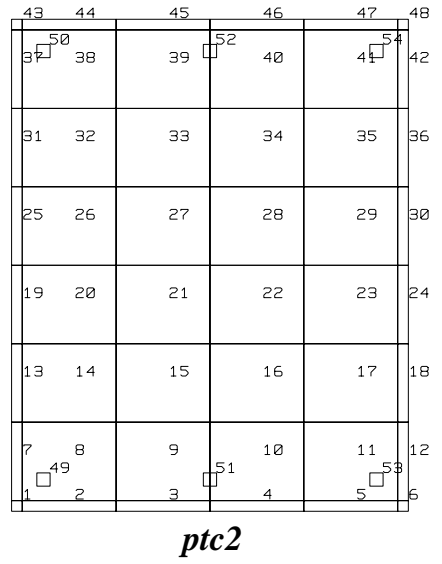

FIGURE 45. User defined integration cross sections for selected elements, (steel and concrete zones shown). 

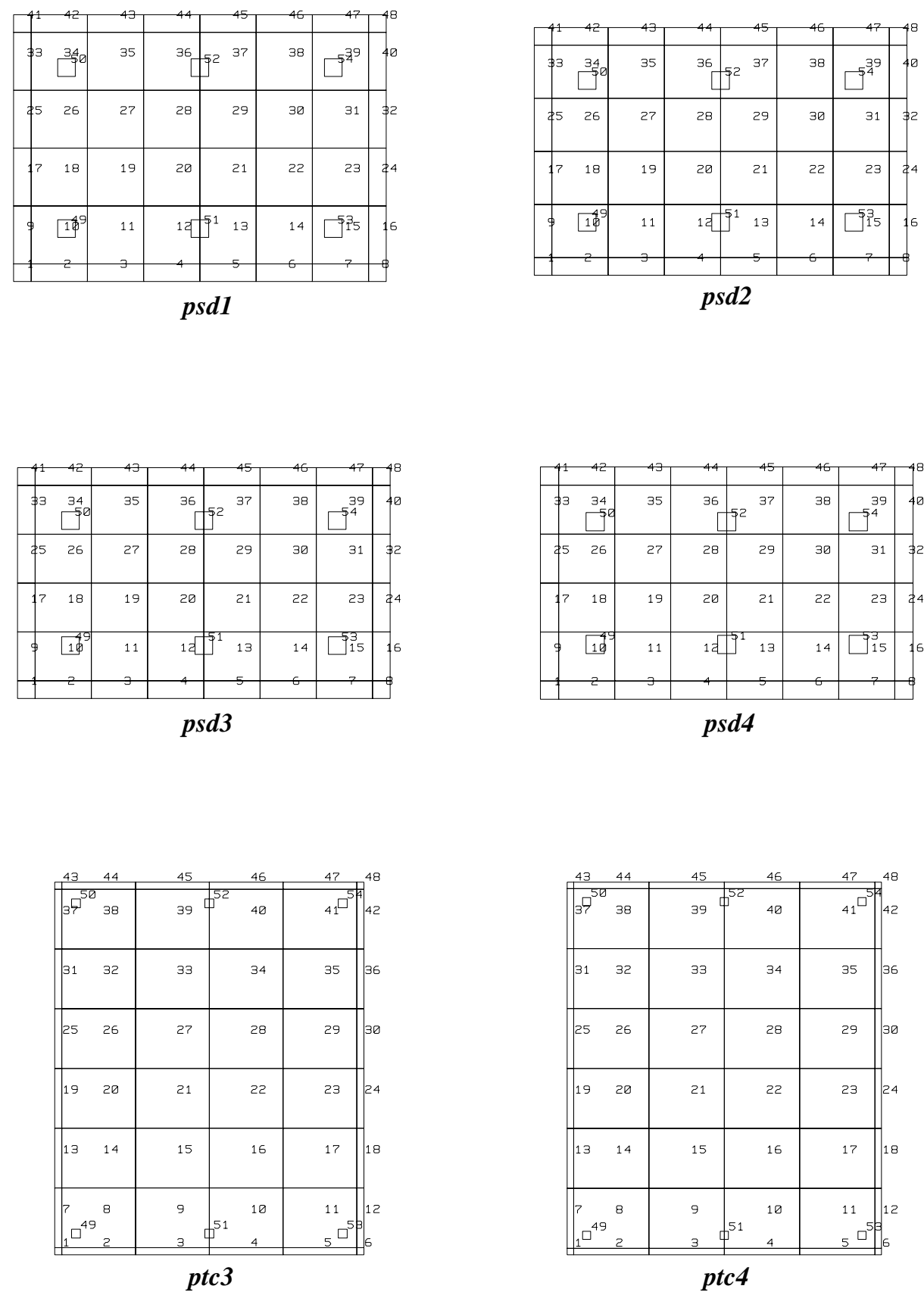

ptc4

FIGURE 46. User defined integration cross sections for selected elements, (steel and concrete zones shown). 


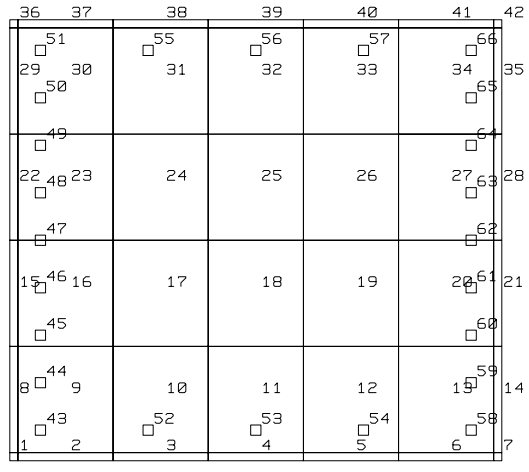

plab6
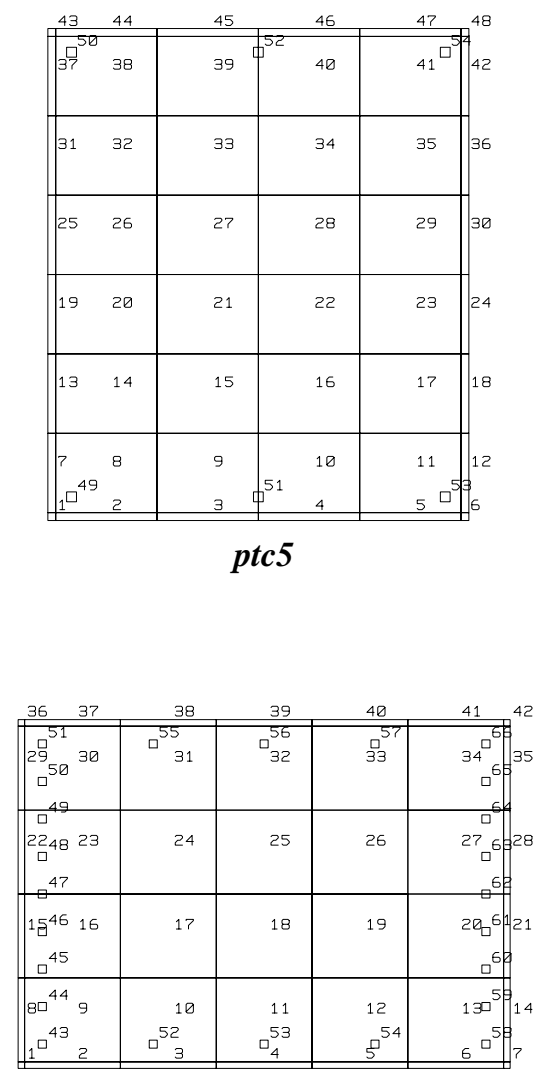

plab2
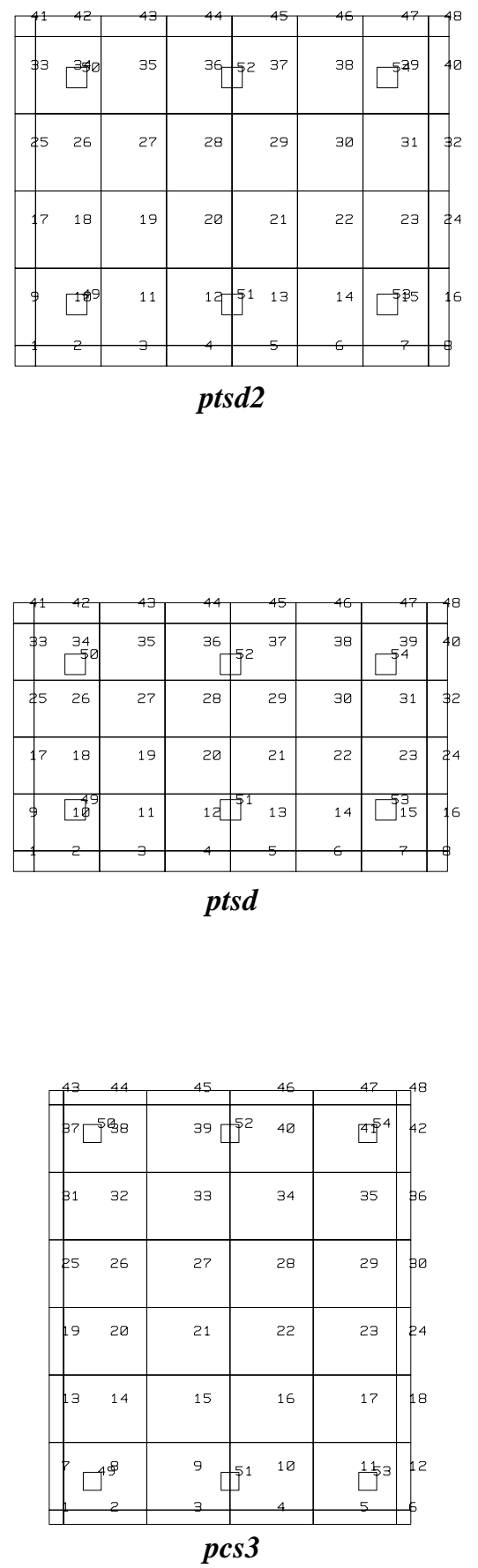

FIGURE 47. User defined integration cross sections for selected elements, (steel and concrete zones shown). 


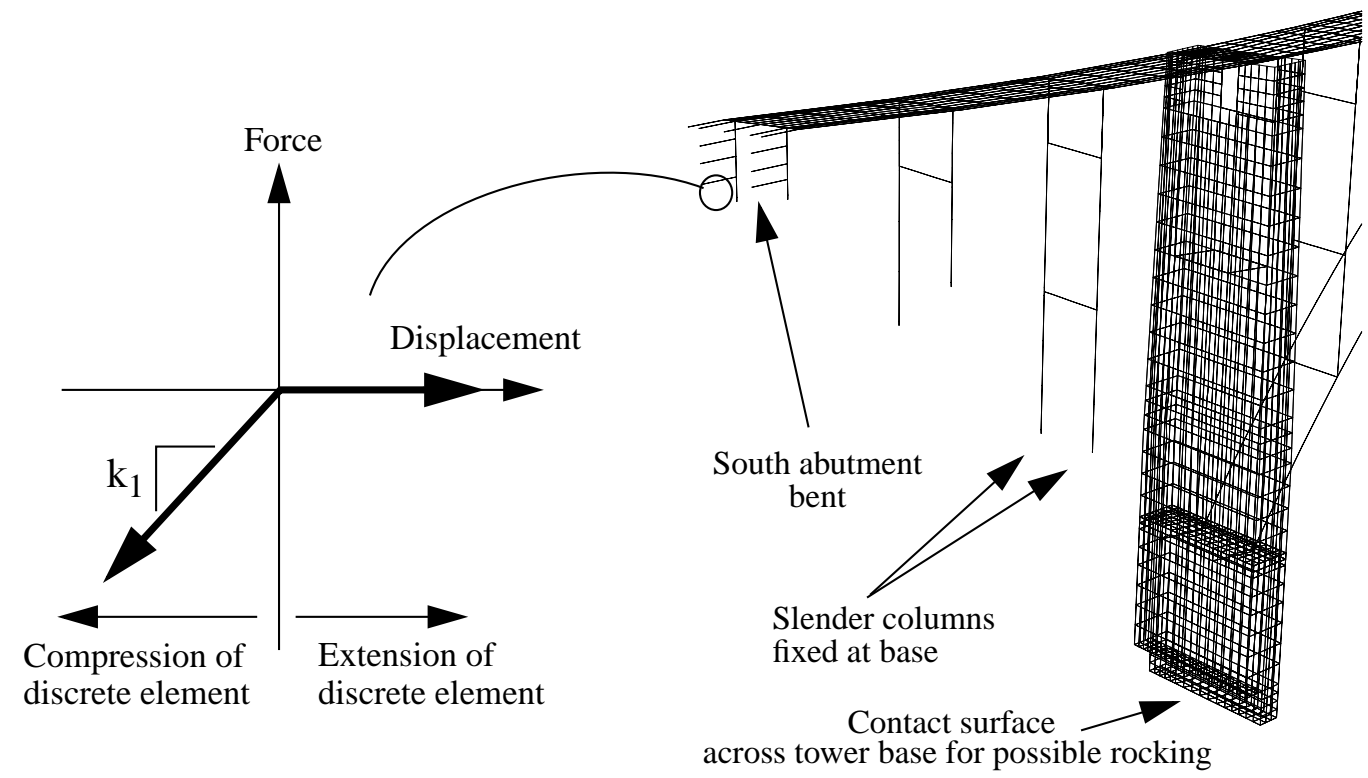

FIGURE 48. Discrete elements at the abutments to account for stiffness supplied by soil under compression.

surfaces in contact with the soil. Each of the discrete elements was assigned a force-displacement as shown in Figure 48. Due to the relatively small displacements occurring at the bridge abutments (on the order of 1.2 inch), it was decided that gross soil failure was not likely and thus the abutment stiffnesses were not reduced to account for soil failure. This concurs with the approach taken by Buckland and Taylor for the as-built structure. The spring stiffness values provided by the individual and aggregate discrete elements are summarized in Table 6 and Table 7.

Table 6: Individual discrete element stiffnesses.

\begin{tabular}{|c|c|c|}
\cline { 2 - 3 } \multicolumn{1}{c|}{} & Location & $\begin{array}{c}\text { Individual spring stiffnesses } \mathbf{k}_{\mathbf{1}} \\
\text { (kips/in) }\end{array}$ \\
\hline \multirow{2}{*}{$\begin{array}{c}\text { Springs running hor- } \\
\text { izontally along } \\
\text { beam }\end{array}$} & South & 190 \\
\cline { 2 - 3 } & North & 190 \\
\hline \multirow{3}{*}{$\begin{array}{c}\text { Springs running ver- } \\
\text { tically down col- } \\
\text { umns }\end{array}$} & South East & South West \\
\cline { 2 - 3 } & North East & 100 \\
\cline { 2 - 3 } & North West & 360 \\
\hline
\end{tabular}

Table 7: Total abutment stiffnesses.

\begin{tabular}{|c|c|c|}
\cline { 2 - 3 } \multicolumn{1}{c|}{} & $\begin{array}{c}\text { Abutment stiffness (kips/ } \\
\text { in) }\end{array}$ & $\begin{array}{c}\text { Abutment stiffness } \\
\text { (kips/ft) }\end{array}$ \\
\hline South & 1,640 & 19,700 \\
\hline North & 3,650 & 43,800 \\
\hline
\end{tabular}


The individual columns of the structure are relatively slender and the foundation material is competent rock. It is not anticipated that the column bases will have significant rotation or deflection as would occur if the structure were founded on a soft soil. Thus a fixed base assumption was employed at the bottom ends of the slender columns in the bridge model. The Buckland and Taylor retrofit design included a number of tie-downs to anchor the towers down to the bedrock and prevent uplift. To investigate the possiblity of tower uplift in the as-built structure, contact surfaces were specified at the base of each tower as indicated in Figure 48. The contact surface is initialized in the static gravity initialization of the bridge to develop the appropriate contact forces, and the contact surface allows the tower to rock and uplift during the transient bridge analysis if the bridge dynamics dictate that uplift will in fact occur.

\subsection{Energy dissipation mechanisms in the computational model}

The computational models which have been utilized in this study vary significantly, ranging from simple linear elastic models to more sophisticated and complex nonlinear models. It is difficult to ensure a completely consistent characterization of the system damping which spans all of these types of models. The energy dissipation assumption which was used in the analysis models consisted of assuming a nominal 5\% modal damping in the materially linear models and 3\% modal damping in the nonlinear models. The nonlinear model input damping was slightly reduced in light of the fact that the nonlinear material models contribute significant damping through material hysteresis. These user defined damping values were input to the models based on a simple mass and stiffness proportional damping matrix (i.e. Rayleigh damping) in which the precise damping was anchored in the first and fifth modes of the specific structural model at hand. For the computational models, it was verified by hand calculations that this form of damping anchoring provided very close to the desired damping in all of the first ten natural modes of the structural model. The frequency variation of damping for models with linear and nonlinear
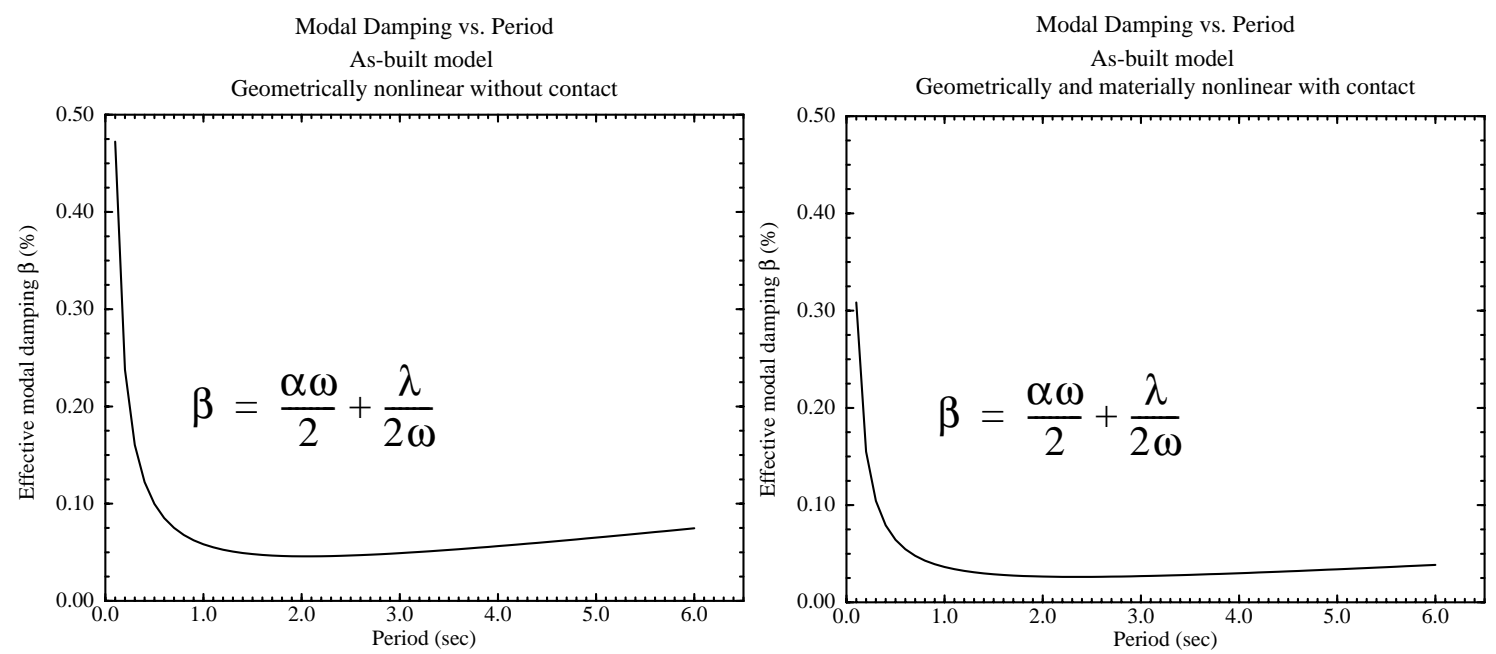

FIGURE 49. Damping variation with frequency for models with linear and nonlinear materials.

material models respectively are shown in Figure 49. 


\subsection{Natural modeshapes and frequencies of the as-built bridge system}

The thermal expansion joints of the Bixby Creek Bridge columns provide a source of geometric nonlinearity when the structure is subjected to strong earthquake motions. These joints can alternate between open and closed with potential impact occurring. The existing column collar retrofits would tend to mitigate this to a degree, but at high amplitude motions the collars would not provide full connectivity between adjacent bridge segments. It is also anticipated that significant pounding could occur between the deck segments and the towers. The solution for the natural modeshapes in a geometrically nonlinear system requires a linearization of the system about a particular configuration. For the Bixby Creek Bridge, eigensolutions were performed for three idealized configurations of the bridge. For the first case, the individual deck segments were assumed completely coupled across the expansion joint interfaces. This assumption leads to the stiffest configuration of the structural system. For the second case, the bridge segments were assumed to expand and contract freely across the expansion joints without any development of tension, shear or pounding. This assumption leads to the most flexible configuration of the structural system. A third case provided translational coupling between adjacent nodes only at the locations of the retrofit collars. This idealization represents an intermediate configuration between the other bounding cases (see Figure 50).

In structures that are subjected to very large compressive or tensile forces, the effective stiffness can be significantly influenced by the large member forces. This effect is illustrated with a simple example in Figure 51. If the axial loads become quite large, and the geometric stiffness contribution becomes numerically significant compared to the elastic stiffness, the effect of axial forces on the system stiffness can become important. If the structure is subjected to large tensile forces, the natural frequencies of the structure can increase, and if the structure is subjected to large compressive forces, the natural frequencies of the structure can decrease as indicated in Figure 51. Classic examples of bridge structures for which the influence of axial forces become important are cable supported bridges, where axial tensile forces are extremely large, and arch bridges, where arch compressive forces become very large and can result in a softening of the bridge system.

Arch bridges are subject to large compressive forces which can significantly decrease the effective stiffness of the arch system when the arch undergoes lateral deformation. To account for the effect of compressive forces on natural frequencies in the arch structure, a nonlinear, static analysis for gravity load is performed as a precursor to the eigensolution for modeshapes and frequencies. In cable bridges, the static initialization must account for changes in the bridge geometry since the geometric changes can be quite significant. This requires special procedures to arrive at the correct gravity induced bridge geometry [Ref 19]. One cannot simply start with the desired final bridge geometry and turn on gravity forces, since the model will sag and deform to an inappropriate final geometry. In arch structures, the changes in global geometry due to gravity initialization are not as significant and the important issue is the computation of the correct gravity induced forces in the arch ribs and subdeck elements. The initialization of the arch system is thus simpler than the cable bridge system and starting with a model constructed on the as-built geometry is appropriate. 

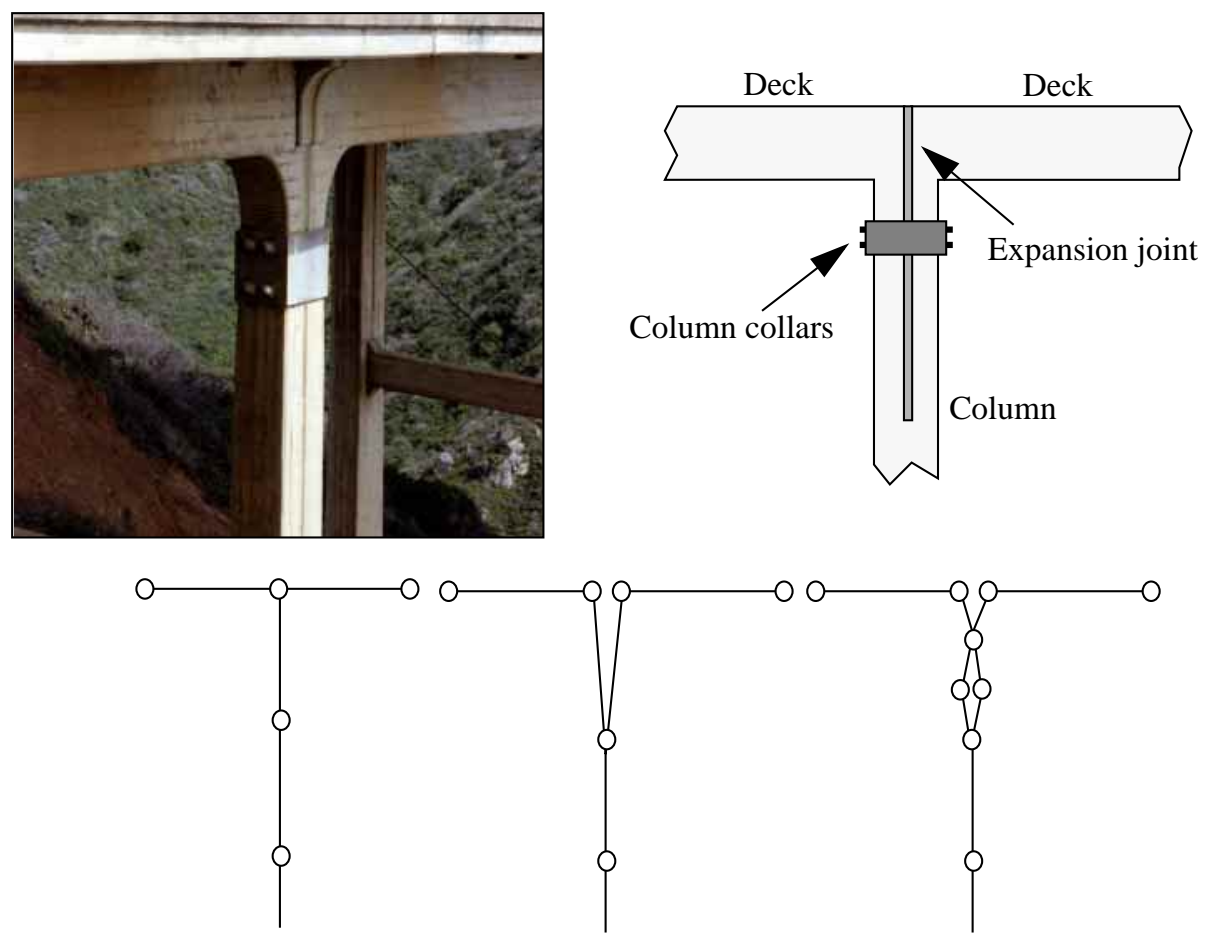

Case 1: complete coupling

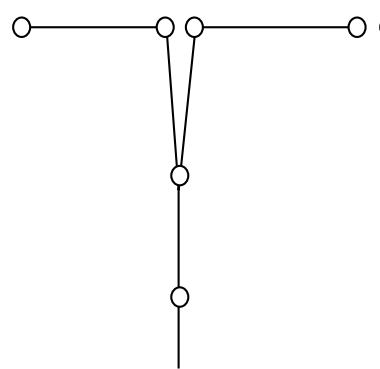

Case 2: complete decoupling

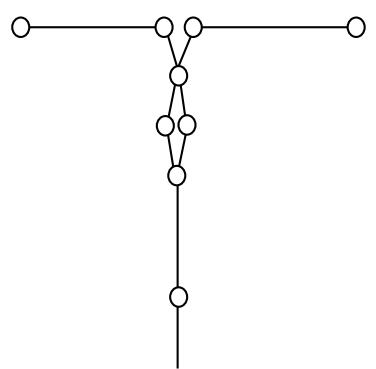

Case 3: coupling at collars

\section{FIGURE 50. Expansion joint idealizations for eigensolution.}

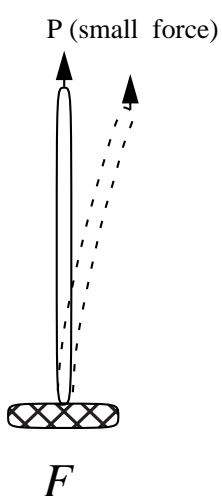

(frequency is not appreciably effected by the axial force $P$ )
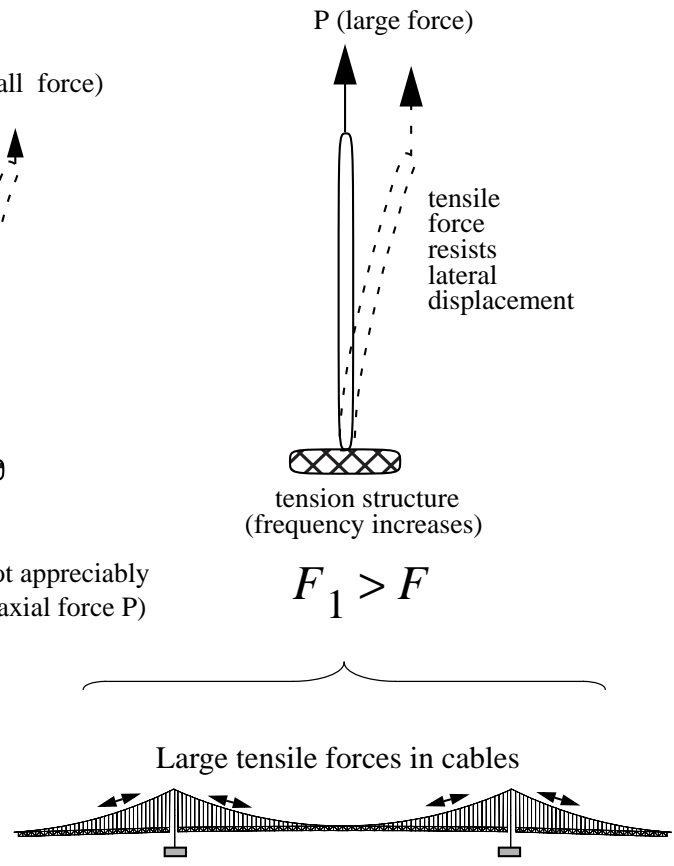

Gravity forces increase frequencies

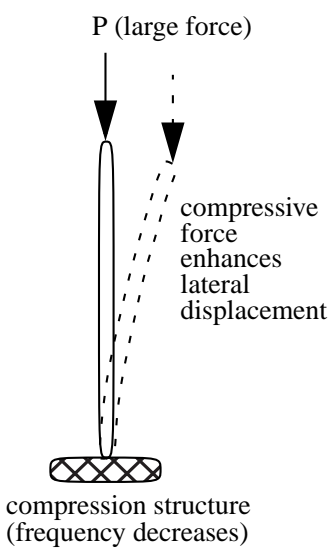

$$
F_{2}<F
$$

Large compressive forces in arches

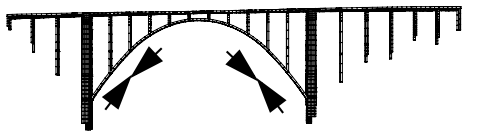

Gravity forces decrease frequencies

FIGURE 51. Structures for which system stiffness is influenced by gravity load forces. 


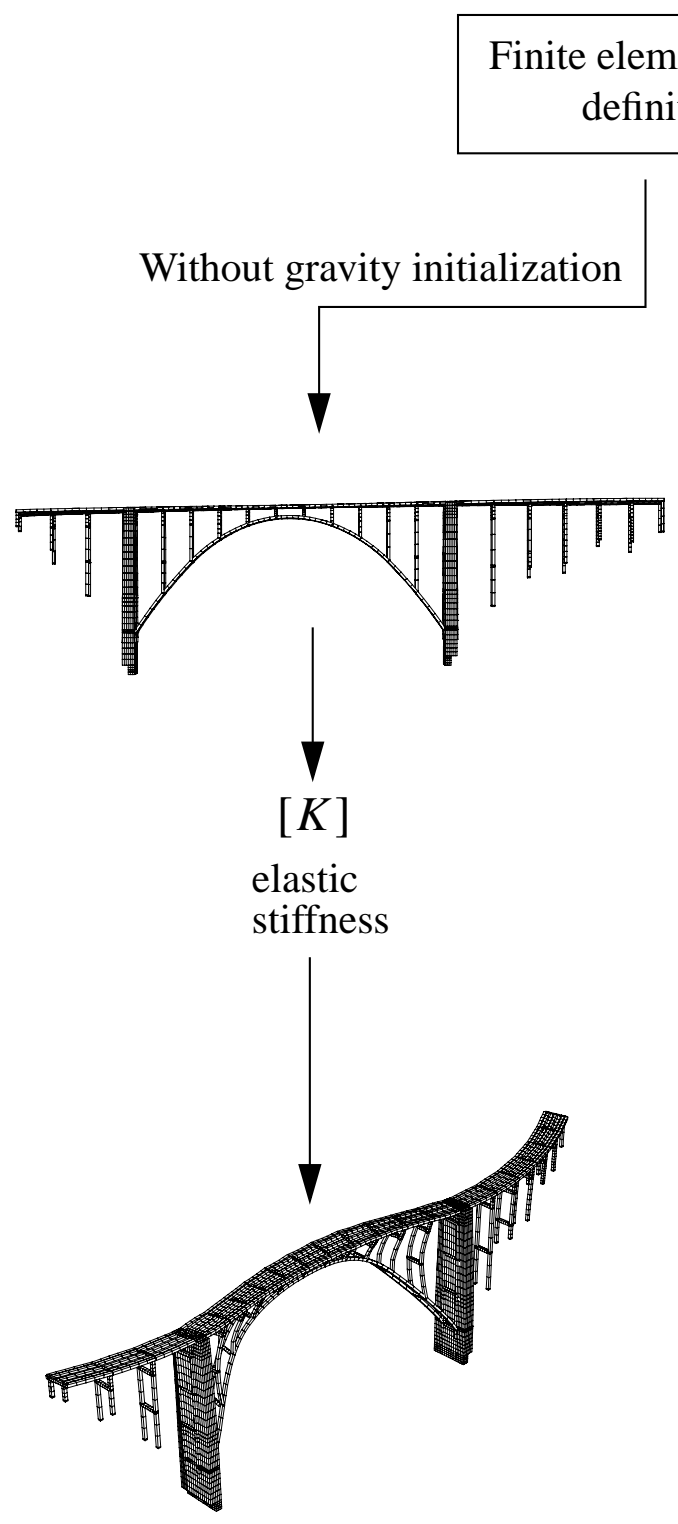

Eigensolution

a)
Including gravity initialization
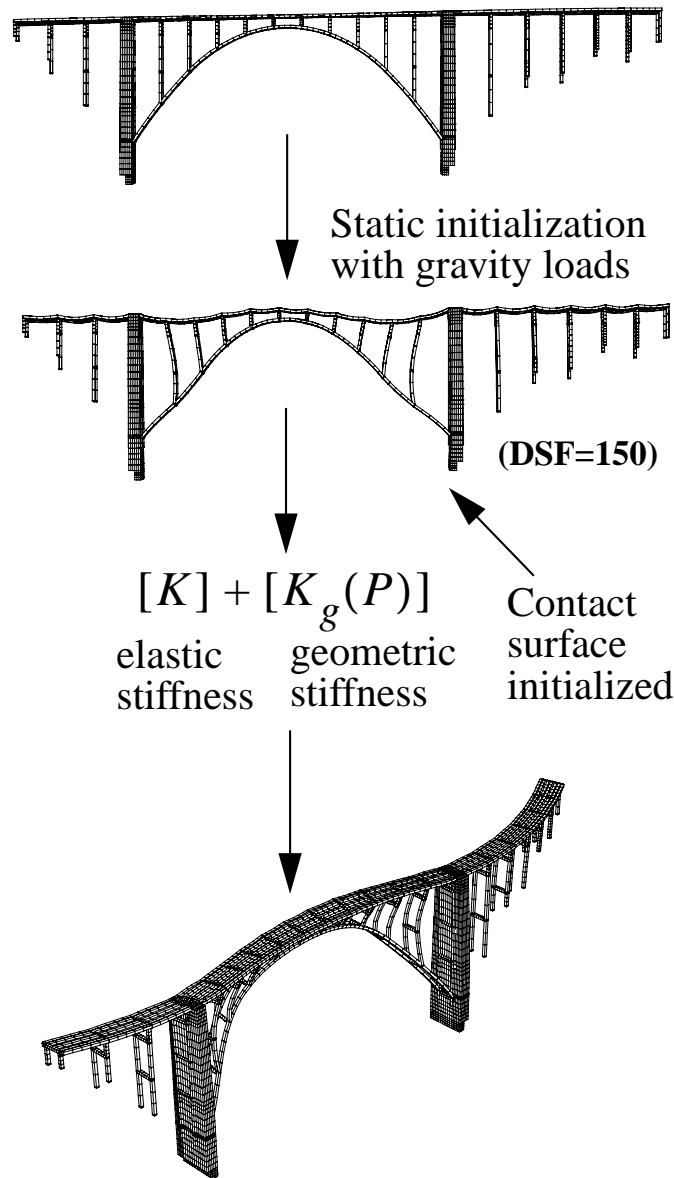

Eigensolution

b)

FIGURE 52. Options for modeshape and frequency eigensolution. a) Neglecting the influence of gravity on the system stiffness; b) including the effect of gravity on the system stiffness.

Figure 52 indicates the model initialization procedures employed with the NIKE3D program for this study. As indicated in Figure 52, the gravity generated axial forces are used to modify the system stiffness matrix via the inclusion of a geometric stiffness component.

The natural periods of vibration of the as-built Bixby Creek Bridge system have been computed for each of the three idealized expansion joint connectivites indicated in 
Figure 50. The first five natural modeshapes obtained from the NIKE3D model of the bridge system for each of the three joint idealization cases are summarized in Figure 53 through Figure 57 and the periods for each case are summarized in Table 8. In Table 8, the

TABLE 8. Natural periods of the bridge system computed with the NIKE3D model.

\begin{tabular}{|c|c|c|c|c|c|c|}
\hline \multirow{2}{*}{$\begin{array}{l}\text { Mode } \\
\text { Number }\end{array}$} & \multicolumn{2}{|c|}{$\begin{array}{l}\text { CASE 1: Tied expansion } \\
\text { joints }\end{array}$} & \multicolumn{2}{|c|}{$\begin{array}{c}\text { CASE 2: Free expansion } \\
\text { joints }\end{array}$} & $\begin{array}{r}\text { CASE } 3 \\
\text { joints ti } \\
\text { loc } \\
\end{array}$ & $\begin{array}{l}\text { xpansion } \\
\text { at collar } \\
\text { ons }\end{array}$ \\
\hline & $\begin{array}{l}\text { Excluding } \\
\text { gravity }\end{array}$ & $\begin{array}{l}\text { Including } \\
\text { gravity }\end{array}$ & $\begin{array}{l}\text { Excluding } \\
\text { gravity }\end{array}$ & $\begin{array}{l}\text { Including } \\
\text { gravity }\end{array}$ & $\begin{array}{l}\text { Excluding } \\
\text { gravity }\end{array}$ & $\begin{array}{l}\text { Including } \\
\text { gravity }\end{array}$ \\
\hline 1 & $1.11(\mathrm{sec})$ & $1.17(\mathrm{sec})$ & $2.92(\mathrm{sec})$ & $3.86(\mathrm{sec})$ & $2.74(\mathrm{sec})$ & $3.52(\mathrm{sec})$ \\
\hline 2 & 0.74 & 0.83 & 1.53 & 1.76 & 1.33 & 1.58 \\
\hline 3 & 0.70 & 0.82 & 1.49 & 1.73 & 1.24 & 1.45 \\
\hline 4 & 0.59 & 0.64 & 1.29 & 1.50 & 1.03 & 1.24 \\
\hline 5 & 0.55 & 0.63 & 1.17 & 1.42 & 0.68 & 0.80 \\
\hline
\end{tabular}

model periods are indicated with gravity effects excluded and gravity effects included respectively. The influence of gravity forces are evident in the system periods shown in Table 8 as the gravity loads incrementally increase the modal periods in all cases. The influence of gravity forces is more pronounced for the flexible joint idealizations as indicated in Table 8. This observation makes sense in light of the fact that the arch ribs represent a more significant portion of the total bridge lateral stiffness when the deck is not acting as a continuous member and thus the geometric stiffness contribution of the arch ribs has a greater overall effect.

For the free expansion joint case, the structure is quite flexible in the transverse direction and the natural period of the fundamental mode is quite long at about 3.9 seconds. The asbuilt model employed by the Bixby Creek retrofit design consultants (Buckland and Taylor) employed the flexible expansion joint idealization and the first transverse mode period computed by Buckland and Taylor was 4.5 seconds. The first longitudinal mode computed by Buckland and Taylor was 2.2 seconds. A comparison between the LLNL computed vibrational periods and the Buckland and Taylor computed periods is presented in Table 9. Inspection of the modal information obtained from the computational model indicates that for this particular structure the degree of flexibility in the expansion joints has a pro- 
nounced effect on the effective stiffness of the bridge structure. In light of the fact that structural frequencies vary as the square root of the effective system stiffness, the ratio of the fundamental mode periods of 3.9/1.2 $=3.3$ represents a tremendous difference in the effective lateral stiffness of the bridge system, in fact, it approaches an order of magnitude difference in effective lateral stiffness. As mentioned previously, the Buckland and Taylor

TABLE 9. Comparison between LLNL and Buckland and Taylor computed modal periods.

\begin{tabular}{|c|c|c|}
\hline \multirow{2}{*}{ Mode } & \multicolumn{2}{|c|}{ Computed modal periods } \\
\cline { 2 - 3 } & $\begin{array}{c}\text { LLNL computer } \\
\text { model }\end{array}$ & $\begin{array}{c}\text { Buckland and } \\
\text { Taylor computer } \\
\text { model }\end{array}$ \\
\hline First transverse & & \\
\hline & & \\
\hline & & \\
\hline
\end{tabular}

analysis employed the flexible (free) joint assumptions. The Buckland and Taylor model also assumed significantly reduced section properties for the finite element model. Based on the information provided in [Ref 3], Buckland and Taylor assumed the model section properties indicated in Table 10. The Buckland and Taylor report does not explicitly state what section property assumptions are invoked for the arch ribs. It appears from the report that the material section property assumptions listed in Table 10 were utilized for both the modal eigensolution extractions and for a response spectrum based seismic analysis.

The nonlinear fiber element model incorporated in the NIKE3D bridge model ignores any tensile capacity of the concrete zones. Consequently, as the model is subjected to gravity load, any member section in which the concrete attempts to go into tension is effectively cracked and zero tension develops. Thus, the nonlinear gravity initialization of the model 
determines the effective "cracked section" for each member. The effect of section cracking was investigated by analyzing a model with the nonlinear concrete elements and comparing it to a model in which a linear elastic representation of the materials was invoked. The frequencies obtained from these two models are summarized in Table 11. The concrete cracking yields a relatively modest decrease in the bridge system stiffness, and is less important than the gravity forces on the small amplitude modeshapes.

The modal period and modeshape plots shown in Table 8 and Figure 53 through Figure 57 show that there are relatively minor modal period shifts when the tied collars are included. The collars do not assist in tying the main span deck system to the bridge towers, and thus the main span deck cannot generate significant lateral stiffness, the deck simply continues to pull away from the towers on one side (see Figure 53 and Figure 55 for example). When the deck is assumed tied, however, the entire deck can act as a deep beam in the transverse bridge direction and significant lateral stiffness is developed.

TABLE 10. Section properties assumed for the Buckland and Taylor as-built Bixby Creek model.

\begin{tabular}{|c|c|c|}
\hline Members & $\begin{array}{c}\text { Effective bending } \\
\text { moment of inertia } \\
\left(\mathbf{I}_{\text {effective }}\right)\end{array}$ & $\begin{array}{c}\text { Effective torsional } \\
\text { constant } \\
\left(\mathbf{J}_{\text {effective }}\right)\end{array}$ \\
\hline Column and strut elements & $0.4 \times \mathrm{I}_{\text {gross }}$ & $0.2 \times \mathrm{J}_{\text {gross }}$ \\
\hline Superstructure elements & $0.75 \times \mathrm{I}_{\text {gross }}$ & $1.0 \times \mathrm{J}_{\text {gross }}$ \\
\hline Bent caps & $1.0 \times \mathrm{I}_{\text {gross }}$ & $1.0 \times \mathrm{J}_{\text {gross }}$ \\
\hline
\end{tabular}

TABLE 11. Comparison of model periods with cracked and uncracked sections.

\begin{tabular}{|c|c|c|}
\hline Mode & $\begin{array}{c}\text { Nonlinear concrete model } \\
\text { (cracked sections) }\end{array}$ & $\begin{array}{c}\text { Linear concrete model } \\
\text { (full cross sections) }\end{array}$ \\
\hline 1 & $3.86(\mathrm{sec})$ & $3.26(\mathrm{sec})$ \\
\hline 2 & 1.76 & 1.66 \\
\hline 3 & 1.73 & 1.63 \\
\hline 4 & 1.50 & 1.40 \\
\hline 5 & 1.42 & 1.28 \\
\hline
\end{tabular}



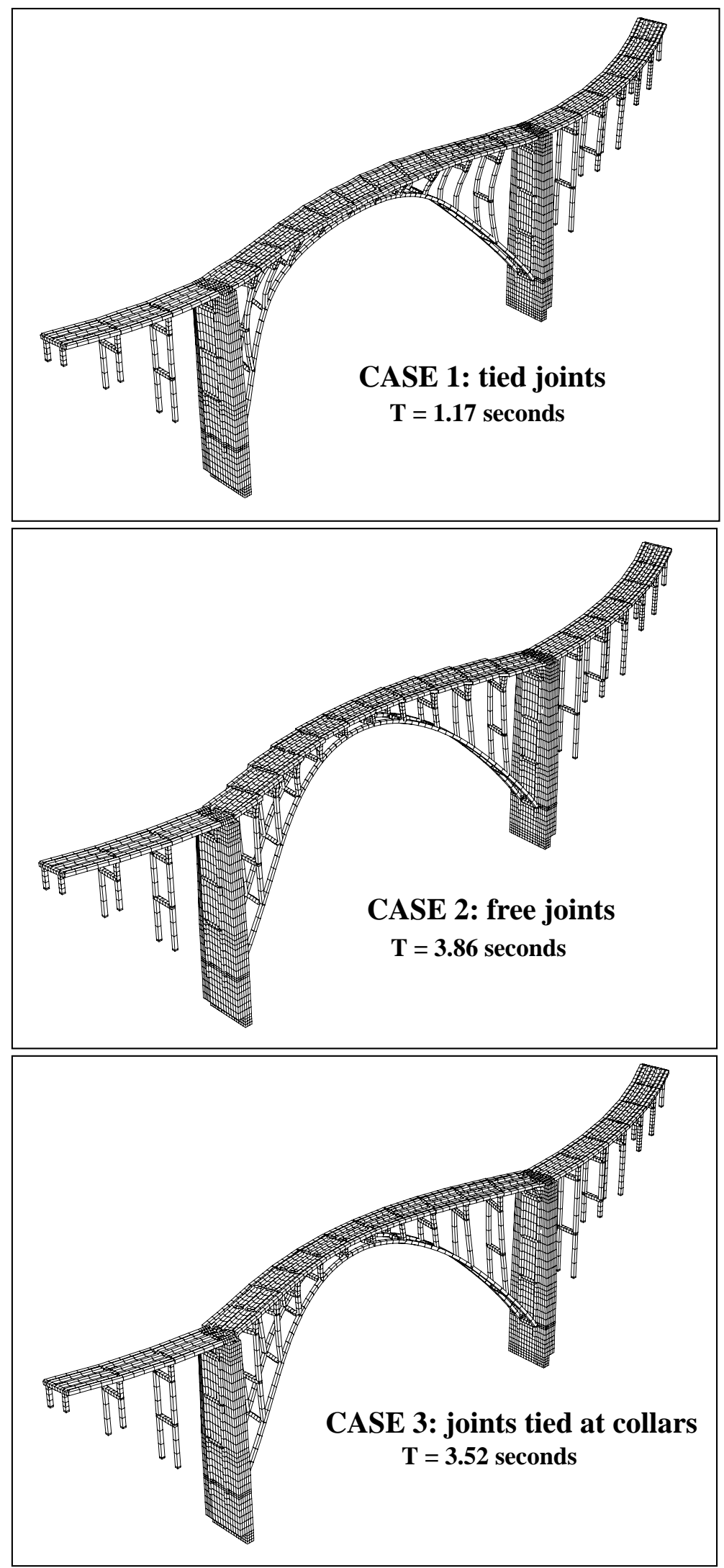

FIGURE 53. Mode \#1 computed with three different joint idealizations. 

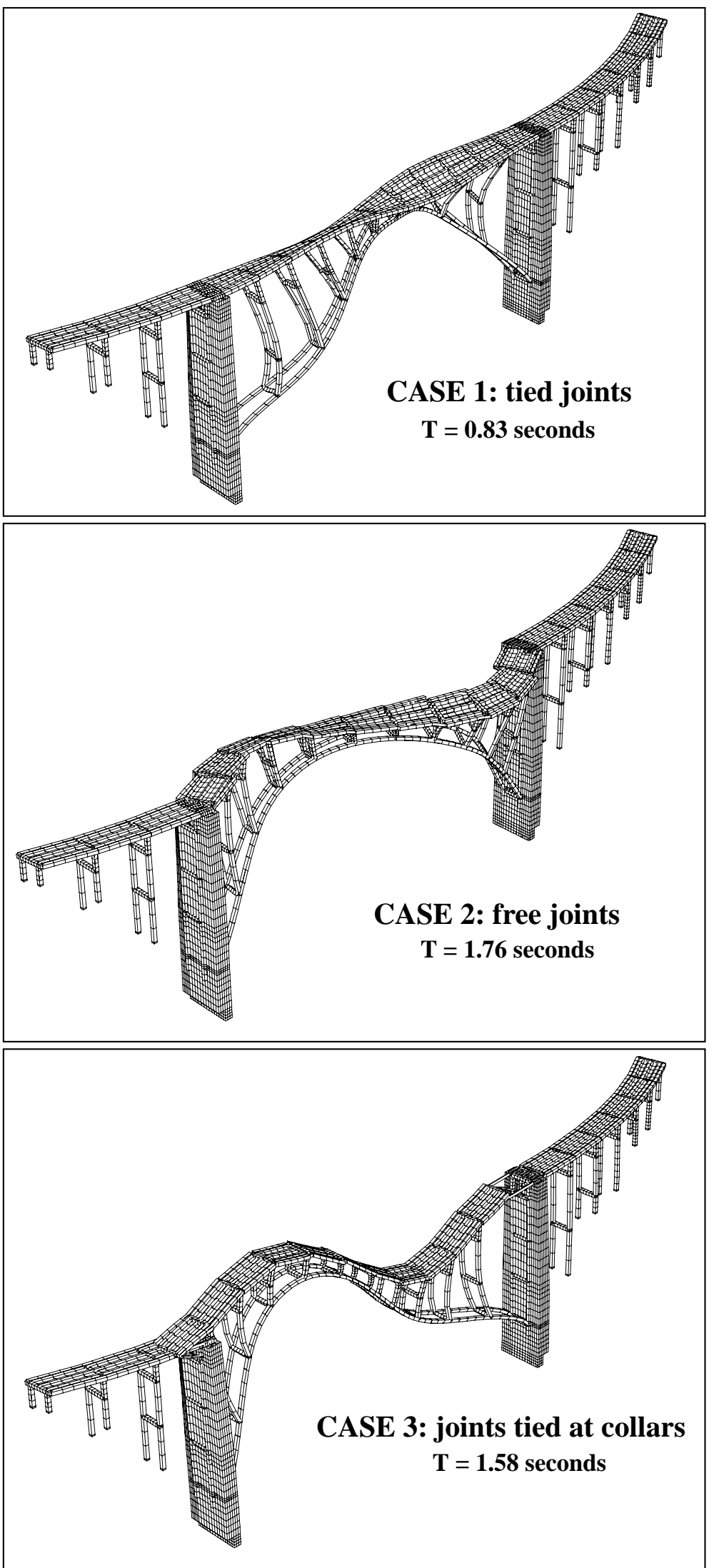

FIGURE 54. Mode \#2 computed with three different joint idealizations. 

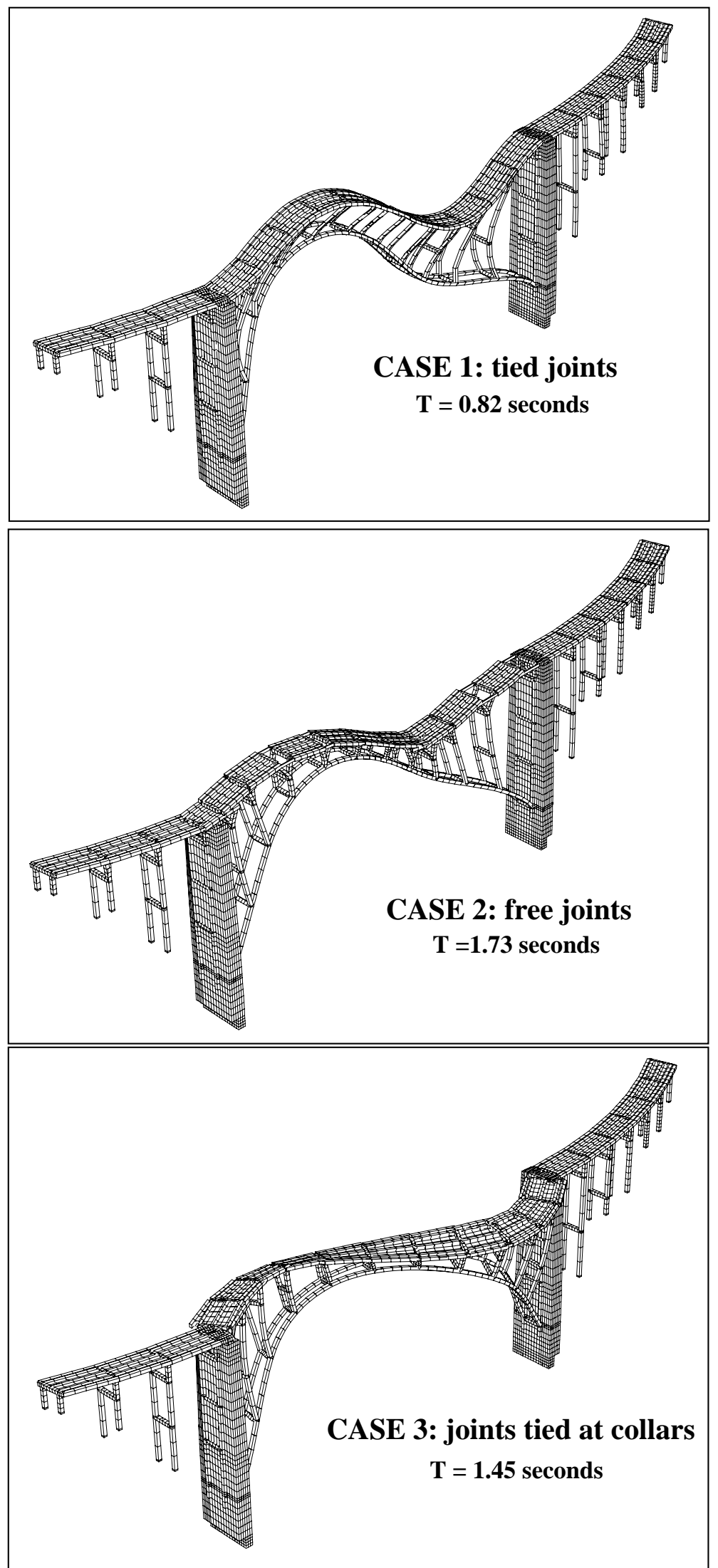

FIGURE 55. Mode \#3 computed with three different joint idealizations. 

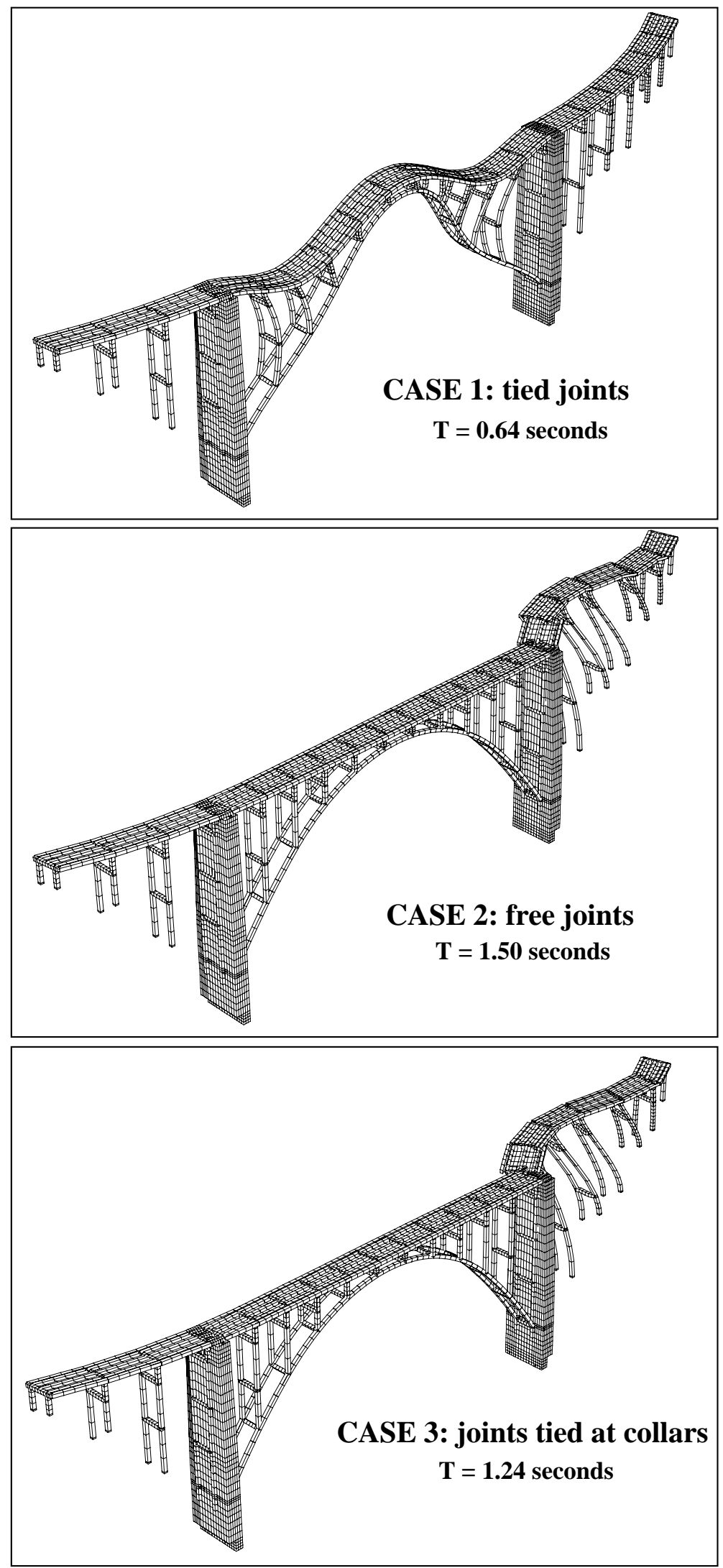

FIGURE 56. Mode \#4 computed with three different joint idealizations. 


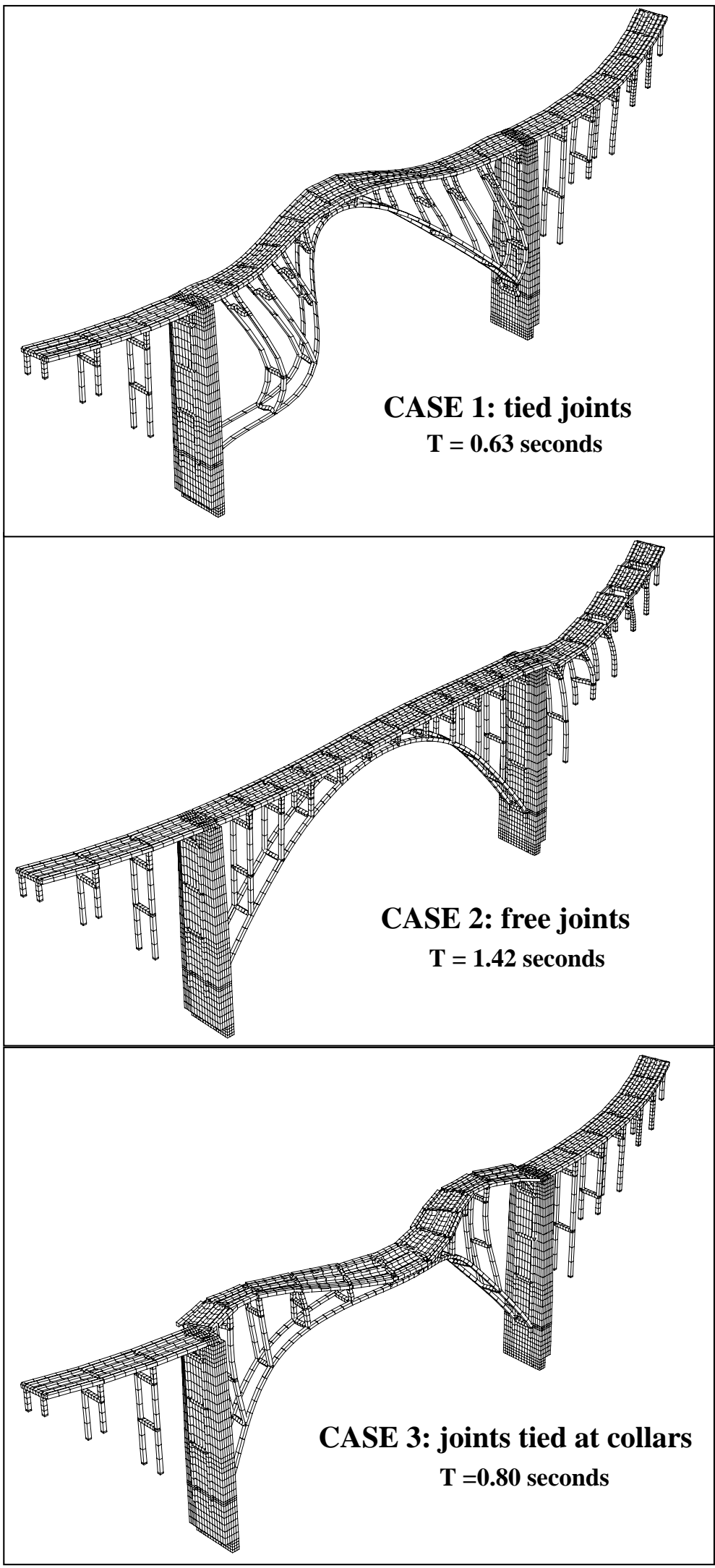

FIGURE 57. Mode \#5 computed with three different joint idealizations. 


\subsection{Vibrational measurements of the as-built bridge structure}

Field testing of the Bixby Creek Bridge was performed to assess the small amplitude, linear regime vibrational characteristics of the structure. Experimental observation of the modal vibrations provides insight into the vibrational characteristics of this large arch bridge and allows for validation of the modal information determined with computational models.

The testing was carried out in cooperation with Caltrans technical staff and Caltrans field crews. The structure was instrumented with an array of triaxial and uniaxial accelerometers at the instrumentation stations indicated in Figure 58. Due to strict time limitations imposed by the limited availability of the Caltrans snooper truck, and the need to maintain traffic flow on the bridge, the array was located primarily on one side of the bridge. This allowed one lane to stay open and to complete the actual testing in essentially two days. The acceleration sensors utilized in the study consisted of Wilcoxon Research 731 A accelerometers, which for stations located on the arch ribs and the towers, were mounted in a triaxial configuration in prefabricated aluminum boxes. The aluminum boxes were attached to the bridge with brackets that coupled the boxes to mounting plates fastened directly to the bridge structure as shown in Figure 59. To ensure appropriate fastening, the mounting plates were anchored to the bridge with robust Hilti concrete anchor bolts. The below-deck access at the Bixby Bridge is very hazardous and impossible to obtain without scaffolding or some other means. For the field experiments, the schedule for testing was arranged around the availability of the Caltrans truck mounted bridge snooper. The snooper permitted rapid and safe mounting of the bridge instrumentation and allowed for the entire bridge experiment to be completed and cleaned up in approximately three days (see Figure 59). For the instrumentation locations on the bridge deck, small aluminum blocks, prethreaded to allow mounting of the Wilcoxon sensors, were strongly anchored to the bridge deck, utilizing the Caltrans highway adhesive which is used to attach road reflectors (see Figure 60). Both the below-deck and on-deck mounting arrangements provide strong and solid coupling between the sensors and the structure.

In addition to the Wilcoxon acceleration measuring sensors, two velocity measuring Geotech GS-13 units were co-located with accelerometers on the deck as insurance against missing any long period vibrations (Figure 60). Based on previous LLNL testing of the signal-to-noise thresholds of the Wilcoxon sensors, the Wilcoxon accelerometers can have difficulties making accurate measurements at periods longer than about 2-3 seconds if the signal in that period range is weak. Since the fundamental mode of the structure computed with the finite element model was on the order of 3.8 seconds for the most flexible joint idealization, the GS-13 instruments were included to ensure that there was adequate capability for capturing any long period modes. The GS-13 units are uniaxial sensors with a very broad frequency band and can adequately measure response for periods up to $10 \mathrm{sec}-$ onds.

The vibrational response of the structure was measured for three different bridge forcing functions. The first forcing function which was considered consisted of normal vehicle traffic flowing across the bridge. The second forcing function consisted of dynamic loading with the massive Caltrans snooper truck. Utilizing the snooper truck, two different 


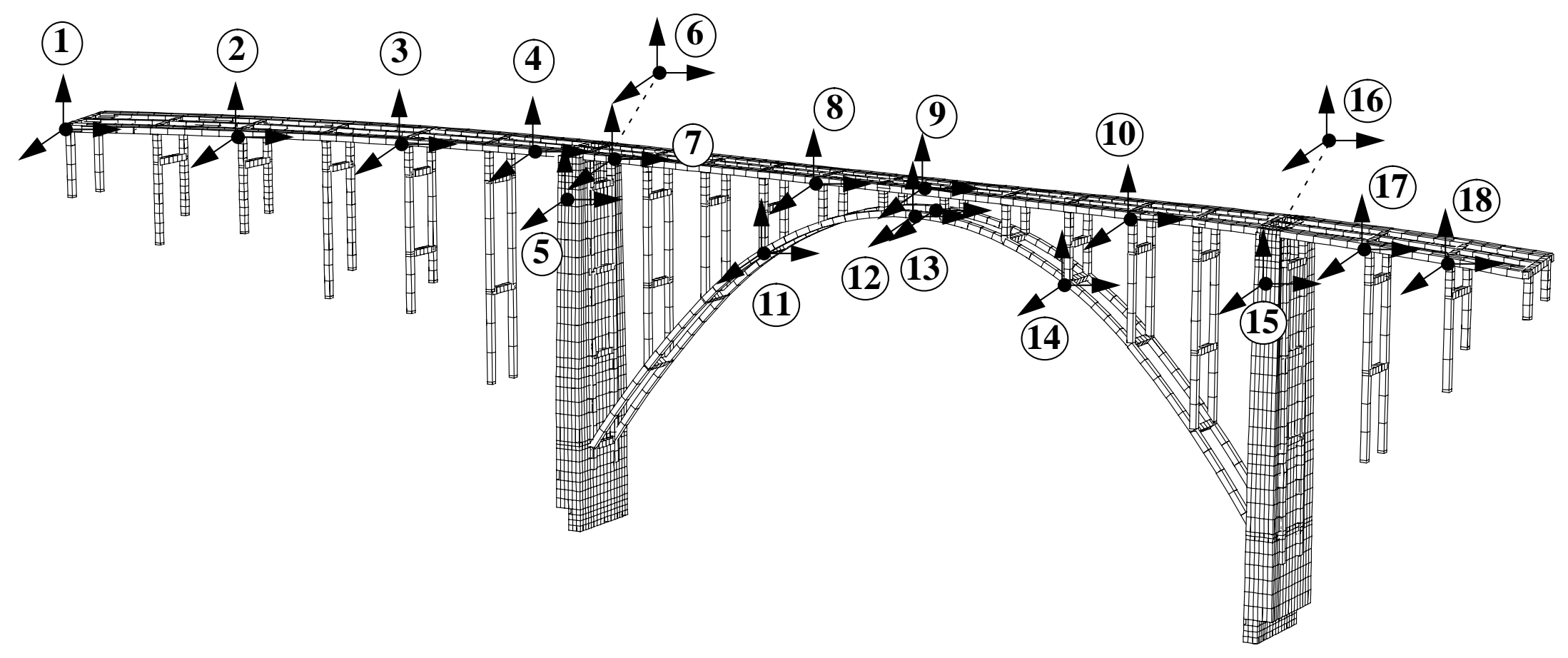

FIGURE 58. Measurement locations for the dynamic vibrational field test, sensors oriented longitudinal and transverse to bridge axis and vertically. 


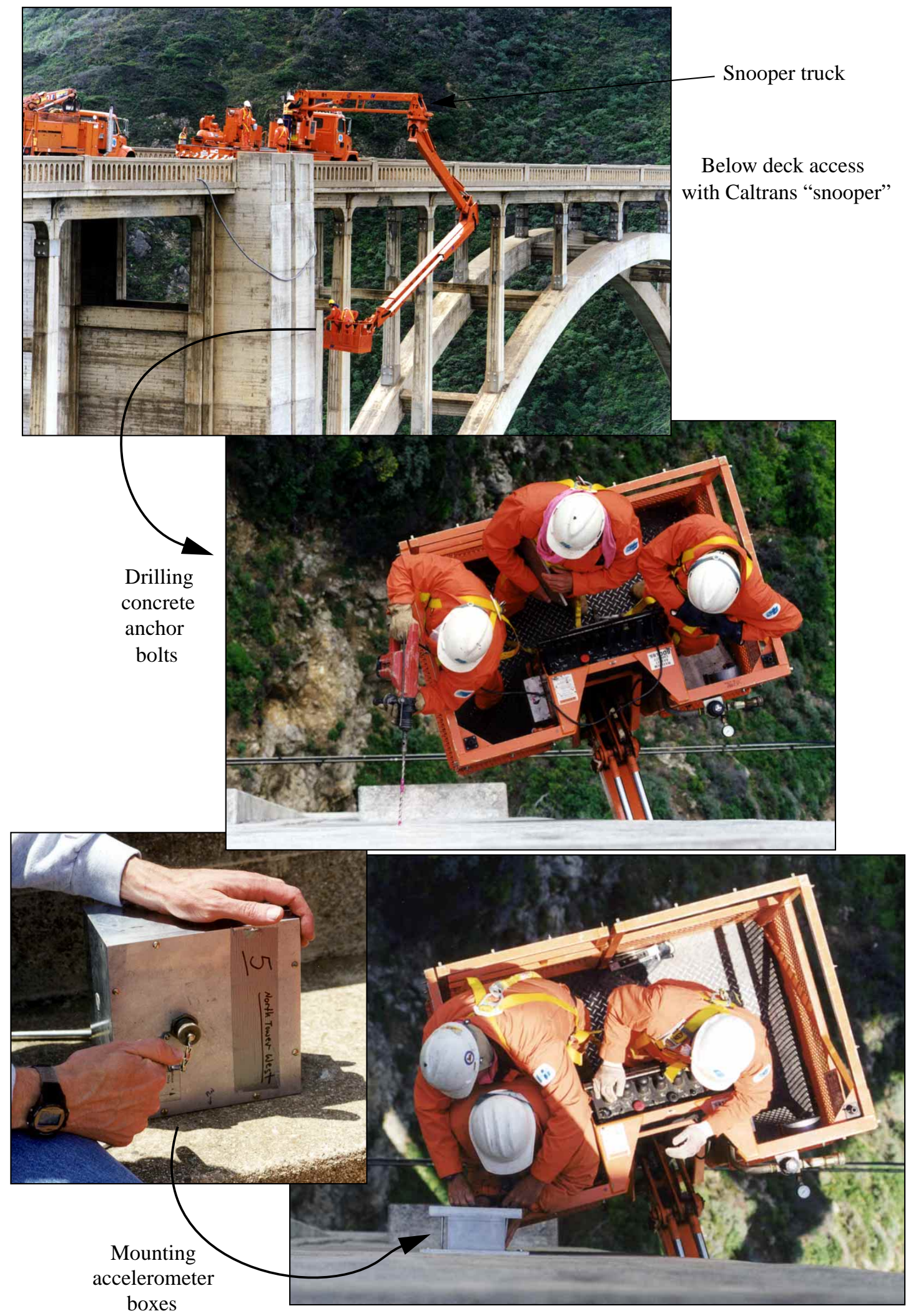

FIGURE 59. Mounting of triaxial accelerometers on the Bixby Creek structure. 


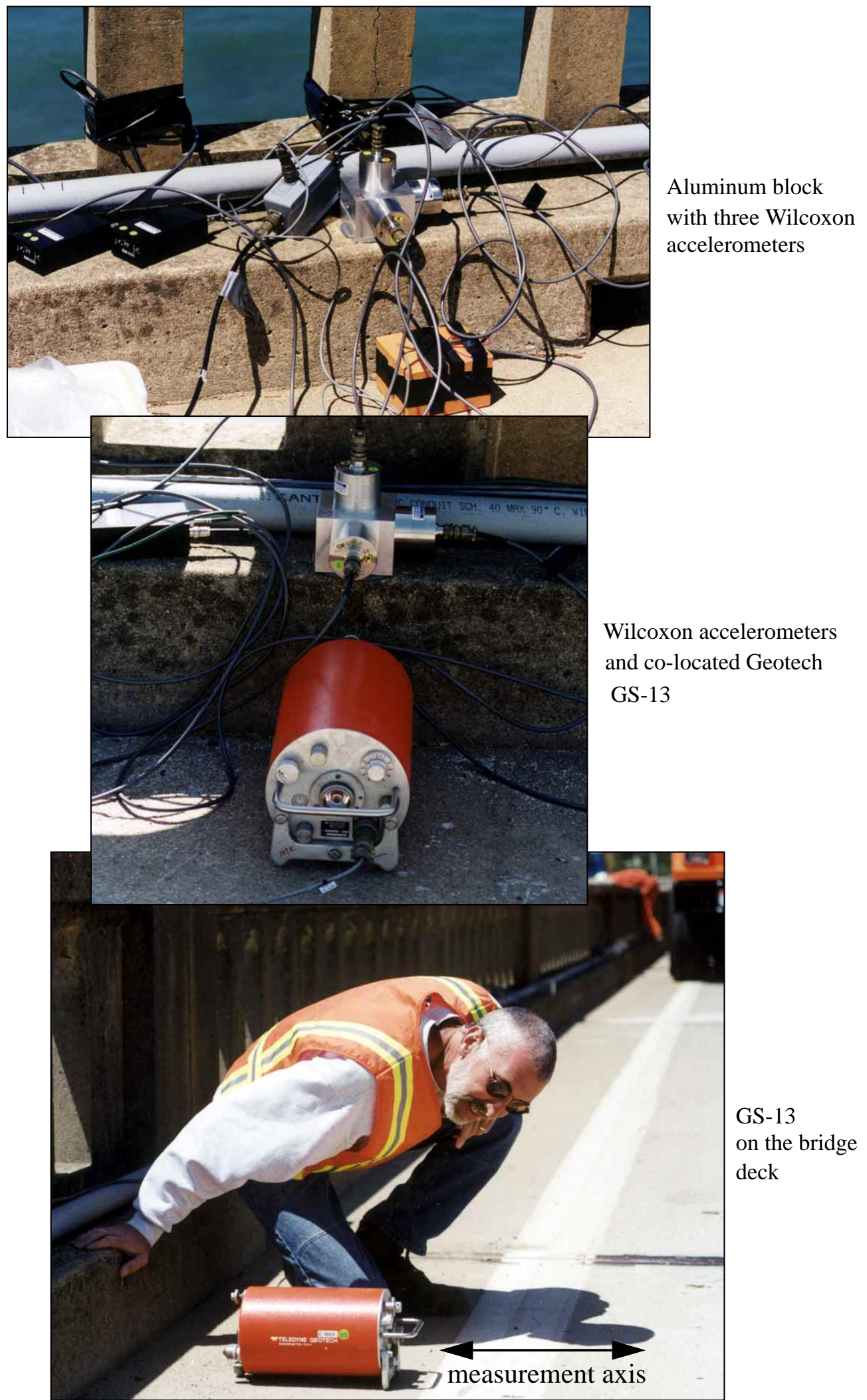

FIGURE 60. Deck sensors: Wilcoxon model 731 accelerometers and Geotech GS-13 velocity sensor. 
loading mechanisms were examined. In the first case, all vehicle traffic was stopped and the snooper truck was run across the bridge at high speed in order to excite bridge vibrations. In the second case, the snooper truck came onto the bridge at a high rate of speed and came to a rapid stop at midspan in order to generate bridge vibrations. The third method of bridge excitation consisted of utilizing a pneumatic hammer owned by the United States Geological Survey to impart a transverse impact to the bridge structure as shown in Figure 61.

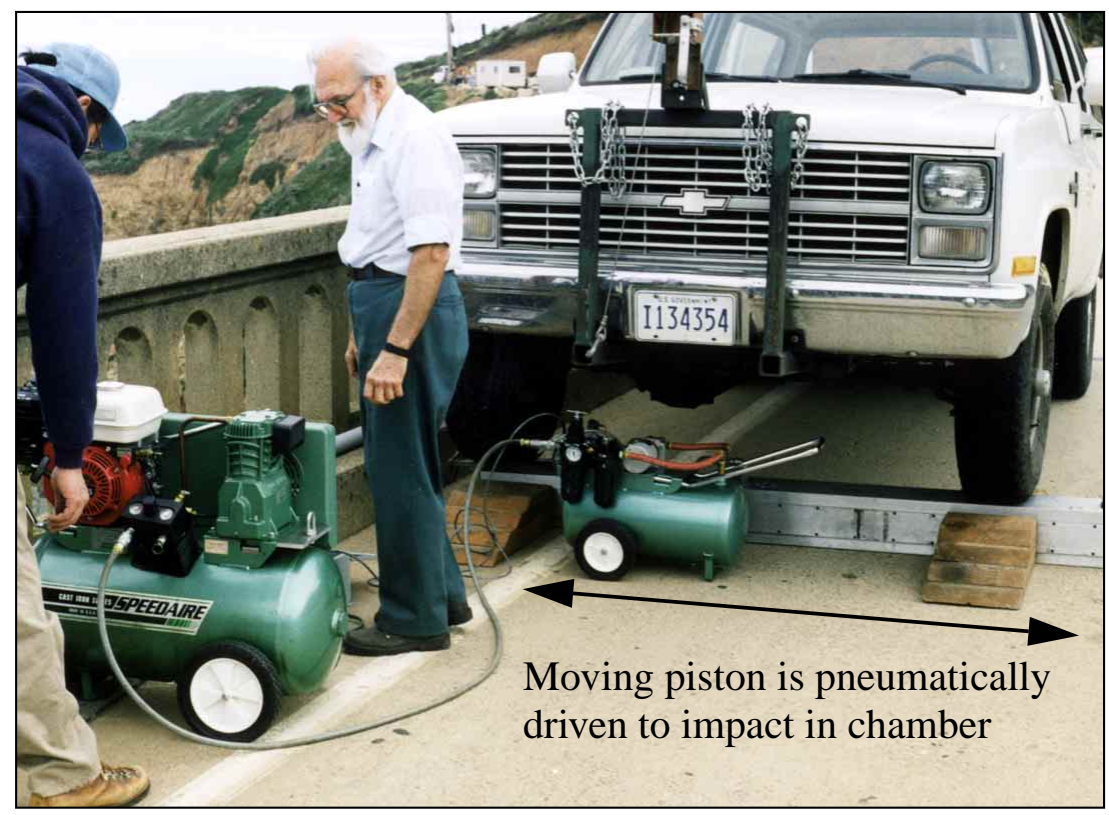

FIGURE 61. USGS pneumatic impact hammer for transverse bridge excitation.

Of the three different methods of excitation, the Snooper truck input provided the best dynamic bridge response for vibrational measurement purposes. When the massive truck sped across the bridge, a person standing on the deck could clearly feel and sense the longer periods of vibration of the bridge structure. With normal vehicle traffic one could feel high frequency vibrations, but not the longer period vibrations generated by the snooper truck. For the analysis of the vibratory bridge response, the data obtained from the snooper truck excitation generated when the truck abruptly stopped on the bridge proved the most useful.

\subsection{Analysis of bridge vibrational response data}

One of the best experimental data sets consisted of the response data from the snooper truck excitation. Sample time histories from this dataset are shown in Figure 62 and Figure 63. The long period, lower natural modes of vibration of the bridge are clearly evident in the waveforms measured after the truck stops and the bridge is in a state of free vibration. 

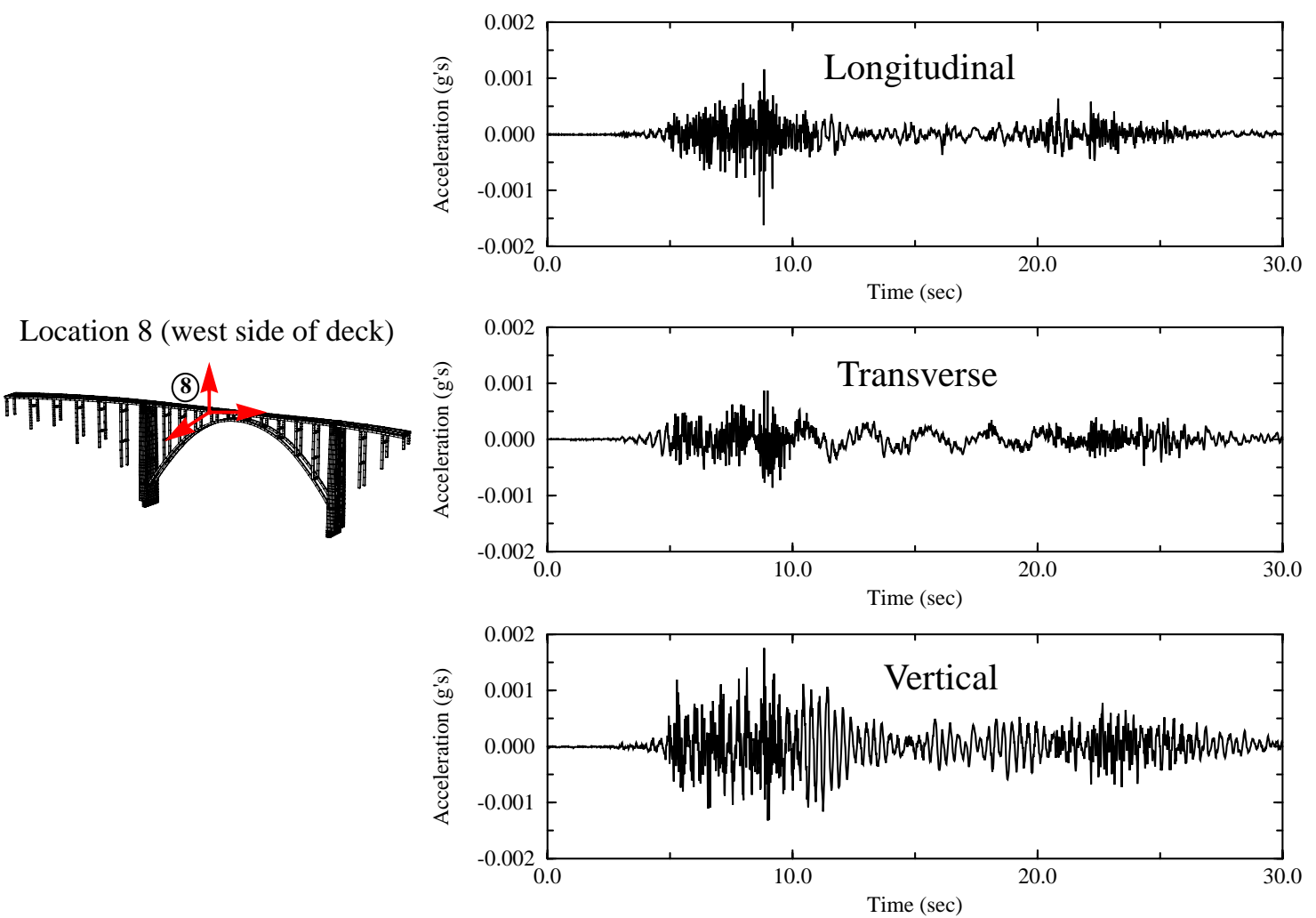

Location 13 (crown of west arch)
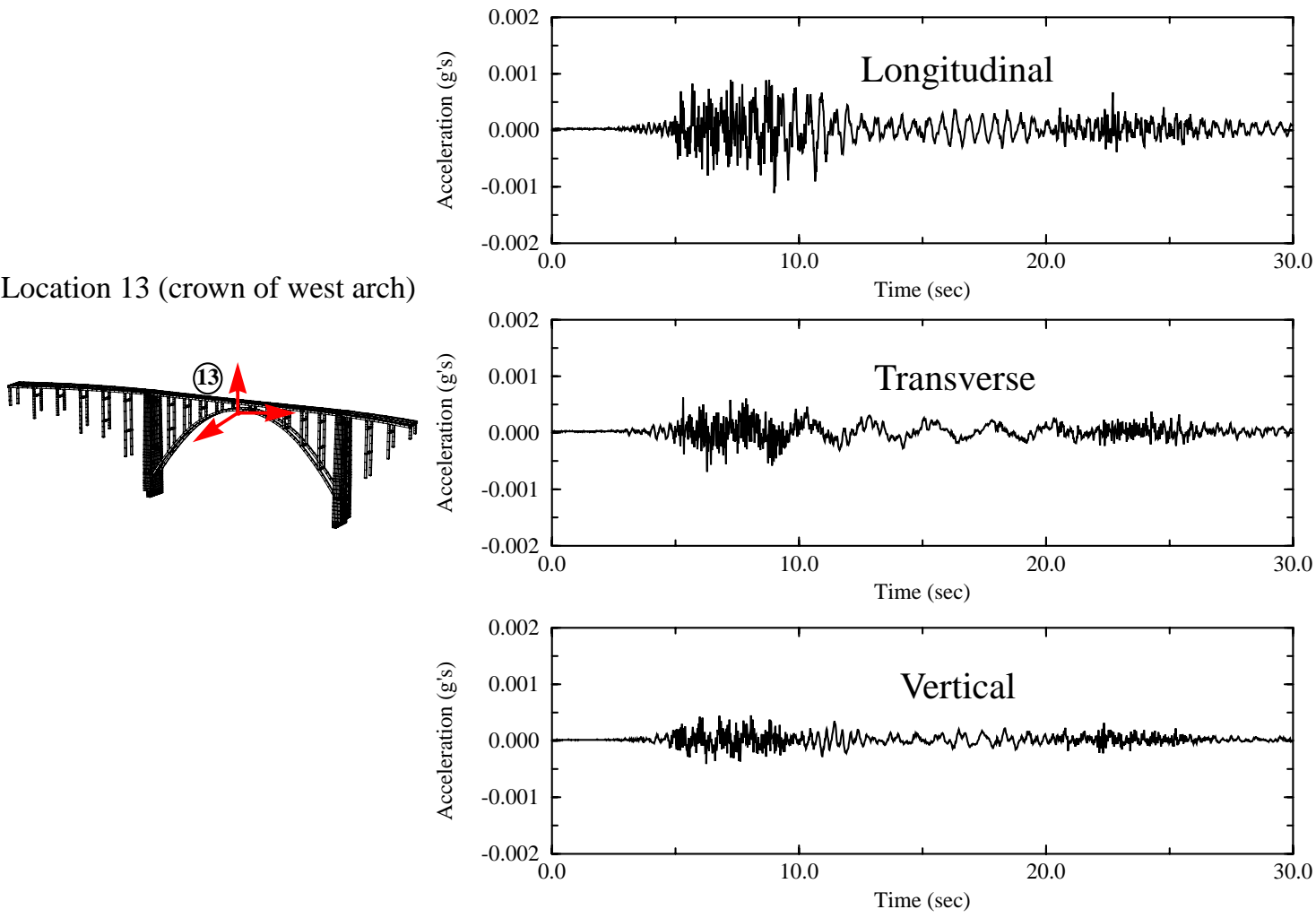

FIGURE 62. Measured time histories from the snooper truck dynamic excitation. 
The results of the vibrational measurement data were analyzed independently with two approaches. A commercial modal analysis software package was employed at LLNL to
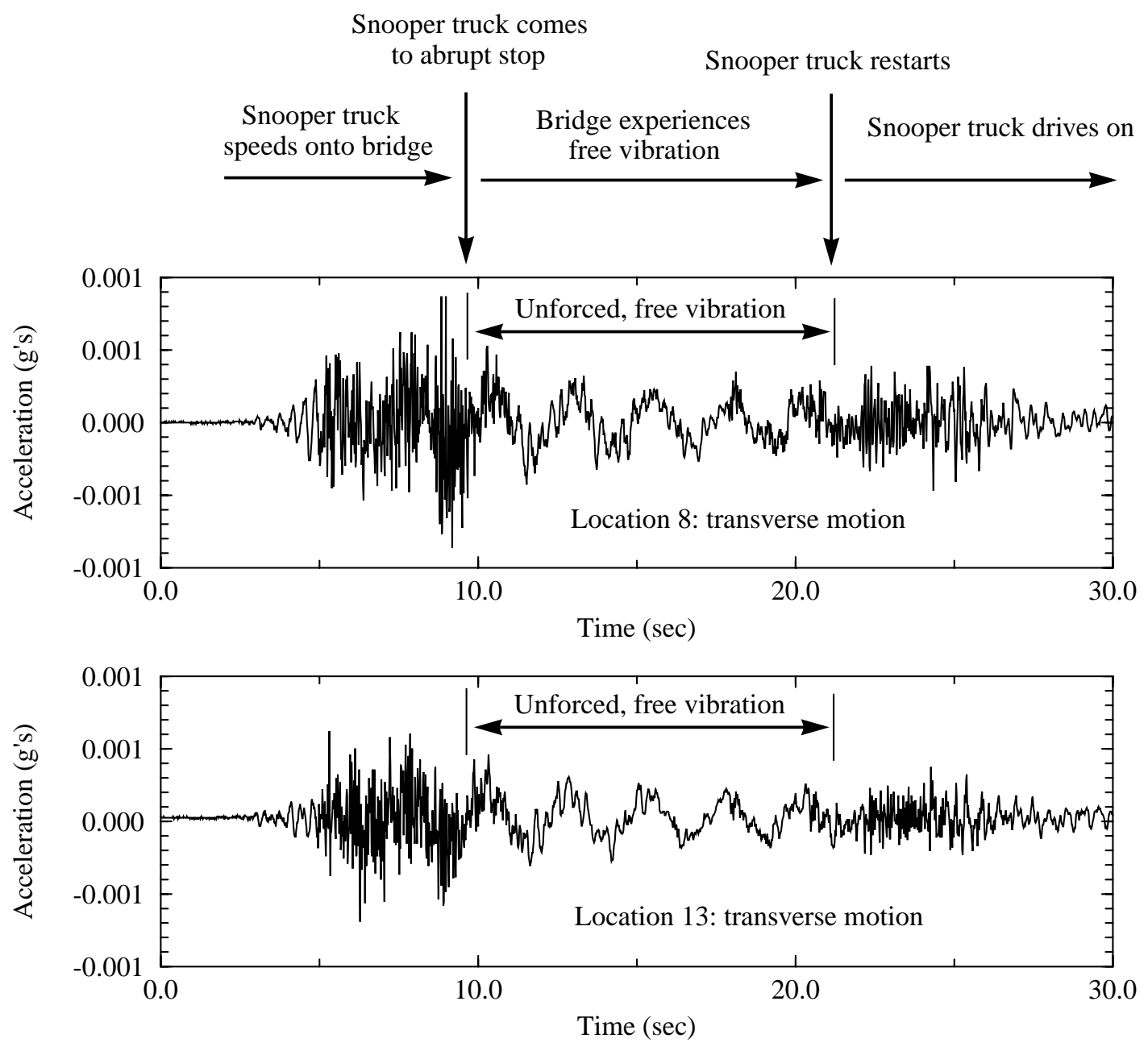

FIGURE 63. Transverse bridge motion for truck induced excitation.

perform modal analysis including identification of modal frequencies and modeshapes. At the United States Geological Survey, Dr. Mehmet Celebi developed Fourier spectra based on the measured time histories. The Fourier amplitude spectra developed for the time histories at selected locations are shown in Figure 64 and Figure 65. Peaks in the spectra are indicative of potential structural modal periods, and some pronounced peaks are evident in the spectra which are shown. The spectral peak at 0.4 Hertz ( 2.5 second period) at a number of station locations appears only in the spectra of the transverse motions. Examination of the transverse motions during the period of free vibration of the bridge for the snooper truck excitation clearly shows the lower period vibration, the period of which can be estimated by counting cycles. For example, four cycles of vibration occur in ten seconds, corresponding to a period of vibration of $10 / 4=2.5$ seconds, which correlates with the frequency peaks in the Fourier spectra. 
The natural modeshapes extracted from the response data using the commercial modal analysis software are shown in Figure 66. Due to limitations in testing time and equipment, the instrumentation array on the Bixby Bridge was not exceedingly dense (Figure 58). Thus the three dimensional identification of modes required some interpretation even after the modes had been "fit". The first transverse mode at 2.5 seconds period was quite easy to identify in all of the data (see Figure 63, Figure 64, Figure 65 and Figure 66). The frequencies of the higher modes were easily identified in the data with both the modal analysis extraction as well as the Fourier amplitude spectra, but the modal shape of these higher modes required more interpretation. The best interpretation of the higher modes are shown in Figure 66.

Natural periods of vibration determined independently by LLNL and the USGS are summarized in Table 12.

TABLE 12. Bridge system natural periods of vibration as independently determined by LLNL and USGS.

\begin{tabular}{|c|c|}
\hline LLNL natural period & USGS natural period \\
\hline $\begin{array}{c}2.5 \text { seconds } \\
\text { (Transverse mode) }\end{array}$ & 2.5 seconds \\
\hline $\begin{array}{c}0.90 \text { seconds } \\
\text { (Longitudinal mode) }\end{array}$ & 0.91 seconds \\
\hline $\begin{array}{c}0.53 \text { seconds } \\
\text { (Deck torsion plus transverse) }\end{array}$ & 0.52 seconds \\
\hline 0.23 seconds & 0.22 seconds \\
\hline
\end{tabular}

\subsection{Comparison of computed and observed frequencies}

The fundamental mode of the bridge system, which consists of transverse motion of the center span, was the most readily identifiable and interpretable modeshape from the small amplitude vibrational bridge tests. The observed period of vibration of this mode was 2.5 seconds and was readily identified by both the LLNL and USGS data processing (see Figure 64, Figure 65 and Figure 66). Based on the LLNL simulations, the computed period of this mode was highly sensitive to the particular assumptions invoked for the bridge expansion joints in the split columns. The computed period of this mode ranged from 1.17 to 3.86 seconds (Figure 53) depending on the idealizations employed at the expansion joints of the model. The 1.17 to 3.86 second periods correspond to bounding idealizations of the expansion joint behavior.

To provide additional insight into the vibrational characteristics of the finite element model, an additional linearization was applied to the model to see if a better correlation of 

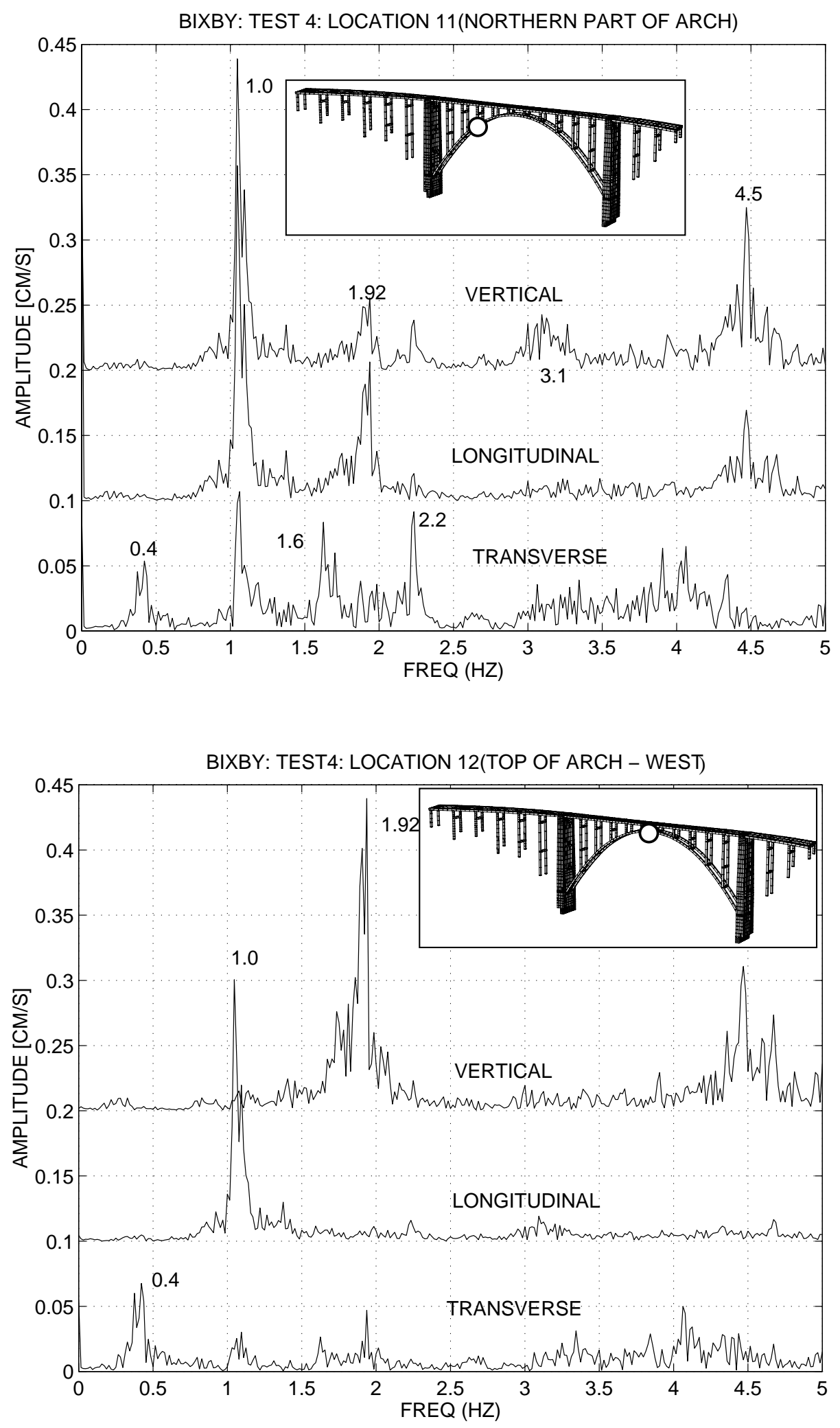

FIGURE 64. Fourier amplitude spectra obtained from time history measurements. 

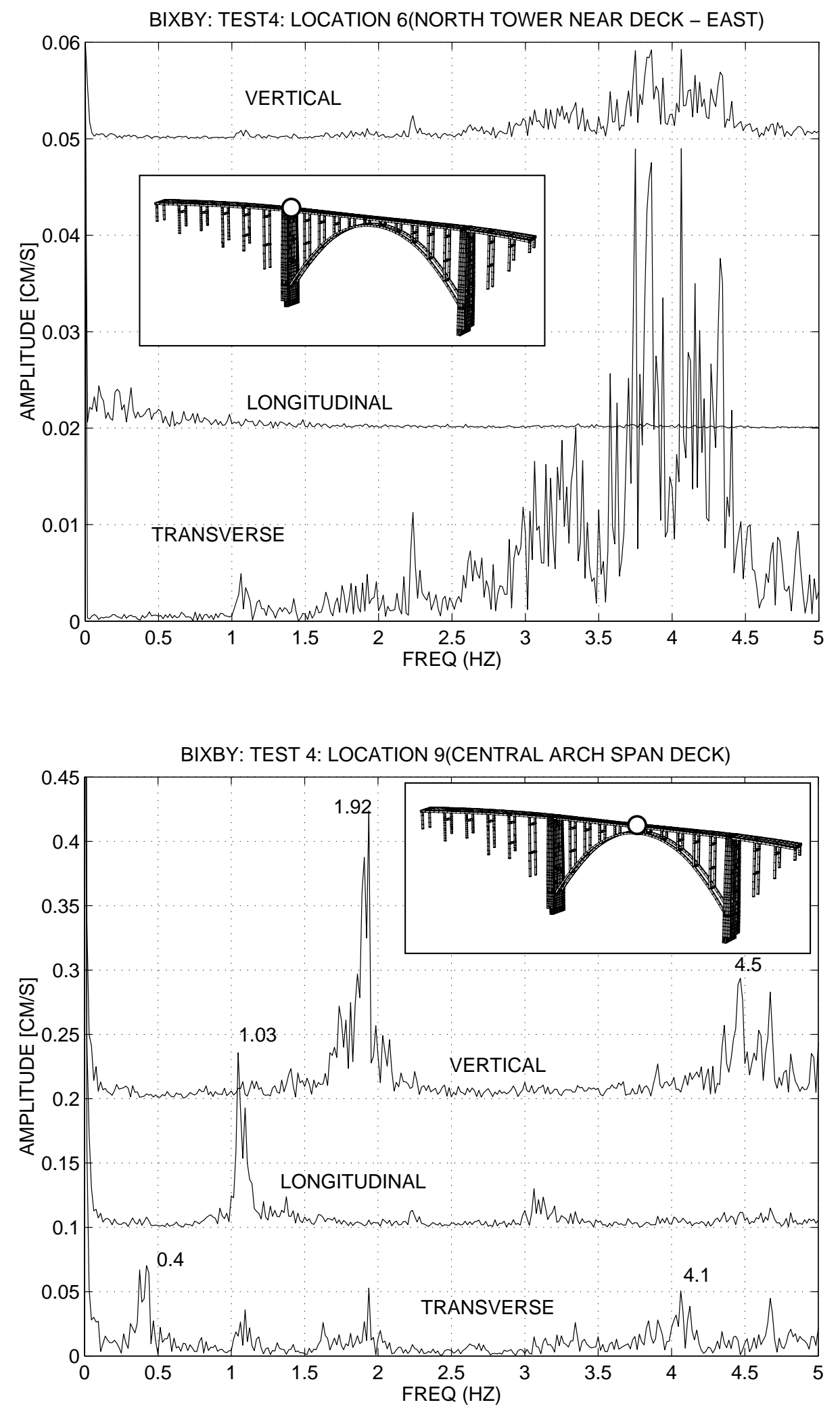

FIGURE 65. Fourier amplitude spectra obtained from time history measurements. 


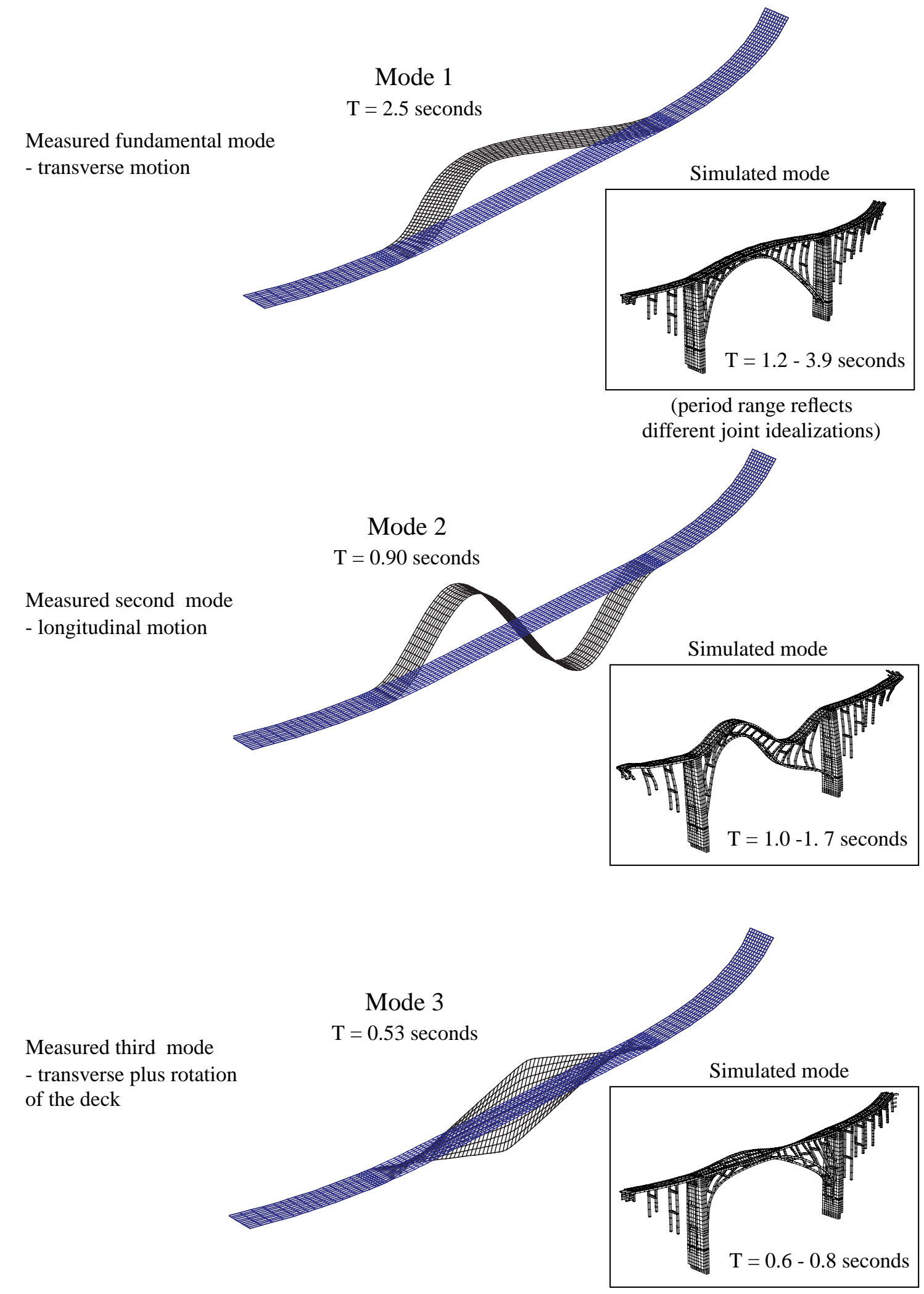

FIGURE 66. Estimation of measured modes based on modal analysis software. 
the fundamental period could be obtained. In this idealization, the finite element model with column collar ties was employed, and the deck system was merged at deck expansion joint locations which would be in compression under a fundamental transverse mode deformation shape. This was intended to represent the actual fundamental mode response in which the transverse deck motion leads to expansion joint opening on one side of the deck and expansion joint closure with contact on the opposite side of the deck. For this deck model, the computed fundamental mode of vibration was 2.6 seconds as indicated in Figure 67.
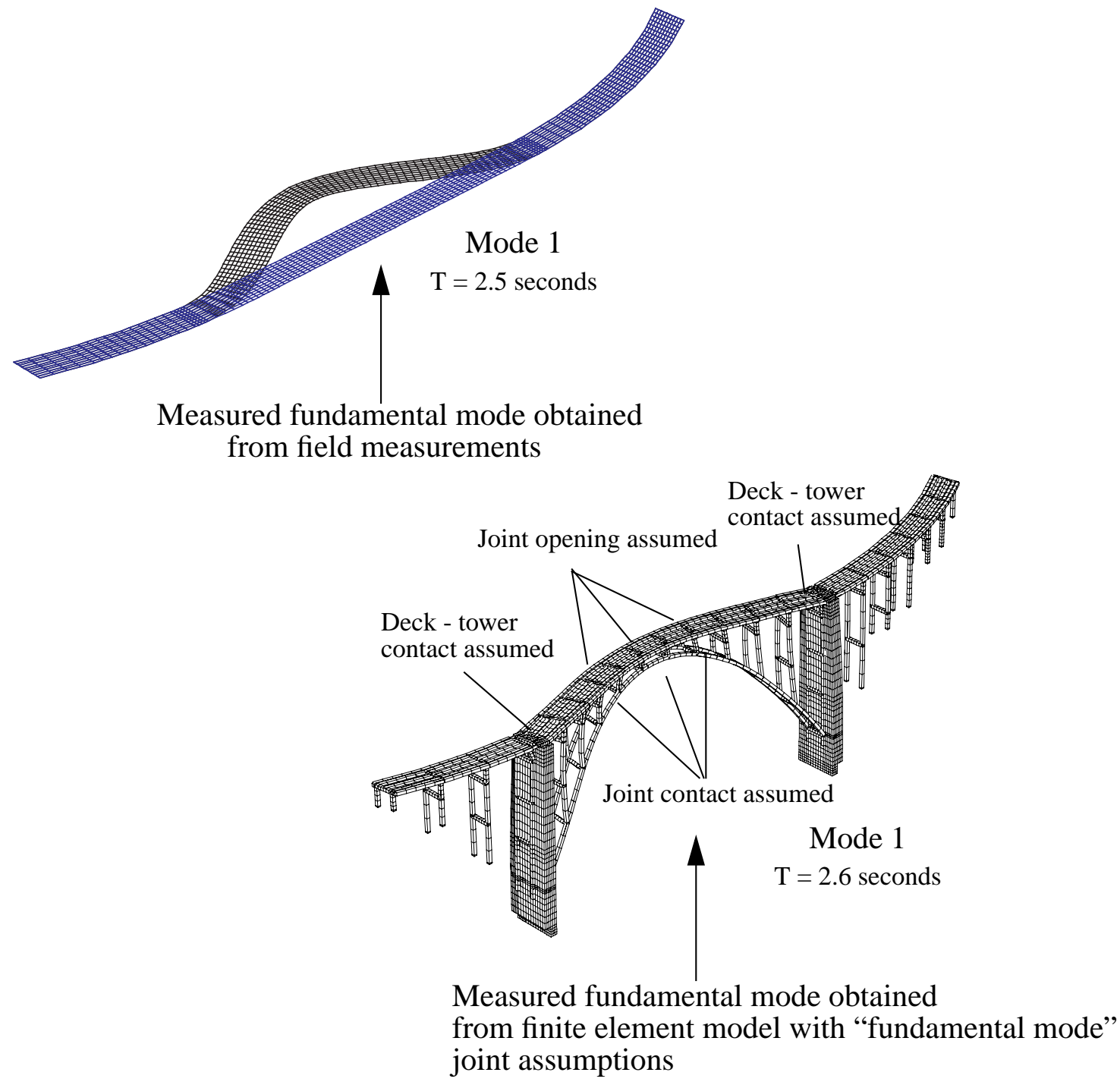

FIGURE 67. Measured and computed fundamental mode of the bridge (joints idealized to match fundamental transverse mode kinematics).

The fully nonlinear bridge model, which includes contact at the expansion joints, will capture the appropriate opened-closed configuration of the expansion joints in the transient analysis as the various joints open and close during the bridge motion. 


\subsection{Transient response of the as-built structure to Caltrans design earthquake motions}

Estimation of the response of the bridge to earthquake excitation was accomplished with a transient, nonlinear time history analysis using the Bixby Creek nonlinear finite element model and the NIKE3D finite element program. The analysis procedure for each synthetic earthquake run is shown schematically in Figure 68. The structure is first initialized with gravity loads in a nonlinear static analysis. Subsequent to the static initialization a transient dynamic analysis is performed with the base input motion defined by the earthquake time histories. At each time step of the dynamic solution, NIKE3D dumps a state file which contains the strains for every fiber element cross section point throughout the structure. This large volume of state data provides a three dimensional picture of the strain levels in the concrete and steel throughout the bridge structure. The large database of strains created by the entire earthquake time history is then automatically post-processed with a computer program developed specifically for analyzing the concrete element results. The CSTRAIN program sorts through all of the strain data (i.e. the demand strains) and for each cross section integration point, compares the value of strain at each instant of time with a user specified allowable strain value (i.e. the capacity strains) for the material at the integration point. The output of the CSTRAIN run includes a listing of the strain demandto-capacity ratios for all of the member cross sections of the bridge.

For the definition of the earthquake input motion, the directional components for the original Caltrans earthquake ground motion records were combined according to a 1, 1/3,1/3 rule as specified in the Buckland and Taylor retrofit report. The original Caltrans records only supplied one horizontal component (denoted " $\mathrm{H}$ ") and one vertical component (denoted "V") of motion time histories as shown in Figure 8 and Figure 9. Thus for each earthquake, three cases were considered as indicated in Figure 69. For the updated Caltrans near-field ground motions, three component motions were supplied which had true physical correlations tied into the three records. Thus, a factor of 1 was applied to these records in all directions simultaneously.

A primary objective of this study was to ascertain the effect of various modeling assumptions and the sensitivity of computed response to parameters such as material nonlinearities. In this section a number of earthquake simulations are presented for different modeling assumptions and material characterizations.

\subsection{Transient response of the as-built structure model with linear materials and free expansion joints (Seed and Idriss time histories)}

The model of the as-built structure which incorporated the free and uninhibited motion at the bridge expansion joints provided the computational model which most closely corresponded to the modeling assumptions invoked by Buckland and Taylor in their linear bridge model. In order to make the modeling idealizations as close as possible to those invoked by Buckland and Taylor, the materials were modified to a linear elastic characterization for both the concrete and steel in the bridge. The primary remaining difference in modeling assumptions between this model and the Buckland and Taylor model is that the 


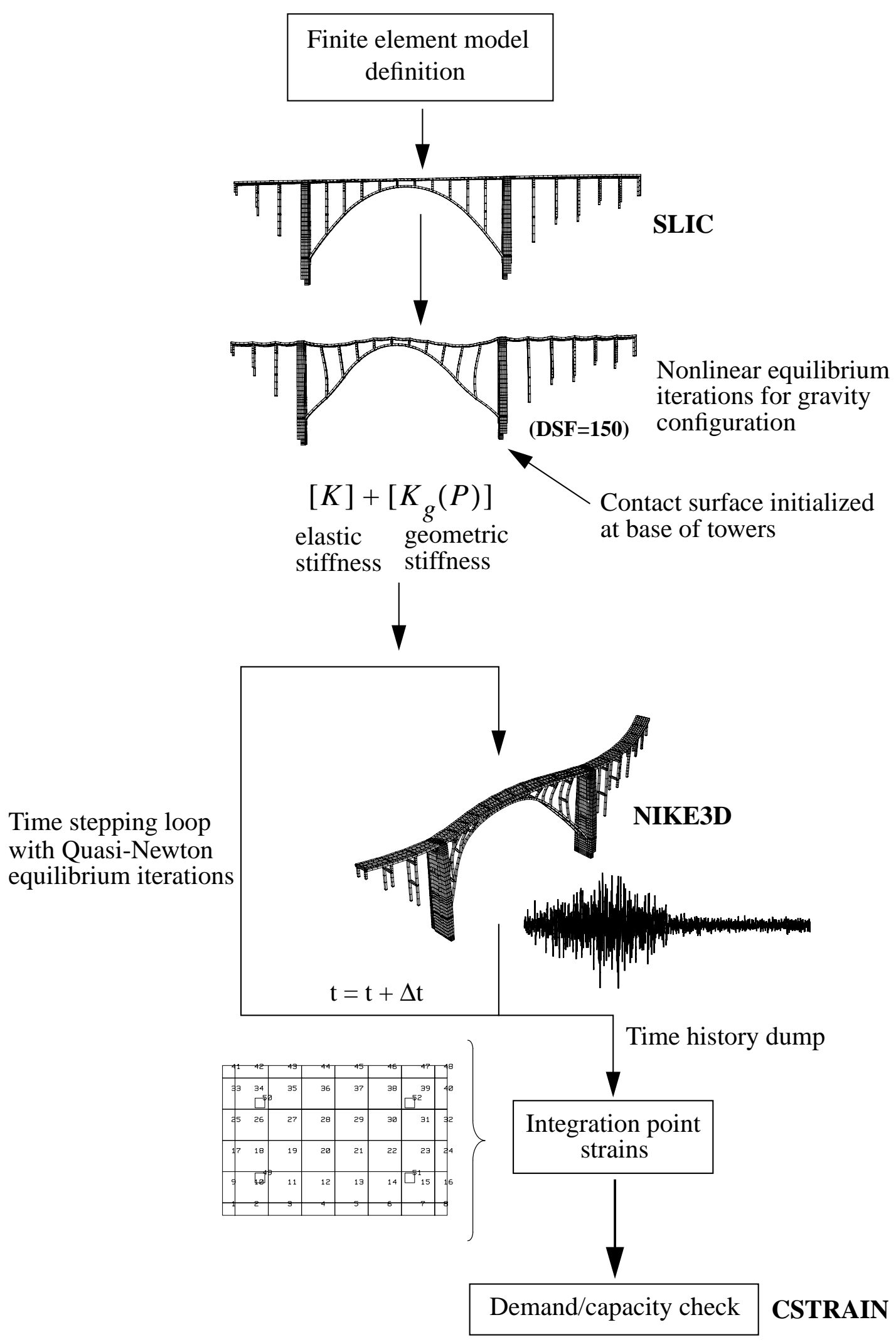

FIGURE 68. Transient analysis procedure for earthquake loading. 

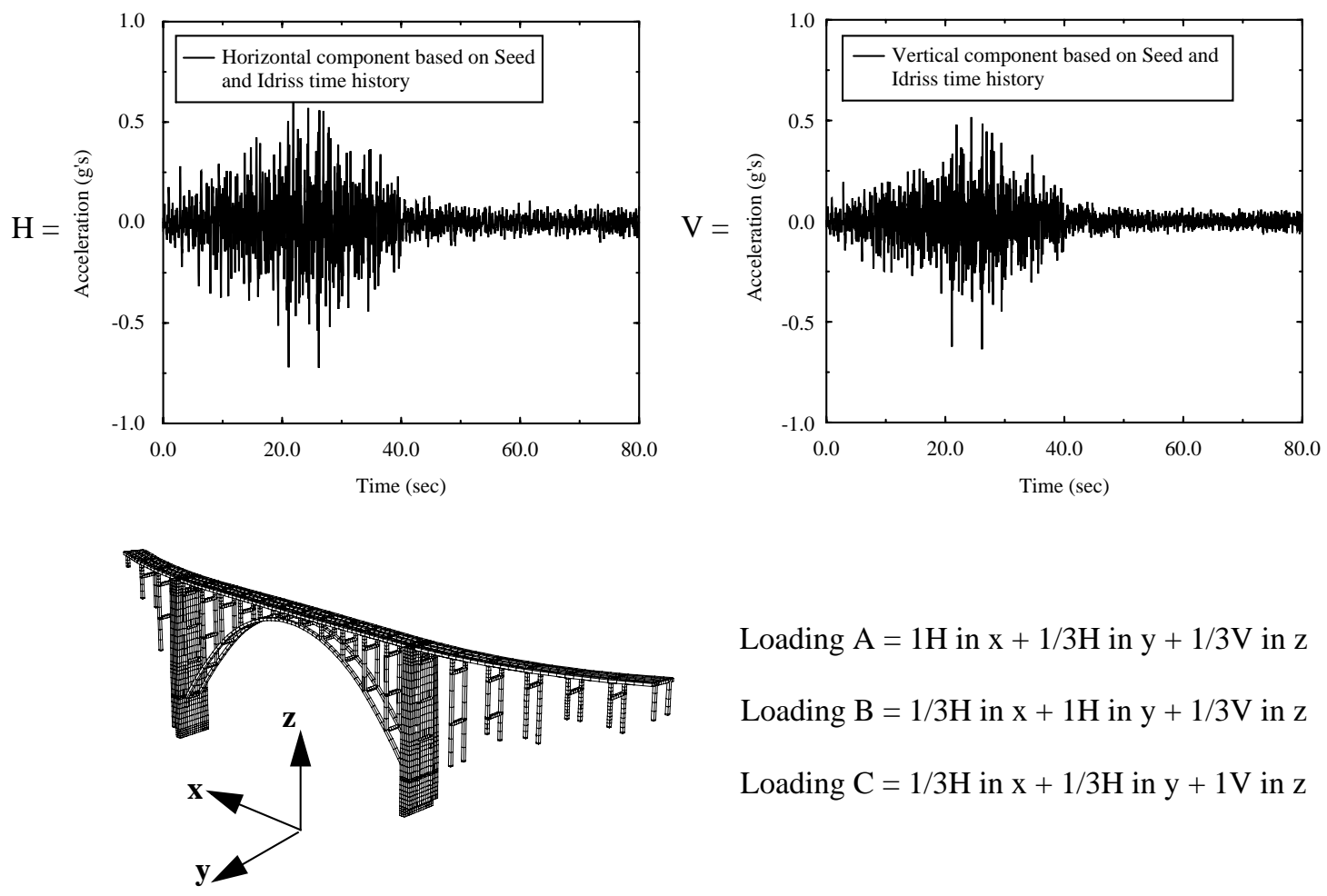

Loading $\mathrm{A}=1 \mathrm{H}$ in $\mathrm{x}+1 / 3 \mathrm{H}$ in $\mathrm{y}+1 / 3 \mathrm{~V}$ in $\mathrm{z}$
Loading $\mathrm{B}=1 / 3 \mathrm{H}$ in $\mathrm{x}+1 \mathrm{H}$ in $\mathrm{y}+1 / 3 \mathrm{~V}$ in $\mathrm{z}$
Loading $\mathrm{C}=1 / 3 \mathrm{H}$ in $\mathrm{x}+1 / 3 \mathrm{H}$ in $\mathrm{y}+1 \mathrm{~V}$ in $\mathrm{z}$

FIGURE 69. Load combination for earthquake loading with original Caltrans time histories.

LLNL linear material model utilized gross sections for the members, whereas the Buckland and Taylor model used the significantly reduced sections described earlier.

For the Seed and Idriss earthquake motion, with the dominant horizontal component applied transverse to the bridge (i.e. loading $\mathrm{B}$ with $1 / 3 \mathrm{H}$ in $\mathrm{x}+1 \mathrm{H}$ in $\mathrm{y}+1 / 3 \mathrm{~V}$ in $\mathrm{z}$ ), the resulting displacements at selected nodes are shown in Figure 70. The maximum transverse displacement obtained at midspan is approximately 21 inches. Computer animation of the response of the bridge indicates that the bridge motion consists of multiple-mode contributions until about 35 to 40 seconds into the record when a few strong displacement pulses occur which are dominated by the fundamental transverse mode of the structure. The input ground motions for the Seed and Idriss time histories exhibit high frequency motions (see Figure 69) and it appears that this high frequency content drives the higher modes of the structure. As the high frequency input begins to wane, the structure fundamental mode (with a period of about 3.9 seconds) continues to build until the strong first mode dominated pulses occur at 40 seconds.

Buckland and Taylor's analysis of the as-built structure consisted of a response spectrum analysis. The response spectrum analysis does not provide waveforms to compare to, but the maximum transverse displacement reported for the midspan of the arch was 27 inches. In light of the fact that the LLNL model is somewhat stiffer than the Buckland and Taylor model (transverse period of 3.9 seconds for the LLNL model compared to 4.5 seconds for 

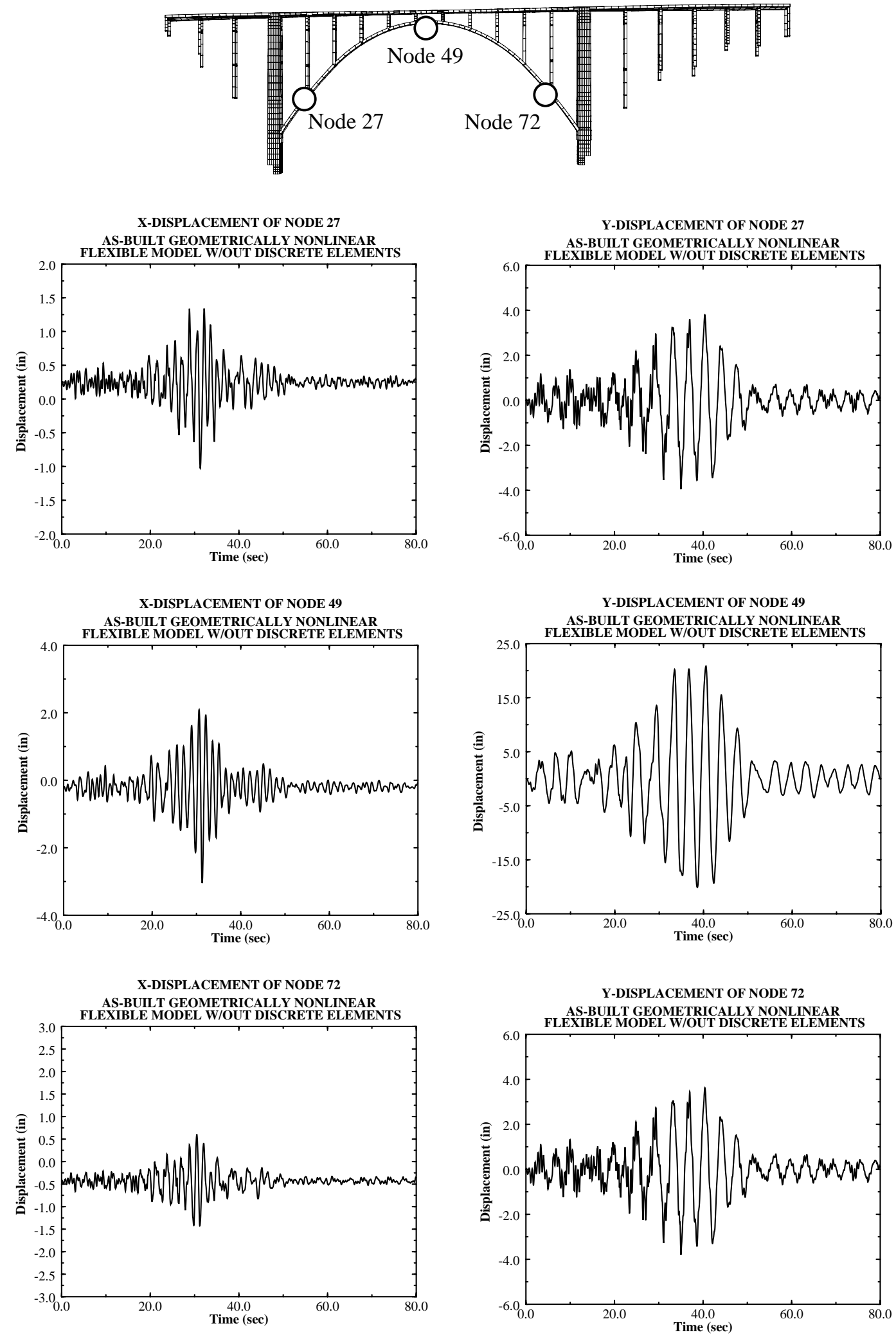

FIGURE 70. Displacement time histories for selected nodes, model based on linear material, geometrically nonlinear without contact at expansion joints. 
the Buckland and Taylor model), the larger displacement provided by the Buckland and Taylor model is reasonable.

Inspection of Figure 70 shows that at locations low on the arch, such as node 27 and node 72 , some high frequency motion is evident in the time histories. This is most likely due to the contact surface at the base of the towers, where some scrubbing is occurring along the side contact surfaces of the tower. Higher in the arch (node 49) the high frequency is not as prevalent. The high frequency has probably attenuated and scattered by the time the motion reaches the top of the structure.

\subsection{Transient response of the as-built structure model with linear materials and contacting expansion joints (Seed and Idriss time histories)}

The second model again considers the response of the model containing linear materials; however, the expansion joints were allowed to close with subsequent contact. The fundamental difference between the previous model is that the discrete elements used to model joint contact were activated. The earthquake loading shown here is the same as with the previous model (i.e. loading $\mathrm{B}$ with $1 / 3 \mathrm{H}$ in $\mathrm{x}+1 \mathrm{H}$ in $\mathrm{y}+1 / 3 \mathrm{~V}$ in $\mathrm{z}$ )

The character of the displacement time histories is similar to the previous model, but a decrease in displacements is observed (Figure 71). Comparing the transverse displacement at midspan, the addition of contact decreased the amplitude of the series of peak displacement pulses from three large pulses at about 21 inches displacement (Figure 70) to a number of pulses around fifteen or less inches (only one pulse nears 20 inches as shown in Figure 71).

\subsection{Transient response of the as-built structure model with nonlinear materials and contacting expansion joints (Seed and Idriss time histories)}

The third model incorporated the nonlinear concrete constitutive model and contacting expansion joints. The displacement time histories at the selected nodes are shown in Figure 72, and inspection of the figure shows that material nonlinearities have a significant effect on the model response. The transverse response at the crown of the arch shows that the amplitude of the response is reduced and the effective period of vibration of the model is significantly longer than for the linear elastic model. The period elongation is a direct result of section cracking, concrete softening and steel yielding.

\subsection{Transient response of the as-built structure model with nonlinear materials and merged-deck, non-opening expansion joints (Seed and Idriss time histories)}

The fourth model included material nonlinearities, but the model segments were assumed merged (i.e. tied) across the various expansion joints. This model results in significant 

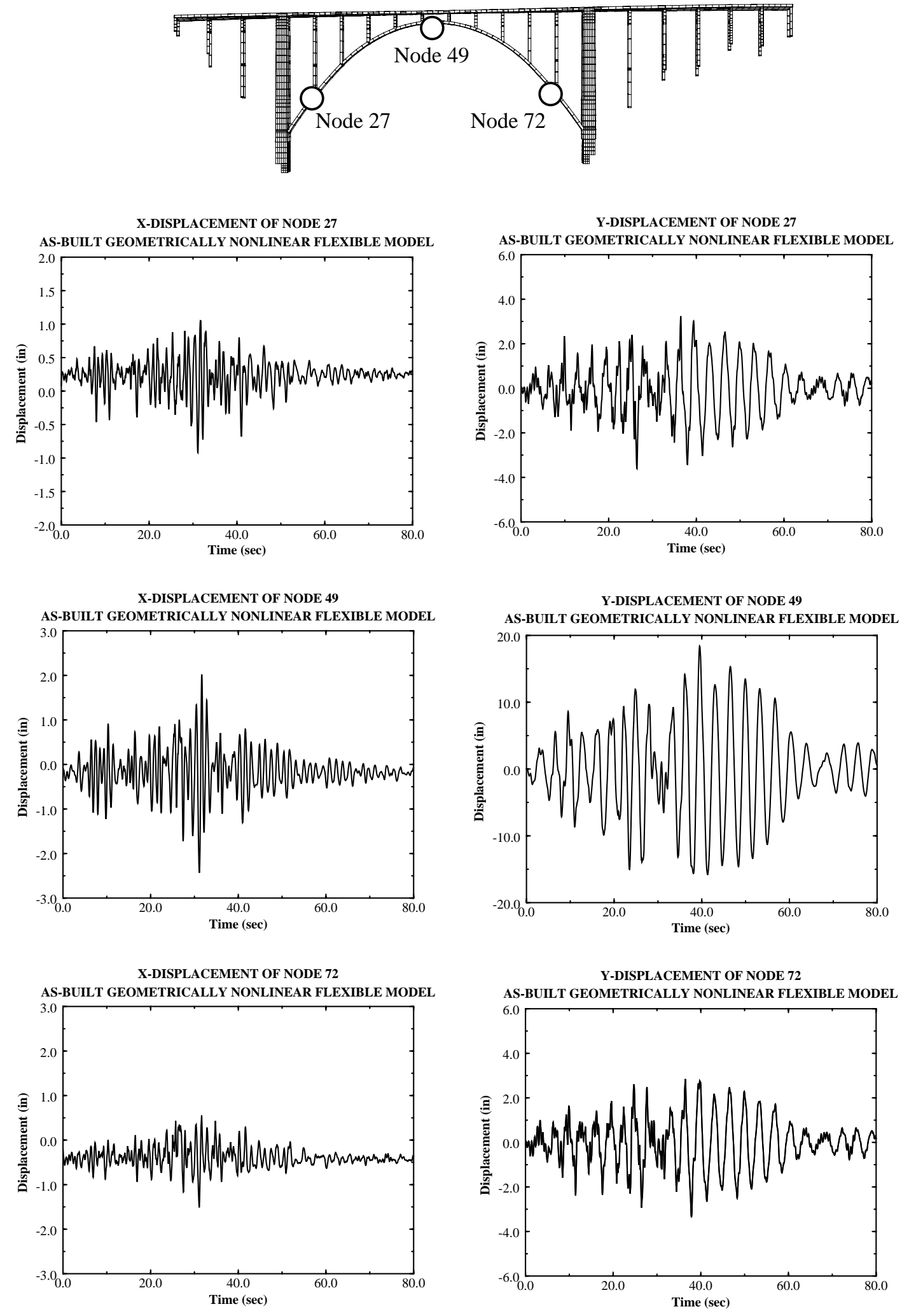

FIGURE 71. Displacement time histories for selected nodes; model based on linear material, geometrically nonlinear with contact at expansion joints. 


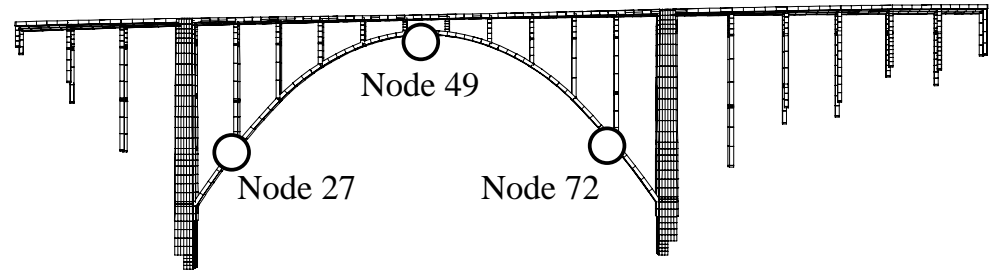

X-DISPLACEMENT OF NODE 27

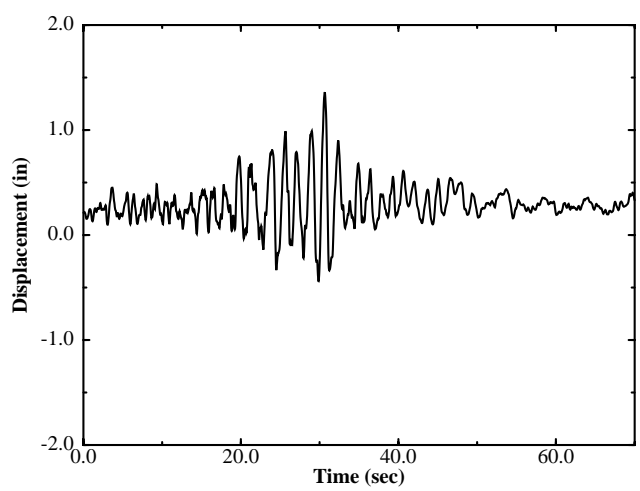

X-DISPLACEMENT OF NODE 49

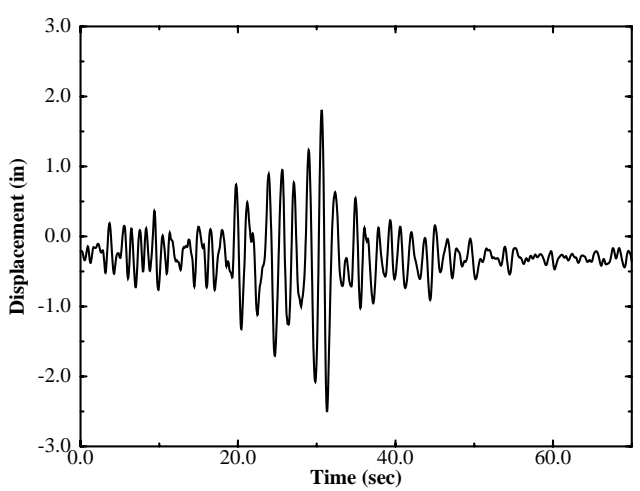

X-DISPLACEMENT OF NODE 72

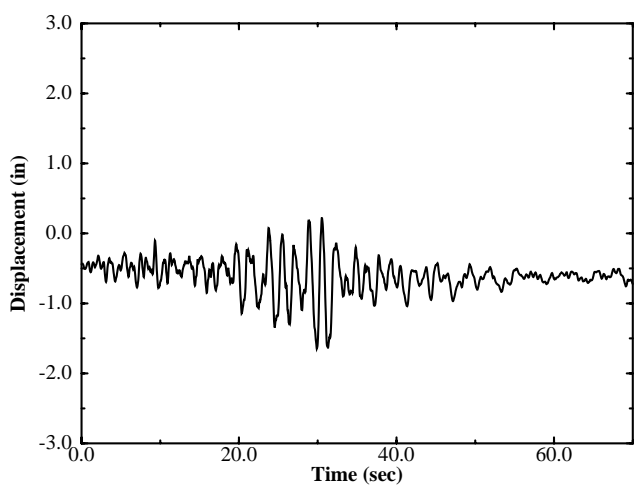

Y-DISPLACEMENT OF NODE 27

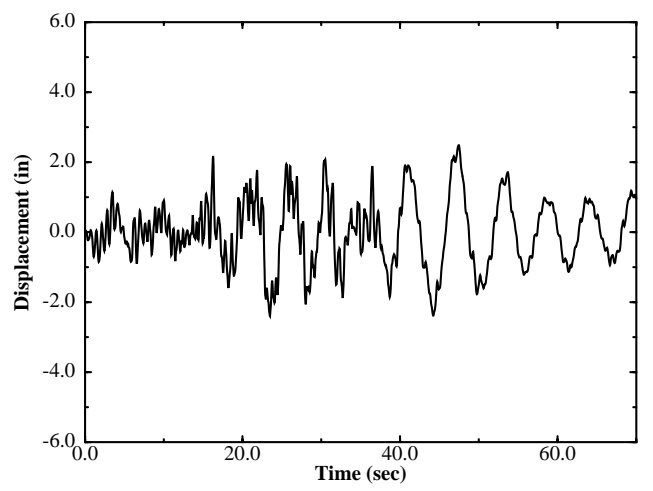

Y-DISPLACEMENT OF NODE 49

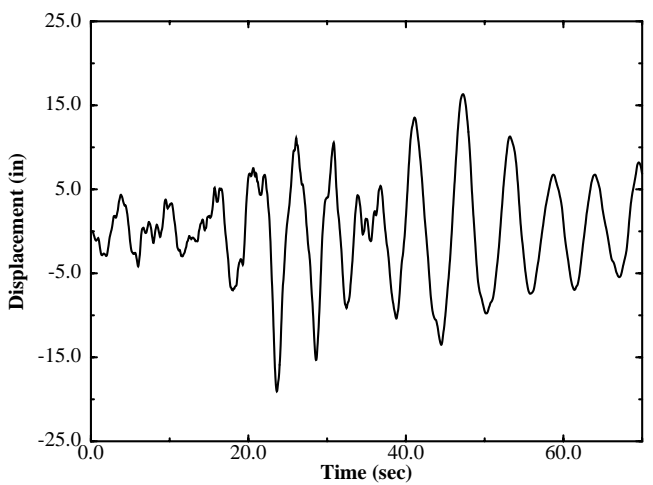

Y-DISPLACEMENT OF NODE 72

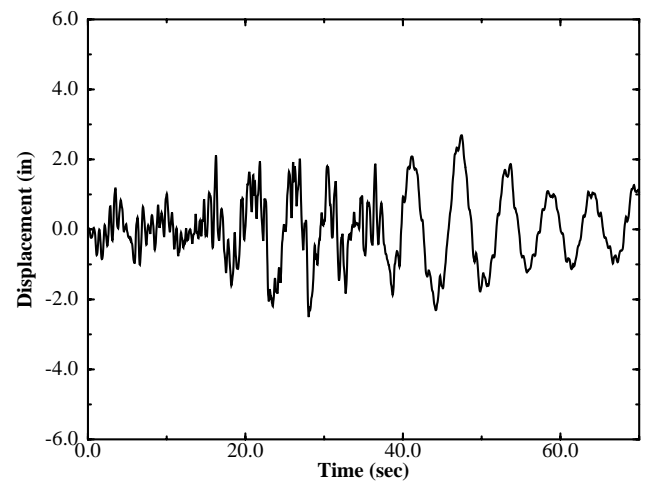

FIGURE 72. Displacement time histories for selected nodes; model based on nonlinear material, geometrically nonlinear with contact at expansion joints. 

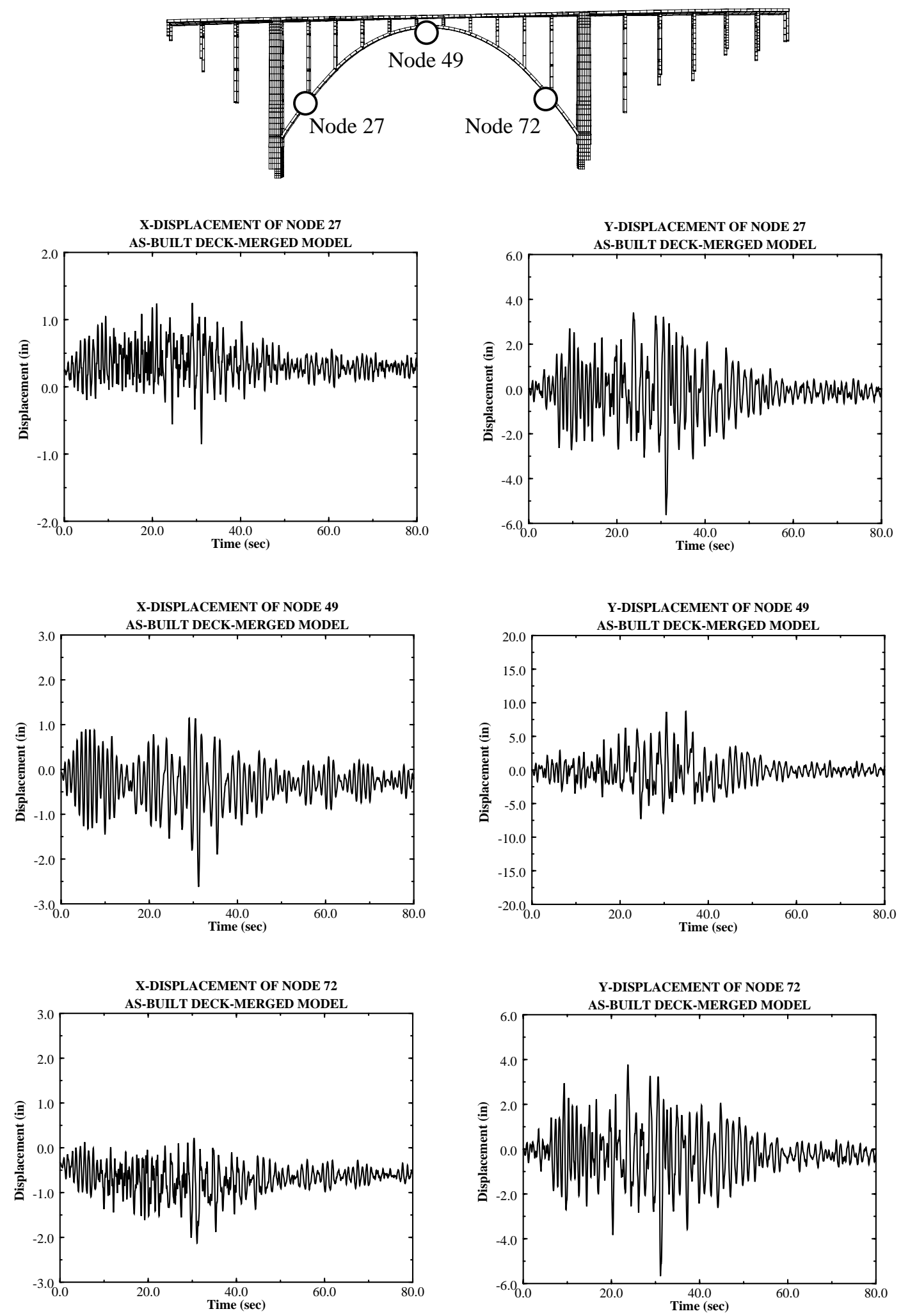

FIGURE 73. Displacement time histories for selected nodes; model based on nonlinear material, geometrically nonlinear with merged, non-opening expansion joints. 
stiffening of the structure since the deck can act as a deep beam transverse to the bridge. The displacement time histories for the selected nodes are shown in Figure 73. As indicated by the displacement time histories, merging the deck across the expansion joints significantly reduces the displacements computed from the structural model, particularly for the transverse displacement at the crown of the arch. The significantly increased stiffness is also evident from the higher frequency response of the transient displacements of the structure.

\subsection{Transient response of the as-built structure model with nonlinear materials and tied collars at the expansion joints (Seed and Idriss time histories)}

This model included beam elements to represent the steel tied collars which have been added to the split columns at the expansion joints of the structure. The computed displacement time histories for this model are shown in Figure 74. For the nonlinear model, the tied columns only have a very minor effect on the displacement time histories (compare to Figure 72). From inspection of the computer animated bridge response, this appears to be due to the fact that the deck still cannot develop significant lateral stiffness because connectivity is lacking between the deck system and the towers. The individual column collars tend to couple adjacent segments of the deck, but there is no mechanism for transferring load to the towers, and the deck is still allowed to pull away from the towers at the deck-tower interface.

A comparison of the bridge transient displacements for a number of different modeling assumptions is provided in Figure 75. These plots indicate the significantly different response characteristics which can be obtained with different modeling assumptions and different sophistications of models.

\subsection{Member strains and demand-to-capacity ratios (Seed and Idriss time histories)}

The strain levels in the structural members were examined for selected computer models with the CSTRAIN post-processing routine (Figure 68). The strains in the concrete and steel fiber zones are examined throughout the earthquake history to capture the peak strain demands at each point in the structure. The physical locations at which the model computed strains exceeded prescribed peak strains are summarized in Figure 76 through Figure 79. The models indicate that the concrete compressive strains exceed the 0.003 compressive strain level associated with the Whitney stress block ultimate strain level assumed in the ACI code for concrete bending (Figure 76); however, as indicated in Figure 77, the strains do not exceed the Caltrans specified allowable strain level of 0.005 .

The locations at which the steel strains surpass a strain of 0.0014 (the yield strain for 40 ksi steel), a strain of 0.014 (10 x the yield strain) and a strain of 0.12 (the Caltrans allowable) are shown in Figure 78 through Figure 80 respectively. It is observed that the strains do not surpass the Caltrans specified allowable at any location. 


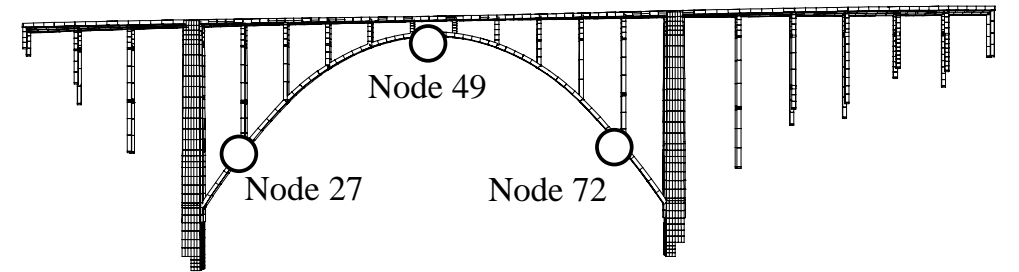

X-DISPLACEMENT OF NODE 27

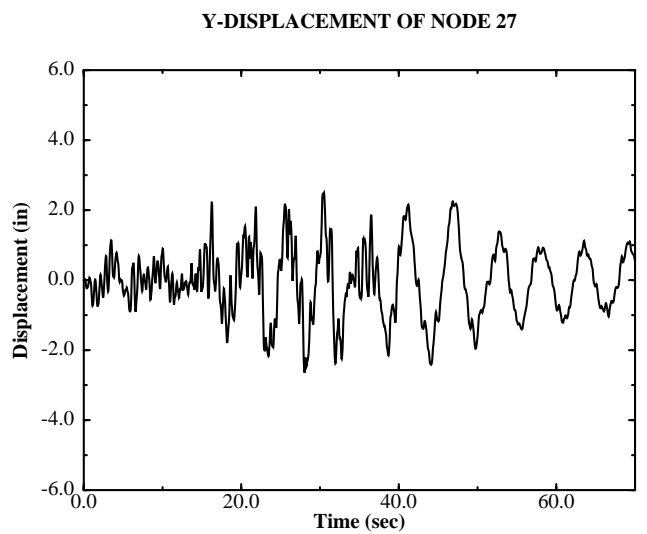

X-DISPLACEMENT OF NODE 49

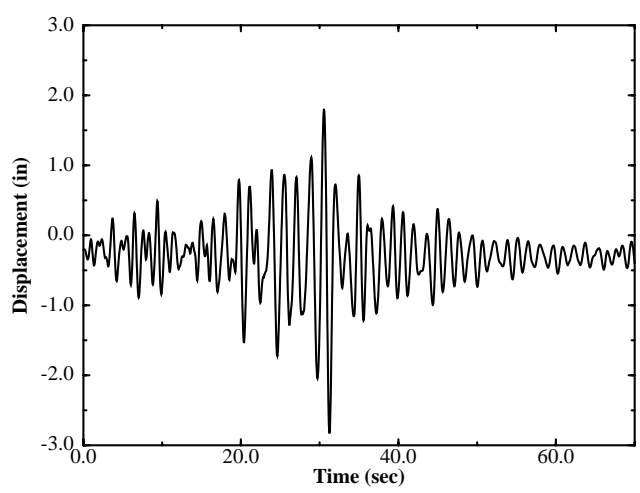

Y-DISPLACEMENT OF NODE 49

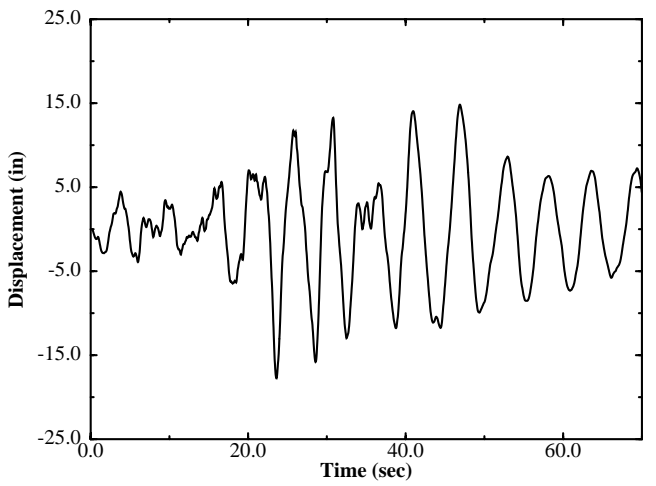

X-DISPLACEMENT OF NODE 72
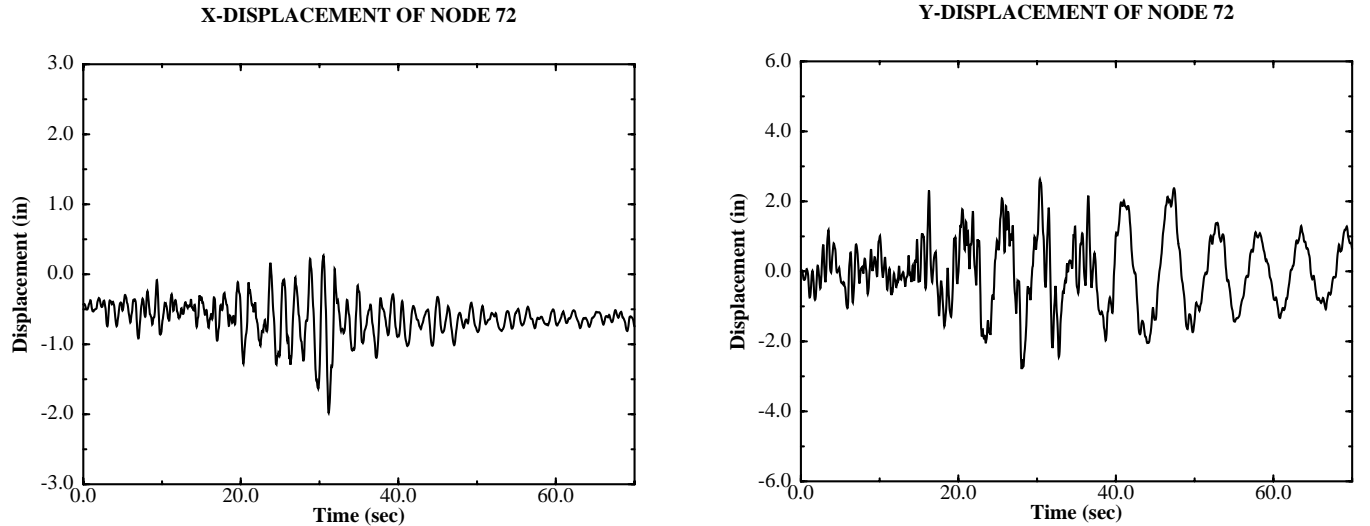

FIGURE 74. Displacement time histories for selected nodes, model based on nonlinear material, geometrically nonlinear with contact at expansion joints and collar ties. 


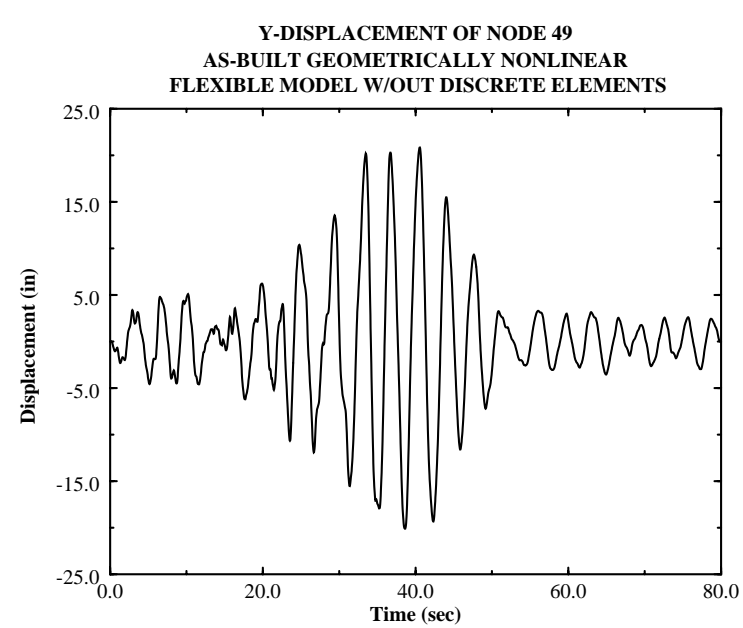

a)

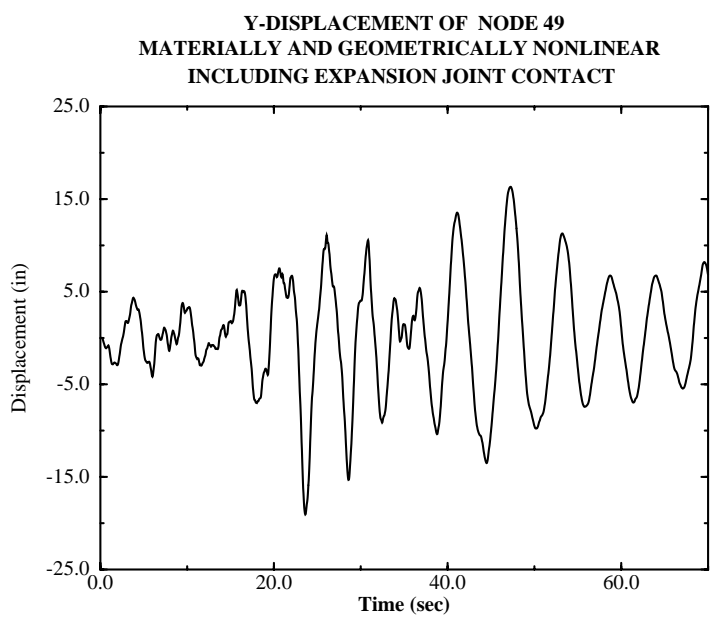

c)

Y-DISPLACEMENT OF NODE 49 MATERIALLY AND GEOMETRICALLY NONLINEAR DECK-MERGED MODEL

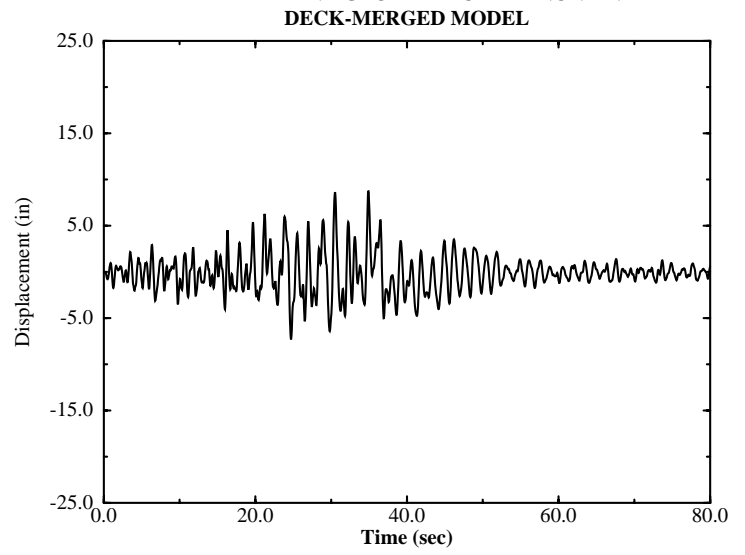

e)

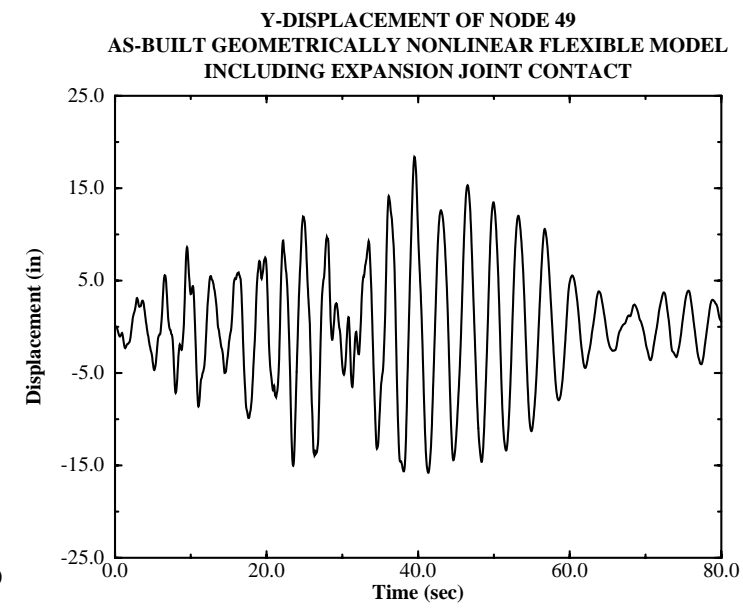

b)

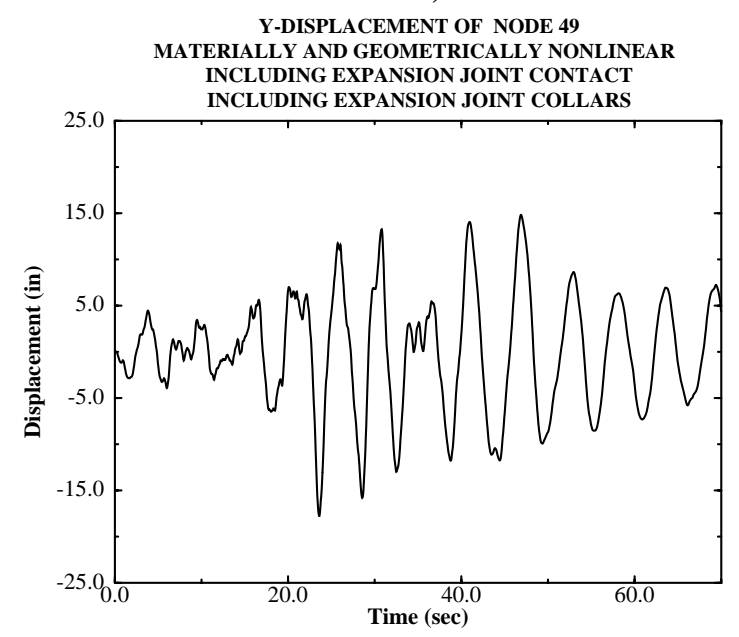

d)

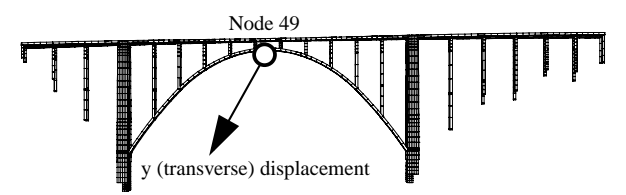

FIGURE 75. Comparison of five modeling cases. a) Linear elastic material model with noncontacting expansion joints; b) linear elastic material model with contacting expansion joints; c) nonlinear material model with contacting expansion joints; d) nonlinear material model with tied collars and contacting expansion joints; e) nonlinear material model with tied (closed) expansion joints. 
Linear material flexible expansion joints with no contact

Linear material flexible expansion joints with contact

Nonlinear material flexible expansion joints with contact

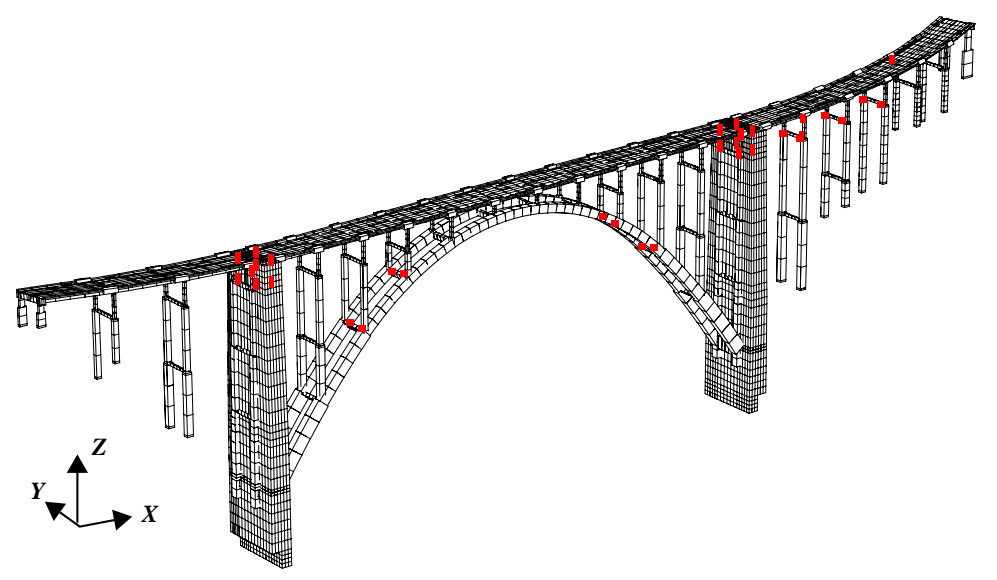

MODEL LOADS: GRAVITY + EQ JOINT: FLEXIBLE MATERIALLY LINEAR GEOMETRICALLY NONLINEAR SEED \& IDRISS TIME HISTORY (NO CONTACT)

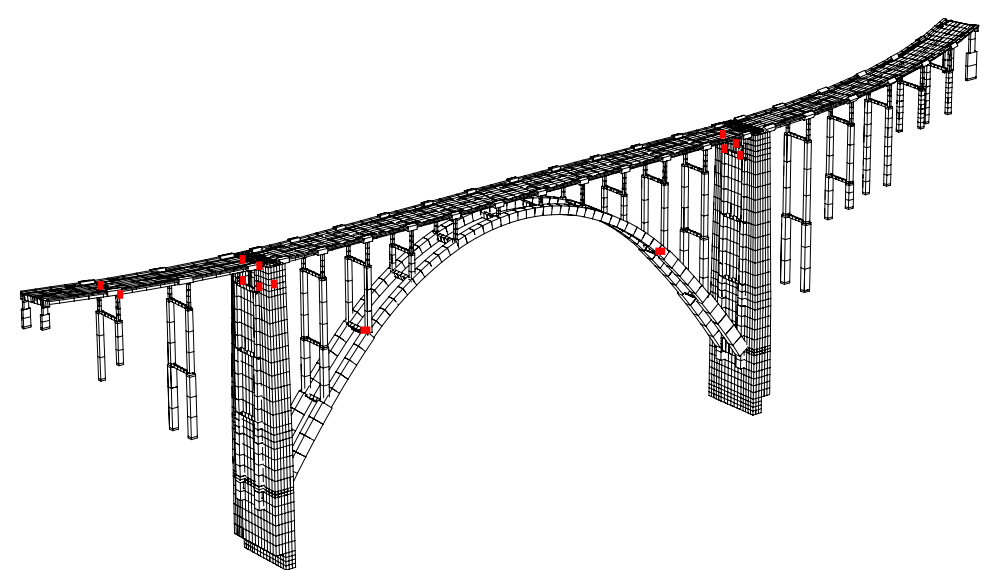

MODEL: LOADS: GRAVITY +EQ JOINT: CONTACT GATERIALLY LINEAR $E Q=0.3 x+1.0 y$ GEOMETRICALLY NONLINEAR SEED \& IDRISS TIME HISTORY

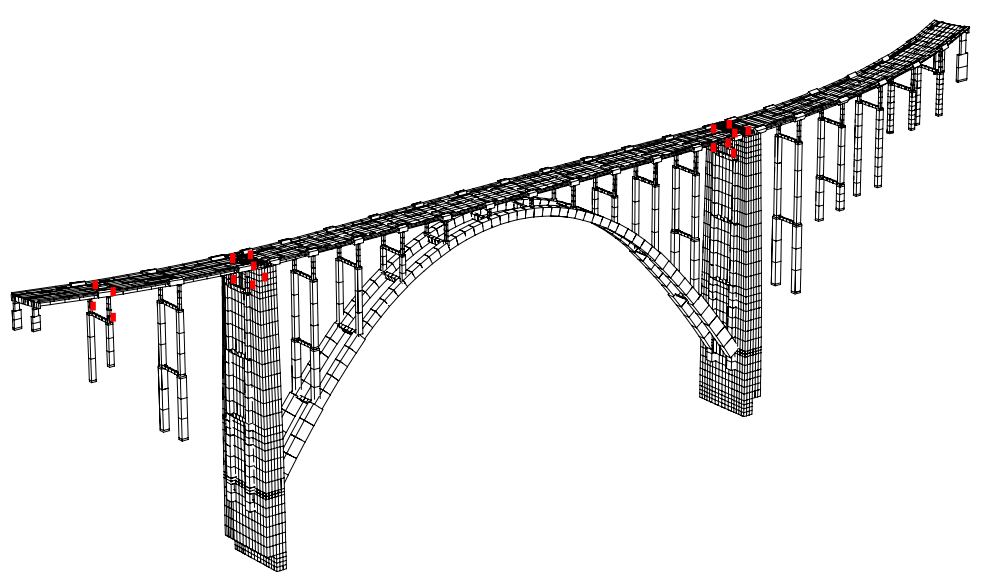

MODEL: LOADS: GRAVITY + EQ JOINT: CONTACT

MATERIALLY NONLINEAR GEOMETRICALLY NONLINEAR

FIGURE 76. Locations for which concrete compressive strains exceed 0.003 . 
Linear material flexible expansion joints with no contact

Linear material flexible expansion joints with contact

Nonlinear material flexible expansion joints with contact
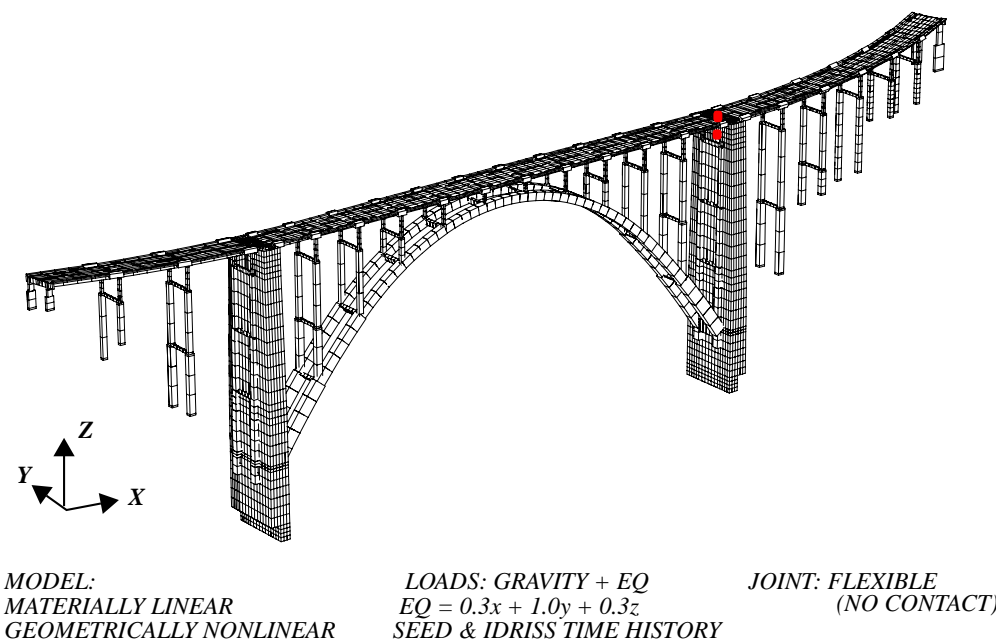
GEOMETRICALLY NONLINEAR SEED \& IDRISS TIME HISTORY
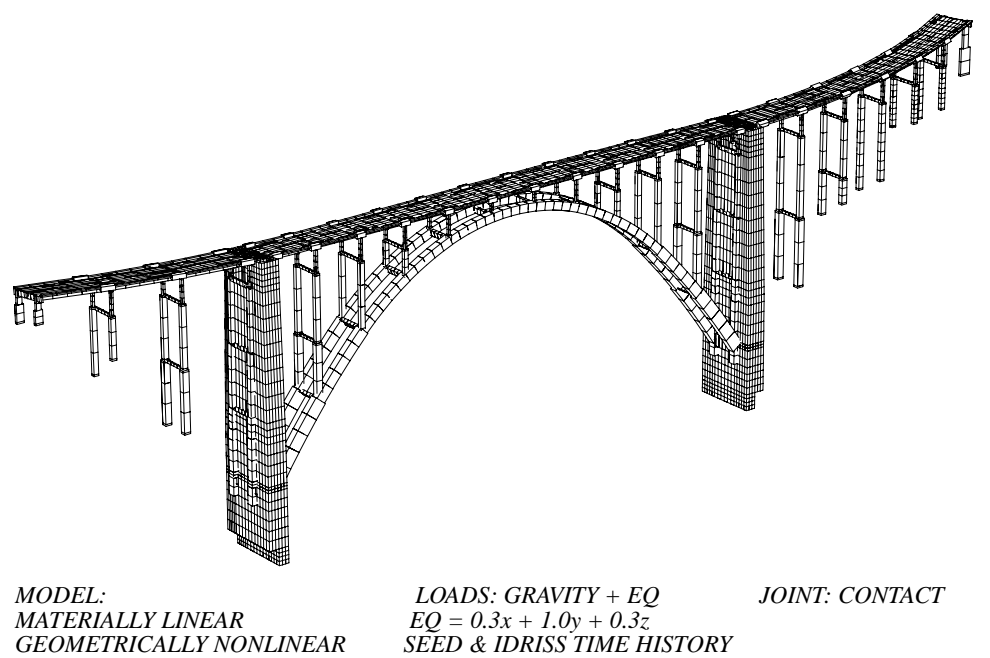

$$
\begin{array}{ll}
\text { MATERIALLY LINEAR } & E Q=0.3 x+1.0 y+0.3 z \\
\text { GEOMETRICALLY NONLINEAR } & \text { SEED \& IDRISS TIME HISTORY }
\end{array}
$$

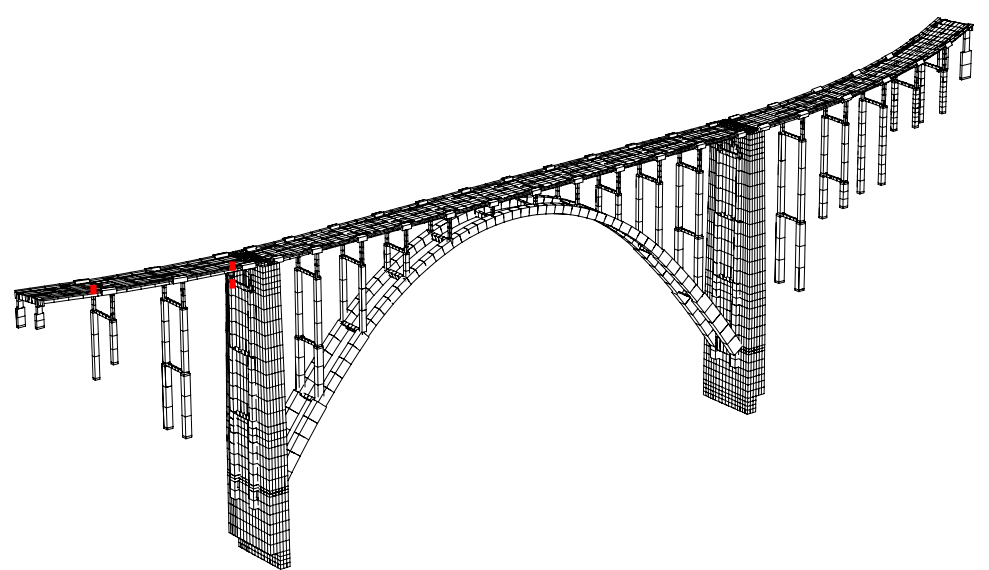

MODEL:

LOADS: GRAVITY +EQ JOINT: CONTACT

MATERIALLY NONLINEAR GEOMETRICALLY NONLINEAR

$E Q=0.3 x+1.0 y+0.3 z$

SEED \& IDRISS TIME HISTORY

FIGURE 77. Locations for which concrete compressive strains exceed 0.005 (Caltrans allowable). 
Linear material flexible expansion joints with no contact

Linear material flexible expansion joints with contact

Nonlinear material flexible expansion joints with contact

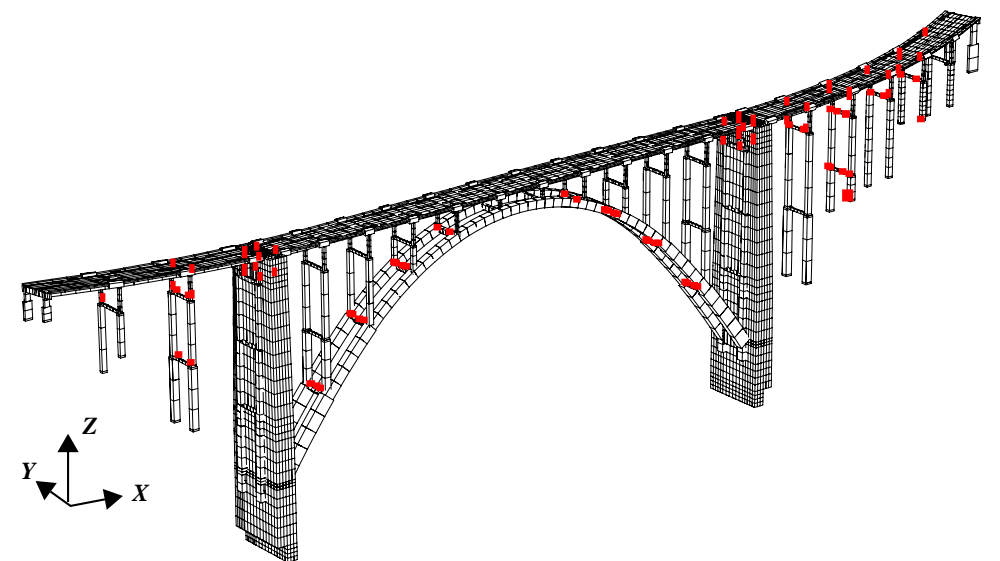

$\begin{array}{lcc}\text { MODEL: } & \text { LOADS: GRAVITY +EQ } & \text { JOINT: FLEXIBLE } \\ \text { MATERIALLY LINEAR } & \text { EQ }=0.3 x+1.0 y+0.3 z & \text { (NO CONTACT) } \\ \text { GEOMETRICALLY NONLINEAR } & \text { SEED \& IDRISS TIME HISTORY } & \end{array}$

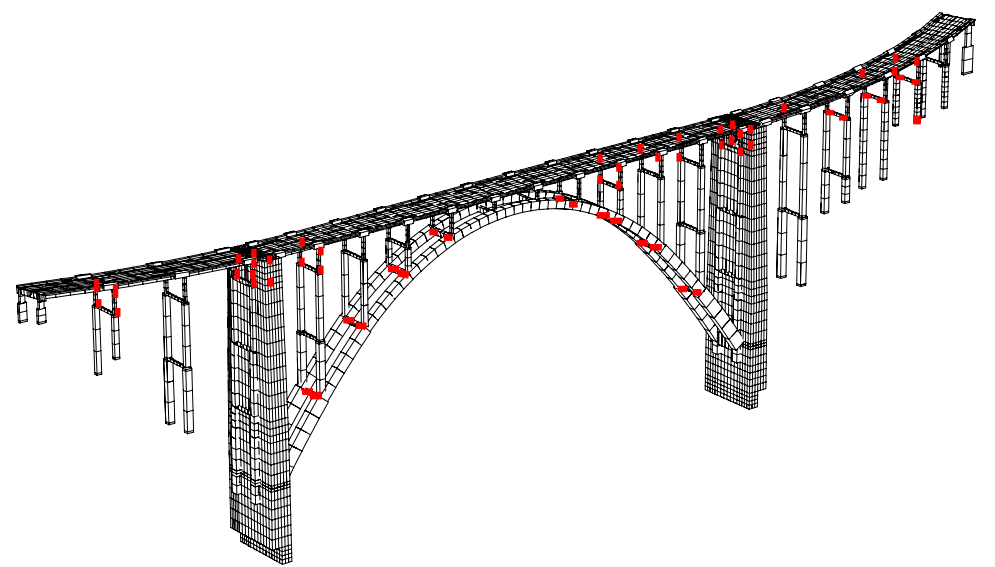

MODEL:

LOADS: GRAVITY $+E Q$ $E Q=0.3 x+1.0 y+0.3 z$

JOINT: CONTACT

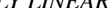

SEED \& IDRISS TIME HISTORY

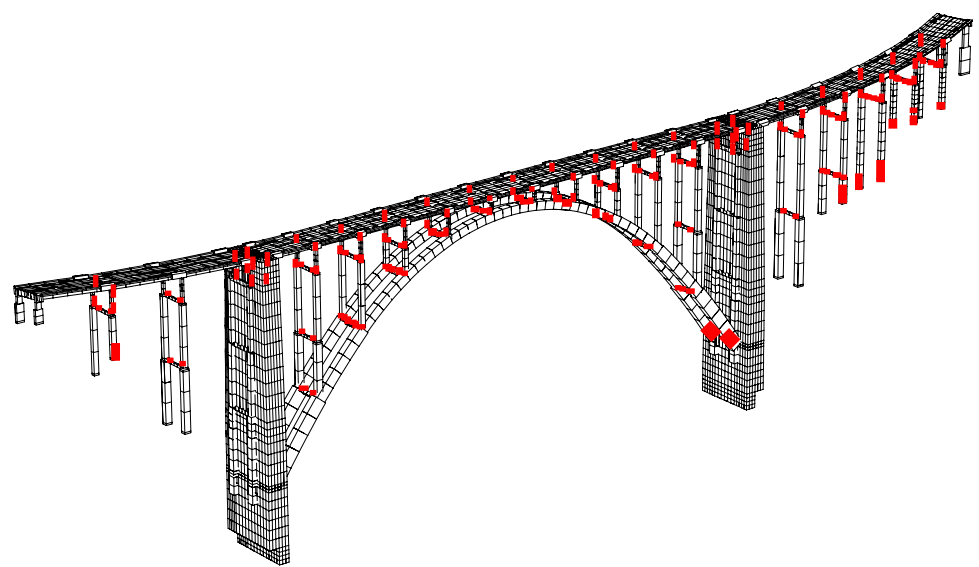

MODEL:

MATERIALLY NONLINEAR

LOADS: GRAVITY + EQ
$E Q=0.3 x+1.0 y+0.3 z$

JOINT: CONTACT GEOMETRICALLY NONLINEAR

FIGURE 78. Locations for which steel strains exceed 0.0014 (yield strain). 
Linear material flexible expansion joints with no contact

Linear material flexible expansion joints with contact

Nonlinear material flexible expansion joints with contact

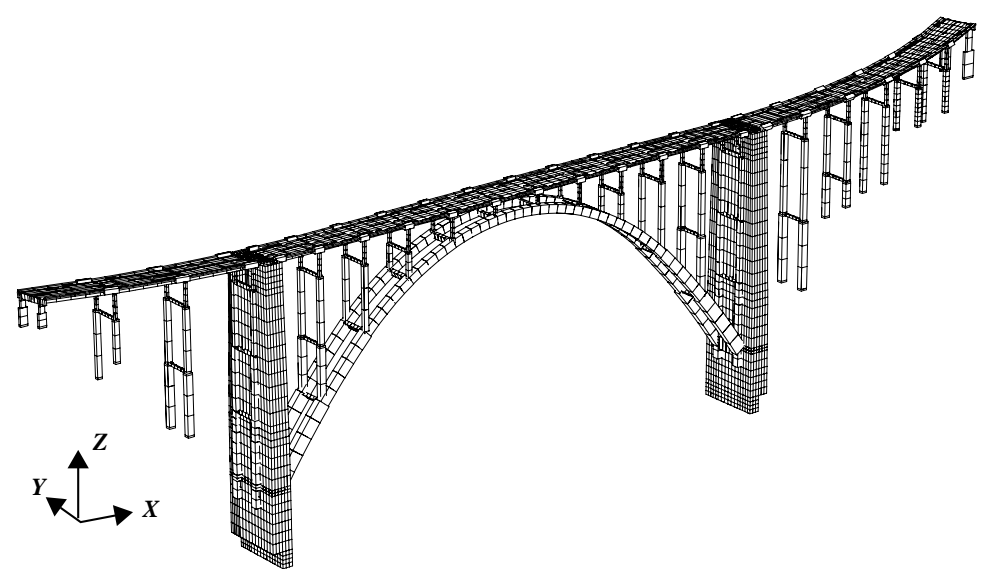

MODEL:

MATERIALLY LINEAR GEOMETRICALLY NONLINEAR

LOADS: GRAVITY + EQ
$E O=0.3 x+1.0 y+0.3 z$ SEED \& IDRISS TIME HISTORY

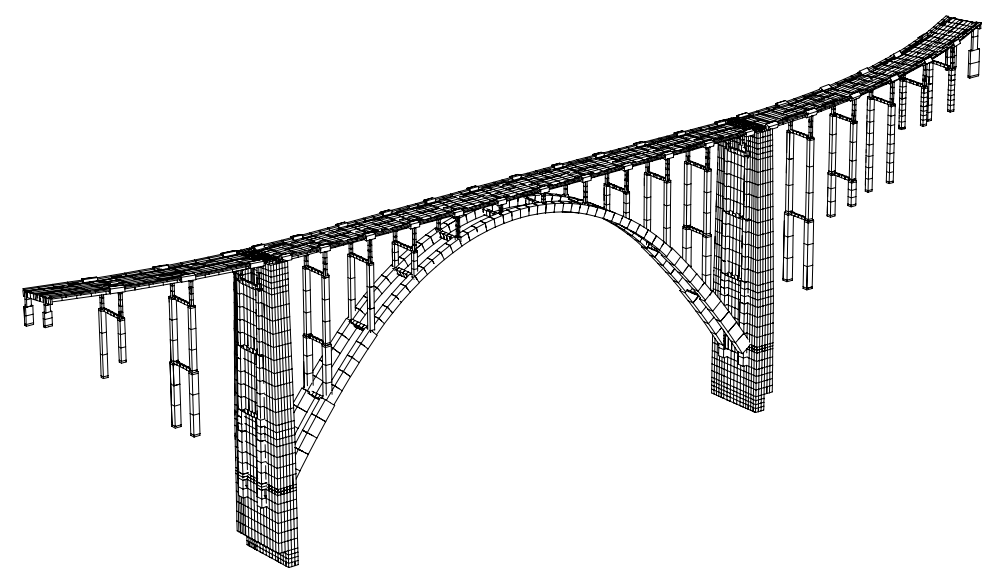

MODEL MATERIALLY LINEAR GEOMETRICALLY NONLINEAR

LOADS: GRAVITY + EQ $E Q=0.3 x+1.0 y+0.3 z$ SEED \& IDRISS TIME HISTORY

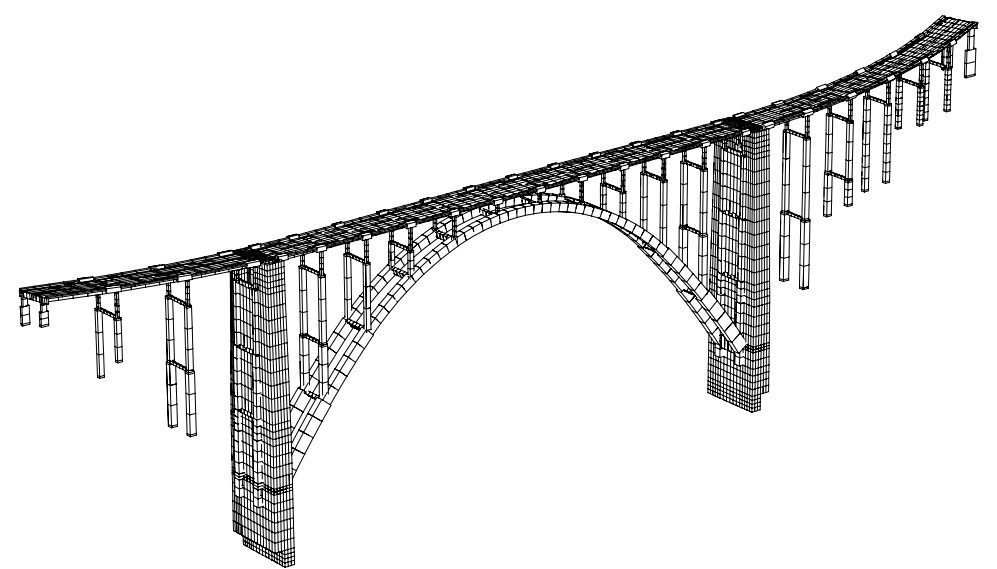

MODEL: MATERIALLY NONLINEAR GEOMETRICALLY NONLINEAR
LOADS: GRAVITY + EQ

SEED \& IDRISS TIME HISTORY
JOINT: CONTACT

FIGURE 79. Locations for which steel strains exceed 0.014 ( $10 \times$ yield strain). 
Linear material flexible expansion joints with no contact

Linear material flexible expansion joints with contact

Nonlinear material flexible expansion joints with contact

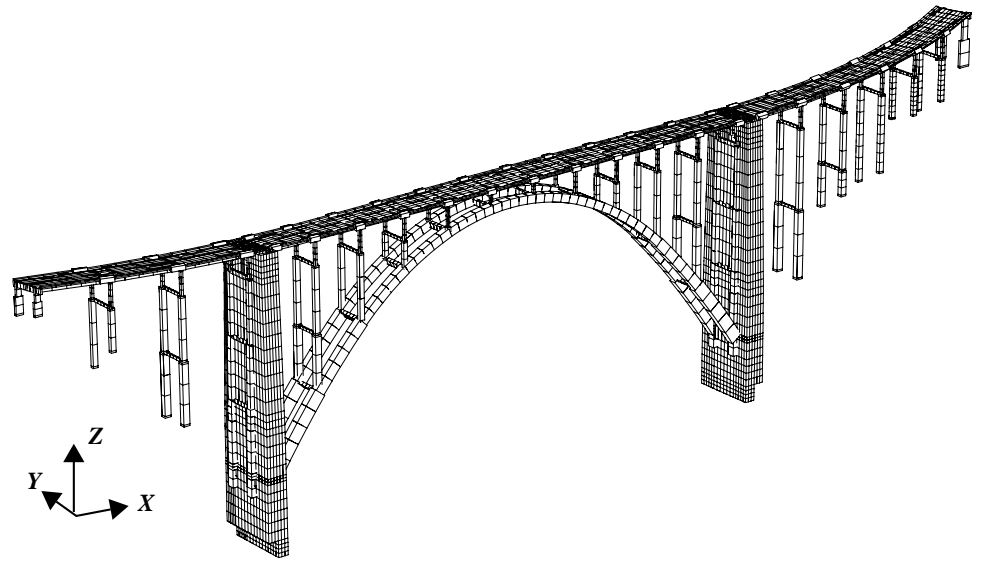

MODEL:

MATERIALLY LINEAR GEOMETRICALLY NONLINEAR

LOADS: GRAVITY +EQ JOINT: FLEXIBLE $E Q=0.3 x+1.0 y+0.3 z \quad$ (NO CONTACT)

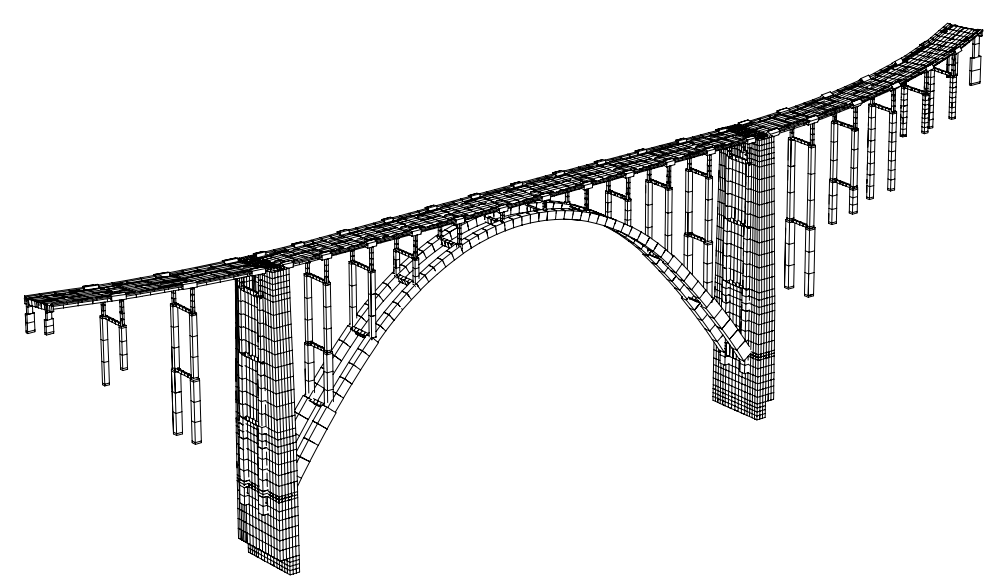

MODEL :

LOADS: GRAVITY +EQ $E Q=0.3 x+1.0 y+0.3 z$

JOINT: CONTACT MATERIALLY LINEAR GEOMETRICALLY NONLINEAR SEED \& IDRISS TIME HISTORY

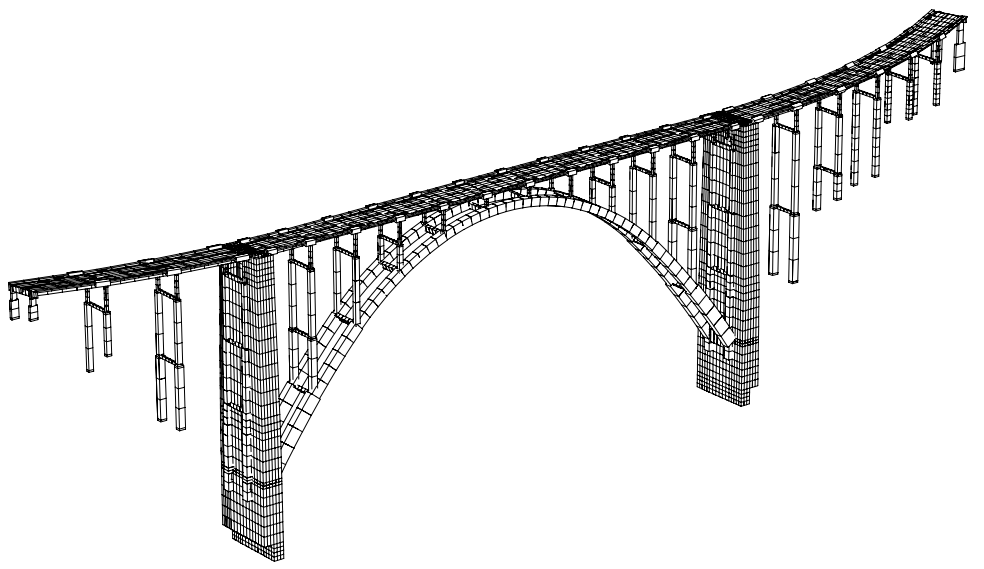

MODEL:

MATERIALLY NONLINEAR

LOADS: GRAVITY $+E Q$ $E Q=0.3 x+1.0 y+0.3 z$

JOINT: CONTACT GEOMETRICALLY NONLINEAR

FIGURE 80. Locations for which steel strains exceed 0.12 (Caltrans allowable). 
The strain values obtained from the computations indicate that the models predict significant yielding over a large area (Figure 78) and high compressive strains over a few areas (Figure 76); however, the Caltrans specified allowables are not surpassed. As an additional check on these deformation based criteria, a strength check was performed for selected members with an ACI type interaction equation. To accomplish this, the PCACOL personal computer based software, which performs a concrete section strength check, was employed to investigate the full three dimensional force interaction on selected members. Buckland and Taylor's analysis included strength checks where a number of members were found to be significantly overloaded in an ultimate strength check, and it was decided to verify this observation.

In order to perform a rapid assessment of the strength demand to capacity, the selected members shown in Figure 81 were examined with the PCACOL concrete interaction software. To perform this assessment, the time histories of the member force resultants were combined with an appropriate time dependent arithmetic combination using the time histories for all member force resultants. A maximum scalar demand-to-capacity ratio for the member was computed based on the ratio of magnitude of the vector to the stress resultant space of the member stress resultants to the magnitude of the vector which has the same direction, but intercepts the interaction diagram for the particular member (see Figure 81), i.e demand/capacity $=\mathrm{D}_{1} / \mathrm{D}_{2}$. The member demand-to-capacity ratios for the selected members are shown in Figure 81. As indicated in Figure 81, the nonlinearities in the system result in a large reduction of the member forces for the highly stressed members as the forces redistribute due to inelastic action (highly stressed members were selected for the member capacity check based on the members with large demand-to-capacity ratios as identified in the Buckland and Taylor analysis report).

The stress levels obtained in the towers and deck membranes during the earthquake motions are shown in Figure 82 at selected peak response times and the maximum and minimum principal stresses are summarized in Table 13. The stress levels indicate that there is the potential for tensile cracking in the concrete at the base of the towers (red areas in Figure 82 indicate regions for which maximum tensile stress surpasses the modulus of rupture (500 psi) of the concrete material).

Table 13: Maximum and minimum principal stresses in bricks and shells.

\begin{tabular}{|c|c|c|c|c|c|c|c|}
\hline BRICKS & $\begin{array}{c}\sigma_{1} \\
(\mathbf{p s i})\end{array}$ & $\begin{array}{c}\sigma_{2} \\
(\mathbf{p s i})\end{array}$ & $\begin{array}{c}\sigma_{3} \\
(\mathbf{p s i})\end{array}$ & SHELLS & $\begin{array}{c}\sigma_{1} \\
(\mathbf{p s i})\end{array}$ & $\begin{array}{c}\sigma_{2} \\
(\mathbf{p s i})\end{array}$ & $\begin{array}{c}\sigma_{3} \\
(\mathbf{p s i})\end{array}$ \\
\hline $\begin{array}{c}\text { Maximum } \\
\text { Stress }\end{array}$ & 1200 & 465 & 69.7 & $\begin{array}{c}\text { Maximum } \\
\text { Stress }\end{array}$ & 552 & 117 & \\
\hline Location & $\begin{array}{c}\text { Brick } \\
1152\end{array}$ & $\begin{array}{c}\text { Brick } \\
574\end{array}$ & $\begin{array}{c}\text { Brick } \\
1152\end{array}$ & Location & $\begin{array}{c}\text { Shell } \\
1143\end{array}$ & Shell 990 & \\
\hline Time & 26.16 & 26.16 & 24.42 & Time & 19.56 & 28.83 & \\
\hline $\begin{array}{c}\text { Minimum } \\
\text { Stress }\end{array}$ & -105 & -370 & -2080 & $\begin{array}{c}\text { Minimum } \\
\text { Stress }\end{array}$ & & -155 & -1110 \\
\hline
\end{tabular}



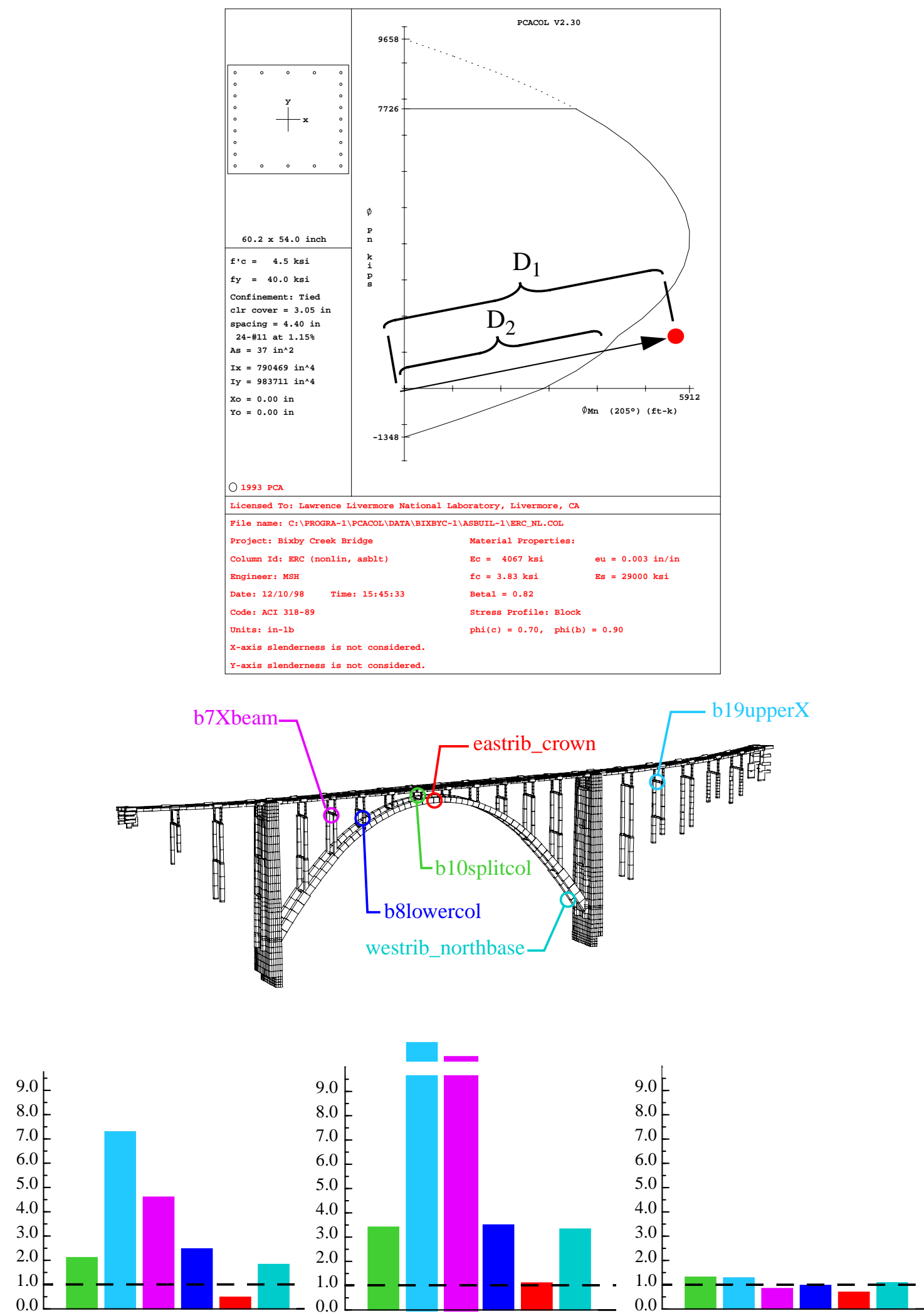

Buckland \& Taylor

LLNL Linear

LLNL Nonlinear

FIGURE 81. Strength check for selected members. 


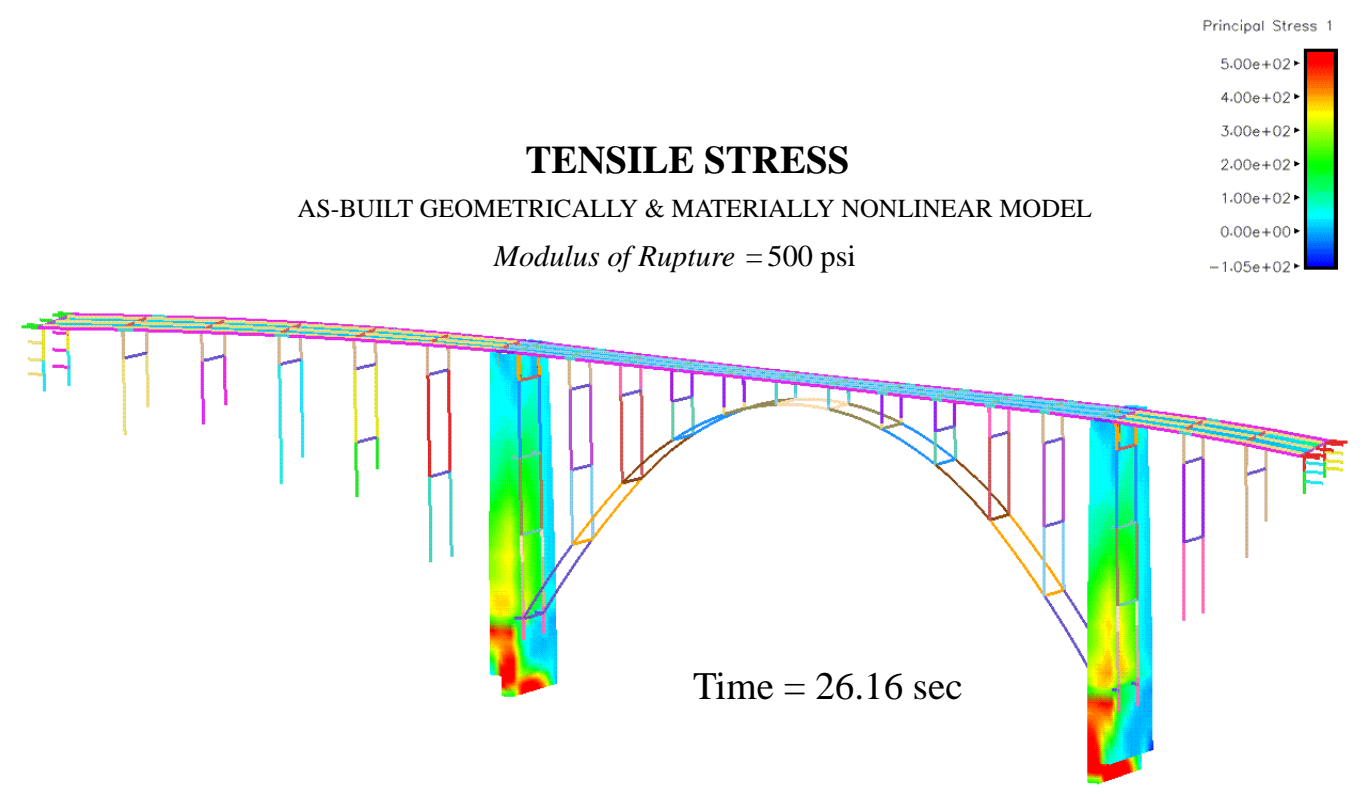

FIGURE 82. Stress levels in the tower and deck membranes.

Table 13: Maximum and minimum principal stresses in bricks and shells.

\begin{tabular}{|c|c|c|c|c|c|c|c|}
\hline BRICKS & $\begin{array}{c}\sigma_{1} \\
(\mathbf{p s i})\end{array}$ & $\begin{array}{c}\sigma_{2} \\
(\mathbf{p s i})\end{array}$ & $\begin{array}{c}\sigma_{3} \\
(\mathbf{p s i})\end{array}$ & SHELLS & $\begin{array}{c}\sigma_{1} \\
(\mathbf{p s i})\end{array}$ & $\begin{array}{c}\sigma_{2} \\
(\mathbf{p s i})\end{array}$ & $\begin{array}{c}\sigma_{3} \\
(\mathbf{p s i})\end{array}$ \\
\hline Location & $\begin{array}{c}\text { Brick } \\
1537\end{array}$ & $\begin{array}{c}\text { Brick } \\
529\end{array}$ & Brick 1 & Location & & $\begin{array}{c}\text { Shell } \\
1142\end{array}$ & Shell 951 \\
\hline Time & 26.13 & 26.16 & 26.16 & Time & & 6.24 & 39.87 \\
\hline
\end{tabular}

\subsection{Shear demand-to-capacity check for the as-built structure}

The shear strength demand-to-capacity ratios of the individual bridge members were evaluated with an ACI codified check of the member strengths. The time history of individual member shears were obtained from the transient computer simulation and the maximum individual member shears were compared to the codified shear capacities which are obtained from a combination of the concrete and shear reinforcing tie bar strengths. For the case of the Seed and Idriss ground motion applied transverse to the bridge axis, which is the worse case loading for the original retrofit design time histories, the locations at which the shear strength demands exceed the shear strength capacities are summarized in Figure 83. Extensive potential is exhibited for member shear failures.

\subsection{Failure estimates for existing collar ties}

Though not stated explicitly, the modeling work performed by Buckland and Taylor apparently assumed that the existing steel collar ties were ineffectual in coupling the split columns together and the columns were therefore neglected in their finite element analyses. The nonlinear model simulations performed by LLNL and discussed above indicated that 


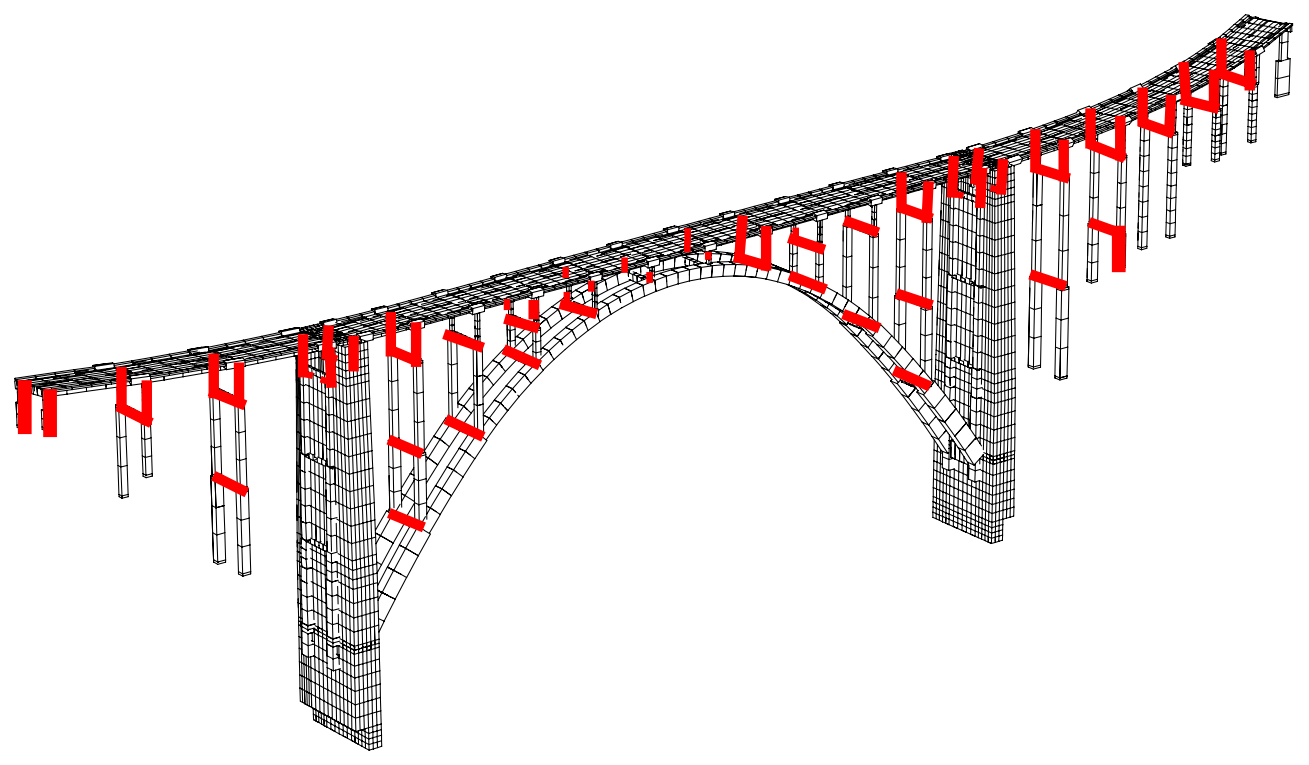

FIGURE 83. Locations at which shear failure is predicted (geometrically nonlinear, materially linear with free, noncontacting expansion joint model).

including the collars in the model did not make a major difference in the nonlinear response of the structure (see Figure 75) for the retrofit design motions. As a check to see if the column ties do indeed fail, a simple analysis was performed to determine the demand to capacity values of the tied collars. To estimate the seismic forces to which the collars would be subjected, beam elements were placed in the finite element model between adjacent nodes on the split columns. An estimate of the appropriate beam stiffnesses were obtained from a local three dimensional analysis of a typical tied collar (Figure 35). The beam elements allowed retrieval of estimates of the time histories of the forces to which the collars would be subjected. Based on the time histories of the force resultants, a simple interaction equation for the bolted connections was checked. Following the methodology of the AISC for the interaction of forces on a bolted connection, the interaction equation for the bolts are given by:

$$
\left(\frac{f_{v y}}{0.83 F_{u v}}\right)^{2}+\left(\frac{f_{v z}}{0.83 F_{u v}}\right)^{2}+\left(\frac{f_{t}}{F_{u t}}\right)^{2}<1.0
$$

where, $f_{v y}$ and $f_{v z}$ are the respective shears acting on the bolts and $f_{t}$ is the bolt tension. A simple post processor computer program was written to take the force resultant time histories of each tied connection from the transient finite element analysis and check the interaction given by EQ. 14 at each instant throughout the earthquake time history. Based on 


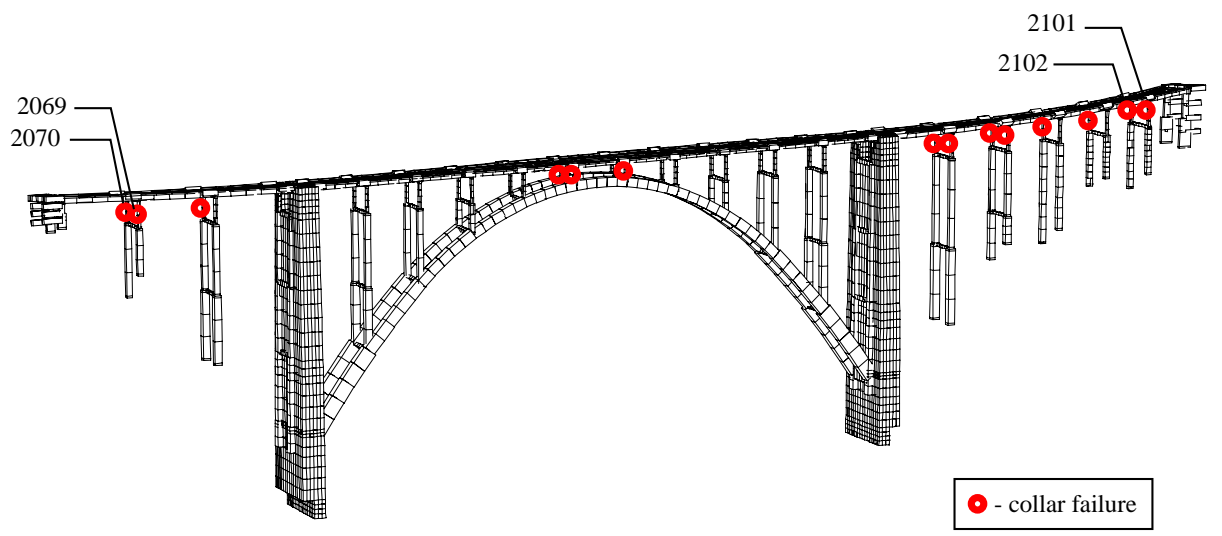

FIGURE 84. Locations of collar failures from transient earthquake analyses.

the indicated interaction check, which is summarized in Table 14, the ties at the columns indicated in Figure 84 were found to fail due to the Seed and Idriss earthquake motions.

Table 14: Interaction check for tied collars.

\begin{tabular}{|c|c|c|c|c|}
\hline $\begin{array}{c}\text { Collar } \\
\text { Number }\end{array}$ & $\begin{array}{c}\text { Global Maximum } \\
\text { Axial } \\
\text { (lbs) }\end{array}$ & $\begin{array}{c}\text { Global Maximum } \\
\text { Shear }_{y} \\
\text { (lbs) }\end{array}$ & $\begin{array}{c}\text { Global Maximum } \\
\text { Shear }_{\mathrm{z}} \\
\text { (lbs) }\end{array}$ & $\begin{array}{c}\text { Maximum Single } \\
\text { Step } \\
\text { Combination Value } \\
(>1.0=\text { failure })\end{array}$ \\
\hline 2069 & 84743 & 102686 & 56973 & 1.47 \\
\hline 2070 & 101628 & 108122 & 40619 & 1.52 \\
\hline 2071 & 91393 & 82029 & 15971 & 0.97 \\
\hline 2072 & 158331 & 70206 & 20981 & 2.84 \\
\hline 2073 & 88685 & 54220 & 25534 & 0.95 \\
\hline 2074 & 79601 & 53262 & 19930 & 0.80 \\
\hline 2075 & 72074 & 73004 & 25775 & 0.60 \\
\hline 2076 & 72546 & 75512 & 30870 & 0.86 \\
\hline 2077 & 50667 & 59898 & 28406 & 0.40 \\
\hline 2078 & 57503 & 66630 & 28496 & 0.58 \\
\hline 2079 & 57351 & 53629 & 14781 & 0.40 \\
\hline 2080 & 62307 & 52398 & 17401 & 0.53 \\
\hline 2081 & 117959 & 56479 & 13228 & 1.57 \\
\hline 2082 & 103189 & 47669 & 16900 & 1.25 \\
\hline 2083 & 102885 & 41516 & 31761 & 1.26 \\
\hline 084 & 91573 & 47606 & 19209 & 0.97 \\
\hline 2085 & 50478 & 53481 & 18406 & 0.36 \\
\hline 2086 & 54210 & 57432 & 17743 & 0.52 \\
\hline 2087 & 53443 & 64296 & 25080 & 0.55 \\
\hline 2088 & 58804 & 64378 & 27400 & 0.49 \\
\hline
\end{tabular}


Table 14: Interaction check for tied collars.

\begin{tabular}{|c|c|c|c|c|}
\hline $\begin{array}{c}\text { Collar } \\
\text { Number }\end{array}$ & $\begin{array}{c}\text { Global Maximum } \\
\text { Axial } \\
(\mathbf{l b s})\end{array}$ & $\begin{array}{c}\text { Global Maximum } \\
\text { Shear } \\
\text { (lbs) }\end{array}$ & $\begin{array}{c}\text { Global Maximum } \\
\text { Shear } \\
\text { (lbs) }\end{array}$ & $\begin{array}{c}\text { Maximum Single } \\
\text { Step } \\
\text { Combination Value } \\
\text { (>1.0 = failure) }\end{array}$ \\
\hline 2089 & 58151 & 64203 & 24568 & 0.53 \\
\hline 2090 & 77787 & 61061 & 26362 & 0.69 \\
\hline 2091 & 71324 & 65966 & 21862 & 0.68 \\
\hline 2092 & 93406 & 62521 & 17859 & 0.99 \\
\hline$t 2093$ & 125506 & 64114 & 22740 & 1.78 \\
\hline 2094 & 100966 & 71090 & 19516 & 1.50 \\
\hline 2095 & 115160 & 59106 & 23938 & 1.50 \\
\hline 2096 & 101227 & 63738 & 16099 & 1.24 \\
\hline 2097 & 86275 & 72031 & 25573 & 0.87 \\
\hline 2098 & 95163 & 80403 & 36270 & 1.04 \\
\hline$t 2099$ & 83529 & 75256 & 37059 & 0.90 \\
\hline 2100 & 93816 & 83764 & 29591 & 1.03 \\
\hline 2101 & 98990 & 60724 & 30312 & 1.16 \\
\hline 2102 & 108479 & 68216 & & 1.41 \\
\hline
\end{tabular}

\subsection{Transient response of the as-built structure to Caltrans ground motions including near-field terms}

The Bixby Creek Bridge site is in very close proximity to the end of the San Gregorio fault system (see Figure 6) and Caltrans ground motion documentation indicates that the site is actually located within approximately $1 \mathrm{~km}$ distance from the end of the fault system. As discussed previously, it is very likely that long period ground motion components associated with fault near-field effects will have a pronounced effect on the ground motions at the Bixby Creek site. Due to the early vintage of the original ground motions developed for the retrofit design (i.e. early 90's), it was requested that Caltrans regenerate and provide updated ground motion time histories which included near-field displacement terms. In response to this request, Caltrans geotechnical staff provided the updated motions shown in Figure 12 through Figure 14. As can be seen in the displacement time history plots, the updated motions included estimates of long-period displacement pulses which can occur when a site is close to the causative fault.

\subsection{Transient response of the as-built structure model with nonlinear materials and contacting expansion joints (Caltrans updated time histories with near-field motions)}

The response of the geometrically and materially nonlinear model of the as-built structure to the Caltrans supplied earthquake motions with near-field terms is shown in Figure 85. Inspection of the displacement plots and computer animations of the bridge response indi- 

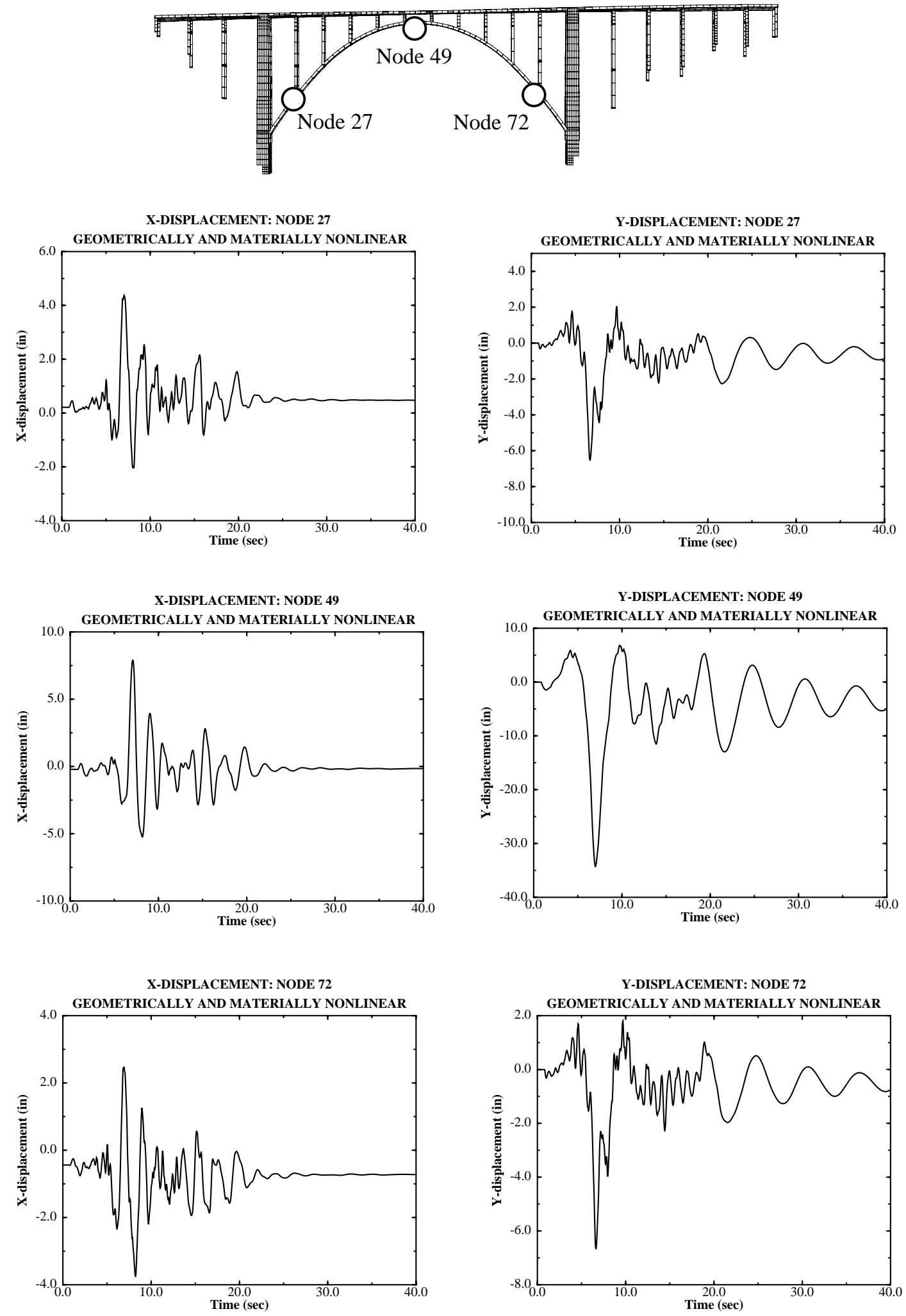

FIGURE 85. Displacement time histories for selected nodes, model based on nonlinear material, geometrically nonlinear with contact at expansion joints and collar ties (updated Caltrans records including near-field terms). 
cates that the bridge responds violently to the initial displacement pulses at the start of the record (see Figure 12). The ground displacement exhibits a large displacement pulse in the fault normal direction (essentially transverse to the bridge) and there is also a coherent displacement pulse in the fault parallel direction (essentially longitudinal to the bridge) which is in phase with the transverse motion. Computer animation of the bridge response indicates that the main arch is simultaneously subjected to a large transverse and longitudinal motion as a result of these ground pulses. The large transverse deck displacements are indicated in Figure 85, where the transverse displacement of the midspan of the bridge deck is almost three feet. This represents an exceedingly large drift for a bridge of only about 330 foot span.

\subsection{Member strains (Caltrans updated time histories with near-field motions)}

The computed strain levels in the concrete and steel of the structure for the updated ground motions are shown in Figure 86 through Figure 89. Two of the computational models were considered for the updated ground motion analyses. The first model considered linear materials with flexible, noncontacting expansion joints, and the second model considered nonlinear materials with contacting expansion joints. The figures indicate that the concrete strains surpass the Caltrans allowable at a number of locations (Figure 87), but that the steel strains still remain below the Caltrans allowable (Figure 89). The nonlinear model results indicate the potential for catastrophic member crushing throughout a significant portion of the bridge structure. It should be noted that the reinforcing steel exhibits yielding throughout the structure. This plot was not included because the yielding was so pervasive as to make the yield indicator regions a continuous red color. Thus, the structural model indicates extensive yielding, but the steel strains do not become excessively large.

\subsection{Comparison of structural response between original retrofit design ground motions and Caltrans updated near-field ground motions}

The mid-span transverse displacement time histories for a number of modeling idealizations and for both the original and updated ground motions are summarized on a common amplitude scale in Figure 90. These plots indicated the sensitivity of the computed bridge response to modeling assumptions (compare the large differences in the linear models with free and tied expansion joints) and the importance of including the near-field ground motion terms in the ground motion records. The very large displacement pulse imparted to the bridge is clearly evident in Figure 90 and the extent of damage in the structure is evident from the extreme degree of softening in the system. 
Linear material flexible expansion joints with no contact

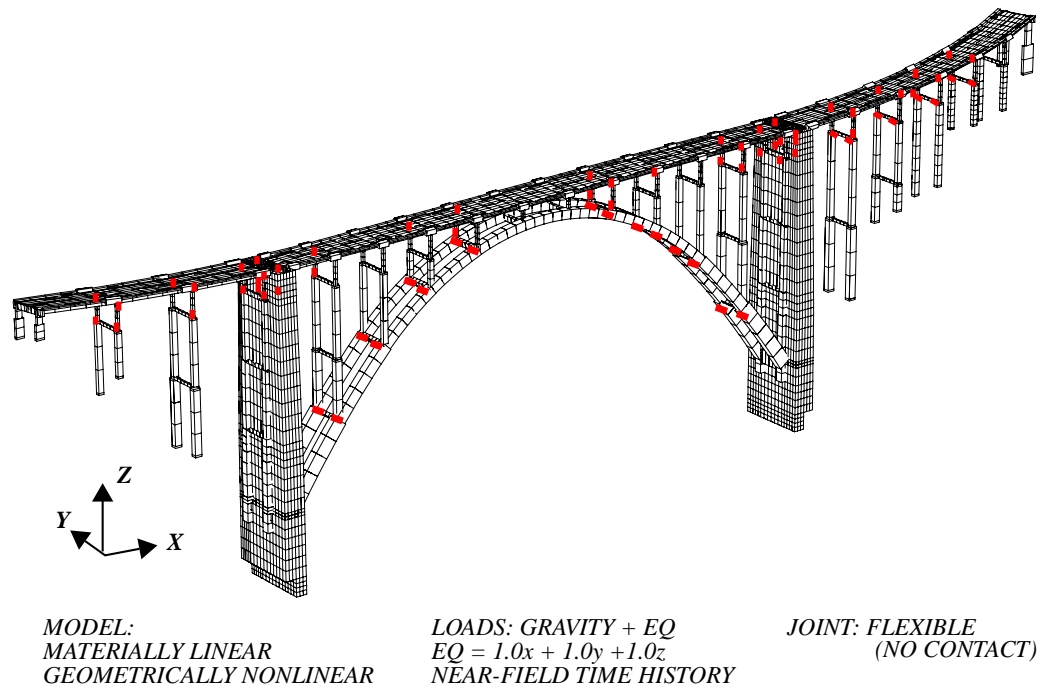

Nonlinear material flexible expansion joints with contact

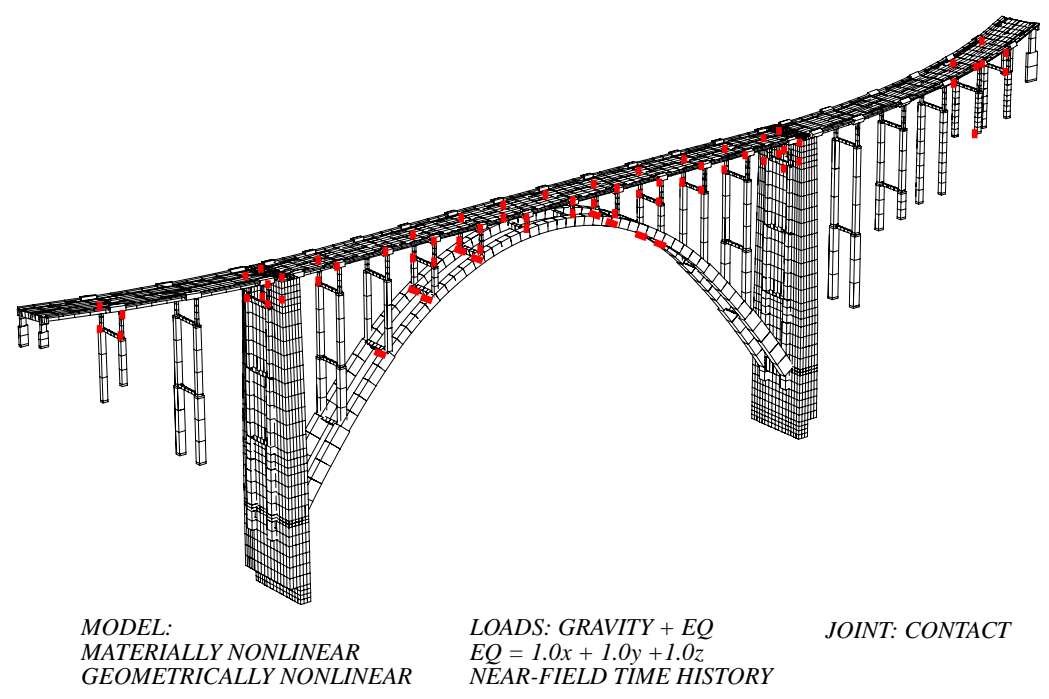

FIGURE 86. Concrete damage zones for near-field motions - locations for which concrete strains exceed 0.003 . 
Linear material flexible expansion joints with no contact

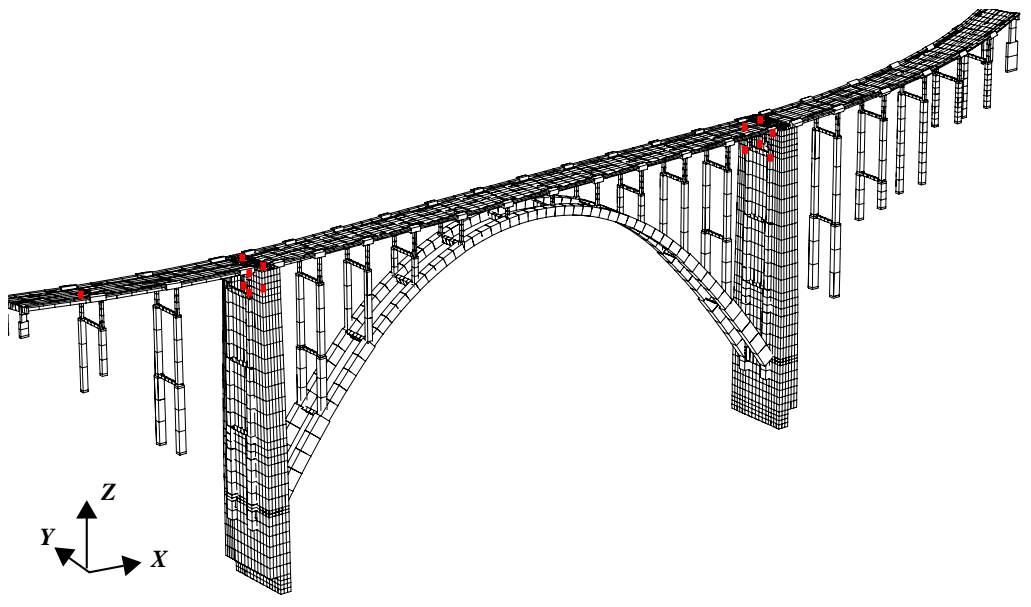

MODEL:

MATERIALLY LINEAR

GEOMETRICALLY NONLINEAR

LOADS: GRAVITY + EQ

$E Q=1.0 x+1.0 y+1.0 z$

JOINT: FLEXIBLE NEAR-FIELD TIME HISTORY

Nonlinear material flexible expansion joints with contact

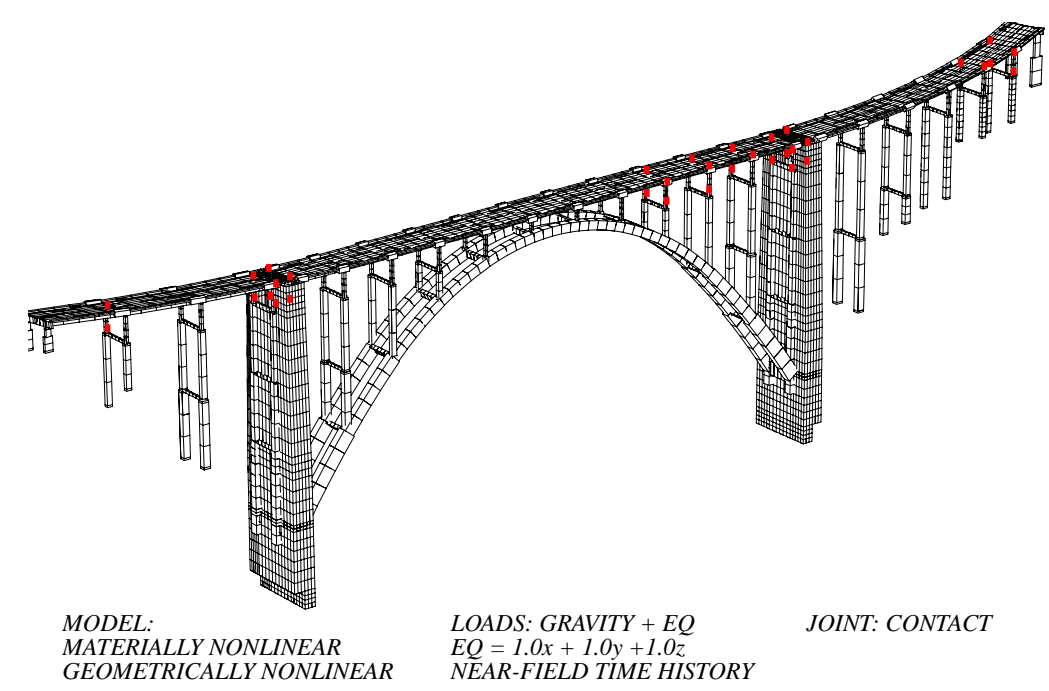

FIGURE 87. Concrete damage zones for near-field motions - locations for which concrete strains exceed 0.005 . 
Linear material flexible expansion joints with no contact

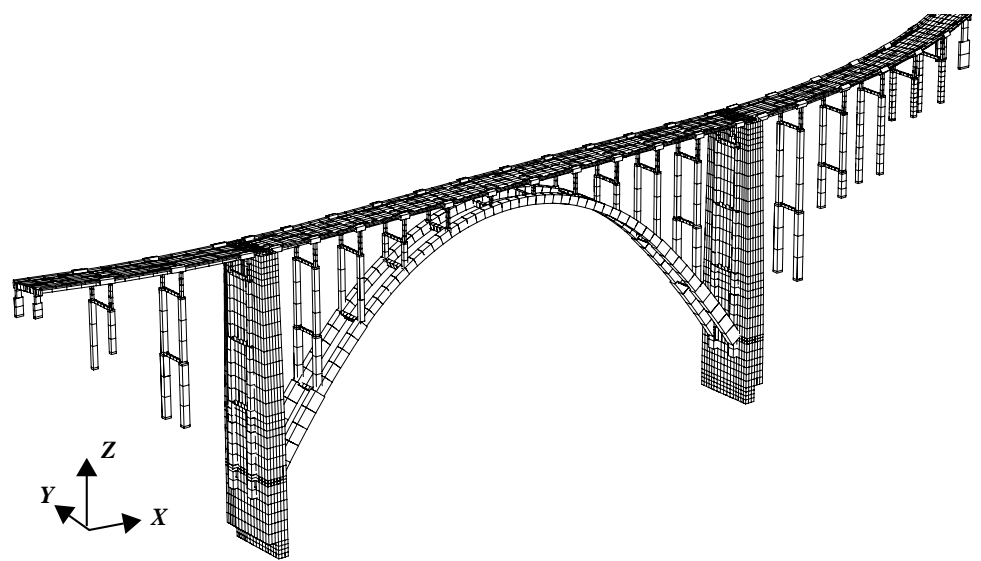

Nonlinear material flexible expansion joints with contact

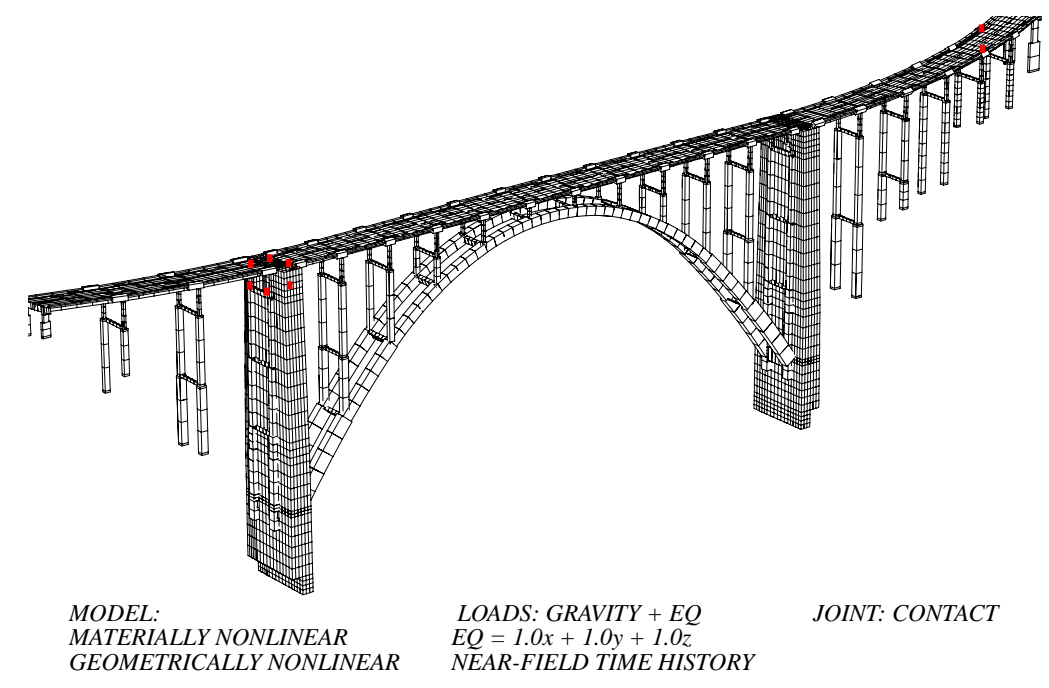

FIGURE 88. Locations for which steel strains exceed 0.014 (10 $\mathrm{x}$ yield strain). 
Linear material

flexible expansion joints with no contact

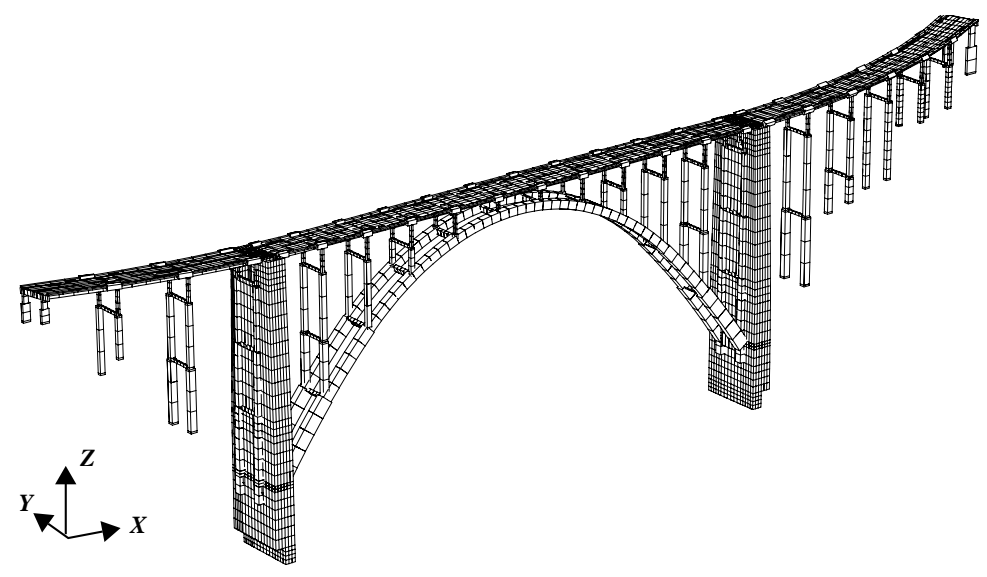
MATERIALLY LINEAR GEOMETRICALLY NONLINEAR
LOADS: GRAVITY +EQ $E Q=1.0 x+1.0 y+1.0 z$ NEAR-FIELD TIME HISTORY
JOINT: FLEXIBLE (NO CONTACT

Nonlinear material flexible expansion joints with contact

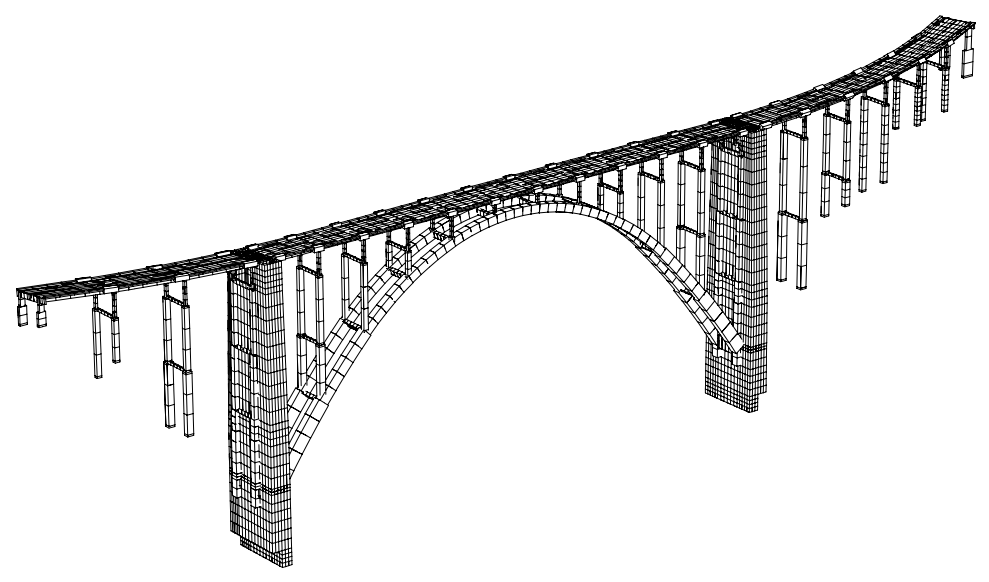

MODEL:

LOADS: GRAVITY + EQ

JOINT: CONTACT

MATERIALLY NONLINEAR GEOMETRICALLY NONLINEAR

(n)



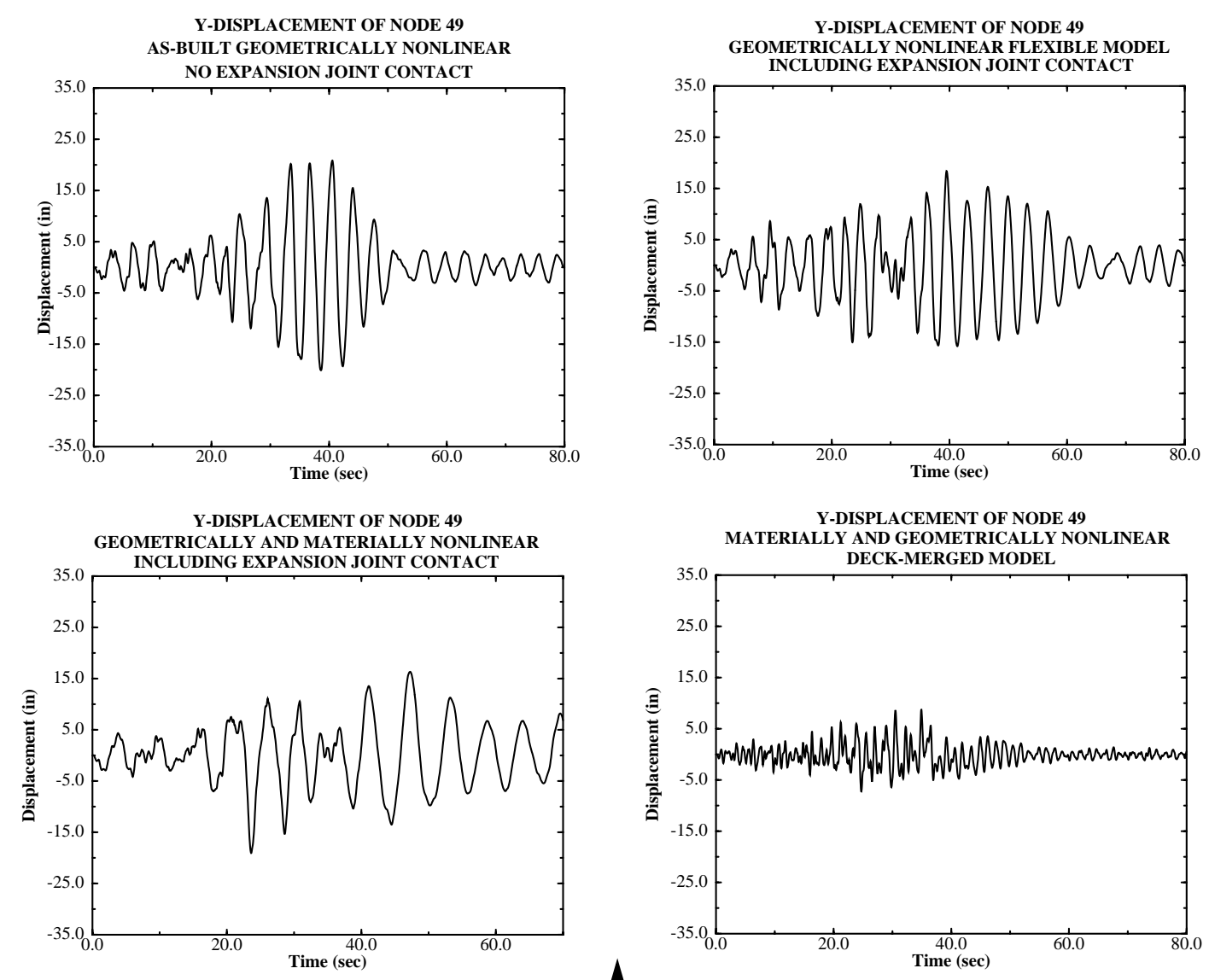

Retrofit design time histories

Near-field time histories

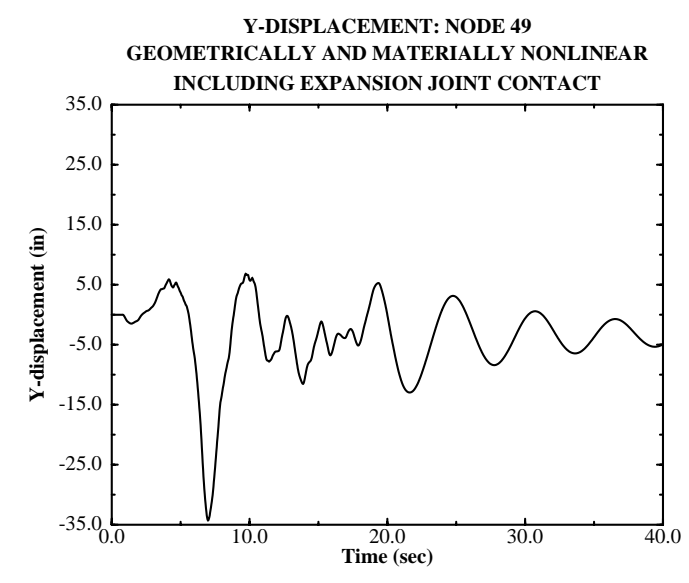

FIGURE 90. Comparison of response with selected models for original retrofit ground motions and Caltrans upgraded motions including near-field effects. 


\subsection{Push-over analysis of the bridge structure}

The transient earthquake response simulations presented in the previous section illustrated the sensitivity of the computed response to specific modeling assumptions and idealizations. Simple static push over simulations can add additional insight into the significance of the manner in which adjacent bridge segments interact across the expansion joints of the structure.

The Bixby Creek model was pushed-over based on a displacement control of specified nodes. Two different types of nodal control were considered. In the first type, displacement control was applied to a single node at the midspan of the deck (Figure 91). This type of single point push-over was similar to the push-over analysis performed by Anatech

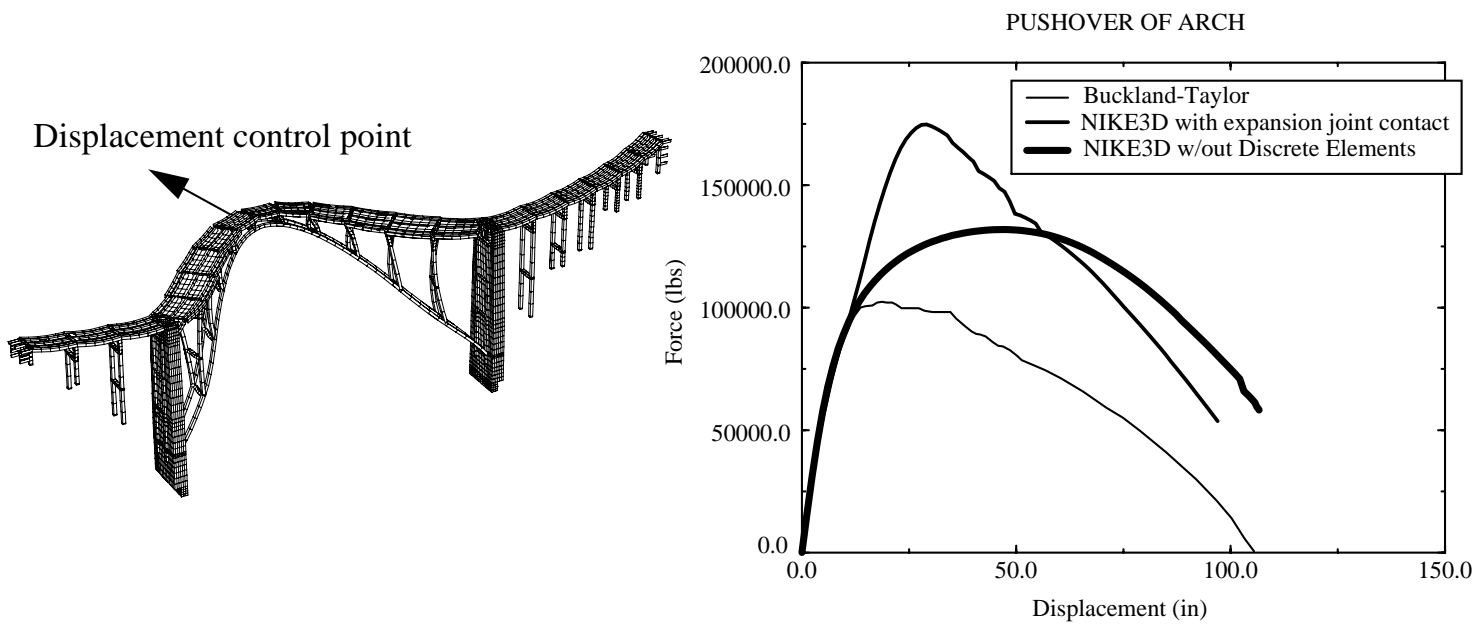

FIGURE 91. Static push-over simulation for control of a single deck point.

in support of the Buckland and Taylor retrofit studies. The Anatech analysis only modeled the arch ribs, the remainder of the structure was represented with a set of discrete springs attached directly to the arch rib model. The LLNL simulation considered the entire threedimensional structure including nonlinear material characterizations. The push-over simulations were performed with and without expansion joint contact as indicated in Figure 91. For all of the push-over analyses computed, the initial slope of the force-displacement curves are in good agreement, indicating that the various models provide a consistent estimation of the small displacement, linear elastic stiffness of the structure. The ultimate strengths of each model, however, are markedly different. The effect of contact at the model expansion joints is quite pronounced in the displacement range of 12 to 30 inches where the contact significantly stiffens the structure and increases the effective ultimate strength. It is noted that both LLNL models provide a higher ultimate effective strength than did the Anatech simulation. This is not surprising since at gross lateral displacements (3-4 feet of transverse deck motion) the parts of the structure connected to the arch ribs undergo large strains and start to constrain the deformations of the ribs to a larger degree than what was represented by Anatech's simple linearized spring idealization.

The effect of expansion joint closure on one side of the bridge as the bridge undergoes transverse displacement can also be seen in the contact forces generated in the discrete 
elements which enforce displacement compatibility at the bridge expansion joints. The individual element contact forces are shown in Figure 92, which indicates that the contact forces are a maximum at midspan and reduce as the towers are approached. In addition, the lag of the contact forces to the transverse displacement is evident in the graph as the initial small gap in the expansion joints must close prior to compressive contact.

The initial push-over simulations were performed with a single point displacement control to emulate the push-over results provided by Anatech. This type of loading is excessively conservative, however, and a push-over simulation which considers a more distributed character of loading is more representative of the type of displacement a bridge will undergo during seismic induced deformation. In order to represent a more distributed type of loading, a displacement field consistent with the fundamental transverse mode of the bridge was applied. The total lateral force applied was obtained by summing the nodal forces at each displacement controlled node. The push-over force displacement relationship which was obtained from this simulation is shown in Figure 93. The distributed dis-

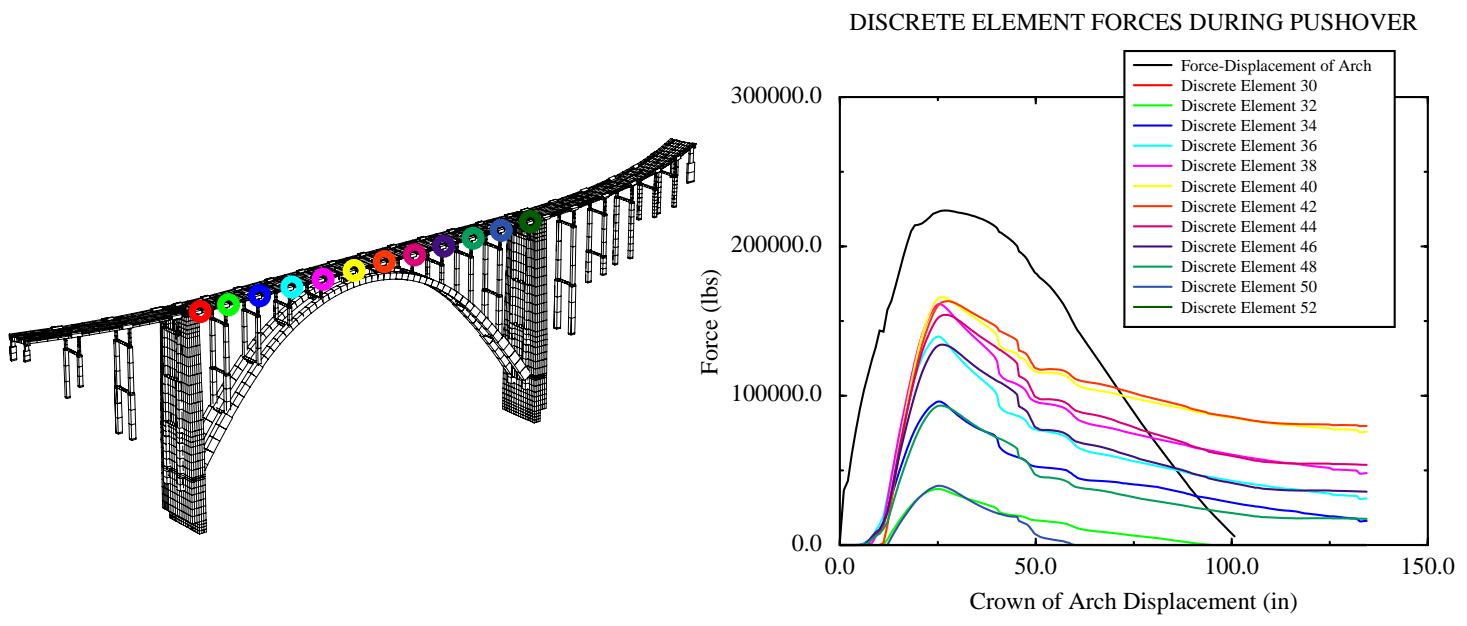

FIGURE 92. Deck contact forces generated by static push-over of the bridge deck.

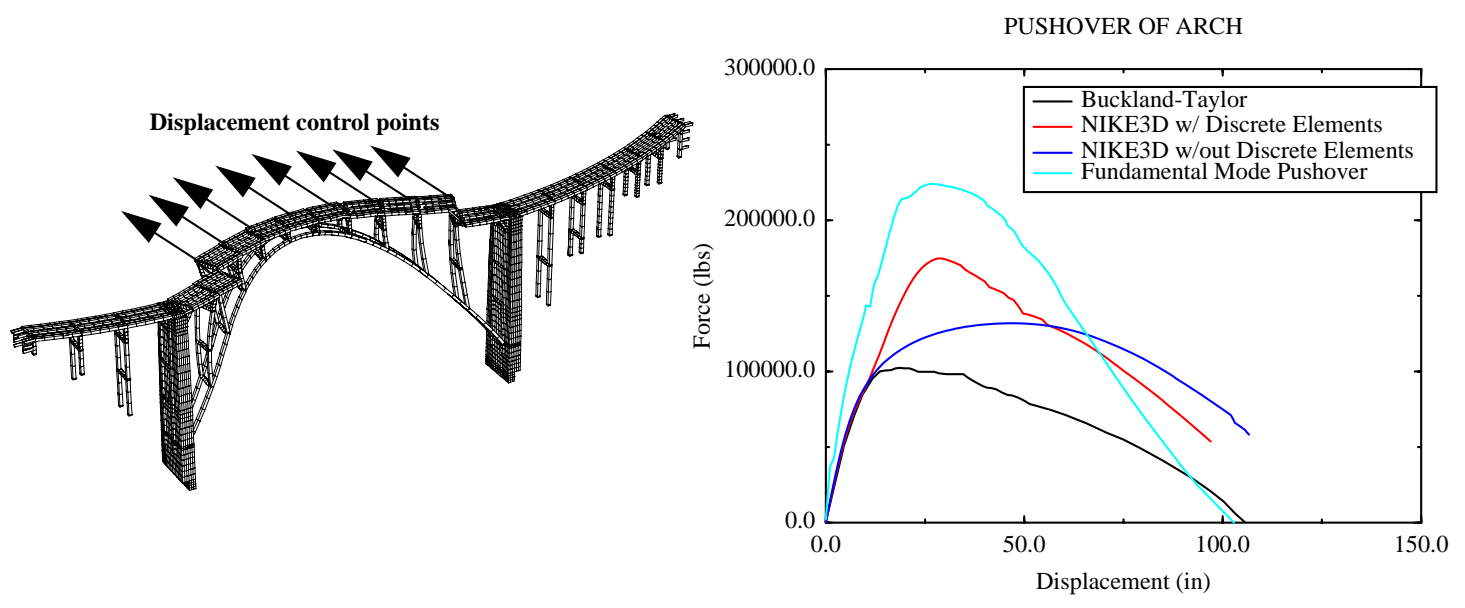

FIGURE 93. Static push-over simulation for control of multiple deck points.

placement push-over indicates a substantially stiffer system, even in the linear range, and 
the effective ultimate strength of the structure is substantially higher than for the single point push-over. This effect is not surprising in that the distributed nature of the loading results in less localization of yielding and cracking in the structure, thus allowing more of the structure to absorb energy as the structure is pushed into the nonlinear regime. It is noted that the ultimate strength of the structure with contacting joints and a distributed loading is substantially higher than the strength obtained by Anatech for a simple single point push of the isolated arch ribs. 


\subsection{Nonlinear finite element simulation model of the retrofit Bixby Creek Bridge structure}

The seismic retrofit scheme developed by Buckland and Taylor for the Bixby Creek Bridge consists of extensive structural modifications with resulting fundamental changes in the structural behavior and load paths of the bridge. The underlying retrofit methodology consists of tying the deck together across the bridge expansion joints to ensure that the deck provides lateral load resistance through in-plane deep beam bending. The technique used to achieve this includes the addition of post-tensioning cables and steel rods which run the length of the deck and are anchored into large floating mass abutments at the end of the bridge as indicated in Figure 94. The existing expansion joints are filled with grout and the cables are post-tensioned to effectively place the deck in compression and clamp the entire deck together from end to end. The floating masses consist of large concrete blocks which can slide longitudinally and laterally through small amplitude motions before engaging the new pile caps and massive piles. The deck system is stiffened by the addition of new longitudinally running edge beams. At the top of the arch ribs, lateral concrete shear panels will be added transverse to the deck to assist lateral load transfer between the deck and the arch ribs and guard against failure of the short, stiff columns at the crown of the arch. The retrofit design includes internal strengthening of the towers by the addition of concrete ribs and the addition of a vertical shear panel in the tower internal void. The design also calls for the addition of vertical post-tensioning cables to anchor the towers vertically into the supporting bedrock (see Figure 94). Because of the large size of the Bixby Creek Bridge, the proposed retrofit scheme entails a significant amount of construction. The underlying retrofit design concept, which ensures that the deck acts as a continuous structural member which can transfer structural loads to the towers and abutment, which are in turn strengthened to take the loads, is actually a common retrofit concept for many arch bridges. As documented in Appendix A, the retrofit for other arch bridges similarly assure this type of load path between the deck and abutment is achieved. The uniqueness of the Bixby Creek retrofit lies in the manner in which the deck continuity is ensured via a system of post-tensioning cables and rods.

A nonlinear finite element model has been constructed to represent the retrofit structure model as shown in Figure 95. The static, gravity load initialization of the nonlinear retrofit model was significantly more complex than the initialization of the as-built structure. The model initialization had to ensure that the appropriate gravity forces were placed on the model and the post-tensioning cables in the model had to have the appropriate tensions at the end of the initialization. It was also necessary for the model to end the static initialization phase with floating foundation masses at the appropriate seating location with the correct expansion gaps between the floating mass and pile cap in both the transverse and longitudinal directions of the bridge. A three step model initialization process was implemented to achieve these initial conditions as shown in Figure 96. The first step entailed nonlinear equilibrium iterations to apply the gravity loads, the second step consisted of application of fictitious thermal loads to the post-tensioning members. The post tensioning step required two or three iterations on the users part since the deck post-tensioning stresses are dependent on the deformations of the deck system. It was found that in practice, the post-tensioning forces converged to the correct values quite rapidly. The third and final step was the adjustment of the force-deflection curve of the discrete elements at the 


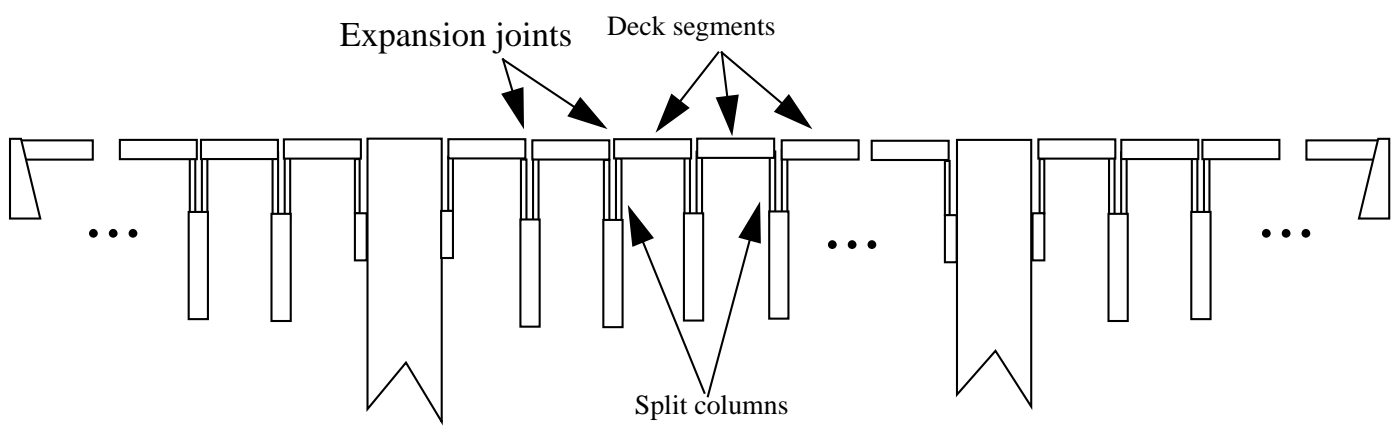

(a)

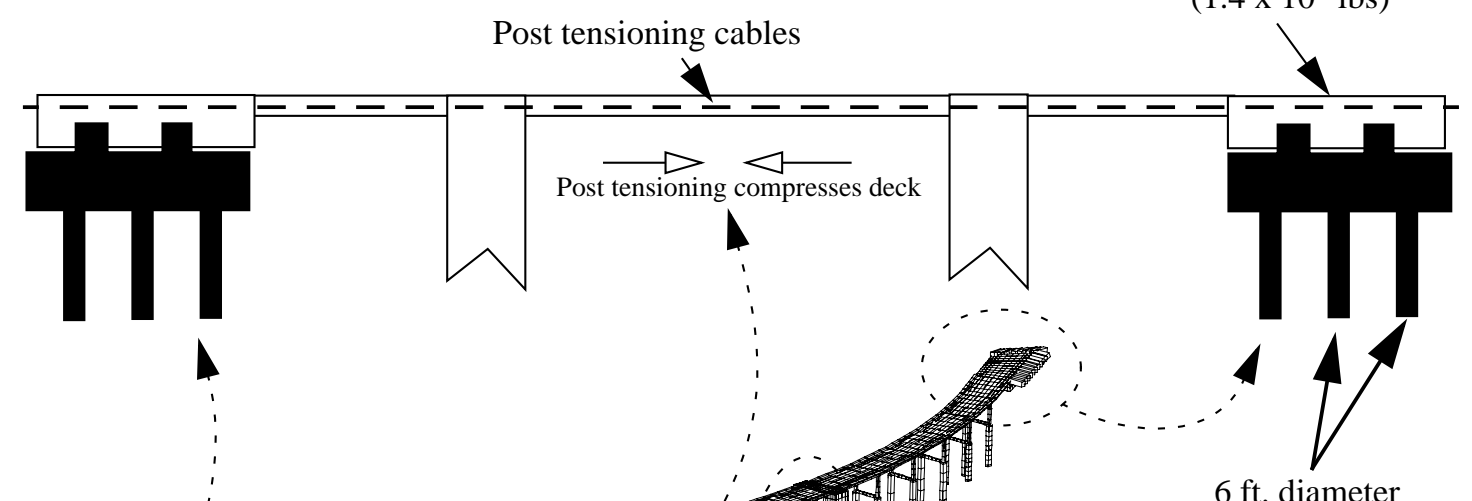
Cast in drilled hole concrete piles (6)

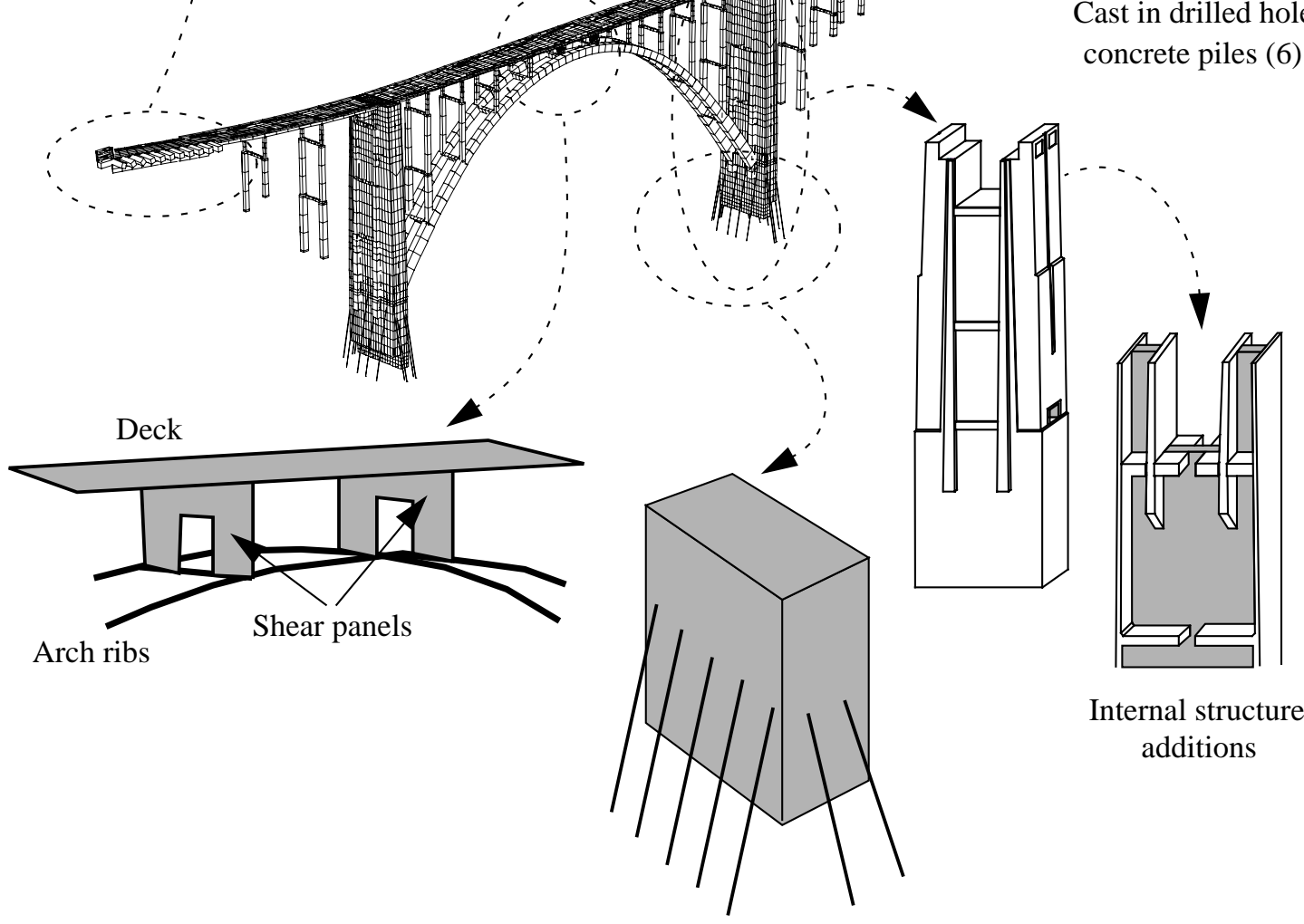

(b)

Tower tie-downs

FIGURE 94. Retrofit design concept for the Bixby Creek Bridge. a) As-built deck system; b) retrofit additions. 

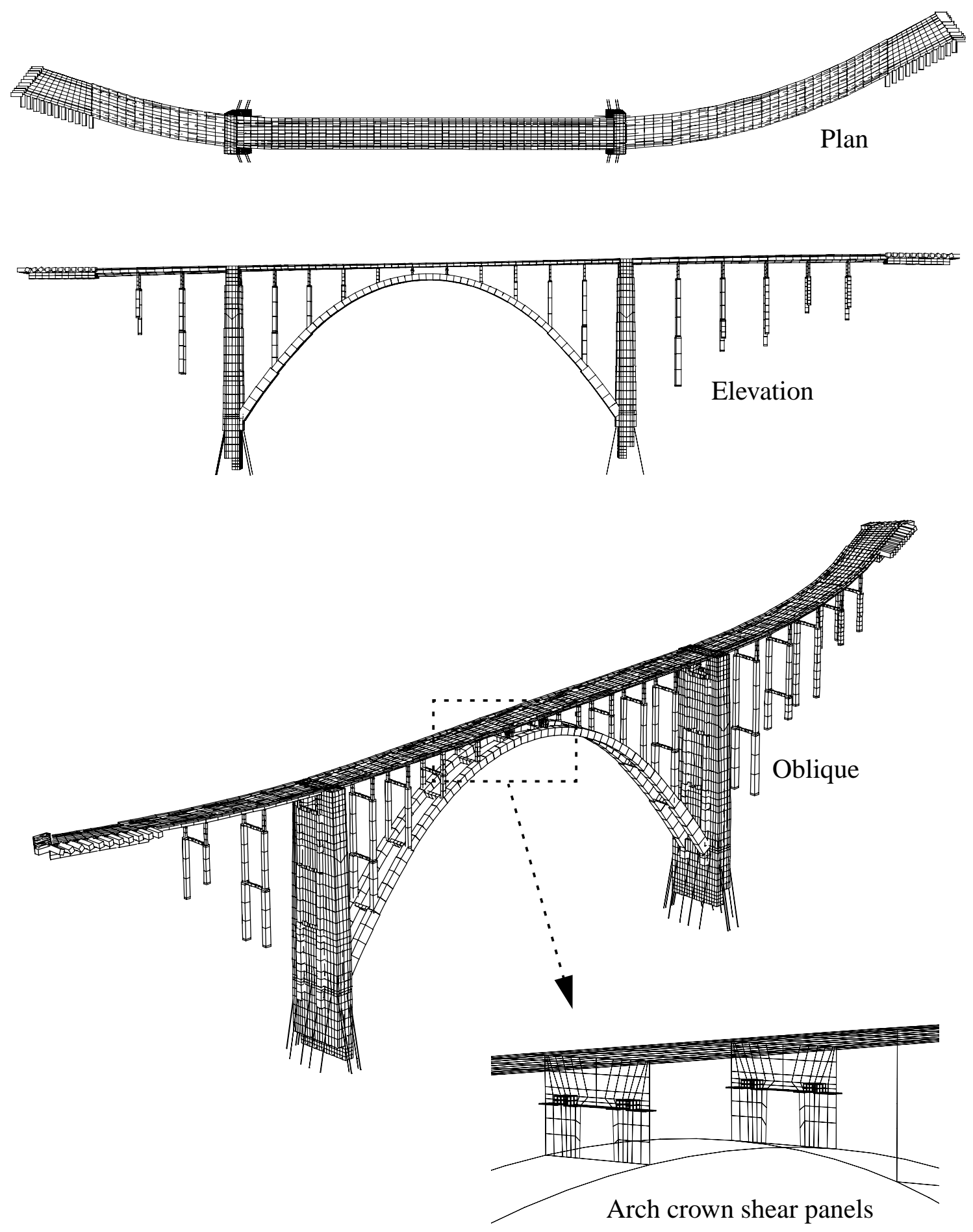

FIGURE 95. Three dimensional NIKE3D model of the retrofit Bixby Creek Bridge structure.

abutments to set the appropriate gaps between the floating masses and the pile caps. This last adjustment accounted for the displacements of the floating masses which occur during the gravity and post-tensioning steps. 
Similar to the as-built structure, once the appropriate gravity initialization was completed, the transient seismic analysis was performed with the retrofit model. This included writing to storage all of the fiber element's strains to allow post processing of the three dimensional strain field of the model at each instant of time.

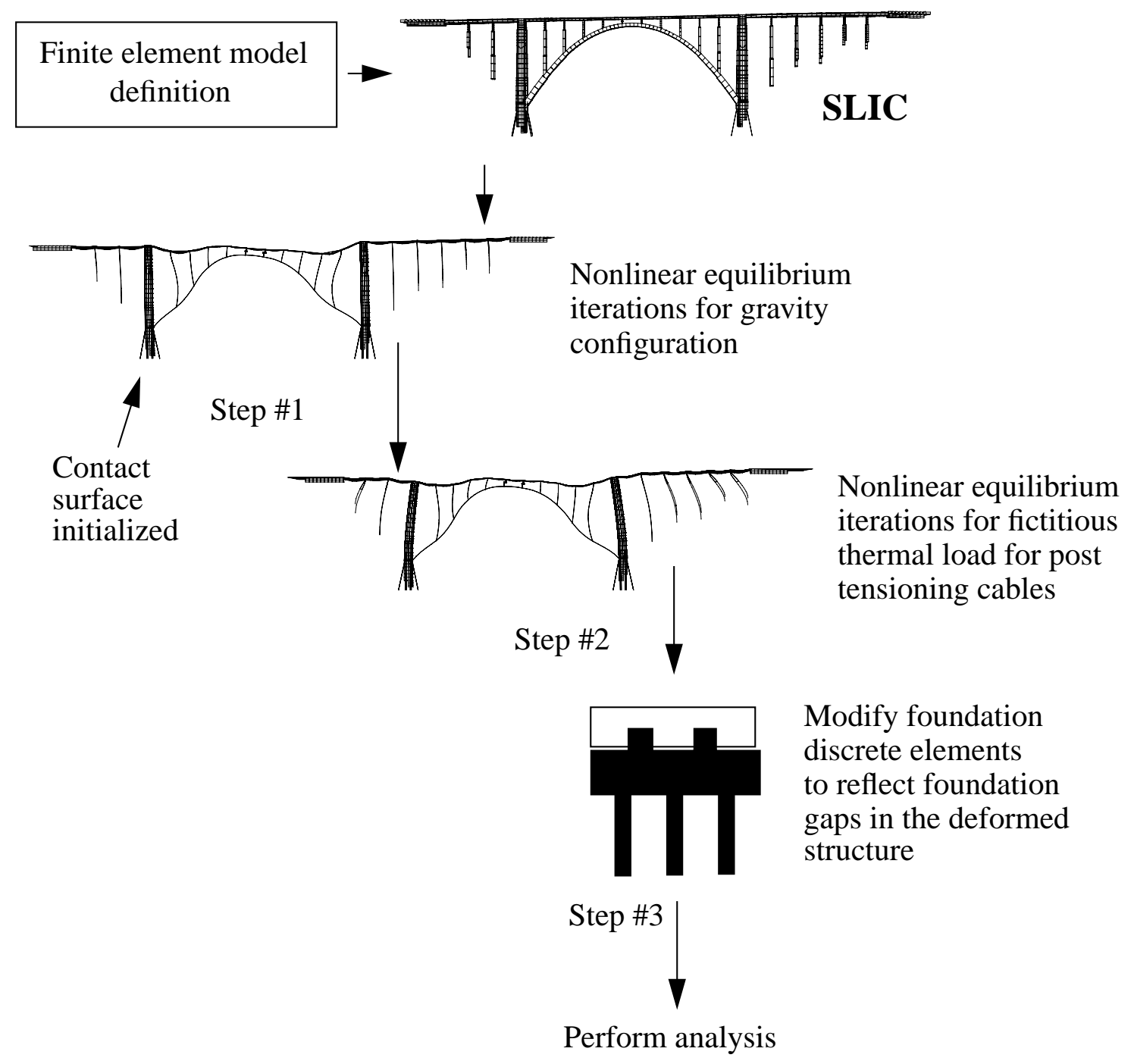

FIGURE 96. Model initialization sequence for the retrofit model.

The effective stiffness provided by the pile cap and piles was estimated with a detailed three dimensional model of the foundation system (Figure 97). The three dimensional model of the foundation was initialized first with gravity loading, and the foundation was then pushed horizontally to estimate the effective spring constants of the foundation system. Once the effective spring constants were determined, discrete elements were applied around the floating masses in the global model to represent the foundation compliance. The effective spring stiffness employed by Buckland and Taylor in the retrofit structure design and the effective spring stiffness determined by LLNL's model are summarized in 

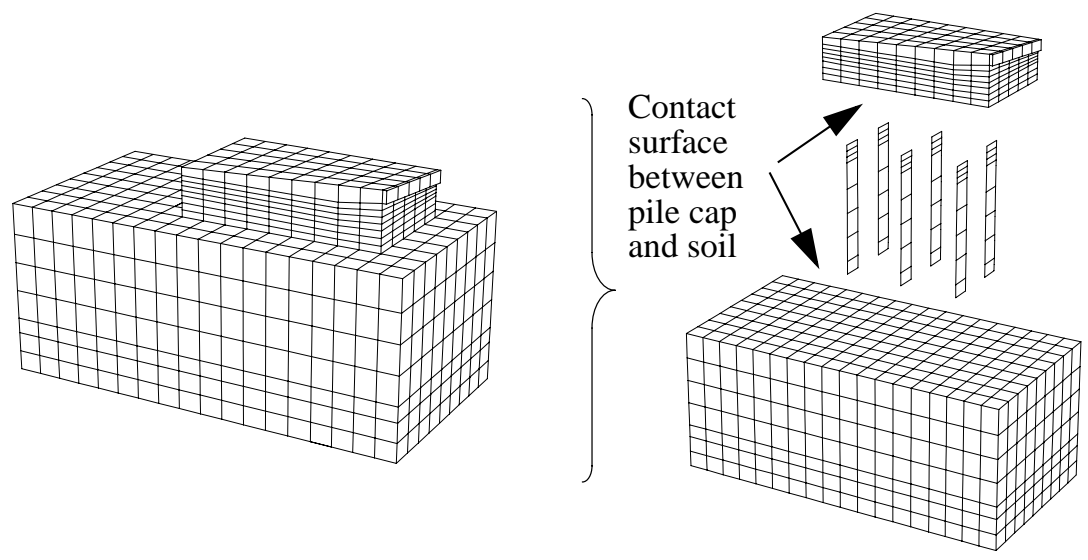

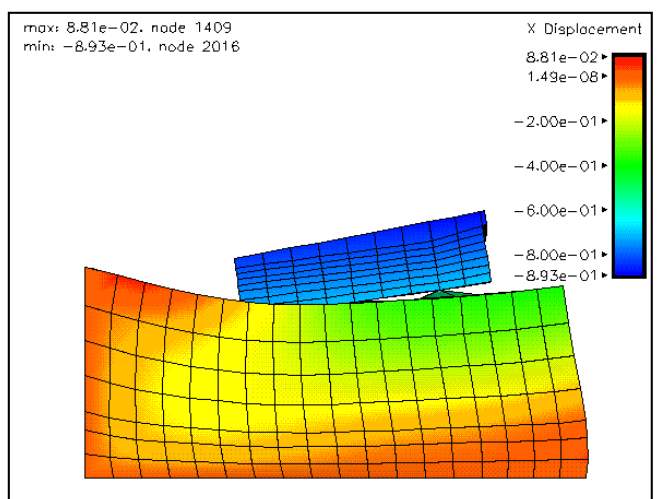

Effective foundation stiffnesses found from loading of detailed model

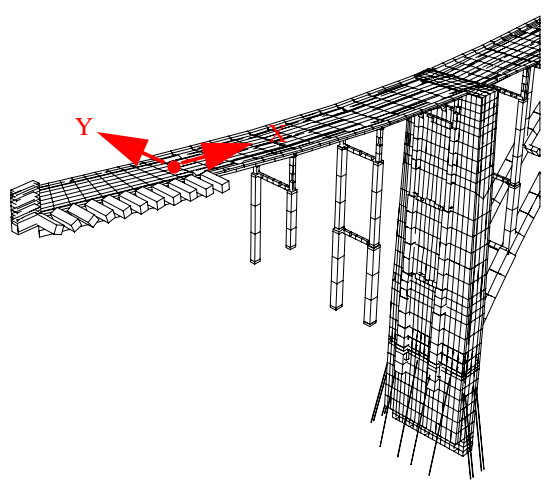

Foundation springs distributed to floating masses

FIGURE 97. Detailed model of retrofit foundation.

Table 15 and Table 16. The effective soil modulus assumed in the LLNL simulation model was approximately 10,000 psi.

Table 15: Foundation stiffnesses used in global model (Buckland and Taylor).

\begin{tabular}{|c|c|c|}
\hline \multirow{2}{*}{ Location } & $\mathbf{K}_{\mathbf{x}}$ & $\mathbf{K}_{\mathbf{y}}$ \\
\cline { 2 - 3 } & \multicolumn{2}{|c|}{ kips / foot } \\
\hline South Abut. & 33600 & 50400 \\
\hline North Abut. & 33600 & 54000 \\
\hline
\end{tabular}

Table 16: Foundation stiffnesses used in detailed model (LLNL).

\begin{tabular}{|c|c|c|}
\hline \multirow{2}{*}{ Location } & $\mathbf{K}_{\mathbf{x}}$ & $\mathbf{K}_{\mathbf{y}}$ \\
\cline { 2 - 3 } & \multicolumn{2}{|c|}{ kips / foot } \\
\hline South Abut. & 33613 & 26844 \\
\hline North Abut. & 33613 & 26844 \\
\hline
\end{tabular}




\subsection{Natural modeshapes and frequencies of the retrofit bridge system}

The determination of the natural modeshapes and frequencies of the retrofit system required the appropriate initialization of the model for gravity loads and cable post tensioning. The eigensolution procedure outlined in Figure 98 was employed to ensure appropriate model initialization. The computed natural modeshapes and frequencies of the first six modes of the retrofit structure model are shown in Figure 99 and Figure 100. The

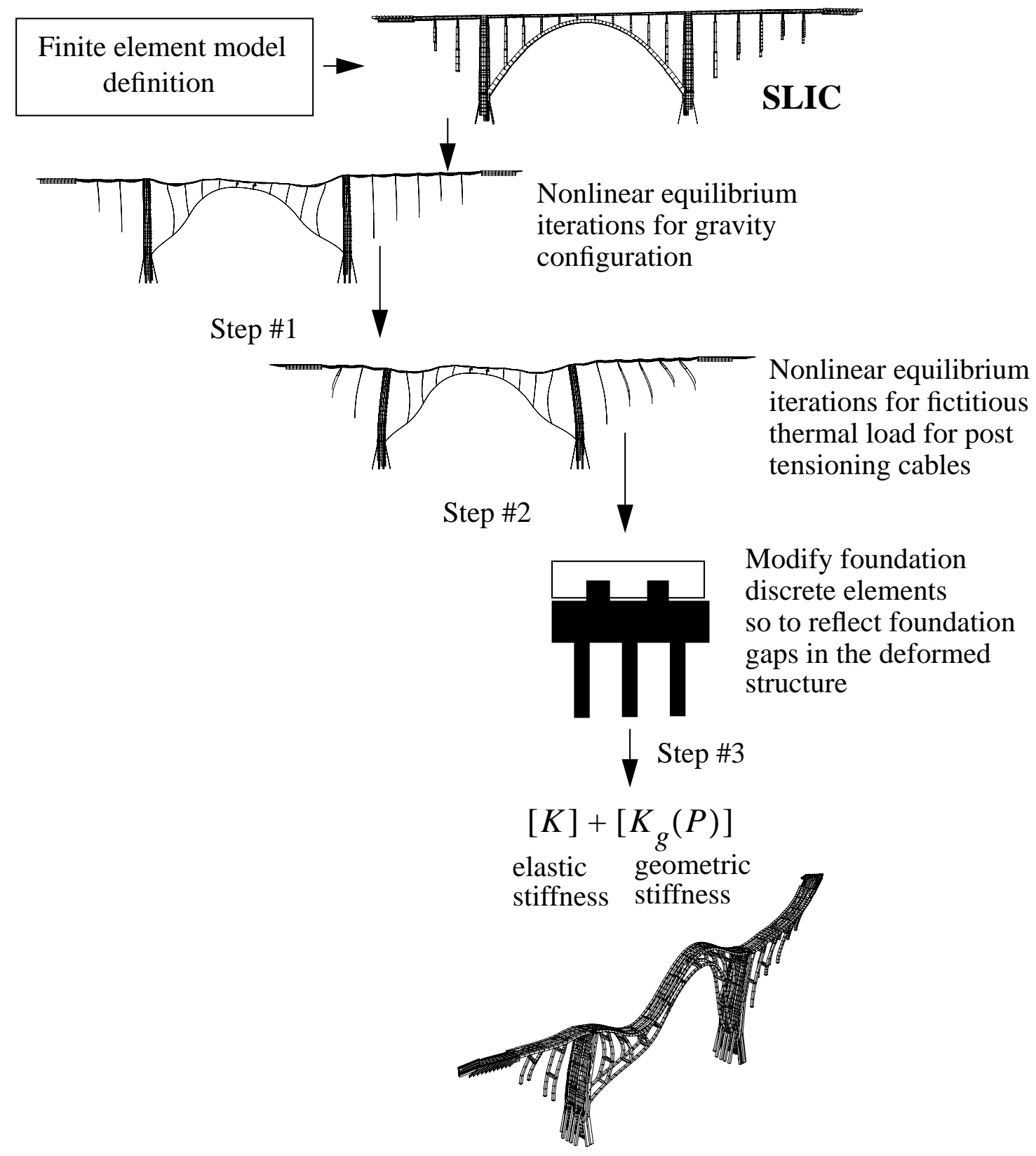

Eigensolution

FIGURE 98. Computation of the retrofit model natural frequencies. 

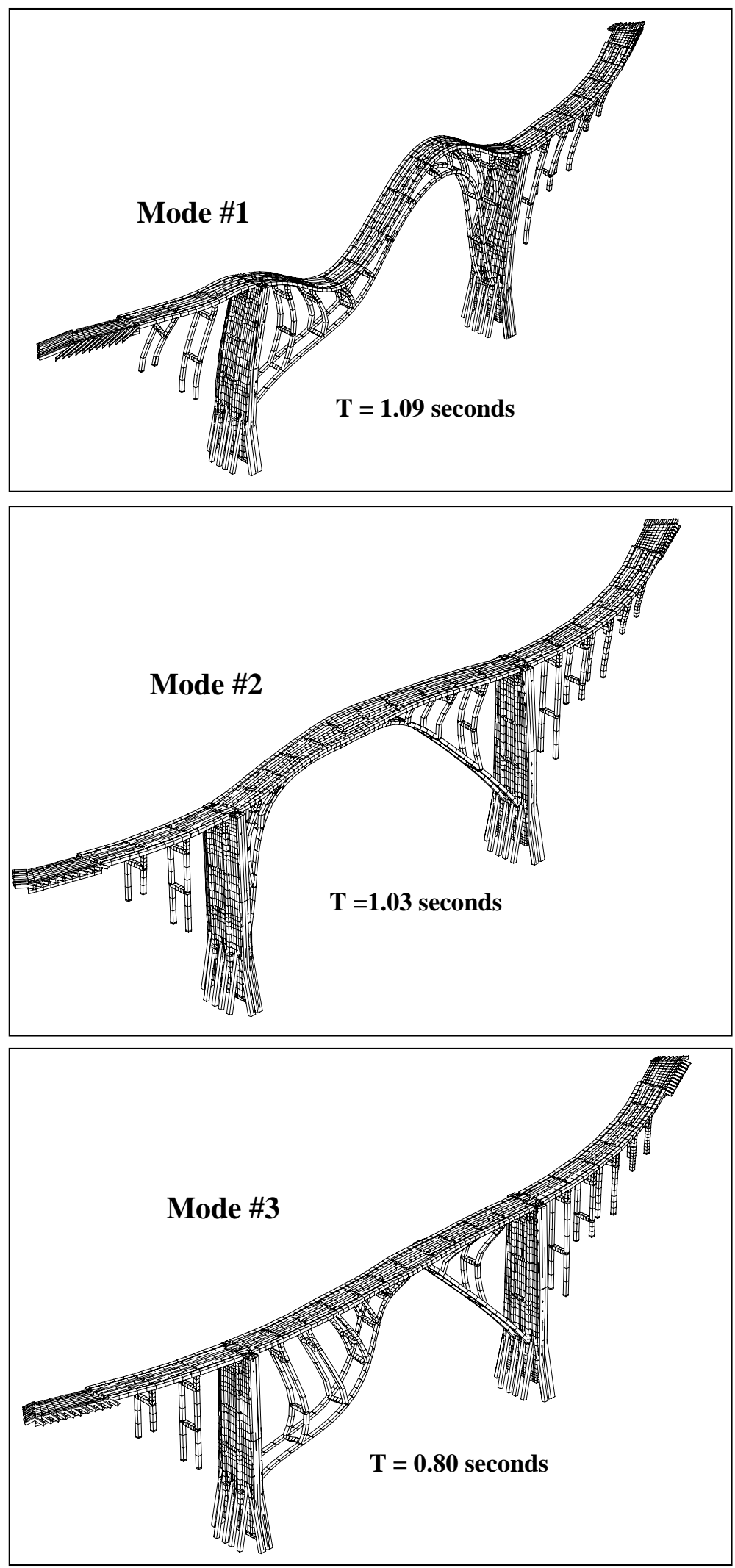

FIGURE 99. Modes 1-3 of the retrofit structure. 
natural vibration characteristics of the retrofit model were essentially identical for both linear elastic and nonlinear materials. Thus, only one set of natural modes is shown. As expected, the retrofit structure is substantially stiffer than the as-built structure. The grouting of the expansion joints and post-tensioning of the deck system allows the deck to act as a continuous structural member, with a corresponding dramatic increase in stiffness of the structural system. 

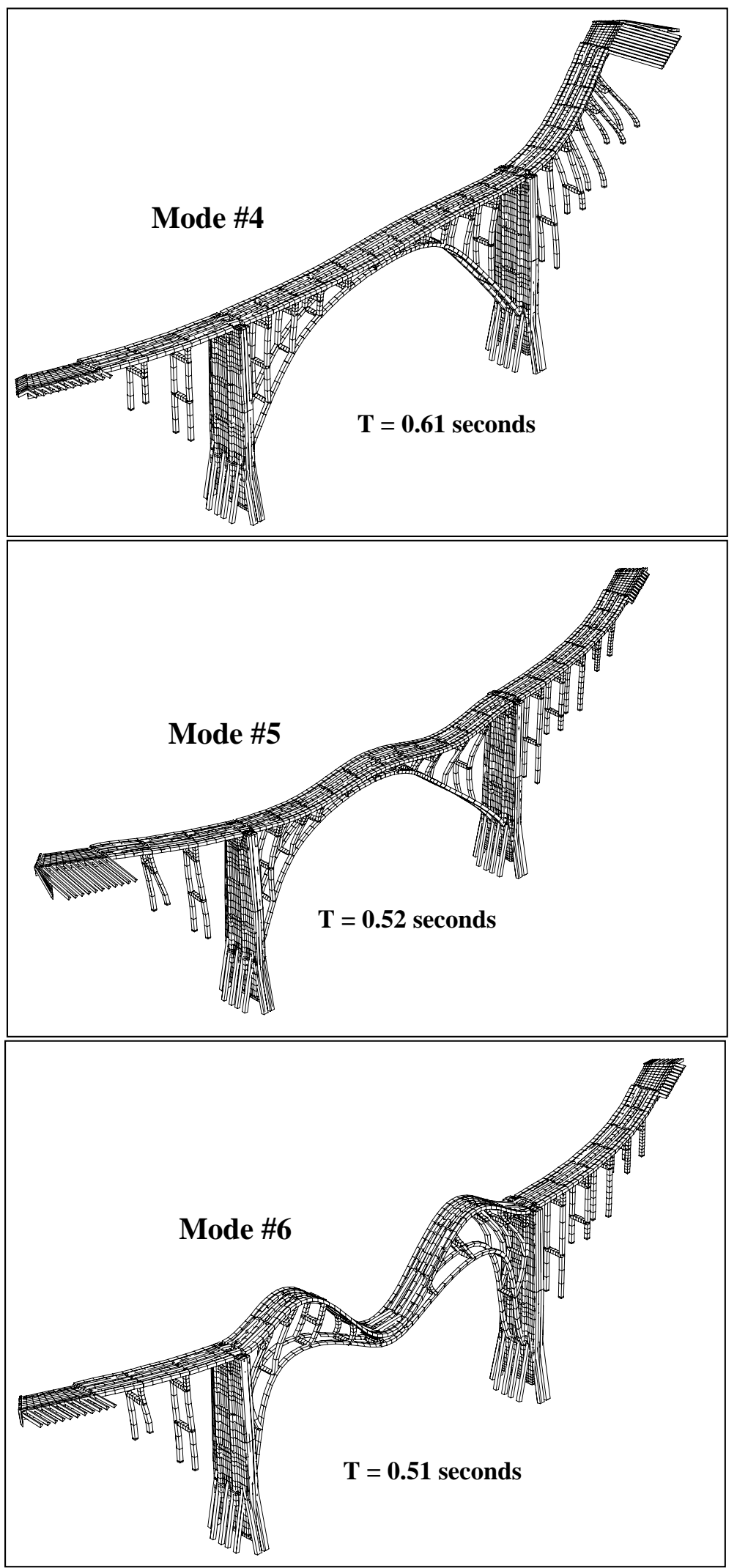

FIGURE 100. Modes 4-6 of the retrofit structure. 


\subsection{Transient response of the retrofit structure to Caltrans design earthquake motions}

The model initialization sequence for transient analysis with the retrofit model is illustrated in Figure 101. Similar to the as-built model, the seismic analysis consisted of saving time histories of strain values of steel and concrete sections throughout the earthquake time histories and comparing these values to specified allowables.

\subsection{Transient response of the retrofit model with linear and nonlinear materials (Seed and Idriss time histories)}

The displacement time histories computed from the retrofit model for the Seed and Idriss ground motion time histories are shown in Figure 102 and Figure 103 for the cases of linear and nonlinear materials respectively. When compared with time histories from the asbuilt structure, the time histories clearly indicate the significant increase in system stiffness with a corresponding dramatic decrease in displacements. The waveforms for the retrofit structure exhibit considerably higher frequency content. The effects of material nonlinearities are also less pronounced for the retrofit structure than for the as-built structure. For the as-built structure, inclusion of expansion joint contact and material nonlinearities resulted in substantial changes in the model response in terms of both amplitude and frequency content. The retrofit structure is less sensitive to material nonlinearities. This is not unexpected since the deck has become a major structural element in the retrofit structure and the deck system is less susceptible to significant inelastic action than is the substructure of the bridge. The response of the retrofit structure was also checked for the case in which the strong component of earthquake motion is applied in the longitudinal direction of the bridge (Figure 104). As might be expected, this results in a slight increase in longitudinal displacements but a decrease in transverse displacements.

\subsection{Member strains and demand-to-capacity ratios (Seed and Idriss time histories)}

The member strain values obtained from the retrofit model are summarized in Figure 105 and Figure 106. The steel strain values are lower than the Caltrans specified maximum strain (0.12) throughout the structure. There is, however, still significant steel yielding at many locations in the substructure. The concrete strains exceed the Caltrans specified maximum (0.005) in a small region near the crown of the arch and at the deck-tower connection. This indicates some localized crushing is still possible in the retrofit structure near the crown and at these locations.

\subsection{Shear demand-to-capacity check for the retrofit structure (Seed and Idriss time histories)}

The members for which the ACI codified shear allowables were exceeded are shown in Figure 107. Compared with the unretrofit structure, the regions of potential shear failure 

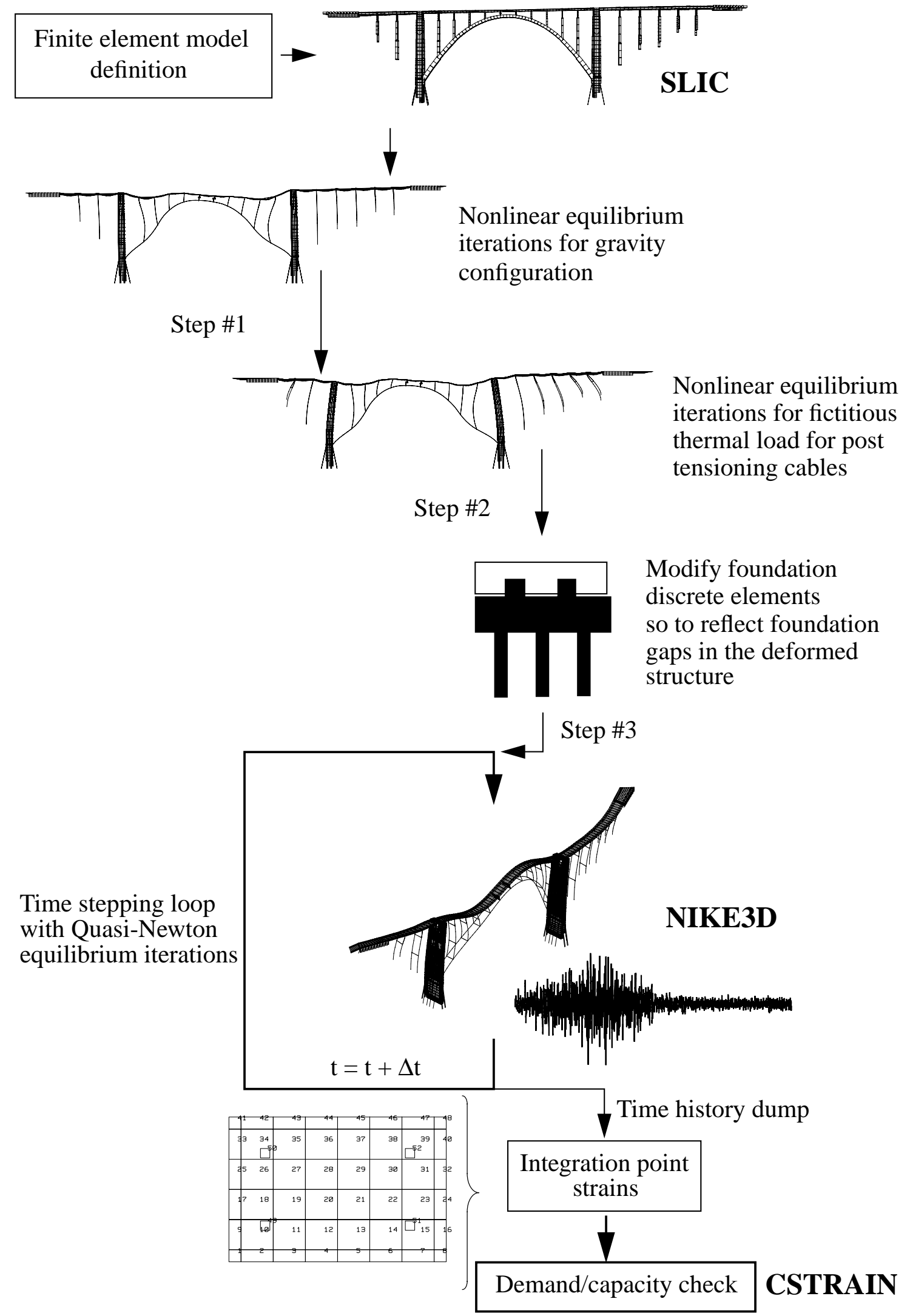

FIGURE 101. Transient analysis procedure for earthquake loading (retrofit model). 

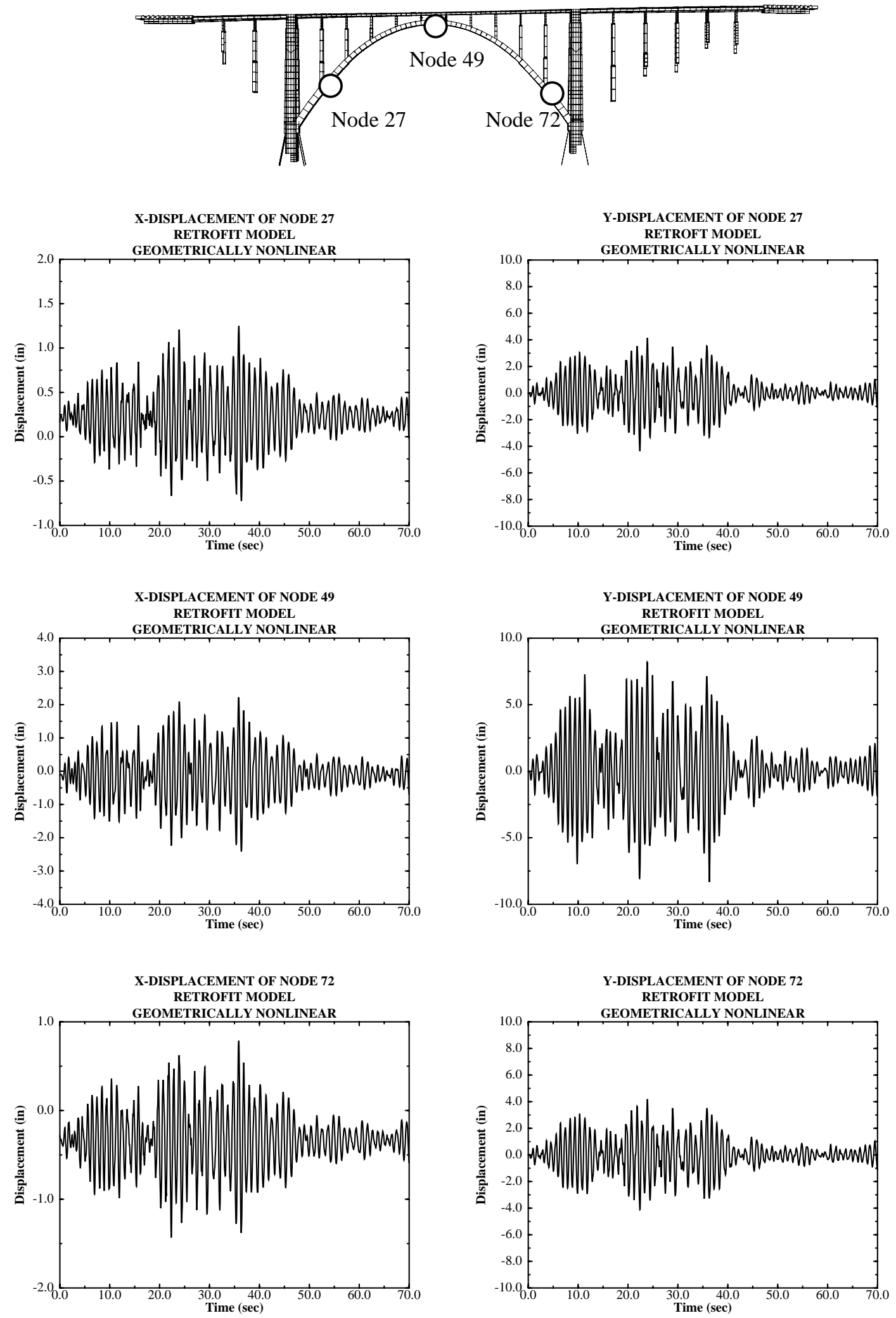

FIGURE 102. Displacement time histories for selected nodes; model based on linear material, geometrically nonlinear; Seed \& Idriss time histories $(E Q=0.3 x+1.0 y+0.3 z)$. 

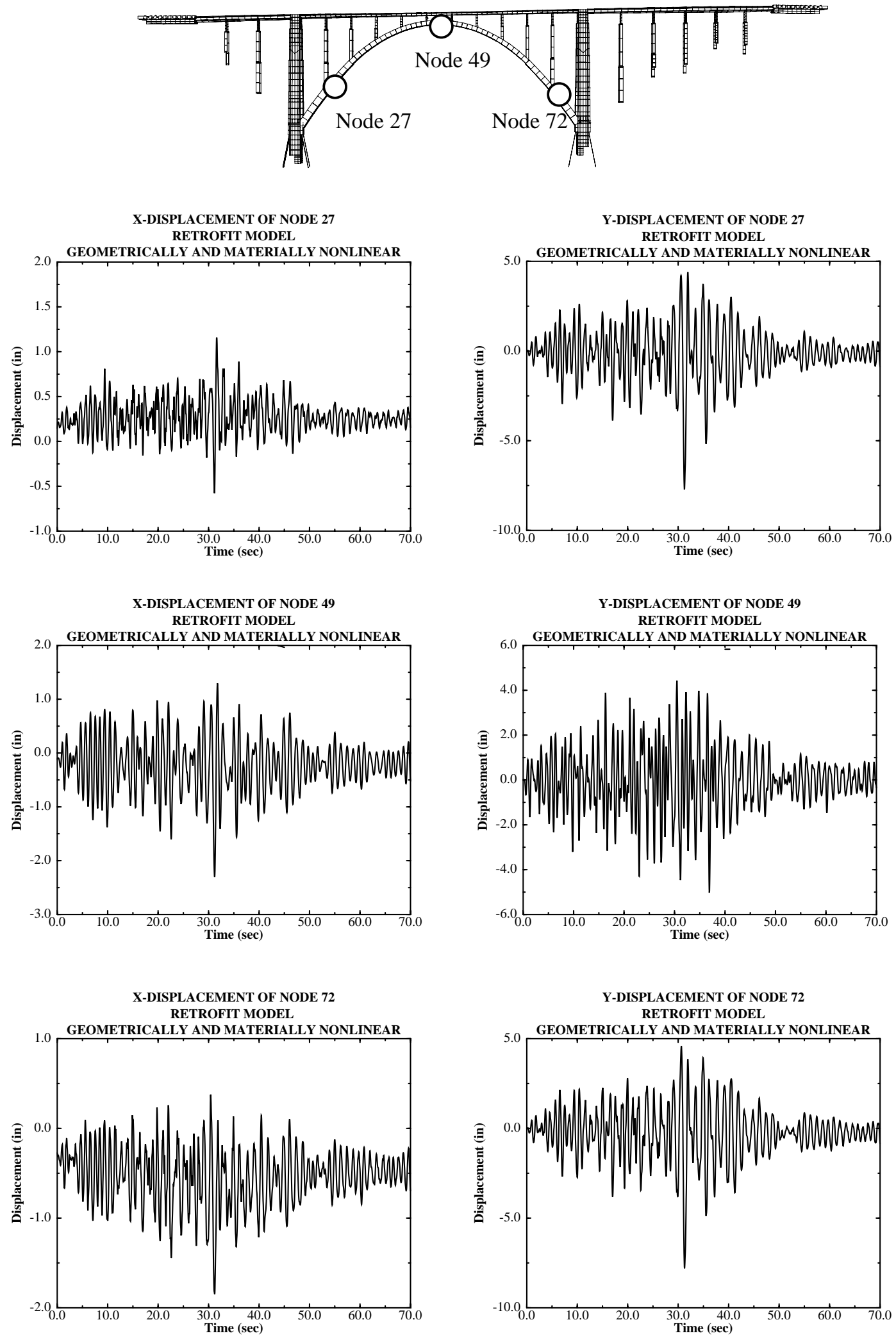

FIGURE 103. Displacement time histories for selected nodes; model based on nonlinear material, geometrically nonlinear; Seed \& Idriss time histories $(E Q=0.3 x+1.0 y+0.3 z)$. 

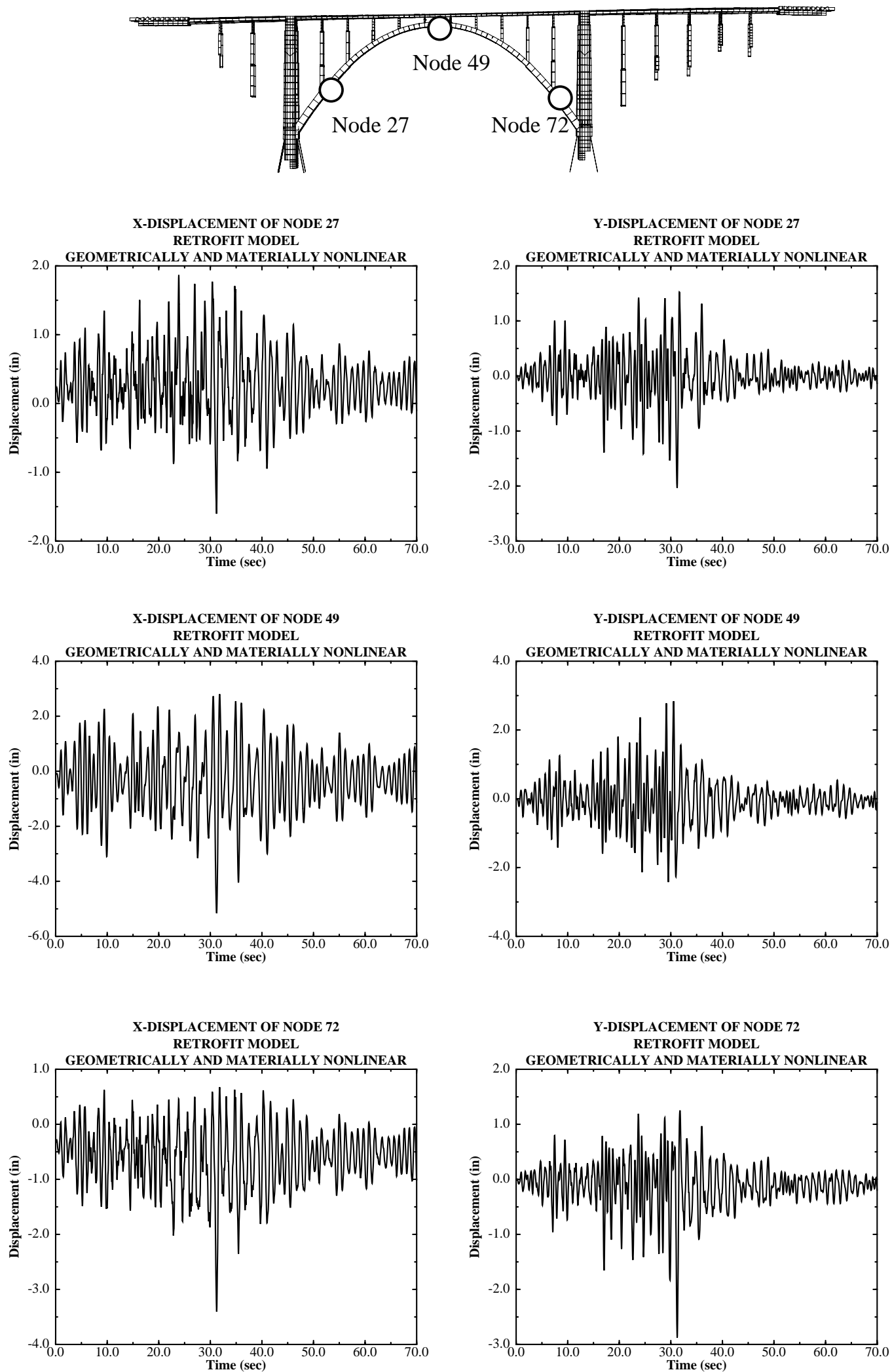

FIGURE 104. Displacement time histories for selected nodes; model based on nonlinear material, geometrically nonlinear; Seed \& Idriss time histories $(\mathrm{EQ}=1.0 \mathrm{x}+0.3 \mathrm{y}+\mathbf{0 . 3 z})$. 
Concrete $>0.003$ strains

Concrete $>0.005$ strains

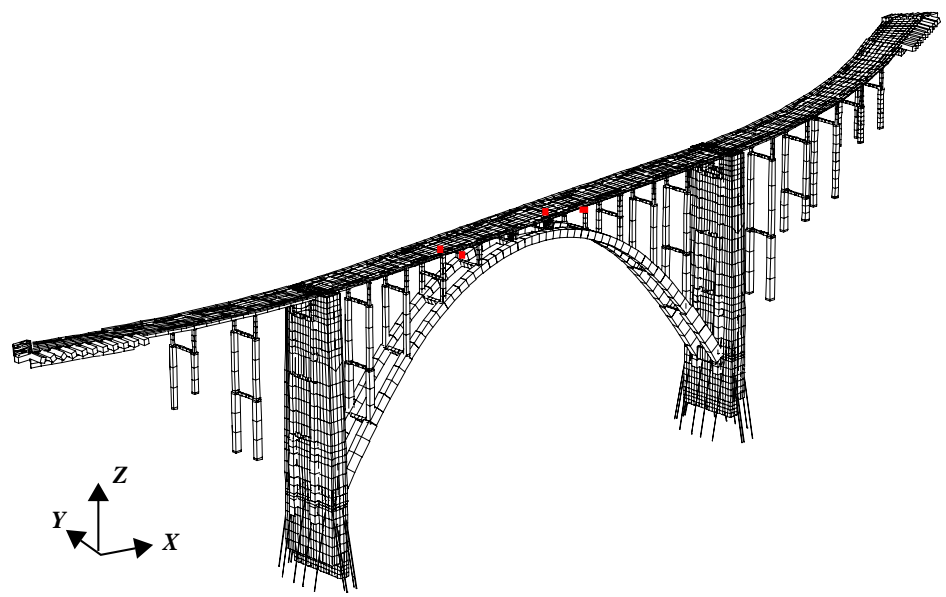

MODEL:

MATERIALLY NONLINEAR

LOADS: GRAVITY $+E Q \quad$ JOINT: N/A GEOMETRICALLY NONLINEAR

$E Q=0.3 x+1.0 y+0.3 z$

SEED \& IDRISS TIME HISTORY

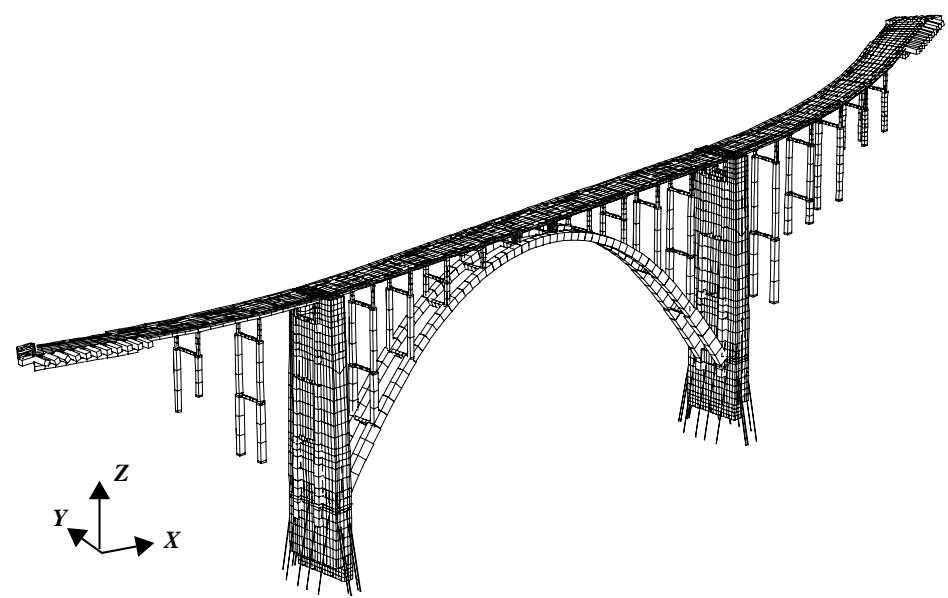

MODEL:

MATERIALLY NONLINEAR

LOADS: GRAVITY +EQ
$E Q=0.3 x+1.0 y+0.3 z$

JOINT: N/A

GEOMETRICALLY NONLINEAR SEED \& IDRISS TIME HISTORY

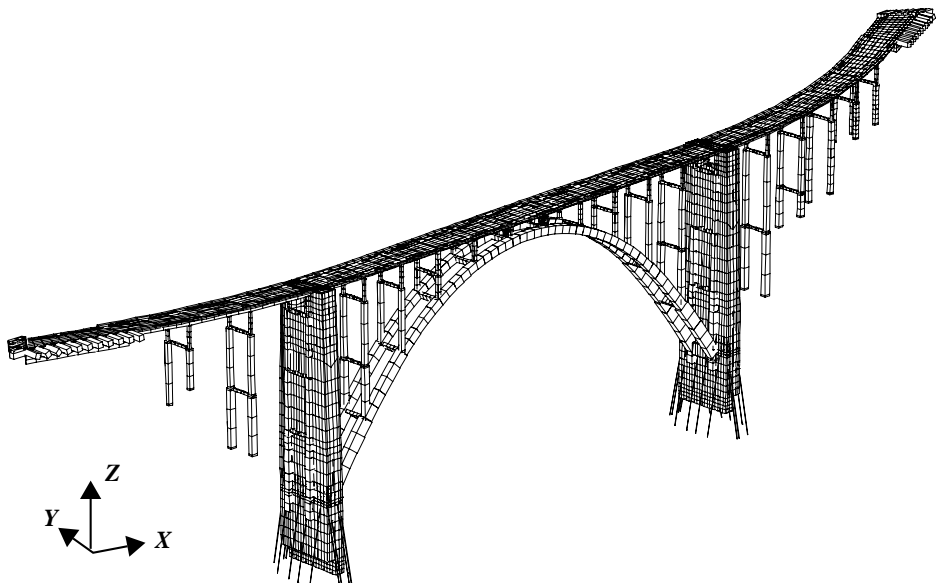

MODEL:

LOADS: GRAVITY + EQ

JOINT: N/A

MATERIALLY NONLINEAR

$E Q=0.3 x+1.0 y+0.3 z$

SEED \& IDRISS TIME HISTORY

FIGURE 105. Concrete and steel strains for the retrofit structure (Seed and Idriss ground motions). 
Steel $>0.014$

strains

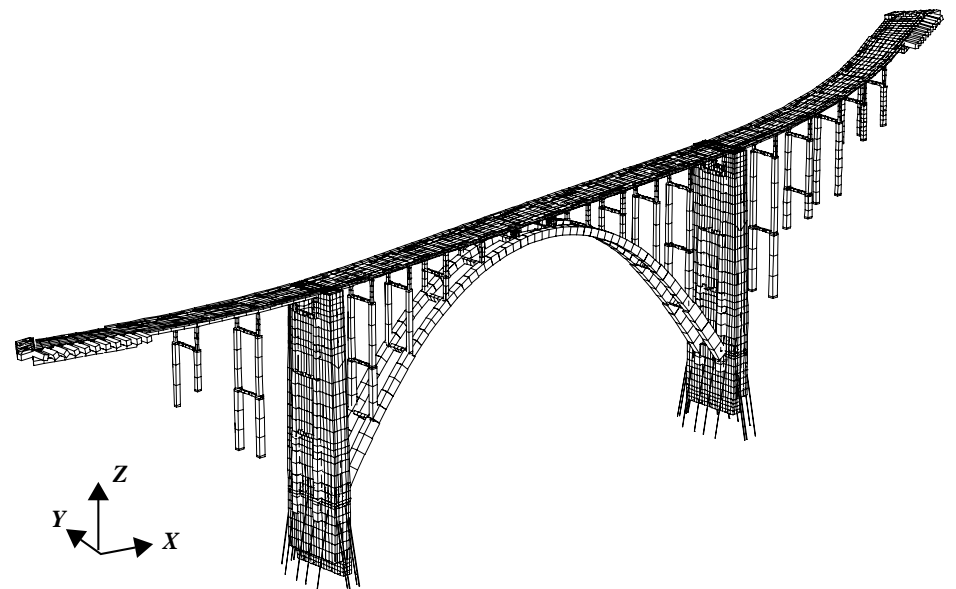

MODEL:

MATERIALLY NONLINEAR

LOADS: GRAVITY +EQ

$E Q=0.3 x+1.0 y+0.3 z$

JOINT: N/A

GEOMETRICALLY NONLINEAR

Steel $>0.0014$

strains

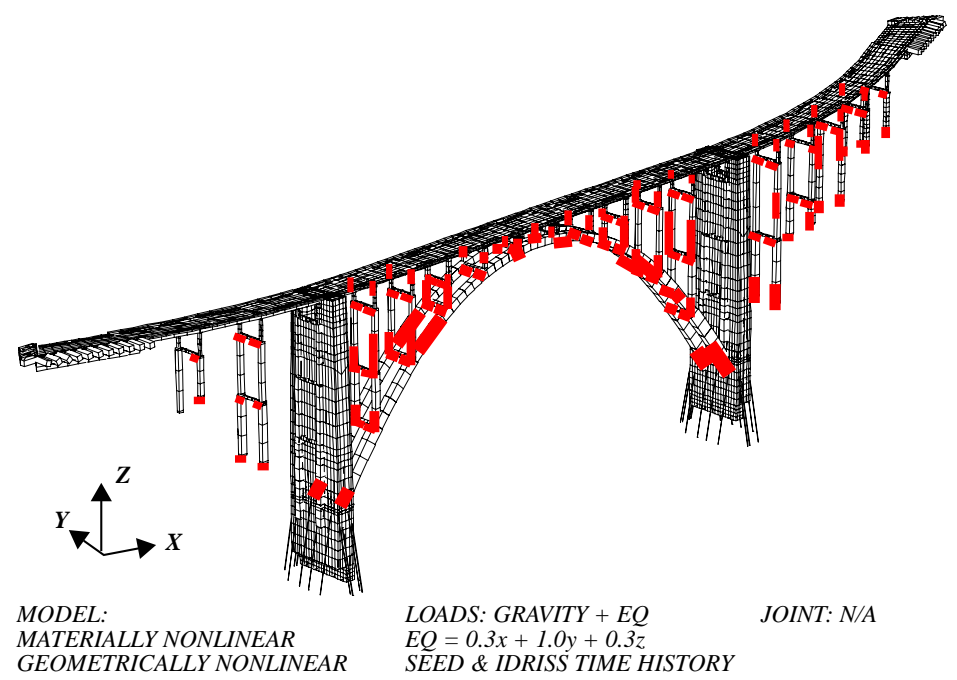

FIGURE 106. Steel strains for the retrofit structure (Seed and Idriss ground motions).

have been drastically reduced in the retrofit structure. The reduction in potential shear failures is the most dramatic performance improvement exhibited by the retrofit scheme.

\subsection{Transient response of the retrofit model with nonlinear materials to the Caltrans ground motions including near-field terms}

As with the as-built structure model, the retrofit model was analyzed for the updated Caltrans ground motions which included the long period, near-field components embedded in the ground motion time histories. 


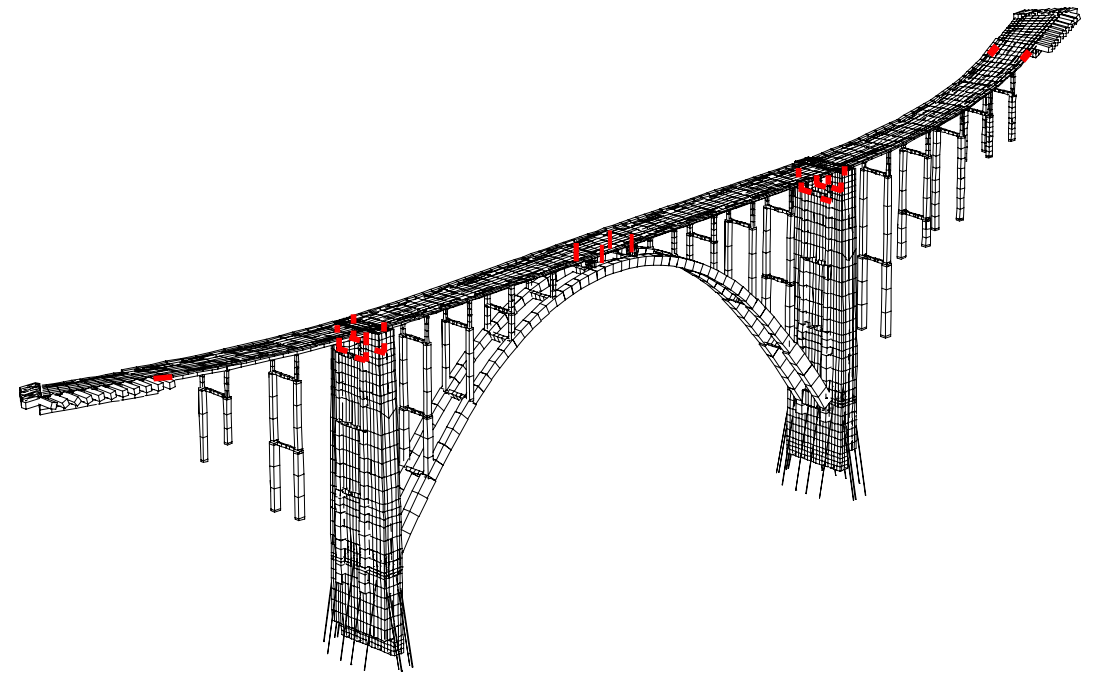

FIGURE 107. Locations at which shear failure is predicted (Seed and Idriss ground motions).

\subsection{Transient response of the retrofit structure with material nonlinearities (Caltrans updated time histories with near-field motions)}

The displacement time histories for the retrofit model subjected to the updated ground motions are shown in Figure 108. The updated motions lead to both larger amplitude motions as well as lower frequency content in the waveforms of the displacement time histories. This is expected due the effects of the long period displacement pulses in the ground motion records. The retrofit structure displacements are substantially less than the displacements computed for the as-built structure for this ground motion. Unlike the asbuilt structure, the updated motions including near-field terms do not increase the displacements of the retrofit structure over the original design motions. This results from the fact that the retrofit structure is very stiff, with a fundamental period on the order of one second, and thus does not respond as strongly to the long period displacement pulses.

\subsection{Member strains and demand-to-capacity ratios (Caltrans updated time histories with near-field motions)}

The concrete and steel strain levels obtained with the updated ground motions are summarized in Figure 109 and Figure 110. There is substantially more steel yielding with the updated ground motions, however, the regions at which Caltrans ultimates are reached remain essentially unchanged. 

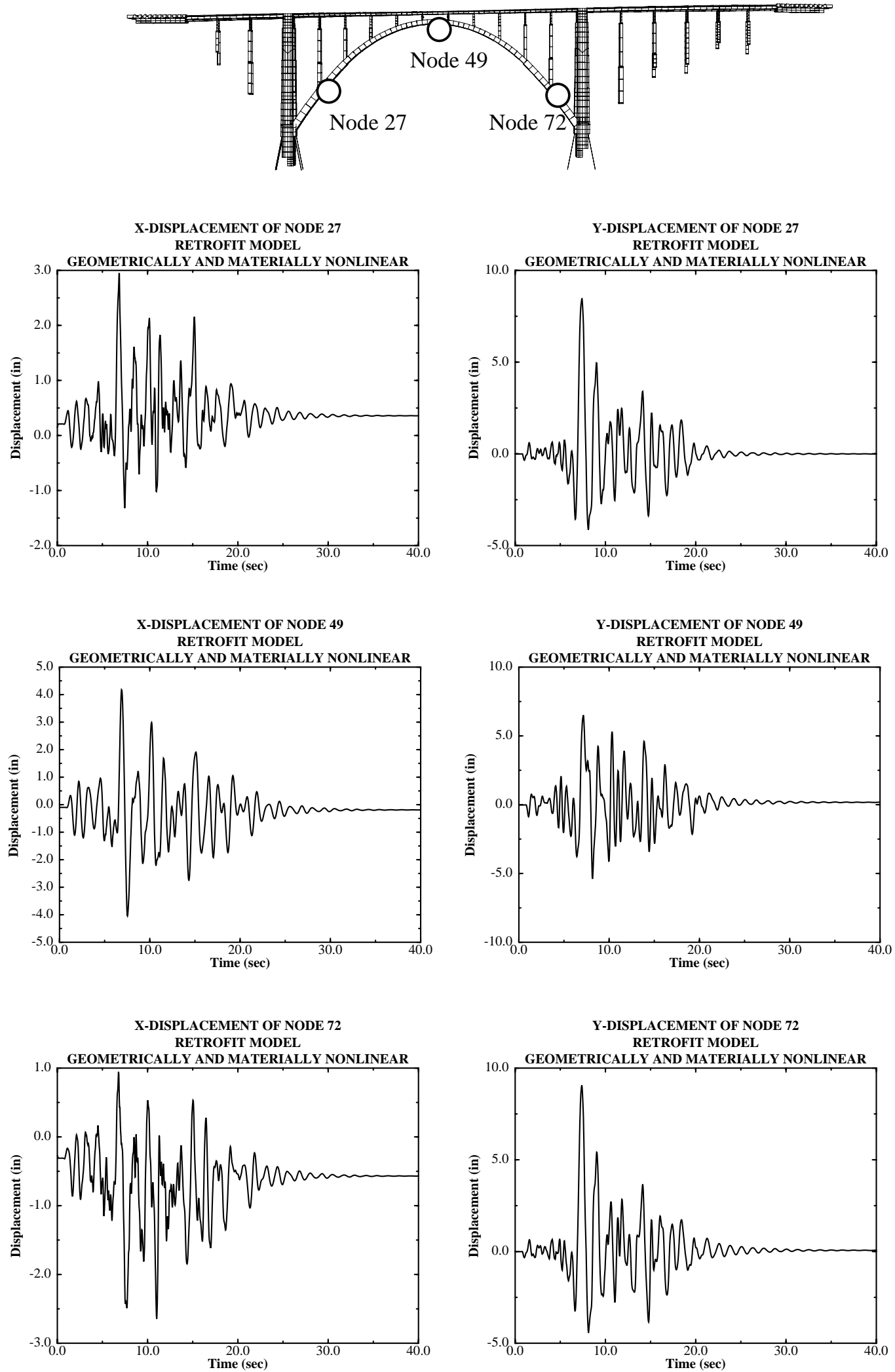

FIGURE 108. Displacement time histories for selected nodes; model based on nonlinear material, geometrically nonlinear (updated Caltrans records including near-field terms). 
Concrete $>0.003$ strains

Concrete $>0.005$ strains

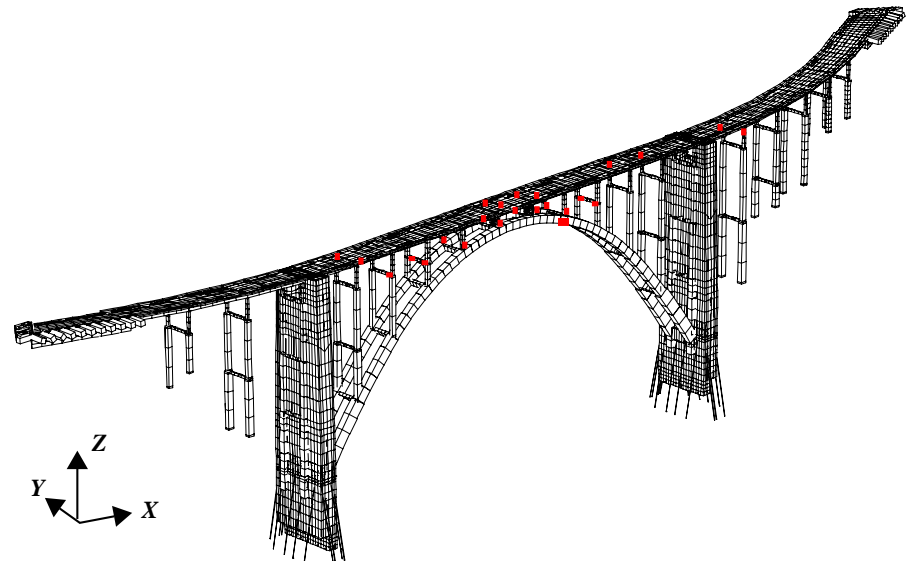

MODEL:

MATERIALLY NONLINEAR

LOADS: GRAVITY + EQ

JOINT: N/A

\section{GEOMETRICALLY NONLINEAR}

$E Q=1.0 x+1.0 y+1.0 z$

NEAR-FIELD TIME HISTORY

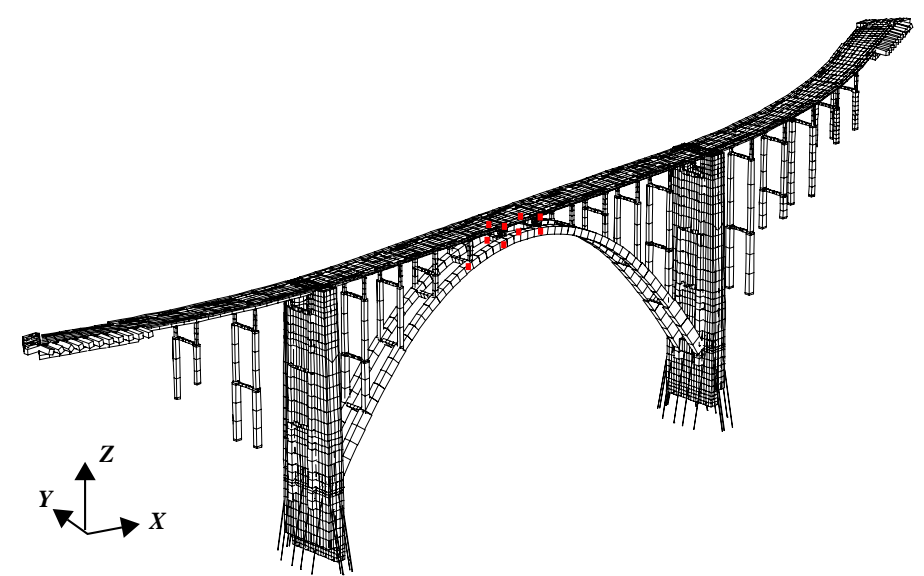

MODEL:

MATERIALLY NONLINEAR

LOADS: GRAVITY + EQ

JOINT: N/A

GEOMETRICALLY NONLINEAR

NEAR-FIELD TIME HISTORY

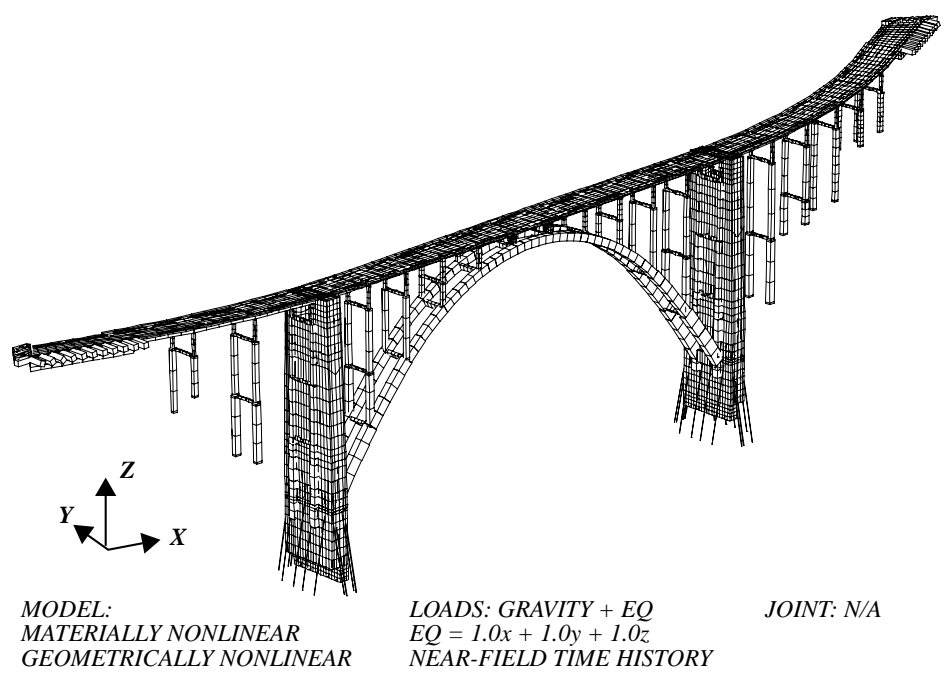

Steel $>0.12$ strains GEOMETRICALLY NONLINEAR

$E Q=1.0 x+1.0 y+1.0$

NEAR-FIELD TIME HISTORY

FIGURE 109. Strain levels in concrete and steel for nonlinear model with updated Caltrans ground motions. 


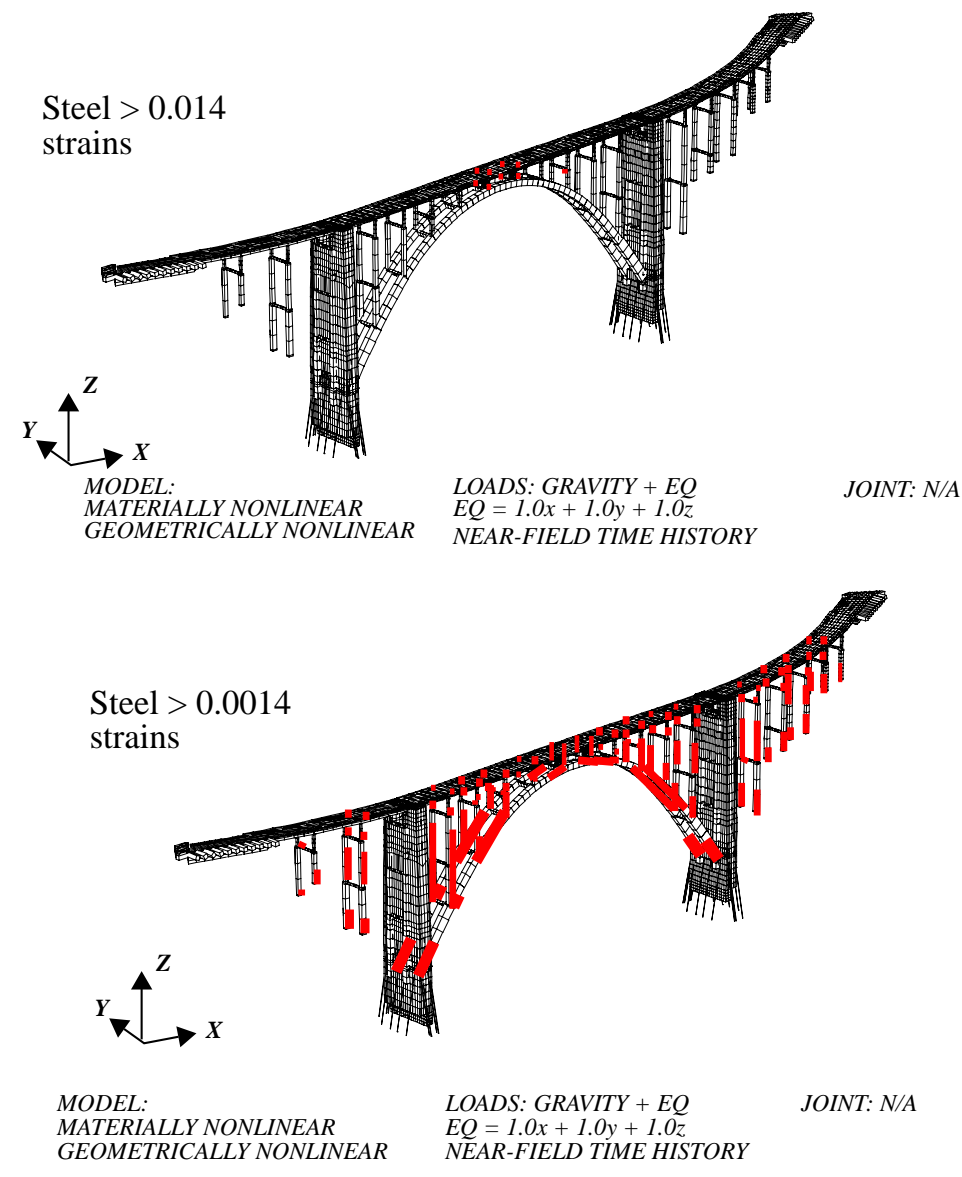

FIGURE 110. Strain levels in concrete and steel for nonlinear model with updated Caltrans ground motions.

\subsection{Shear demand-to-capacity check for the retrofit structure (Caltrans updated time histories with near-field motions)}

The members for which the ACI codified shear allowables were exceeded are shown in Figure 111. Potential shear failure locations are evident in the deck beams at the abutment, in the columns at the towers, and in the short stiff columns at the arch crown.

\subsection{Comparison of displacements from as-built and retrofit structures}

The transverse displacement time histories at mid-span of the retrofit and unretrofit structures are shown in Figure 112 for the Seed and Idriss and the Caltrans updated ground motions respectively. The plots indicate the dramatic decrease in system displacement drift with the retrofit installed. For the updated motions, the structure displacement at midspan decreased from approximately 35 inches to approximately 5 inches, corresponding to a reduction factor of about 6 . 


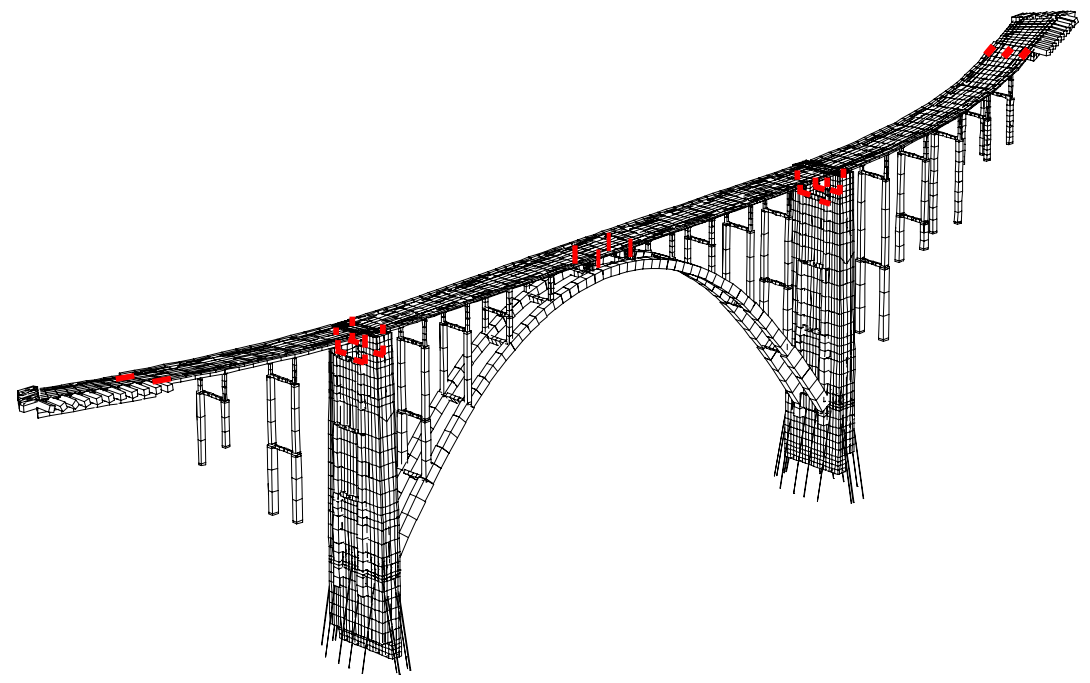

FIGURE 111. Locations at which shear failure is predicted (Caltrans updated ground motions with near-field terms).

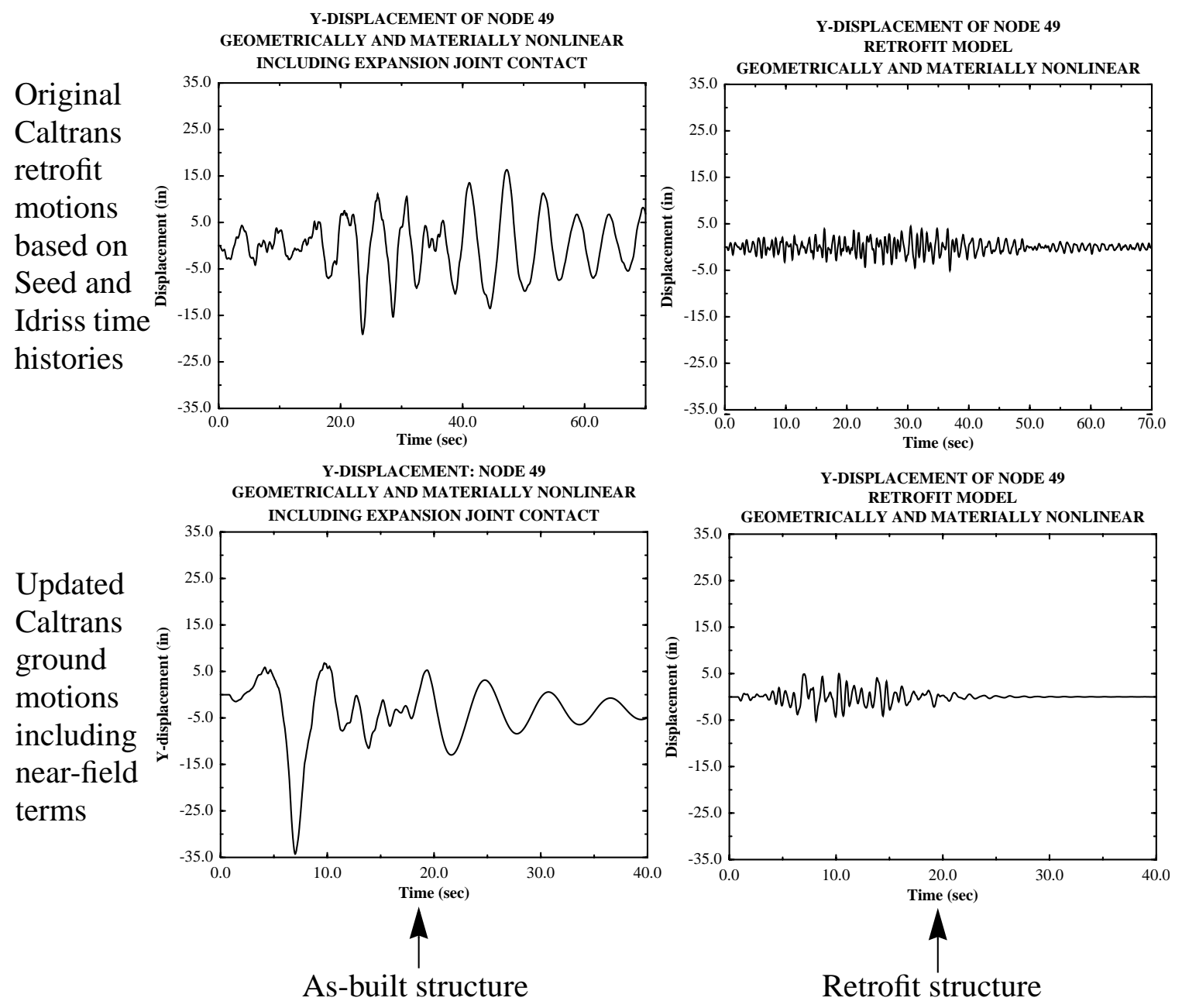

FIGURE 112. Comparison of transient response of as-built and retrofit structures for two ground motion records. 


\subsection{Demand-to-capacity values for the abutment piles}

The demand-to-capacity ratios for the large cast in drilled hole piles (CIDH) were estimated by obtaining the peak foundation displacement demands from the global finite element model and imposing the displacements on the detailed local model of the foundation system. The resulting biaxial force resultants in the individual piles were then utilized in a capacity check with the PCACOL post-processing program. The resulting demand to

Table 17: Demand to capacity ratios for the CIDH foundation piles

\begin{tabular}{|c|c|c|}
\cline { 3 - 3 } \multicolumn{1}{c|}{} & D/C Ratios \\
\hline \multirow{4}{*}{$\begin{array}{c}\text { South } \\
\text { Abutment }\end{array}$} & Pile 1 & 0.55 \\
\cline { 2 - 3 } & Pile 2 & 0.57 \\
\cline { 2 - 3 } & Pile 3 & 0.51 \\
\cline { 2 - 3 } & Pile 4 & 0.52 \\
\cline { 2 - 3 } & Pile 5 & 0.62 \\
\cline { 2 - 3 } & Pile 6 & 0.62 \\
\hline
\end{tabular}

\begin{tabular}{|c|c|c|}
\cline { 3 - 3 } \multicolumn{1}{c|}{} & D/C Ratios \\
\hline \multirow{4}{*}{$\begin{array}{c}\text { North } \\
\text { Abutment }\end{array}$} & Pile 1 & 0.70 \\
\cline { 2 - 3 } & Pile 2 & 0.72 \\
\cline { 2 - 3 } & Pile 3 & 0.65 \\
\cline { 2 - 3 } & Pile 4 & 0.66 \\
\cline { 2 - 3 } & Pile 5 & 0.79 \\
\cline { 2 - 3 } & Pile 6 & 0.79 \\
\hline
\end{tabular}

capacity ratios are summarized in Table 17 . The foundation piles were found to all have demand-to-capacity ratios less than 1 . 


\subsection{Summary of analysis and field measurement results}

An extensive series of computational analyses have been performed to evaluate the computer simulated linear and nonlinear response characteristics of concrete arch bridges with particular focus on the Bixby Creek Bridge. Two detailed, nonlinear computational models were constructed for this study. The first model simulated the original as-built structure and the second model simulated the structure with the new earthquake retrofit in place. The analyses which have been performed indicate the importance of modeling assumptions and the wide variation in response predictions which can result from employment of models of different complexity and sophistication. The principal conclusions of this study are summarized below.

\subsection{Vibrational characteristics of the as-built structure}

The natural vibration characteristics of a structure, as defined by the natural modeshapes and frequencies, provide significant insight into the manner in which a given structure will respond to a particular earthquake ground motion. The natural vibration characteristics of the Bixby Creek Bridge system were examined both computationally and through field observations. The computational simulations included a bounding range of idealizations of the connectivity at the many expansion joints in the structure, and it was found that the vibrational characteristics of the structure were quite sensitive to the expansion joint behavior. For example, the fundamental mode of the as-built bridge system model, which consisted of transverse vibration of the mainspan deck, exhibited a wide frequency variability depending on the connectivity assumed at the bridge expansion joints as indicated in Figure 113.

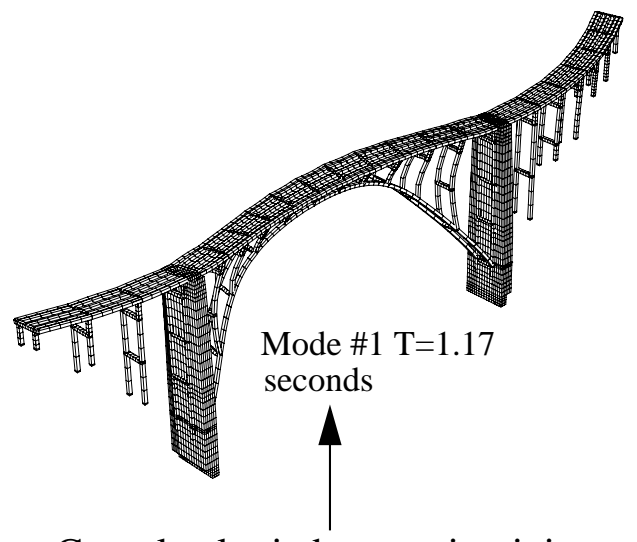

Completely tied expansion joints

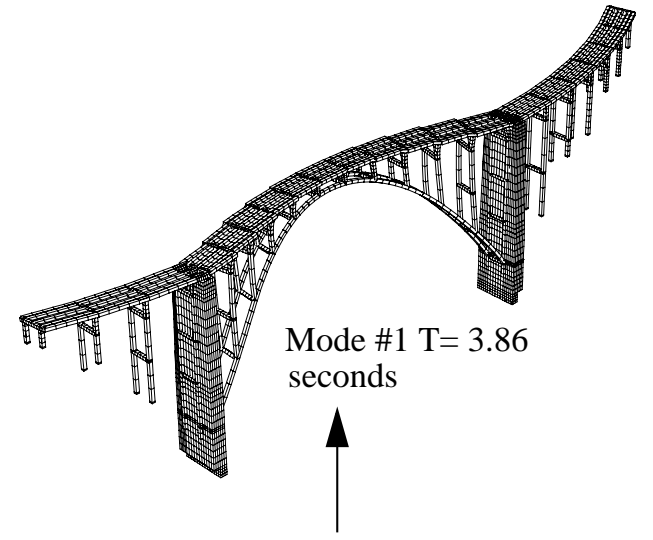

Completely free expansion joints

FIGURE 113. Fundamental natural modes of the structure based on two bounding idealizations of the thermal expansion joints.

The field observations of the natural frequencies, which were obtained from a short term deployment of accelerometers on the actual structure, exhibited a clear fundamental transverse mode at 2.5 seconds period (Figure 114). The observed period is almost precisely in the middle between the computed periods in Figure 113. This is not surprising, in that the 


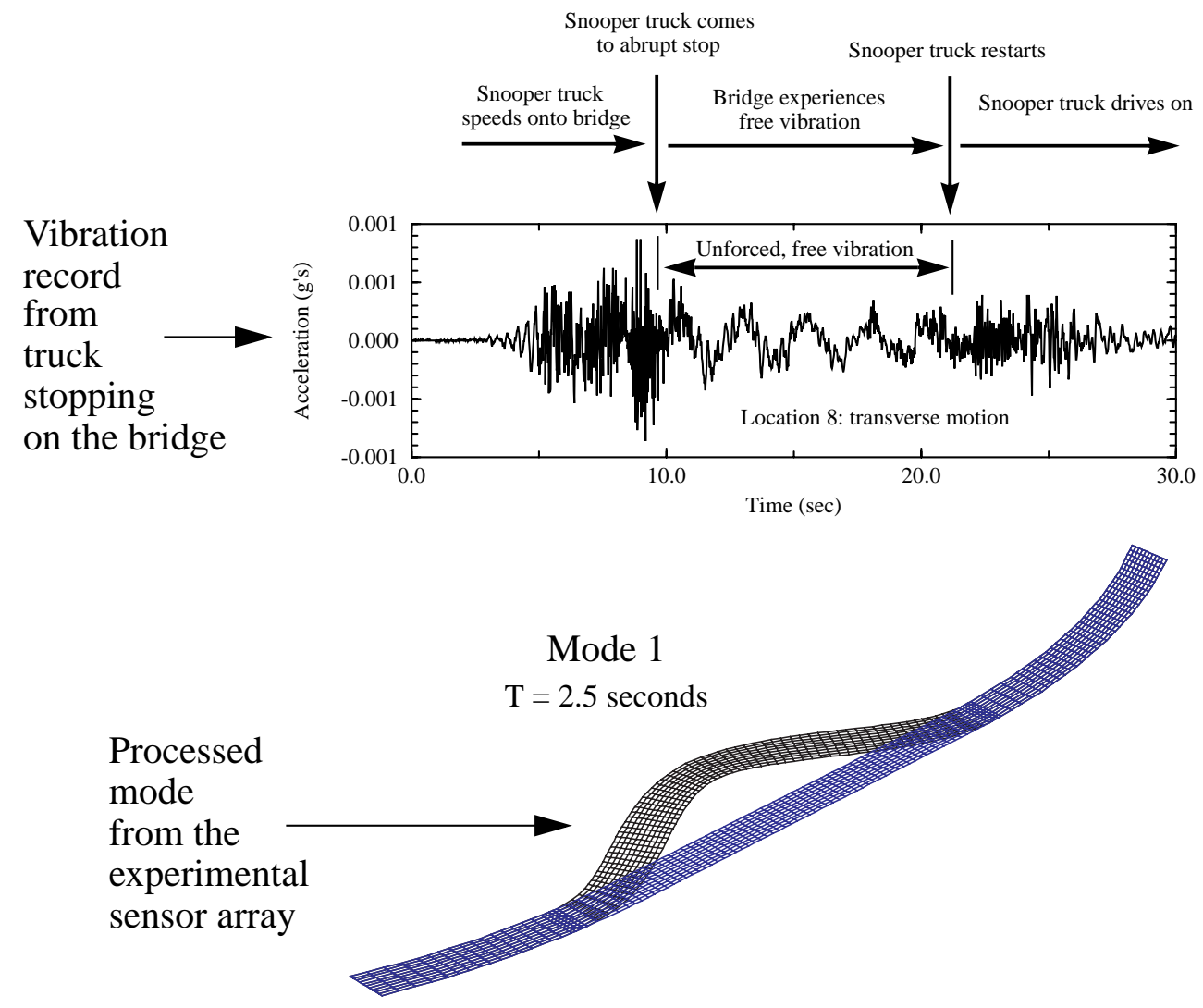

(a)

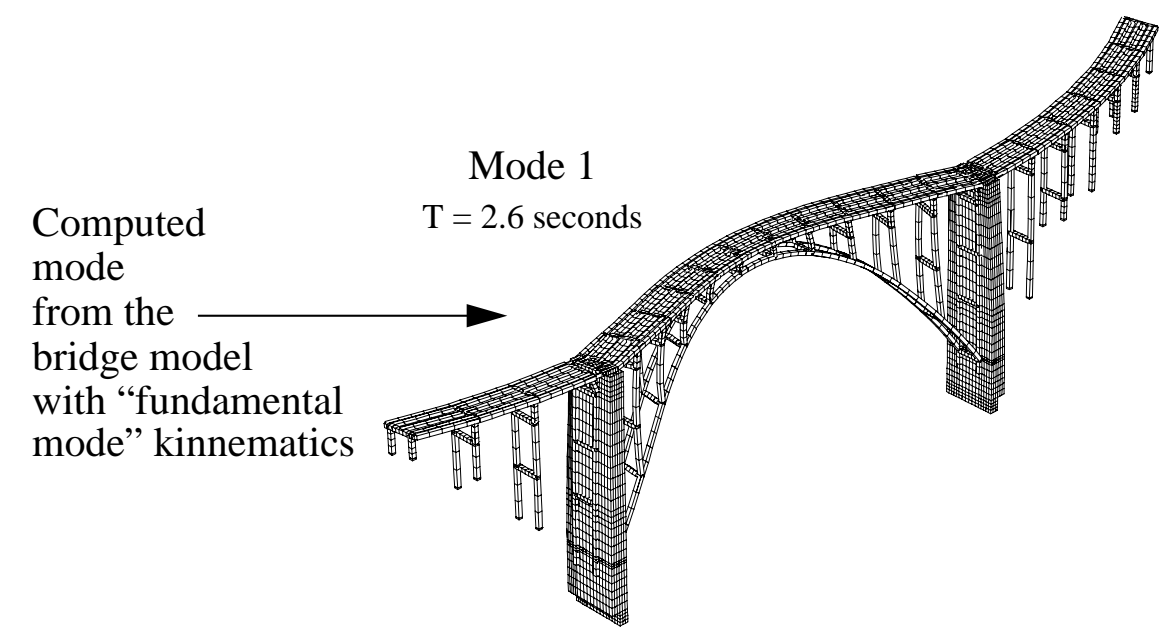

FIGURE 114. Fundamental mode of the Bixby Creek Bridge. a) Experimentally observed fundamental mode of the Bixby Creek Bridge; b) bridge mode computed with a model specific to the fundamental mode deck kinematics.

actual small amplitude behavior of the expansion joints is not completely fixed or completely free, but something in between, and the experimentally observed period demonstrates this. It is likely that the true expansion joint behavior will be amplitude dependent. For example, if the structure is subjected to larger motions, which are higher amplitude 
than the ambient vibrations, it is likely that many of the expansion joints will "breakloose" as friction is overcome and the structure will appear somewhat more flexible. At very high amplitude motions, on the other hand, the expansion joints will begin to contact and the structure can appear stiffer than at moderate amplitude motions. The expansion joints essentially lead to amplitude dependent vibratory behavior and thus constitute a significant nonlinearity in the system. The computed natural frequencies, based on bounding idealizations and linearizations of the computational model, bracket the observed natural frequency, indicating the computational model has reasonably captured the system stiffness.

To further investigate the model dynamic characteristics, a model was run in which the expansion joints were idealized in a fashion which was intended to be representative of the fundamental transverse mode, i.e. the deck was merged on the side where compressive contact would occur and the deck was left free to open on the other side where tensile opening of the deck would occur. The fundamental mode obtained from this type of idealization (an idealization which is only appropriate for the fundamental transverse mode) was in very good correlation with the computed mode as indicated in Figure 114.

\subsection{Synthetic earthquake ground motions for the Bixby Creek site}

Caltrans provided synthetic earthquake ground motions for the bridge seismic analyses. Three different sets of time histories were specified for the response computations. The first two sets were developed for the site by Caltrans in the early 1990's and were the earthquake records employed in the retrofit design of the bridge (Figure 115). Both of these motions exhibited very high frequency content and lacked long period displacements which might be expected for sites close to a causative fault. Many recent major earthquakes have demonstrated this potential for long-period ground displacement pulses to occur at sites in close proximity to the causative fault. Because of the close location of the nearby San Gregorio fault system (about $1 \mathrm{~km}$ distance) to the Bixby Creek site, near-field long period ground motion components are a distinct possibility. The third set of records were constructed by Caltrans geotechnical staff specifically for this project and represented an updated set of records which incorporated near-field displacement pulses as shown in Figure 115.

\subsection{Variable support motion in the Bixby Creek Canyon}

The effects of canyon topography were investigated with a simple two dimensional finite element model of the canyon (Figure 116). The canyon system was analyzed to determine the steady-state response to incident sinusoidal SV waves of varying frequency. The response analysis indicated that the canyon topography would begin to influence the surface ground motions at frequencies of about $2-3 \mathrm{~Hz}$. By $5-7 \mathrm{~Hz}$, the scattering effects of the canyon topography were quite pronounced (Figure 116). Measurements of small earthquakes at the Bixby site tended to confirm this observation. Differential motion between the north and south towers was evident in the bandpassed ground displacement time histories at $2 \mathrm{~Hz}$ and by $5 \mathrm{~Hz}$ the north and south tower motions were clearly out of phase. The as-built structure is quite flexible and the effects of variable support motion are probably 

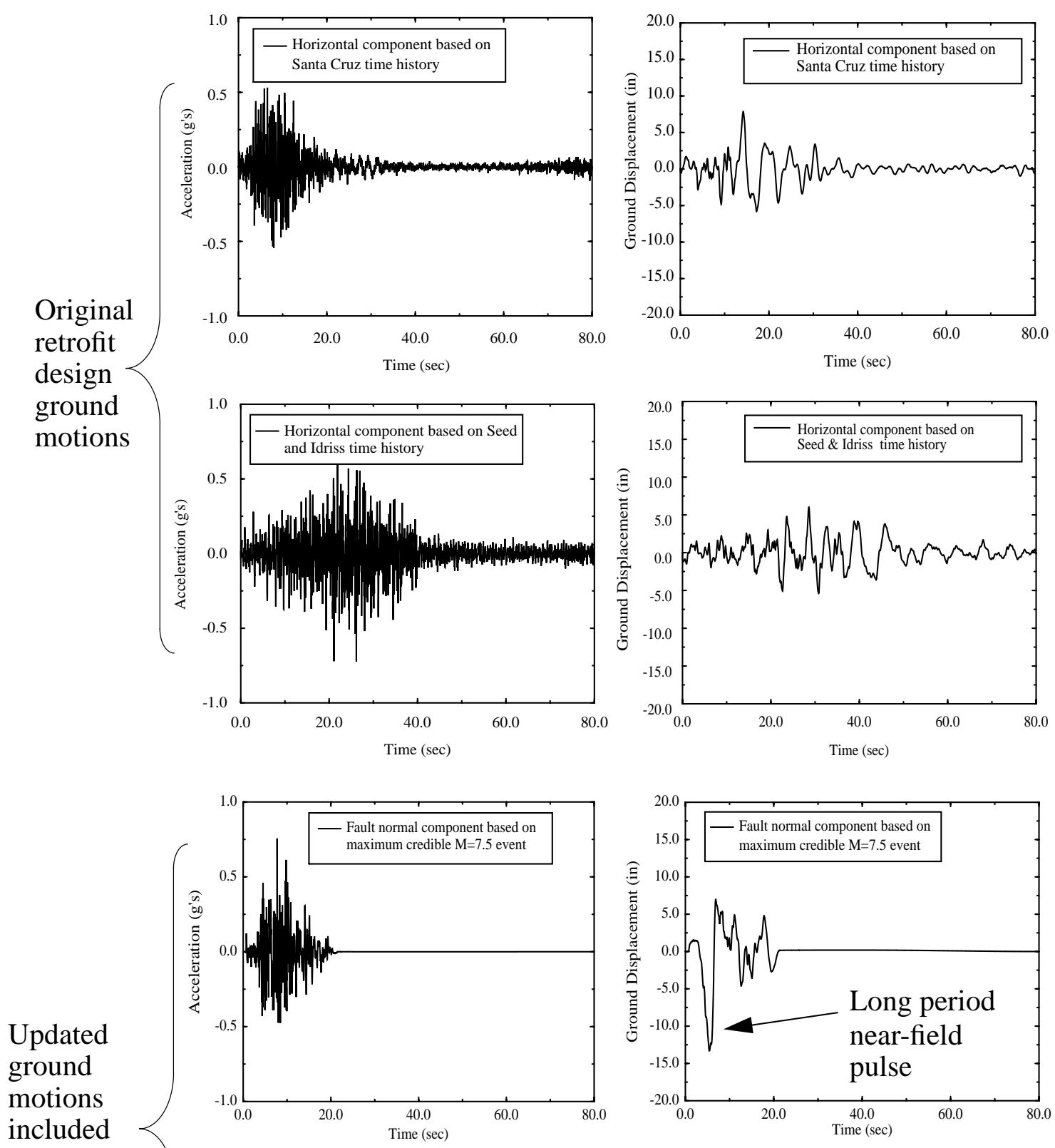

long period displacement pulses
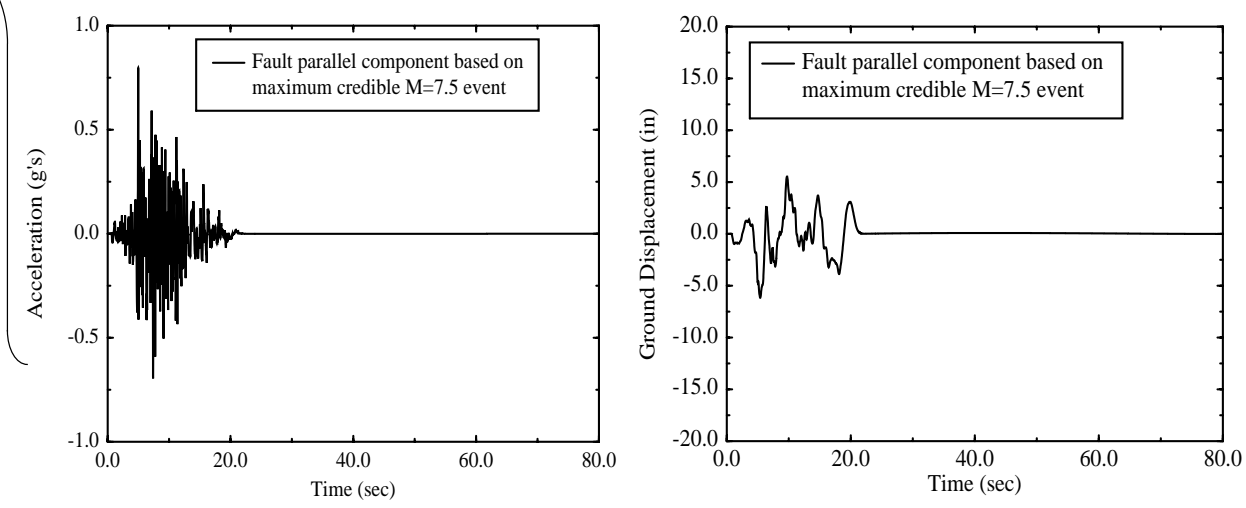

FIGURE 115. Caltrans' synthetic earthquake ground motions for the Bixby Creek site. a) Original retrofit design motions; b) updated motions including near-field terms. 

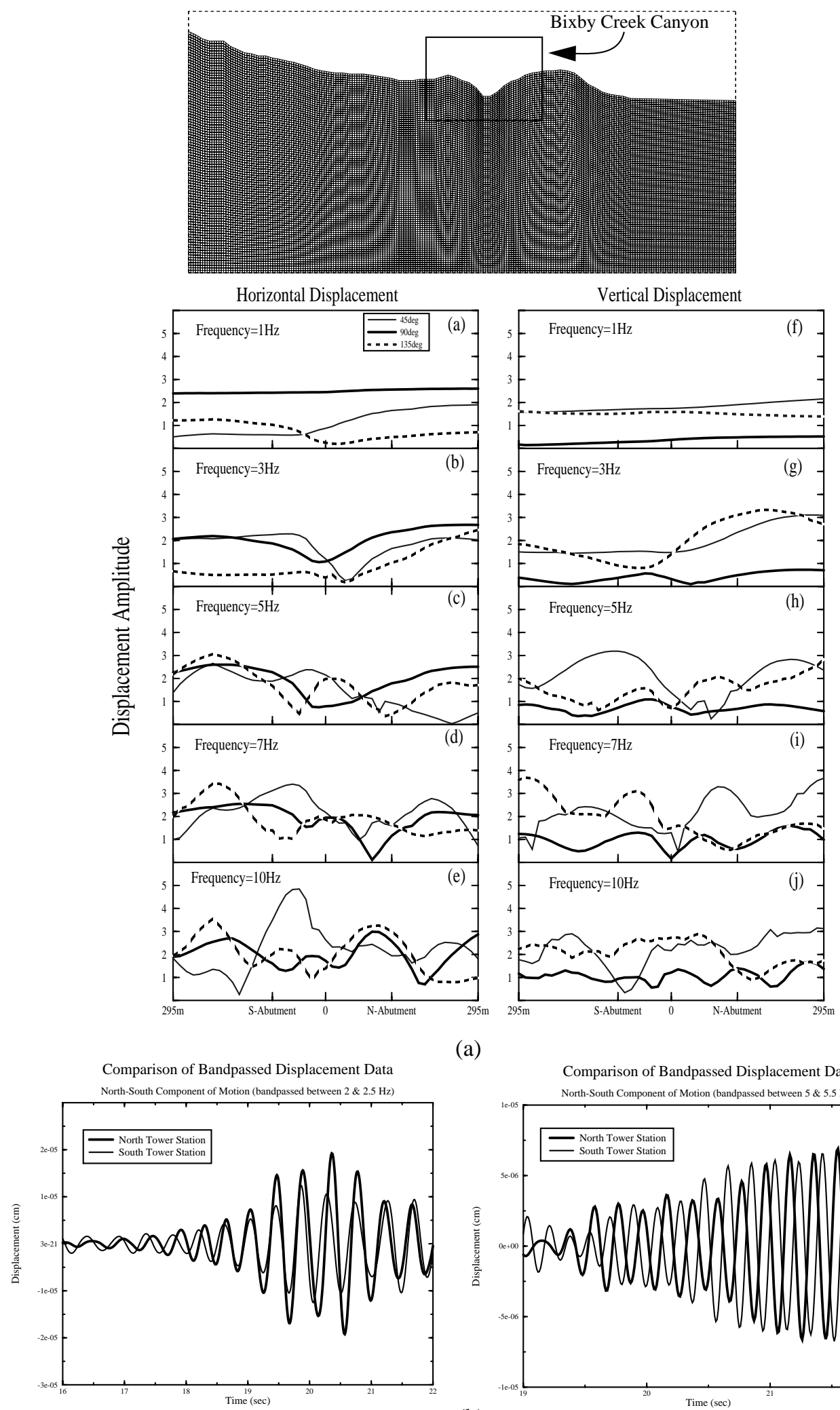

(a)

Comparison of Bandpassed Displacement Data

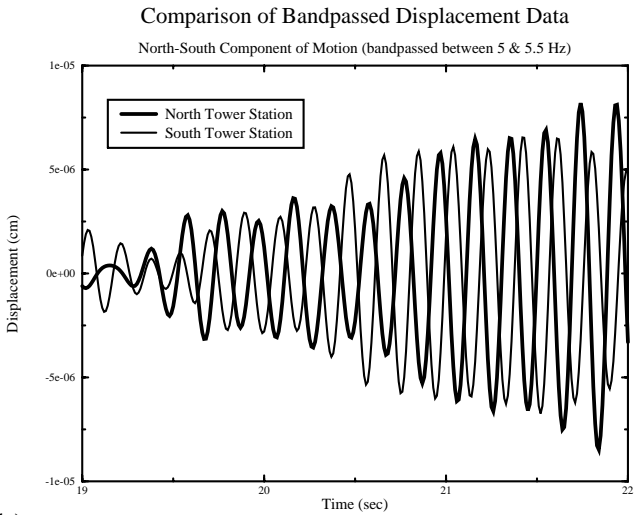

(b)

FIGURE 116. Variable ground motion potential at the Bixby Creek site. a) Simulation of wave scattering in the Bixby Creek topography; b) measured displacements for a $M=3$ earthquake (bandpassed records). 
not a significant issue. For the retrofit structure, however, the system is significantly stiffer and the frequencies of the higher modes are such that variable support motion could be an important issue.

\subsection{Transient response and the effect of expansion joint behavior}

As discussed in the body of this report, the Bixby Creek structural system is quite segmented with a large number of expansion joints. Essentially every bent and the deck-totower connections have expansion joints which prevent the deck from acting as a continuous structural member in load resistance. Depending on the modeling assumptions invoked for the expansion joints, there is a major difference in the computed bridge behavior. Figure 117, for example, shows the computed transverse displacement with three different computational models. In the first model, the expansion joints are assumed free to expand and contact with no interaction between adjacent bridge segments, and in the second model, the joints are assumed completely tied and thus capable of transferring all forces across the joint. These two idealizations lead to linear computational models. In the third case, a nonlinear model is employed where the joints are free to open, but contact occurs when the joints close beyond the initial expansion gap dimension. Additional evidence of the significant system stiffness sensitivity to expansion joints is obtained from push-over analyses of the bridge system. The computed force-deflection behavior of the bridge system for free and contacting expansion joints are indicated in Figure 118. The

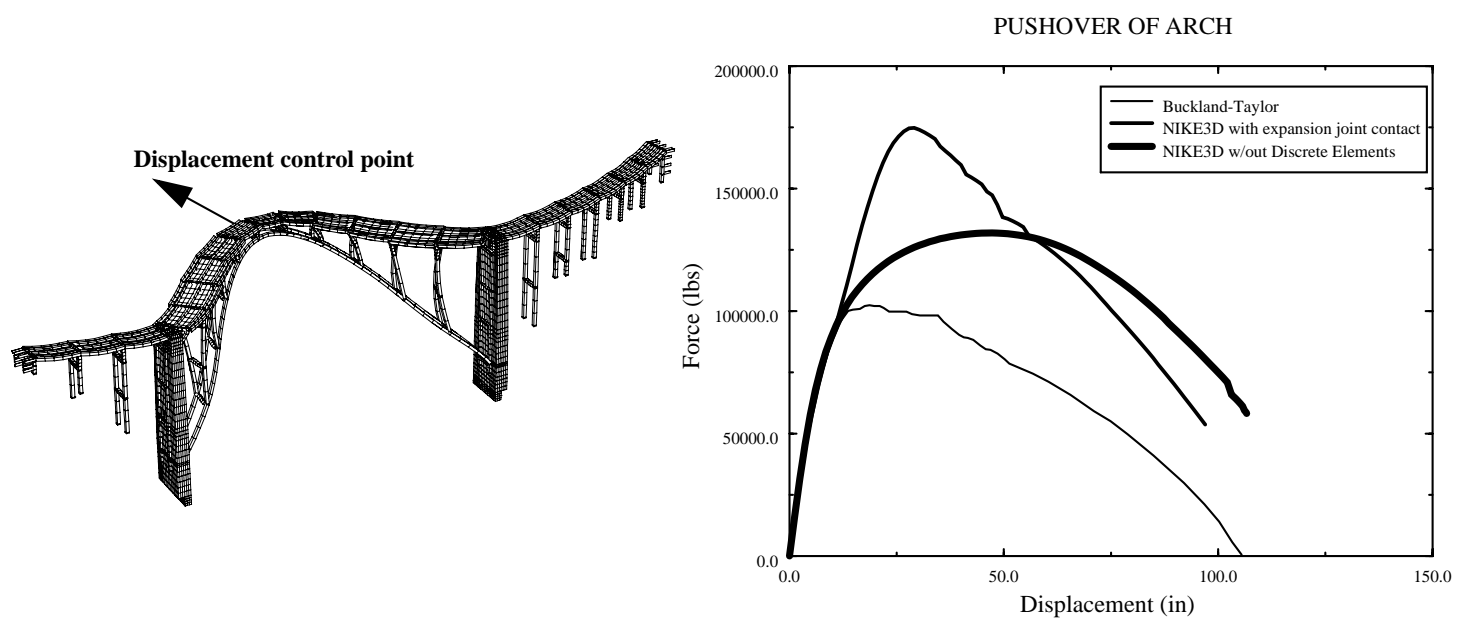

FIGURE 118. Push-over results for bridge system with free and contacting expansion joints.

effective ultimate strength of the bridge system is significantly increased when the bridge expansion joints are allowed to contact and generate contact forces between adjacent deck segments. 
Node 49
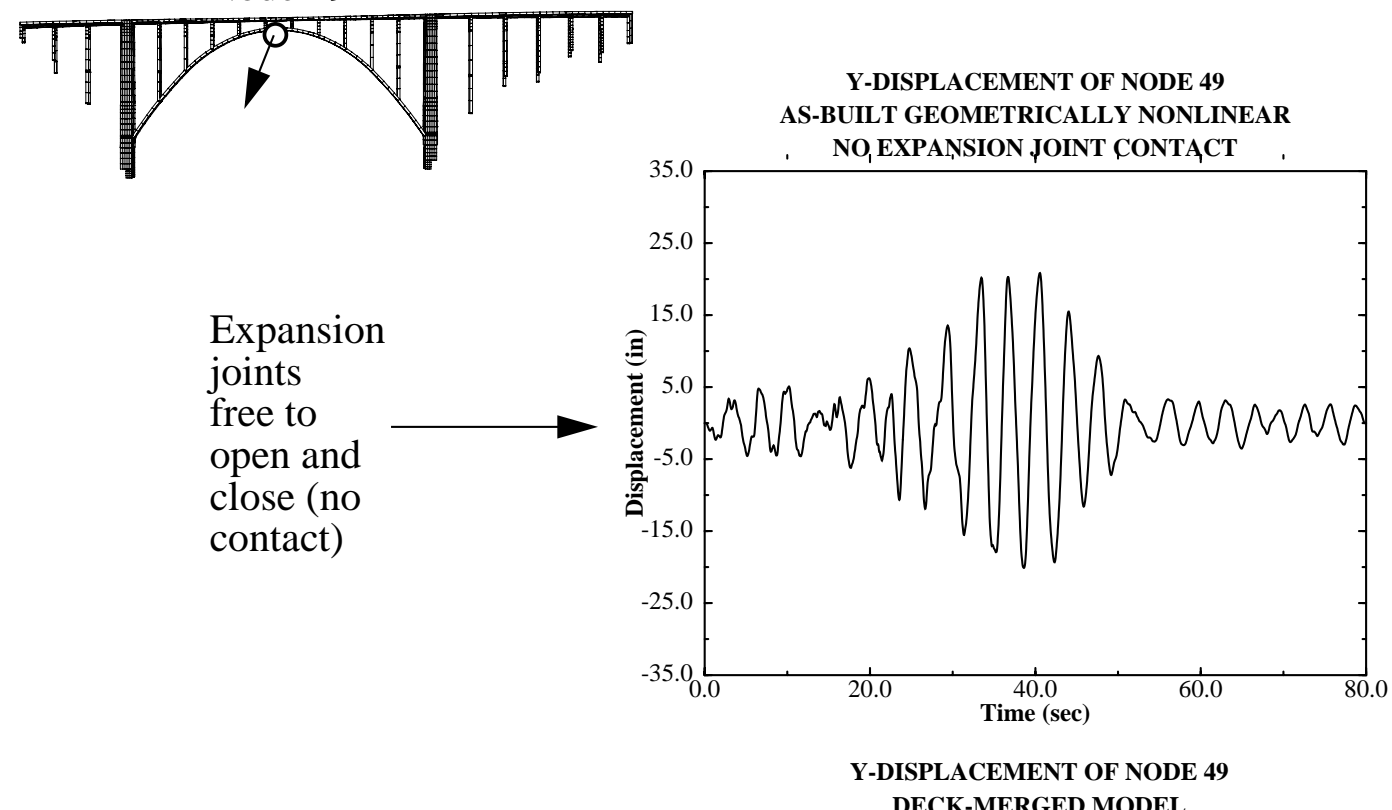

Expansion

joints

free to

open and

close (no

contact)

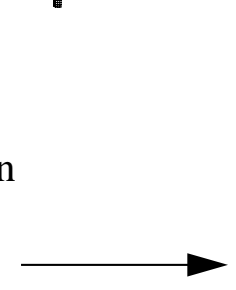

Expansion

joints

not free to

open and

close (completely

tied shut)

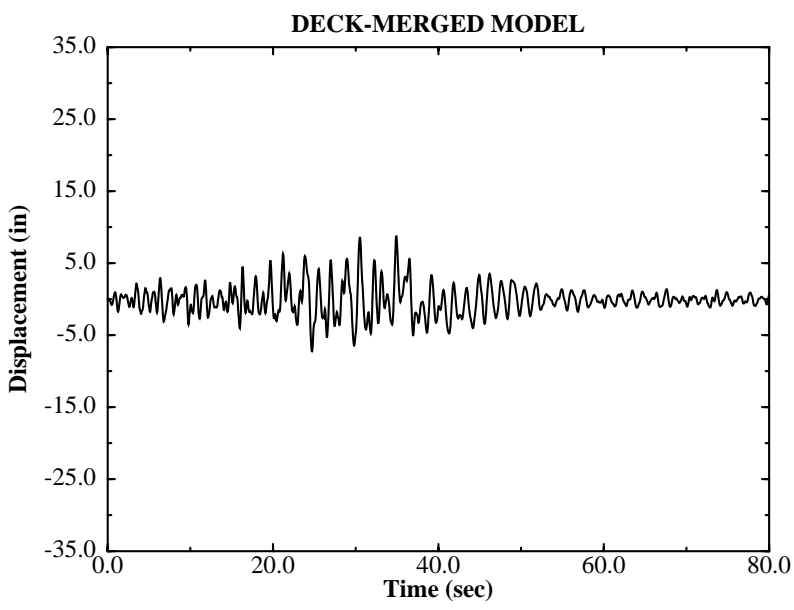

Expansion

joints

free to

open but

contact

upon closure

Y-DISPLACEMENT OF NODE 49

GEOMETRICALLY NONLINEAR FLEXIBLE MODEL INCLUDING EXPANSION JOINT CONTACT

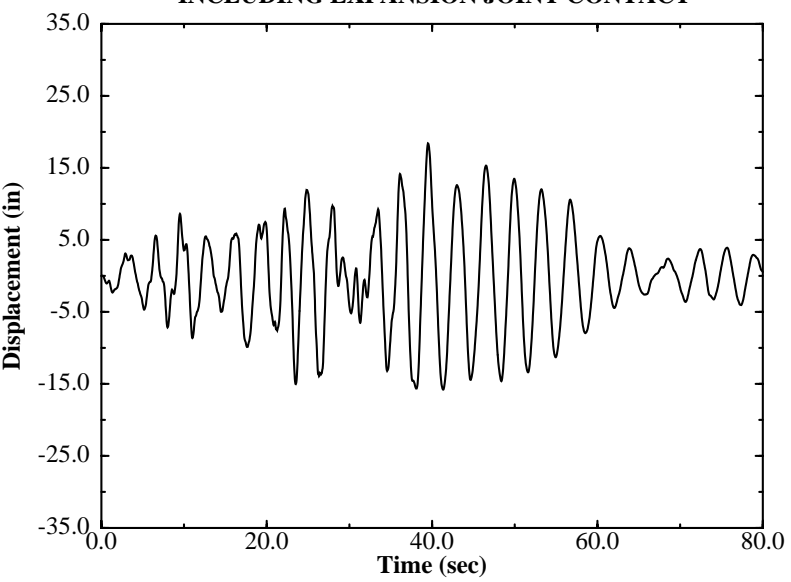

FIGURE 117. Transverse displacement at mid-span of the bridge for different expansion joint idealizations. 


\subsection{Effects of material nonlinearities}

The effects of material nonlinearities were studied in the Bixby Creek simulations by incorporation of detailed, three dimensional characterizations of the nonlinearities in the reinforced concrete elements of the bridge. A nonlinear reinforced concrete model was employed which divided each member into concrete and steel zones and applied the appropriate nonlinear material characterization to each zone (Figure 119). As discussed in the body of this report, this model was validated by comparison with Caltrans sponsored scale-model tests of Bixby Creek column sections. Based on the simulations performed for this study, the as-built Bixby Creek Bridge would be subjected to significant nonlinear material behavior during a major earthquake including significant concrete cracking and reinforcing steel yielding. The effect of material nonlinearity can be clearly observed in

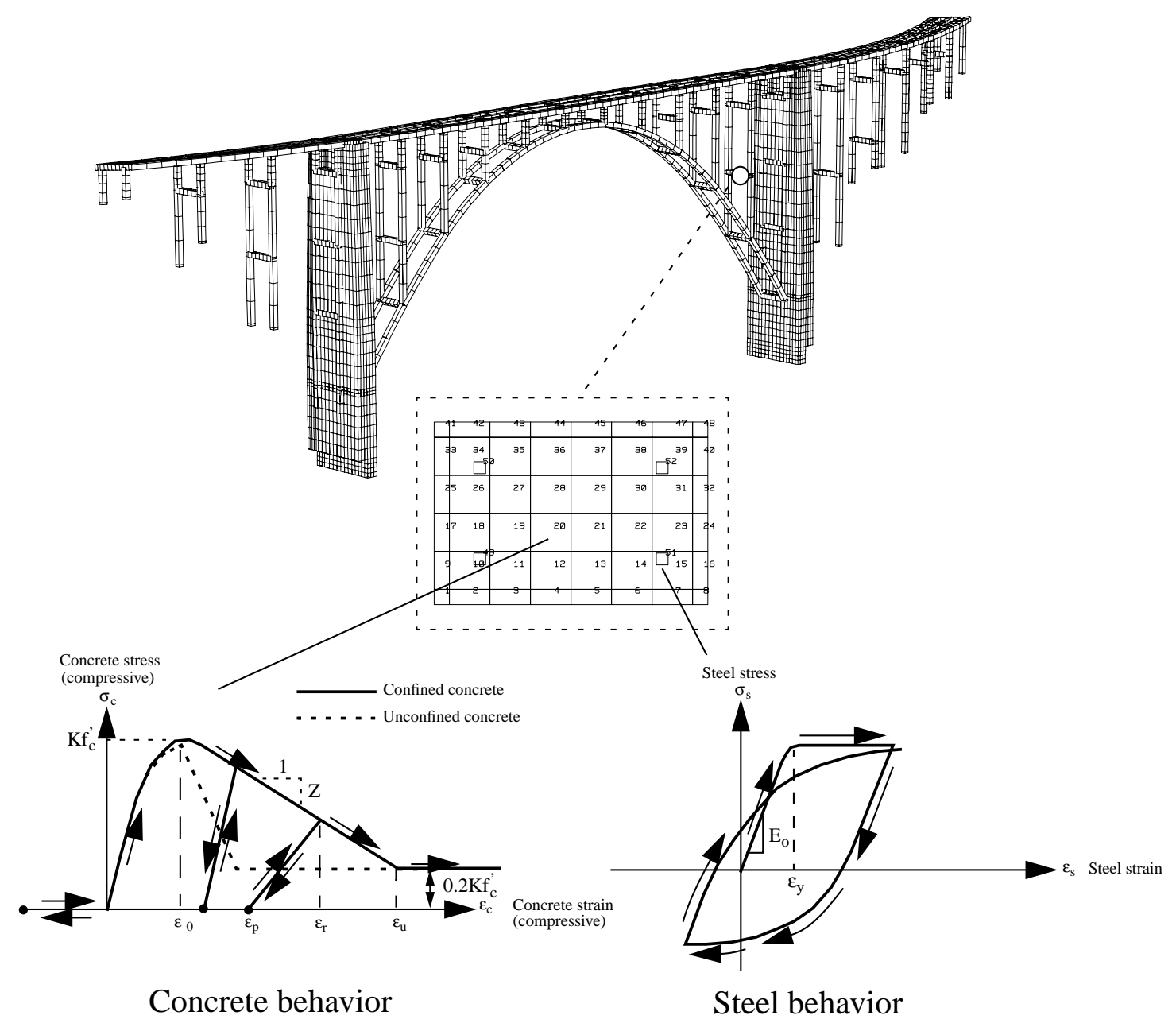

FIGURE 119. Nonlinear reinforced concrete characterization in the Bixby Creek model.

the computed response of the structure as indicated in Figure 120. The material nonlinearities result in significant softening and corresponding elongation in the response period of the bridge system. As discussed below, the system nonlinearities also result in significant redistribution and reduction of force levels in the structure. 


\section{Node 49}

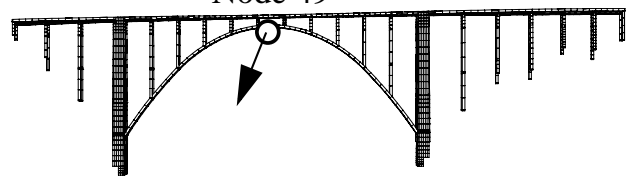

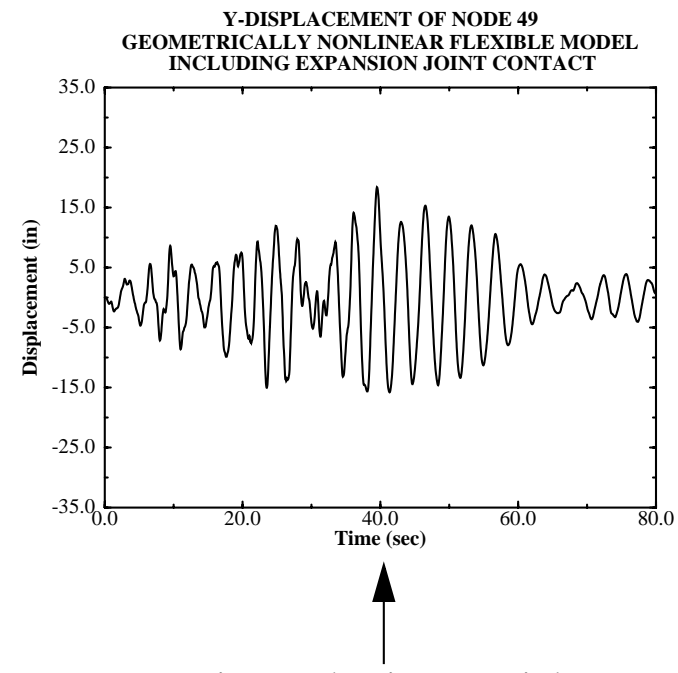

Linear elastic materials

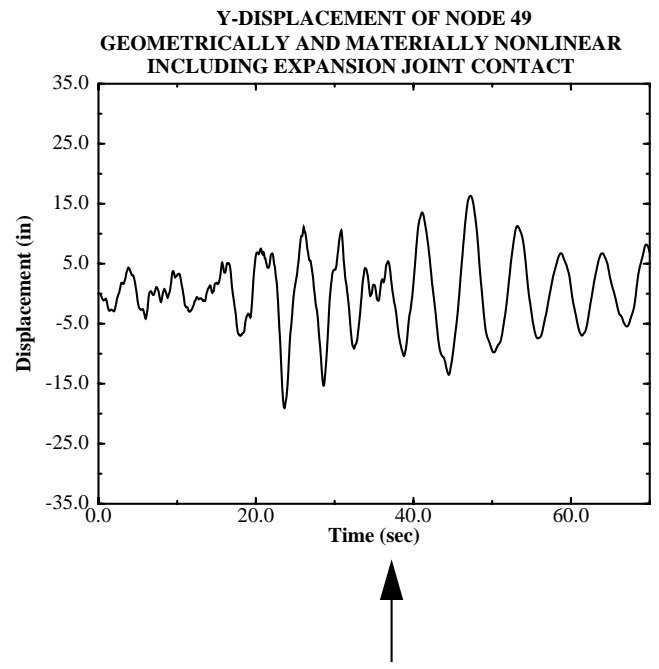

Nonlinear materials

FIGURE 120. Comparison of computed response for linear and nonlinear materials.

\subsection{Vulnerabilities of the as-built structure}

The vulnerabilities of the as-built structure were investigated by examining the time histories of steel and concrete strains throughout the structure for the duration of the earthquake motion. The points in the structure at which steel or concrete strains exceeded a prescribed maximum value were located and plotted. Figure 121 summarizes the damage levels for the structure for the Seed and Idriss retrofit design motions. The structure exhibits extensive steel yielding, but the ultimate steel strains do not surpass the Caltrans allowable values at any location, nor do the concrete strains appear excessively large at many locations. Only two minor excedances of concrete strain occur. Based on an ACI codified strength check, the shear capacities of a large number of members are surpassed as indicated in Figure 121. The analysis studies indicated that the updated ground motions including near-field terms had a significantly higher damage potential for the as-built Bixby Creek structure. The initial displacement pulses in the ground motion records resulted in a large amplitude displacement excursion of the bridge structure with corresponding high strains as indicated in Figure 122. It is noted that the steel strains still did not exceed the Caltrans allowables at any location.

The as-built computations performed by the Caltrans consultants consisted of linear elastic models in which the expansion joints were linearized about an open configuration (i.e expansion joint contact was neglected) and the demand-to-capacity ratios were based on a 


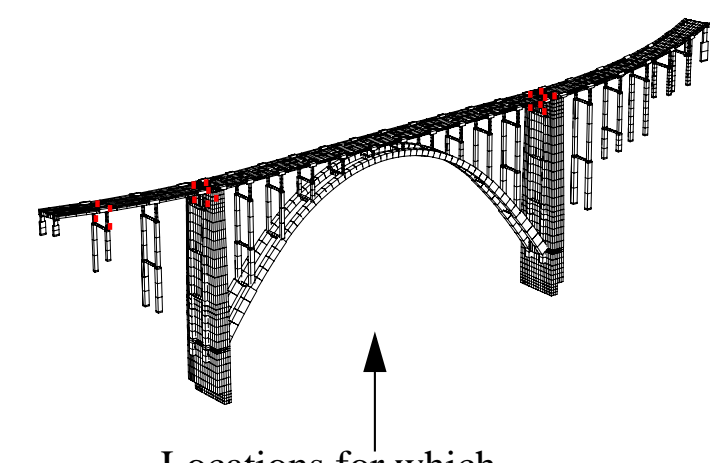

Locations for which

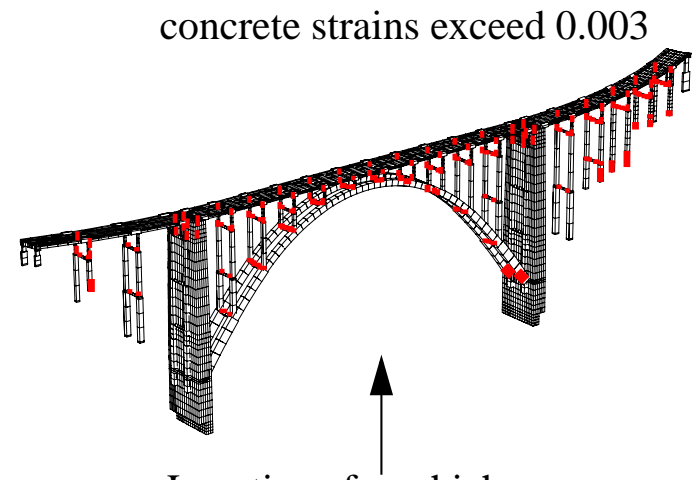

Locations for which steel strains exceed 0.0014 (yield strain)

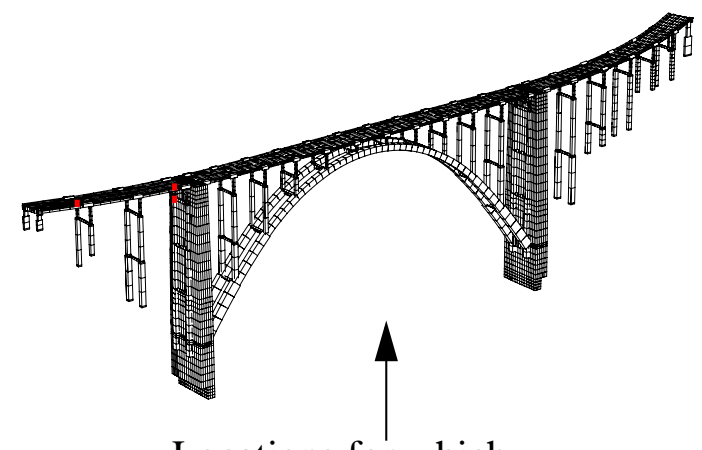

Locations for which concrete strains exceed 0.005

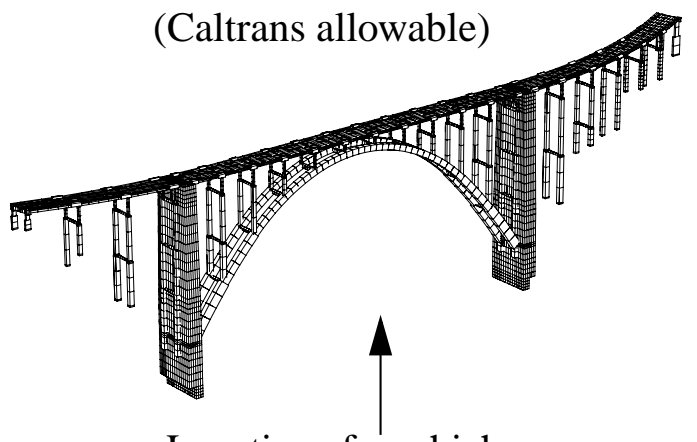

Locations for which steel strains exceed 0.12 (Caltrans allowable)

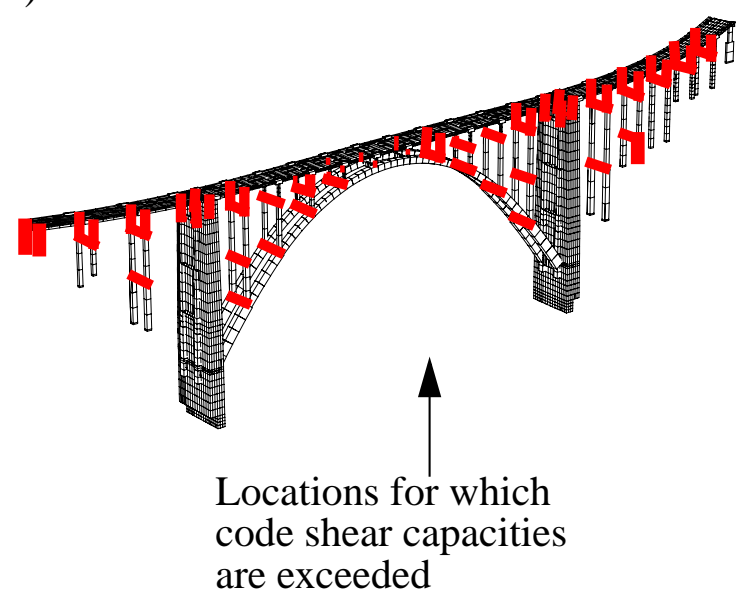

FIGURE 121. Damage levels in the as-built structure for the Seed and Idriss retrofit design motions.

strength check with the member forces obtained from the linear models. The nonlinear model results of the current study indicated that the linear model approach tends to be quite conservative in terms of overestimating displacements and member forces. Accounting for nonlinearities in the system decreases both the displacement drifts of the structure as well as the peak member forces through force redistribution. It is noted that the Caltrans design consultants did not have the more damaging updated ground motions including near-field terms. 


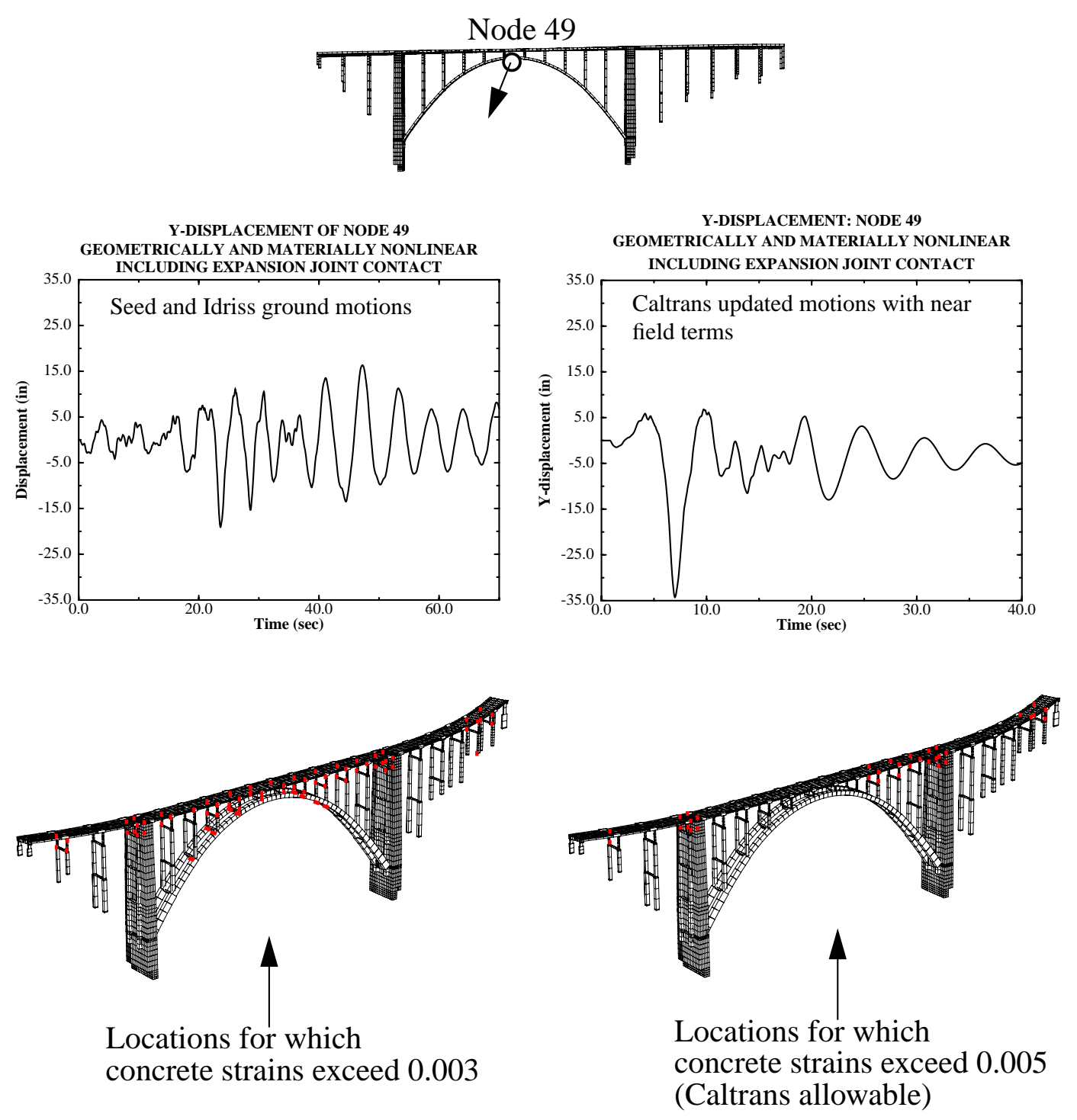

FIGURE 122. Damage levels in the as-built structure for the updated Caltrans site motions.

Many of the California coastal arch bridges are flexible, long-period structural systems. The natural periods of vibration of a sample of these bridges indicates that natural periods of vibration on the order of 2 to 3 seconds are not uncommon (Figure 123). For the longer period arch bridges, it is essential that near-field effects be appropriately included in the seismic hazard assessment if the structure is located near a causative fault.

\subsection{Analysis of the retrofit structure}

Nonlinear computational models were also constructed to allow analysis of the retrofit Bixby Creek structure. Analysis of the retrofit indicated that the structure is substantially stiffened as a result of the retrofit with a dramatic decrease in structural displacements 

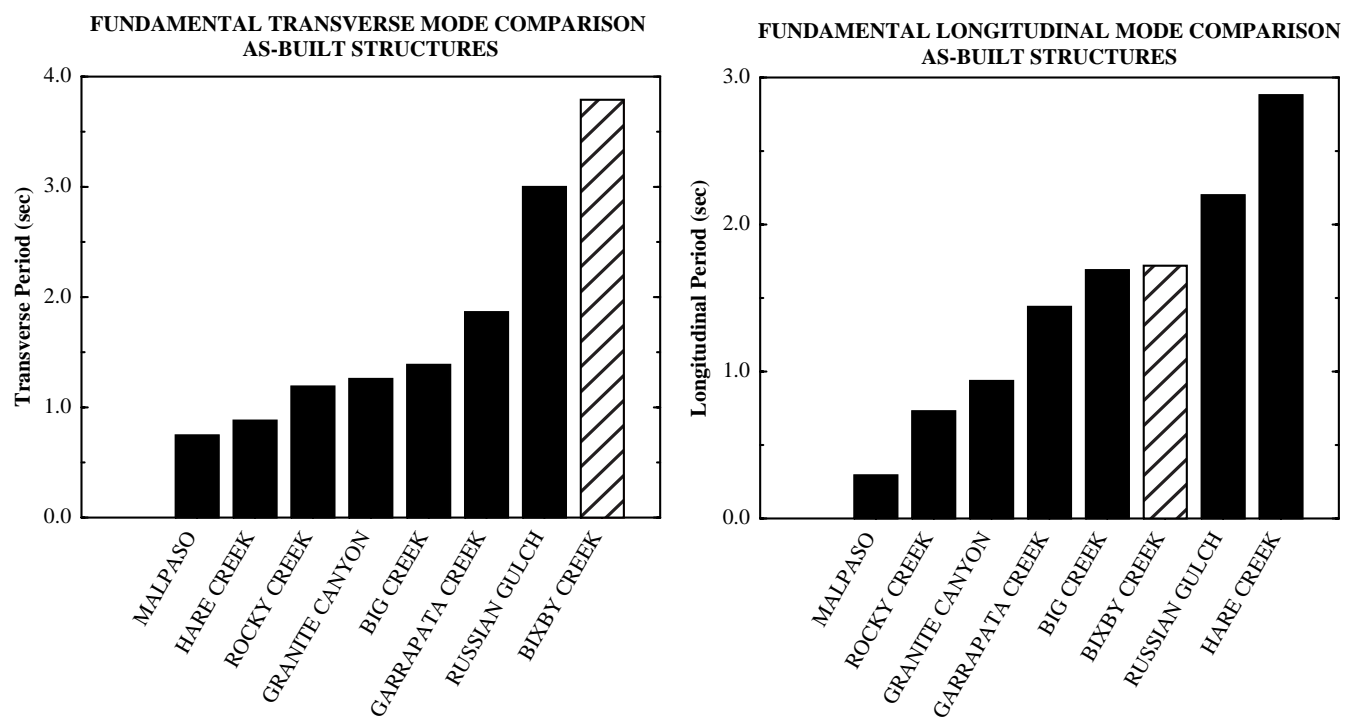

FIGURE 123. Natural vibration periods of a sample of California arch bridges.

(Figure 124). Damage levels indicate that the Caltrans concrete capacities are surpassed in the existing columns at the crown of the arch as shown in Figure 125. The two major shear

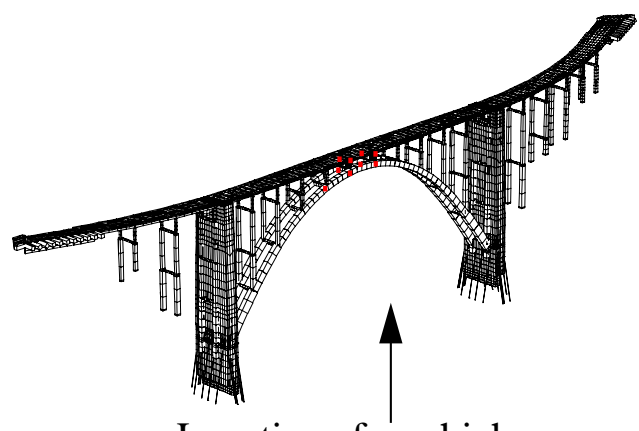

Locations for which concrete strains exceed 0.005 (Caltrans allowable)

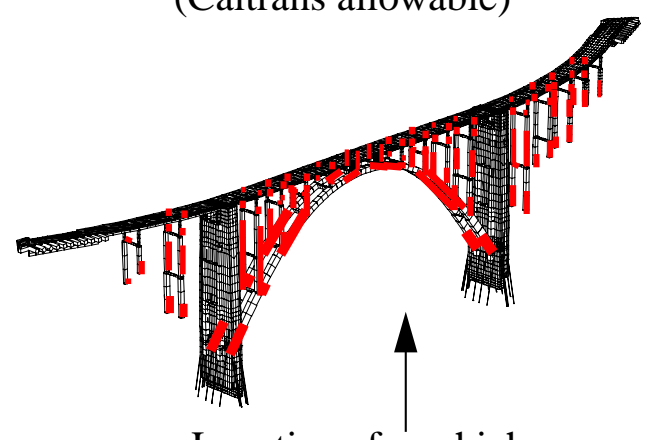

Locations for which

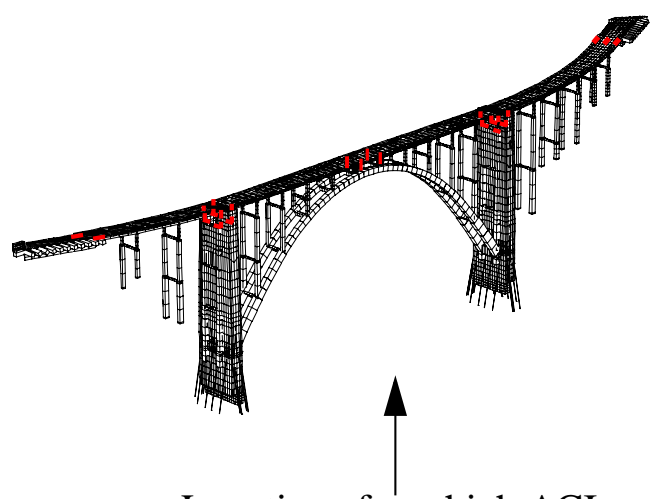

Locations for which ACI code shear capacities are exceeded (Caltrans steel strains exceed 0.0014 updated motions) (yield strain)

FIGURE 125. Damage locations for the retrofit structure.

panels added at the crown of the arch between the arch and the deck, however, assist in lateral load transfer. These panels should provide adequate strength even if the columns at 


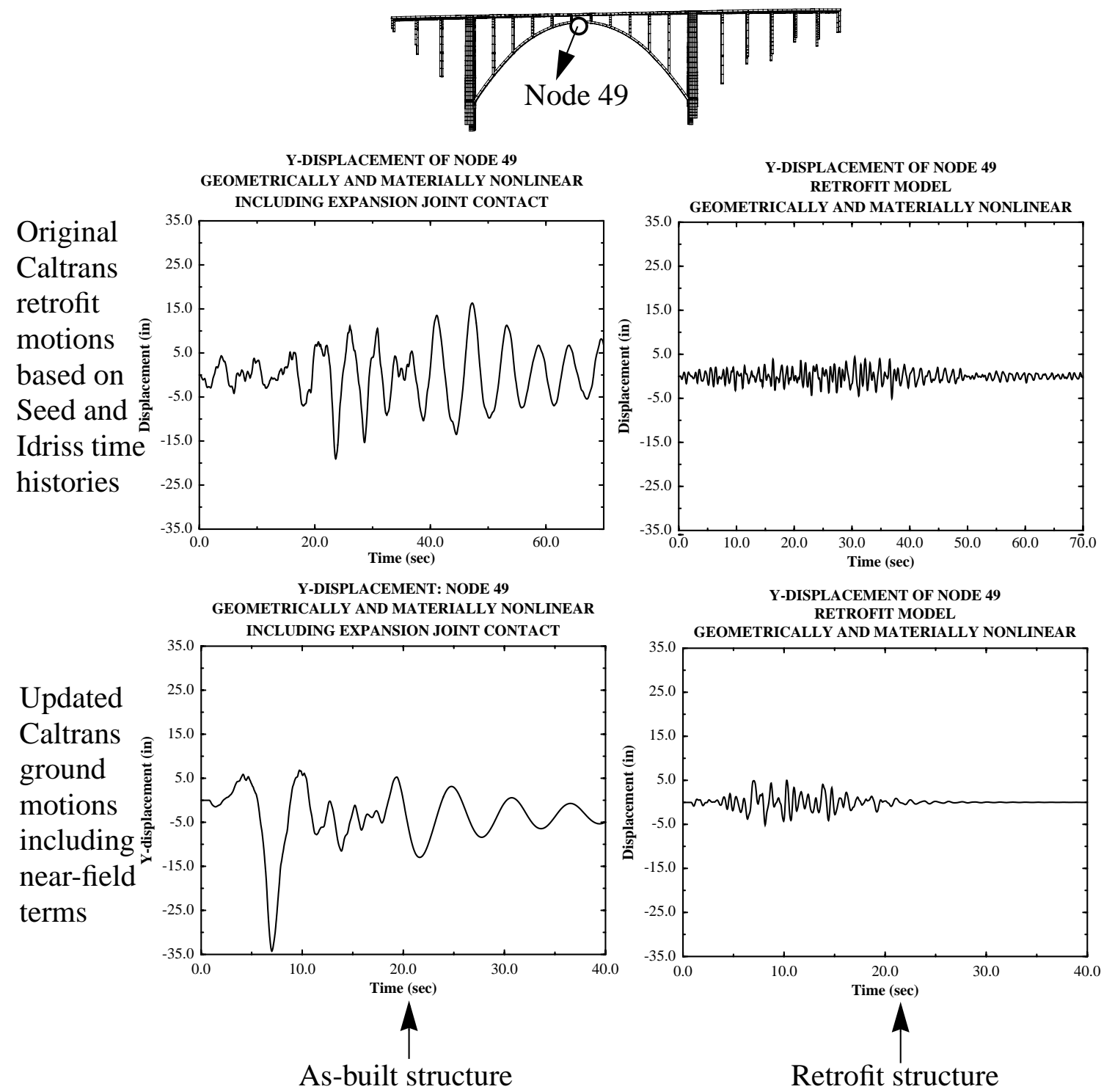

FIGURE 124. Displacement time histories of as-built and retrofit structure for Seed and Idriss and Caltrans near-field motions.

the top are significantly damaged in an earthquake. The reinforcing steel strains do not surpass the Caltrans specified allowable at any location. There is, however, still significant yielding of the steel resulting from the large load transfer between the main arch ribs and the deck system. A major improvement of the retrofit structure over the as-built structure is in the area of adequacy of member shear capacities. Comparing the potential shear failures in Figure 125 with the potential shear failures of the as-built in Figure 121 indicates that the shear demand-to-capacity is significantly improved in the retrofit structure.

The massive CIDH piles added to the abutments were analyzed by imposing the peak earthquake displacements from the global model onto a detailed three dimensional model of the foundation system. A strength capacity check with the resulting biaxial forces in the piles indicated that the piles have adequate strength to resist the earthquake induced forces. 


\subsection{Conclusions}

Based on the extensive analyses performed, a number of conclusions can be stated that are pertinent to arch bridges in general and the Bixby Creek Bridge in particular.

- Long span arches tend to be very flexible systems with relatively long natural periods of vibration (field measurements indicated that Bixby Creek has a fundamental mode of vibration on the order of 2.5 seconds). This makes it essential that potential near-field ground displacement pulses be included in the seismic hazard evaluation if the structures are located near a causative fault.

- For stiffer arch bridge structures (e.g. the retrofit Bixby Creek Bridge), some of the vibration modes of the structure are of a frequency which may make the structural response sensitive to incoherent, multiple support input motions.

- The computer simulated responses of arch bridges subjected to earthquake motions are quite sensitive to the modeling assumptions and the sophistication of the model. For Bixby Creek, because of the large number of expansion joints in the system, the computed response was exceedingly sensitive to the manner in which the expansion joints were modeled. Accounting for nonlinearities associated with joint impact can significantly stiffen the bridge system.

- Material nonlinearities in the bridge system play an important role in determining the bridge response. Steel yielding and concrete cracking/softening result in a system which has more flexibility and a longer period of vibration. For the Bixby Creek structure, including material nonlinearities resulted in a reduction in structural displacement drifts and a redistribution of member forces, significantly decreasing peak force values.

- The type of computational model used (i.e. linear vs. nonlinear), the modeling idealizations employed, and the acceptance criteria can significantly impact the conclusions regarding the adequacy of the structural system.

- For the original design motions provided by Caltrans, the retrofit design appeared to be conservative based on nonlinear simulation models; however, with the updated Caltrans motions including near-field terms, the retrofit appears appropriate.

- For certain arch bridges, Caltrans geotechnical staff should consider the possibility of defining variable support motions in the earthquake hazard definition. Previous studies have illustrated that due to the stiffness of the arch system, arch bridges can be susceptible to the effects of variable support motions. The current study indicates that some of the natural modes of arch bridges can fall into the frequency range where deep canyon topography and geology effects lead to significant variable support motions. 


\subsection{Acknowledgements}

This study was supported by the California Department of Transportation and the support and guidance of Mr. Jim Roberts is gratefully acknowledged. The authors would like to thank Mr. Mark Yashinsky of Caltrans, the project technical monitor, for his input and technical guidance on the project. The authors also acknowledge the contributions of Dr. Larry Hutchings, Don Rock and Pat Lewis of LLNL for their efforts in field instrumentation, Mr. Thomas Woehrle of LLNL for his assistance in the field testing of the Bixby Creek Bridge, and Dr. Mehmet Celebi of the United States Geological Survey for his assistance in field testing and analysis of the measured bridge dynamics. Dr. Mike Puso and Dr. Phani Nukala of LLNL made modifications to the NIKE3D program for this study and their timely help is appreciated. The authors would also like to thank Mr. Paul Lukkarila of Caltrans and his maintenance crew for the excellent job performed in the rapid placement and removal of sensors on the Bixby Creek Bridge.

This work was performed at the Lawrence Livermore National Laboratory under the auspices of the United States Department of Energy, contract W-7405-Eng-48. 


\subsection{References}

1. Mitchell, S. (1933), A 320-Ft. Concrete Arch on Scenic Route Along California Coast, Engineering News-Record, April 13.

2. Bachhuber, J. and J. M. Benoit (1998), State of California Arch Bridge Over Bixby Creek Caltrans Phase II Seismic Retrofit Geotechnical Summary Report. Buckland and Taylor LTD. Report EA No. 391501.

3. Panian, L., J. G. Wilson and J. M. Benoit (1995), State of California Bixby Creek Bridge No: 44-019 Seismic Retrofit Strategy Report. Buckland and Taylor LTD. Report EA No. 4391501.

4. Maxwell, J. S. and R. S. Dunham (1996), Nonlinear Finite Element Analyses of Reinforced Concrete Arch Bridges on California's Central Coast. Anatech Corporation Report ANA-96-0185.

5. Nazmy, A.S. (1996), Earthquake-Response Characteristics of Long-Span Arch Bridges, Proceedings of the Eleventh World Conference on Earthquake Engineering.

6. Nazmy, A. S. and E. G. Konidaris (1995), Nonlinear Seismic Behavior of Steel DeckType Arch Bridges, Proceedings of the Fifth U.S. National Conference on Earthquake Engineering, Chicago, Illinois, 367-376.

7. Chai, J. and K. A. Jackura (1994), Preliminary Site Specific Analysis, Caltrans Memorandum file no. 05-Mon-01 SRP 309 05-39150K.

8. M. Khojasteh and A. Abghari (1998), Bixby Creek Bridge Seismic Retrofit Project Ground Motion, Caltrans Memorandum file no. 05-Mon-01 05-391511.

9. Hoehler, M.S. (1998), The Effects of Canyon Topography on Ground Motion at Bixby Creek, California, B.S. Thesis, Department of Civil Engineering and Operations Research, Princeton University.

10. Wong, H. L. and P. C. Jennings (1975), Effects of Canyon Topography on Strong Ground Motion, Bulletin of the Seismological Society of America, No. 65, 1239-1257. 
11. Maker, B. N., R. M. Ferencz and J.O. Hallquist (1991), NIKE3D A Nonlinear, Implicit, Three Dimensional Finite Element Code for Solid and Structural Mechanics, Lawrence Livermore National Laboratory Report UCRL-MA-105268.

12. Malhotra, P. K., M. J. Huang and A. F. Shakal (1995), Seismic Interaction at Seperation Joints of an Instrumented Concrete Bridge, Earthquake Engineering and Structural Dynamics, No. 24, 1055-1067.

13. Taucer, F., E. Spacone and F. C. Filippou (1991), A Fiber Beam-Column Element For Seismic Response Analysis of Reinforced Concrete Structures, University of California Berkeley Earthquake Engineering Research Center Report UCB/EERC-91/17.

14. Menegotto, M. and P. E. Pinto (1973), Slender RC Compressed Members in Biaxial Bending, ASCE Journal of Structural Engineering, No. 103, 587-605.

15. Kent, D. C. and R. Park (1971), Flexural Members with Confined Concrete, ASCE Journal of the Structural Division, No. 97.

16. Scott, B. D., R. Park and M. J. N. Priestley (1982), Stress-Strain Behavior of Concrete Confined by Overlapping Hoops at Low and High Strain Rates, ACI Journal, No. 79-2, $13-27$.

17. McCallen, D. B., M. A. Gerhard, D. J. Trummer and R. C. Murray (1997), Independent Seismic Evaluation of the 24-580-980 South Connector Ramps, Lawrence Livermore National Laboratory Report UCRL-CR-123201.

18. Baumgartner, J., D. Innamorato and F. Seible (1998), Bixby Creek Bridge Composite Retrofit Program “As-Built” Column Test, University of California San Diego Report TR98/03.

19. McCallen, D. B. and A. Astaneh-Asl (1997), SUSPNDRS: A Numerical Simulation Tool for the Nonlinear Transient Analysis of Cable Supported Bridge Structures Part I: Theoretical Development, Lawrence Livermore National Laboratory Report, UCRL-ID127626. 
APPENDIX A: Retrofit strategies for a number of California arch bridges 


\section{Retrofit Strategy Comparison}

The extensive seismic retrofit modifications for the Bixby Creek Bridge are unique in terms of the expansive scope and the post-tensioning procedure by which the deck is tied together. The underlying methodology for the retrofit strategy being used for the Bixby Creek Bridge, however, is similar to the strategies being used on other arch bridges throughout California. The main theme for the arch bridge retrofits is to include measures to create an alternative load path for the earthquake loads, thereby minimizing the demands on the main arch ribs and on other vulnerable parts of the bridge not designed to withstand extreme seismic loads. This is accomplished by implementing modifications so the deck can behave as one continuous member, or diaphragm, and by retrofitting the abutments to resist longitudinal and transverse diaphragm loads. To achieve this deck continuity, the decks were either strengthened by adding reinforcement in new bolsters attached to the inside of the existing girders, or by retrofitting expansion hinges with high-strength rods or dowels. Most of the abutment retrofits either include adding longitudinal infill walls, CIDH piles with approach slab on edge girders, or CIDH piles and pile cap. Many retrofit strategies, like Bixby Creek, also include improving the arch crown shear connections. Some bridges are being retrofitted with transverse infill walls, reinforcing bars that are placed through cored holes from the deck, or transverse shear keys. In addition, the towers of Cedar Creek and Big Dann Creek bridges, the two bridges that have substantial towers, will be retrofitted for ductility and strength in a manner very similar to Bixby Creek. It was proposed that spiral reinforcement cages be installed inside the existing hollow towers and filled with concrete. Furthermore, it was proposed that reinforced concrete struts be installed at the bottom of the towers along with vertical rock anchors. Finally, other proposed strategies resembling those used for Bixby Creek included improving column strength and ductility, modifying deck/column connections, and installing additional shear reinforcement to deficient arch struts. The retrofit strategies for a number of arch bridges are summarized in this appendix. 


\section{PARK ROW OVERCROSSING}

\section{SUPERSTRUCTURE DESCRIPTION:}

- Built in 1941

- Location: Los Angeles Chinatown

- Reinforced concrete flat slab with cross beams between columns

- Total Span Length 191'-0"'

North Approach: 3 Approach Spans; 12'-6”, 12'-0", \& 12'-6"'

South Approach: 2 Approach Spans; 12'-0" \& 12'-6"

Main Arch Span: 12 sets of spandrel columns and 2 arch ribs; 12'-6', 12'-6", 12'-0", 11'-6", 11'-0", 10'-6”, 11'-0', 11'-6”, 12'-0”, 12'-6”, \& 12'-6"

- Main Arch Span Length: 130'-0"

- All columns were designed as pinned top with the exception at Bents 8, 9, 10, and 11, which were designed as pinned top and bottom

- Fundamental Periods: 0.7-1.1 sec

\section{RETROFIT STRATEGY:}

- Install longitudinal infill wall at Span 1 and Span 16 between spandrel columns and abutments of both left and right arch

- Install transverse infill walls at Bent 4, 15, 8, 9, 10, and 11 between spandrel columns

- Spread footing may be required underneath the infill wall at Bent 4 and 15

- Provide seat extender and transverse shear key at expansion joint

\section{SEISMIC DATA:}

- Maximum Horizontal Acceleration $=0.7 \mathrm{~g}$

- $\quad$ Magnitude of Fault $=7.5$

- Fault Zone = Malibu-Santa Monica-Raymond Fault System

- $\quad$ Distance to site from Fault $=3.7 \mathrm{~km}$

- Liquefaction potential $=$ Low

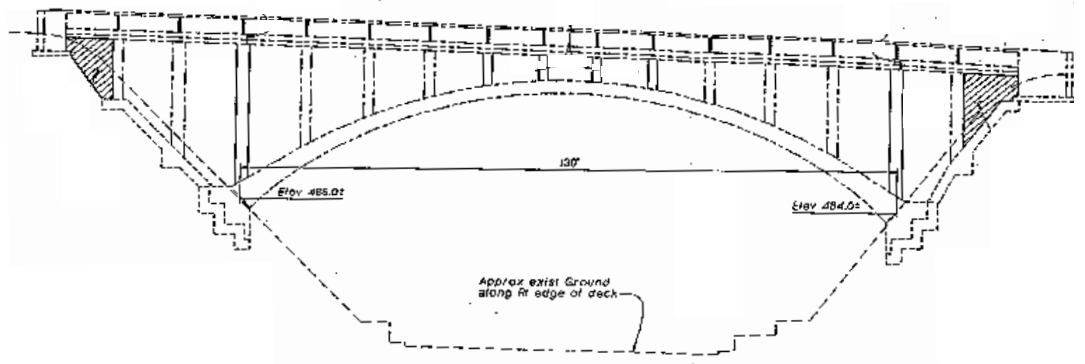




\section{SAN LORENZO RIVER BRIDGE}

\section{SUPERSTRUCTURE DESCRIPTION:}

- Built in 1926

- Location: Near Santa Cruz

- Consists of a 140-ft long single span arch bridge, with approach structures on each side of the arch span

- Arch Bridge: Consists of a pair of parallel arch ribs 19'-10" apart, each supporting twelve spandrel columns. The spandrel columns, 12'-3" on center, in turn support the cap beams and the bridge deck above.

Approaches: The approach structure consists of 20-ft long continuous spans supported by two-column bents. There are five spans in the north approach and three in the south approach.

\section{RETROFIT STRATEGY:}

- Install transverse in-fill walls at Pier A-1 and Pier A-12

- Modify deck expansion joints - tie bridge decks together

- Add transverse shear keys at Piers A-5 through A-8 and at Piers A-1 and A-12

- Install sliding bearings at Piers A-4 through A-9

- Retrofit arch rib sections near base

- Install steel column casings at Piers 2 and 3

\section{SEISMIC DATA:}

- Maximum Horizontal Acceleration $=0.5 \mathrm{~g}$

- $\quad$ Magnitude of Fault $=7.1$

- $\quad$ Fault Zone = Zayante

- $\quad$ Distance to site from Fault $=6.4 \mathrm{~km}$

- Liquefaction potential $=$ Low

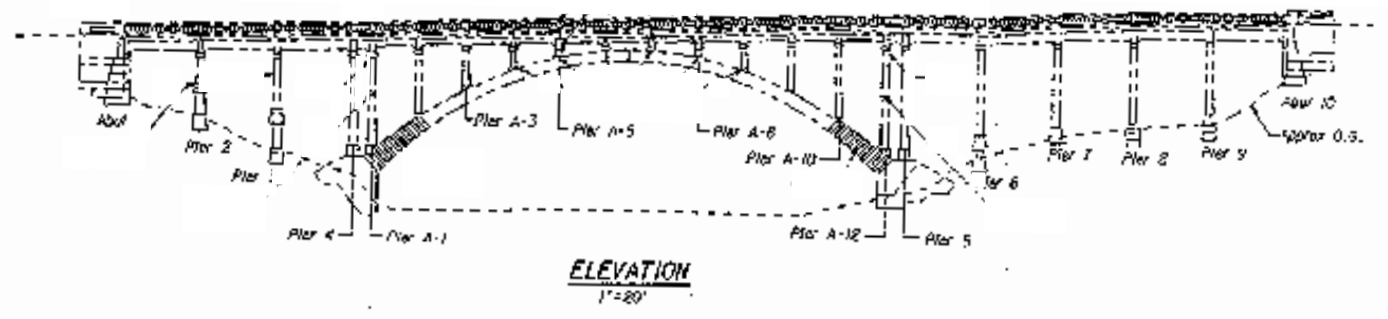




\section{HARE CREEK BRIDGE}

\section{SUPERSTRUCTURE DESCRIPTION:}

- Built in 1947

- Location: Between Fort Bragg and Mendocino

- Reinforced concrete arch bridge with a straight alignment across Hare Creek

- The 384' long and 32' wide superstructure consists of three arch spans which support 20 two-column spandrel bents and both south and north abutments.

- All columns are pinned longitudinally at top and short columns (Bents 2, 3, 9, 10, 13, 14, 20, \& 21) are pinned longitudinally at bottom as well.

- Fundamental periods: $2.88 \mathrm{sec}$. longitudinal; $0.88 \mathrm{sec}$. transverse

\section{RETROFIT STRATEGY:}

- Arch Crown Shear Connection: Place reinforcing bars through cored holes from deck to provide shear connection.

- Bent Cap Retrofit: strengthening the bent cap by enlarging the cap size of 6" on each side of the caps at Bents 6 \& 17.

- Abutment Retrofit: Install CIDH piles at both abutments with approach slab on edge girders.

- Strengthen Bent Columns: Enlarge columns to provide shear reinforcement at bents 2, 3, 10, 13, 20, \& 21.

- In-Fill Wall Between Columns: Infill shear wall at bents 6 \& 17.

- Strengthen Bent Columns: Enlarge columns to provide shear reinforcement at bents 2, 3, 10, 13, 20, \& 21.

- In-Fill Wall Between Columns: Infill shear wall at bents $6 \& 17$.

\section{SEISMIC DATA:}

- $\quad$ Maximum Horizontal Acceleration $=0.6 \mathrm{~g}$

- $\quad$ Magnitude of Fault = 8.0

- $\quad$ Fault Zone $=$ San Andreas Fault

- $\quad$ Distance to site from Fault $=5.2$ miles

- Depth to Bedrock $=0<\mathrm{D}<10 \mathrm{ft}$.

- Liquefaction potential $=$ Low

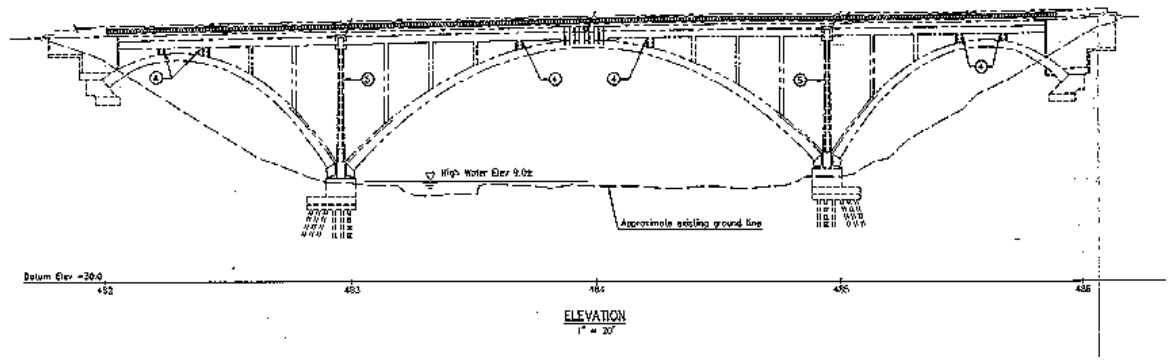




\section{JUGHANDLE CREEK BRIDGE}

\section{SUPERSTRUCTURE DESCRIPTION:}

- Built in 1937

- Location: Between San Francisco and Fort Bragg

- Reinforced concrete arch bridge on a $4000 \mathrm{ft}$ radius curved alignment

- The brige was widened in 1964 using precast box edge girders supported on bent cap extensions

- The superstructure consists of a single arch span with approach spans on each side.

- Two arch ribs support 10 bents (20 columns).

\section{RETROFIT STRATEGY:}

- Abutment Retrofit: CIDH piles with approach slab on edge girders.

- Expansion Hinge Retrofit: High strength rods with extra strong pipes across the hinges using concrete bolsters or steel brackets.

\section{SEISMIC DATA:}

- $\quad$ Maximum Horizontal Acceleration $=0.6 \mathrm{~g}$

- $\quad$ Magnitude of Fault = 8.0

- $\quad$ Fault Zone = San Andreas Fault (North)

- $\quad$ Distance to site from Fault $=8 \mathrm{~km}$ north

- Depth to Bedrock $=\mathrm{D}<10 \mathrm{ft}$.

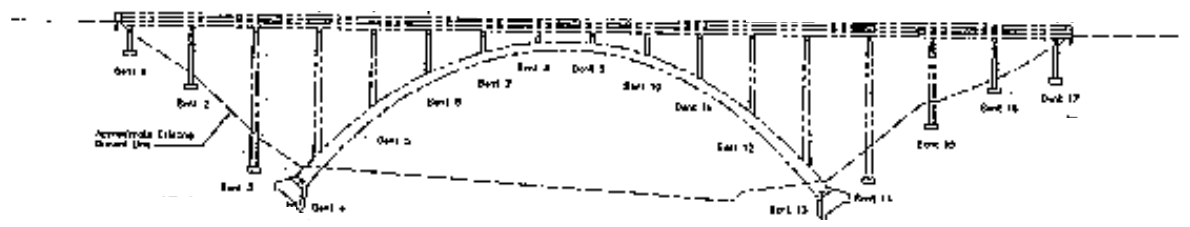




\section{CEDAR CREEK BRIDGE}

\section{SUPERSTRUCTURE DESCRIPTION:}

- Built in 1931

- Location: On State Route 271 between Eureka and Willits

- Reinforced concrete open spandrel arch bridge measuring $27^{\prime}-10^{\prime \prime}$ wide and 620'-0" long

- The arch span is $320^{\prime}-0$ " in length and rises approximately 96' at the centerline

- The length of the bridge consists of nineteen individual spans fixed at one end and pinned at the opposite end, except for the span at the crown of the arch which is fixed at both ends.

- The arch is centered between two symmetrical three-span approach frames with spans ranging in length from 46'-6" to 49'-6"'

\section{RETROFIT STRATEGY:}

- Abutment Retrofit: Install CIDH piles and pile cap. Connect pile cap to abutment with pipe keys.

- Deck Diaphragms: Add reinforcement in new bolsters attached to the inside of the existing girders.

- Deck Restrainers: Install restrainers at revised deck joints.

- Deck/Column Connection: Replace existing connection with new bearings at approach columns and interior spandrel columns.

- Tower Retrofit: Install spiral reinforcement cage inside existing hollow towers and fill with concrete. Install reinforced concrete strut at the bottom of towers. Install vertical rock anchors in new strut.

- Bent Replacement: Replace end spandrel bents. Increase longitudinal reinforcement at base, and shear reinforcement over entire length.

- Arch Retrofit: Install casing and additional shear reinforcement at lower portion of arch. Install reinforced concrete strut at base of arches. Install rock anchors in new struts.

- Arch Strut Retrofit: Install additional shear reinforcement to all arch struts.

\section{SEISMIC DATA:}

- $\quad$ Caltrans ARS $=0.6 \mathrm{~g}$

- 0'-10' Alluvium.

- Liquefaction potential $=$ Low

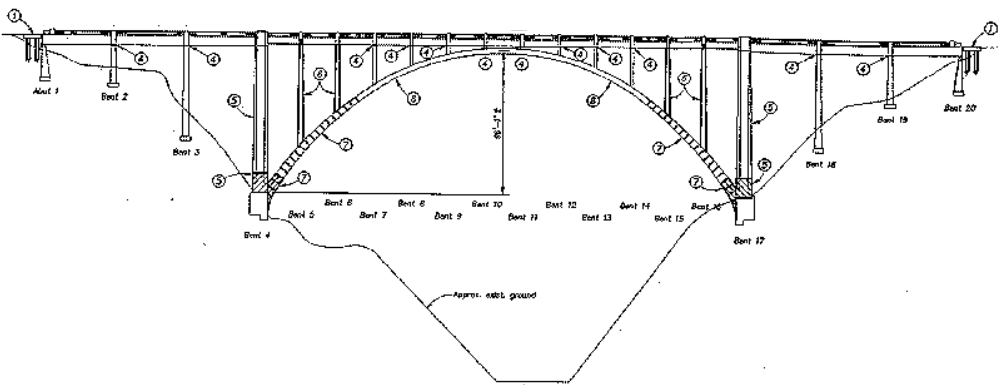




\section{RUSSIAN GULCH BRIDGE}

\section{SUPERSTRUCTURE DESCRIPTION:}

- Location: Between San Francisco and Fort Bragg on Highway 1

- 526'-0" long superstructure

- Bridge consists of a concrete slab deck supported on 29 double-column bents, sixteen of which are supported on a spandrel arch with a span of $240 \mathrm{ft}$ and a rise of $85 \mathrm{ft}$.

- The roadway has a straight alignment with a total width of $31 \mathrm{ft}$. All of the columns (including the arch supported columns) are fixed at the bottom and pinned at the top.

- $\quad$ Fundamental periods: $3.0 \mathrm{sec}$. transverse; $2.2 \mathrm{sec}$. longitudinal

\section{RETROFIT STRATEGY:}

- Abutment Retrofit: CIDH piles with approach slab on edge girders. Connect to existing abutment diaphragms to enable force (tension and compression) and moment transfers between existing deck and newly installed components.

- Expansion Hinge Retrofit: Remove portions of the two sidewalks for a distance of approximately 10 to $15 \mathrm{ft}$ on either side of an expansion joint. Replace the removed sidewalk with a structural concrete block properly anchored to the deck and of same dimensions as removed sidewalk. The new structural block will function as a sidewalk and will accommodate the hinge lock assembly consisting of high strength rods across the joint.

- Columns Retrofit - Moment Release: In order to limit the seismic shear input to the crown columns, cut part of the rebars at the bases of the short spandrel columns at bents 16 through 19. Provide additional vertical drill and bond dowels through the top slab to compensate for the loss of shear capacity due to cutting rebars.

\section{SEISMIC DATA:}

- $\quad$ Maximum Horizontal Acceleration $=0.6 \mathrm{~g}$

- $\quad$ Magnitude of Fault = 8.0

- $\quad$ Fault Zone = San Andreas Fault

- $\quad$ Distance to site from Fault $=5$ miles

- Depth to Bedrock $=0<\mathrm{D}<10 \mathrm{ft}$.

- $\quad$ Liquefaction potential $=$ None

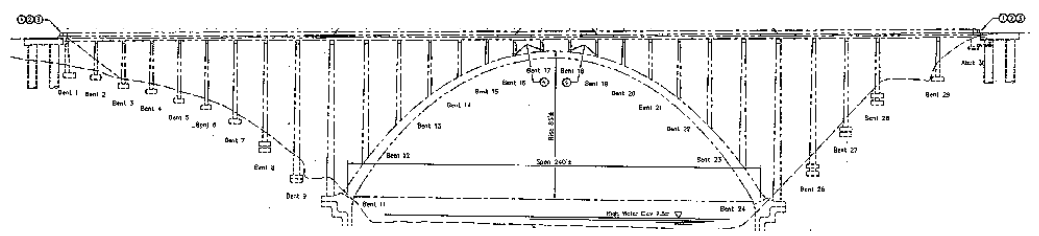




\section{BIG DANN CREEK BRIDGE}

\section{SUPERSTRUCTURE DESCRIPTION:}

- Built in 1931

- Location: State Route 271 between Eureka and Willits

- The superstructure measures $27^{\prime}-1$ " wide and 583'-0" long.

- The arch span is $320^{\prime}-0$ " long and rises approximately $84^{\prime}$.

- All spans except the crown span are fixed at one end, pinned at the other. The crown span is fixed at both ends.

- The approaches are on two columns bents with intermediate struts. The range in length from 39'-6" to 51 '-6".

- The spans across the arch range in length from $24^{\prime}-17 / 8^{\prime \prime}$ to $27^{\prime}-17 / 8^{\prime \prime}$.

\section{RETROFIT STRATEGY:}

- Abutment Retrofit: Install CIDH piles and pile cap. Connect pile cap to abutment with pipe keys.

- Deck Diaphragms: Add reinforcement in new bolsters attached to the inside of the existing girders.

- Deck Restrainers: Install restrainers at revised deck joints.

- Deck/Columns Connection: Replace existing connection with new bearings at approach columns and interior spandrel columns.

- Tower Retrofit: Install spiral reinforcement cage inside existing hollow towers and fill with concrete. Install reinforced concrete strut at the bottom of towers. Install vertical rock anchors in new strut.

- Bent Replacement: Replace end spandrel bents. Increase longitudinal reinforcement at base, and shear reinforcement over entire length.

- Arch Retrofit: Install casing and additional shear reinforcement at lower portion of arch. Install reinforced concrete strut at base of arches. Install rock anchors in new struts.

- Arch Strut Retrofit: Install additional shear reinforcement to all arch struts.

\section{SEISMIC DATA:}

- Caltrans ARS $=0.6 \mathrm{~g}$

- 0'-10' Alluvium.

- Liquefaction potential $=$ Low

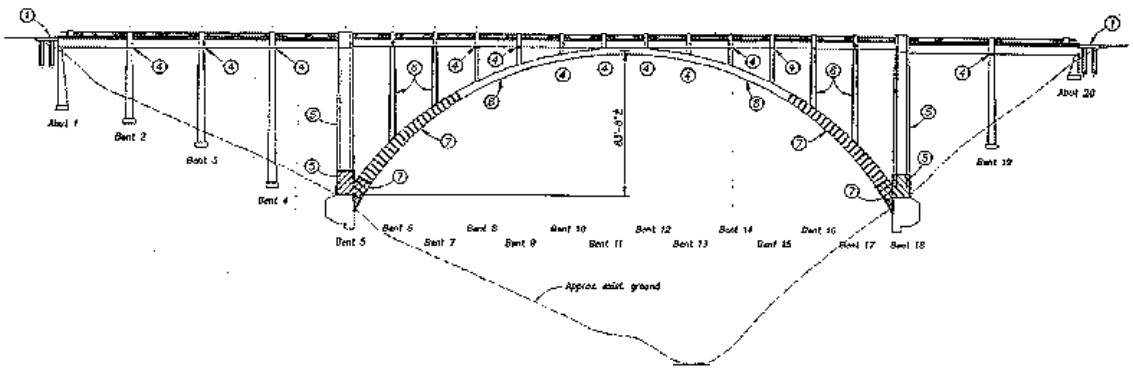




\section{CITY CREEK BRIDGE}

\section{SUPERSTRUCTURE DESCRIPTION:}

- Built in 1948

- Location: San Bernardino National Forest on State Highway 330 approximately 7 miles northeast of the City of San Bernardino.

- Open spandrel reinforced concrete arch bridge.

- The bridge is approximately 32' wide by 430' long. Its twin ribs span 160' with a 58' rise.

- Its approach spans vary from 18.5 ' to $20.0^{\prime}$ in length.

\section{RETROFIT STRATEGY:}

- Modify existing deck expansion joints to reduce seismic demands on the arch ribs. The modifications consist of adding dowels to induce abutment-to-abutment diaphragm action in the bridge deck.

- Retrofit bases of arch ribs to increase their capacity in shear, torsion, and flexure. The retrofit consists of adding rectangular steel jackets to the arch ribs between the thrust blocks and the first interior spandrel columns.

\section{SEISMIC DATA:}

- $\quad$ Maximum Peak Ground Acceleration $=0.7 \mathrm{~g}$

- $\quad$ 0'-10' Alluvium.

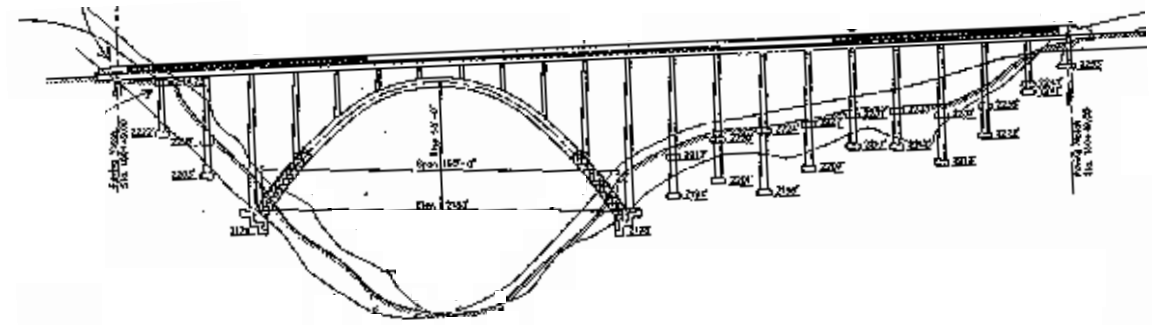




\section{EAST FORK CITY CREEK BRIDGE}

\section{SUPERSTRUCTURE DESCRIPTION:}

- Built in 1948

- Location: San Bernardino National Forest on State Highway 330 approximately 8 miles northeast of the City of San Bernardino.

- Open spandrel reinforced concrete arch bridge.

- The bridge is approximately $36^{\prime}$ 'wide by $152^{\prime}$ ' long. Its twin ribs span $100^{\prime}$ ' with a rise of $20^{\prime}$ '.

- Approach spans vary from 14.5 ' to 28.5 ' in length.

\section{RETROFIT STRATEGY:}

- Modify existing deck expansion joints to reduce seismic demands on the arch ribs. The modifications consist of adding dowels to induce abutment-to-abutment diaphragm action in the bridge deck.

- Retrofit bases of arch ribs to increase their capacity in shear, torsion, and flexure. The retrofit consists of adding rectangular steel jackets to the arch ribs between the thrust blocks and the first interior spandrel columns.

\section{SEISMIC DATA:}

- $\quad$ Maximum Peak Ground Acceleration $=0.8 \mathrm{~g}$

- $\quad$ 0'-10' Alluvium.

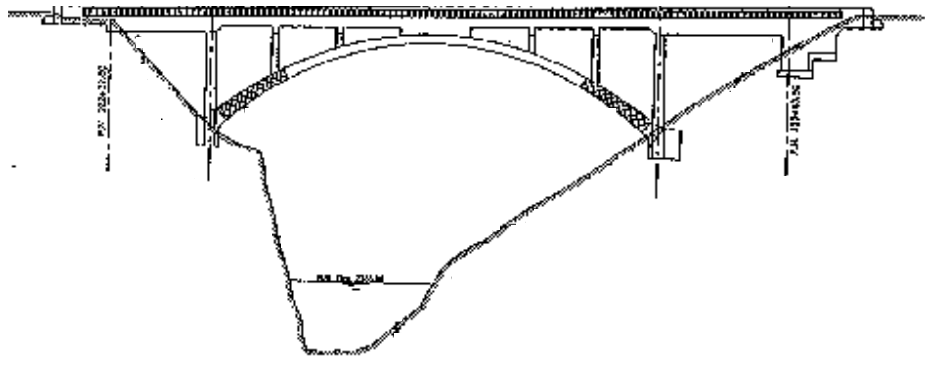




\section{SAN JUAN CANYON BRIDGE}

\section{SUPERSTRUCTURE DESCRIPTION:}

- Built in 1929

- Location: Near Sievers Creek

- Reinforced concrete, double arch, open-spandrel bridge.

- The superstructure consists of a T-beam girder section and reaches a total length of 180 feet. The double arch system has a clear span of 116'-8' and a clear rise of 17'-6 1/2'".

- The bridge has 13 spans with a total of 20 corniced piers.

\section{RETROFIT STRATEGY:}

- Abutment Retrofit: At each abutment, adding concrete-filled steel pipes at the abutments to engage each stem wall.

- Expansion Hinge Conversion: At bents 6 and 9, using concrete bolsters to convert expansion hinges and protect the bent cap.

\section{SEISMIC DATA:}

- Maximum Horizontal Acceleration $=0.4 \mathrm{~g}$

- $\quad$ Magnitude of Fault $=7.5$

- $\quad$ Fault Zone $=$ Whittier-Elsinore Fault

- $\quad$ Distance From Fault $=8.1$ miles

- $\quad$ Depth to Bedrock $=0<\mathrm{D}<10 \mathrm{ft}$

- $\quad$ Liquefaction potential $=$ Unlikely

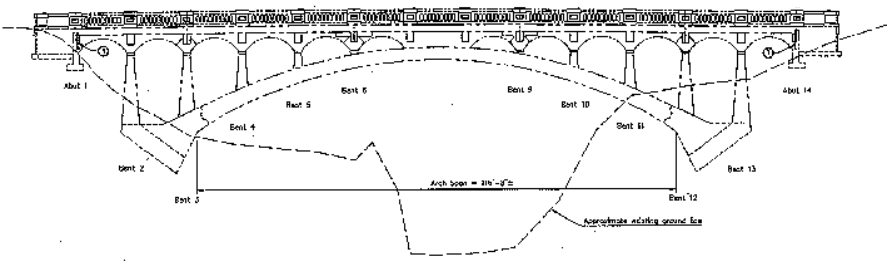


